DESIGN AND ANALYSIS OF A DYNAMIC LOADING SYSTEM FOR A MORPHING WINGLET

\author{
by \\ Raffi S. Buchkazanian \\ Bachelor of Engineering, Ryerson University (2017)

\begin{abstract}
A thesis
presented to Ryerson University

in partial fulfillment of the

requirements for the degree of

Master of Applied Science

in the program of

Aerospace Engineering
\end{abstract}

Toronto, Ontario, Canada, 2019

(C) Buchkazanian, Raffi, 2019 


\section{AUTHOR'S DECLARATION FOR ELECTRONIC SUBMISSION OF A THESIS}

I hereby declare that I am the sole author of this thesis. This is a true copy of the thesis, including any required final revisions, as accepted by my examiners.

I authorize Ryerson University to lend this thesis to other institutions or individuals for the purpose of scholarly research.

I further authorize Ryerson University to reproduce this thesis by photocopying or by other means, in total or in part, at the request of other institutions or individuals for the purpose of scholarly research. I understand that my thesis may be made electronically available to the public 


\title{
DESIGN AND ANALYSIS OF A DYNAMIC LOADING SYSTEM FOR A MORPHING WINGLET
}

\author{
Raffi S. Buchkazanian, B.Eng \\ Master of Applied Science, 2019 \\ Department of Aerospace Engineering, Ryerson University
}

\begin{abstract}
The following thesis paper investigates the possible methods to perform a dynamic load test on a morphing winglet. A morphing winglet design capable of deflecting in the cant direction was developed by a joint partnership between Ryerson University and Bombardier Aerospace. In order to validate the model and complete a proof of concept, a loading fixture was required to test the structural integrity of the winglet under a defined load. Upon completion of an enumeration study of planar four-bar linkages, a passive R-P-R-P mechanism was designed to apply a constant perpendicular load throughout the cant motion. A design of the half size loading fixture was developed, optimized and manufactured to integrate with an existing cant module. The dynamic loading model was validated by producing a positive correlation between the theoretical analysis and the experimental results, leading to a successful proof of concept for a full scale test.
\end{abstract}




\section{ACKNOWLEDGEMENTS}

I would like to acknowledge the staff and professors at Ryerson University for providing me with the required knowledge and opportunity to complete my Masters of Applied Science in Aerospace Engineering. The work was funded by the Ontario Graduate Scholarship (OGS), Queen

Elizabeth II Graduate Scholarships in Science \& Technology (QEII-GSST), Ryerson University and Bombardier Aerospace. I would like to express my sincere gratitude towards my supervisor Dr. Jeff Xi, who has provided me with guidance, knowledge and support throughout my research.

I would also like to thank all the members of Ryerson's Morphing Winglet Team who have provided the required foundation to allow me to complete my research. Additionally, I would like to especially thank Gabriel Campos, Jingyun Gao and Mehran Mohammadpour who have supported me and shared their ideas throughout my post-graduate degree.

Finally, I would like to thank my family and close friends, who have been by my side, encouraging and motivating me throughout this chapter of my life. 


\section{TABLE OF CONTENTS}

AUTHOR'S DECLARATION FOR ELECTRONIC SUBMISSION OF A THESIS ............ ii

ABSTRACT ............................................................................................................................................ iii

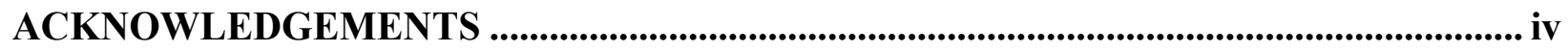

LIST OF TABLES ................................................................................................................... vii

LIST OF FIGURES ........................................................................................................ vii

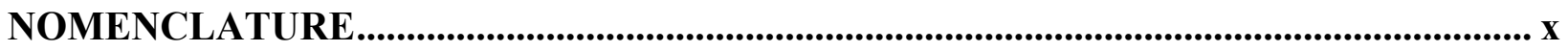

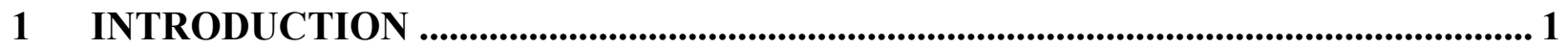

$1.1 \quad$ SCOPE AND OUTLINE ...............................................................................................

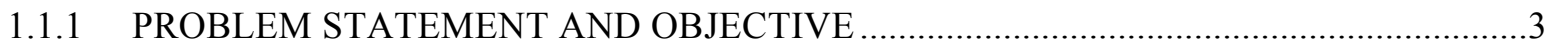

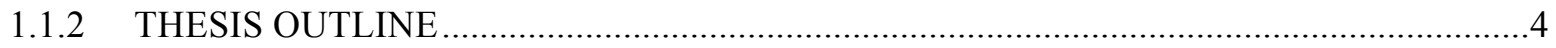

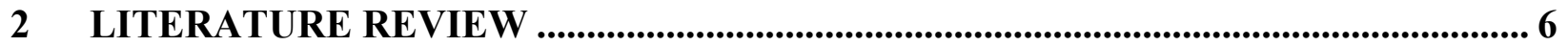

2.1 WING AND WINGLET STRUCTURAL REGULATIONS ...................................................6

2.2 WINGLET LOADING .......................................................................................................

2.3 AIRCRAFT COMPONENT DYNAMIC LOADING...........................................................9

2.4 WING LOADING .............................................................................................11

2.5 AILERON LOADING .....................................................................................14

2.6 RUDDER LOADING ..........................................................................................................18

2.7 WIND TURBINE LOADING …………….....................................................................19

2.8 DISTRIBUTED LOAD VS POINT LOAD .........................................................................20

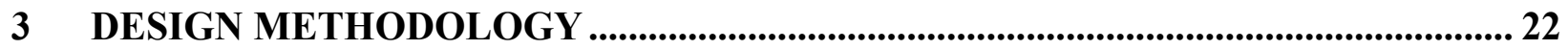

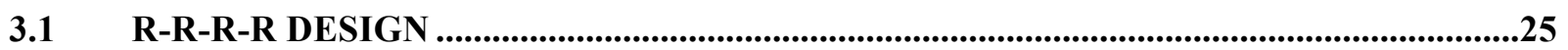

3.2 R-R-P-R DESIGN...................................................................................................................27

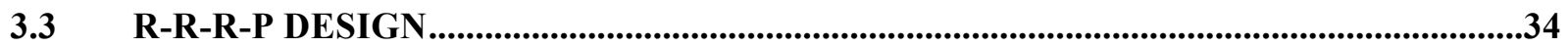

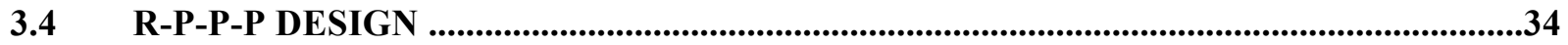

3.5 R-R-P-P DESIGN ……………….....................................................................................35

3.6 R-P-R-P DESIGN ………............................................................................................38

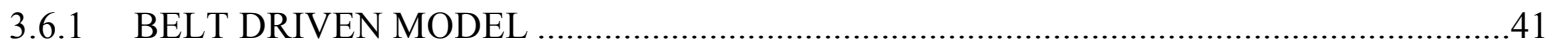

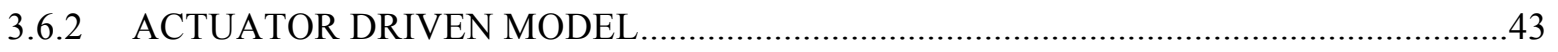

3.7 DESIGN METHODOLOGY SUMMARY …………….............................................................45

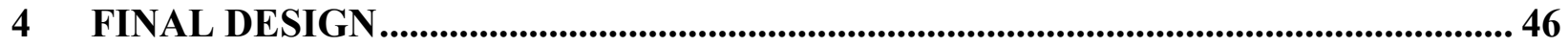

4.1 R-P-R-P ACTIVE LOADING DESIGN …………..........................................................46

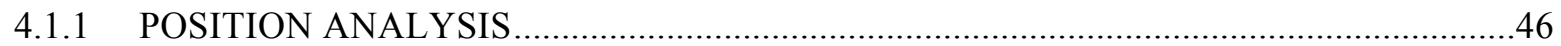

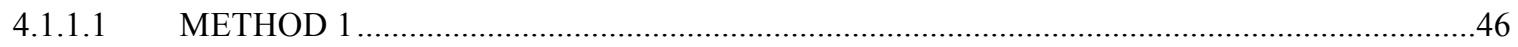

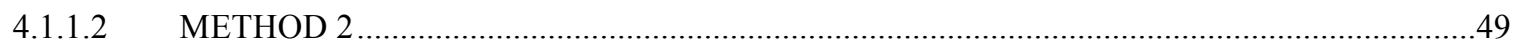

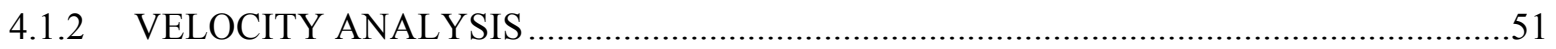

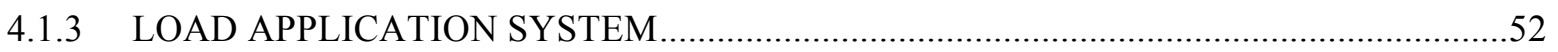

4.2 R-P-R-P PASSIVE LOADING DESIGN …………...................................................................53

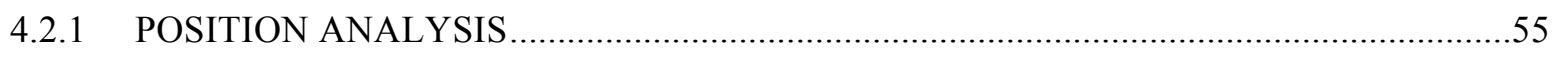

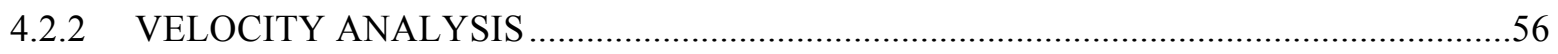

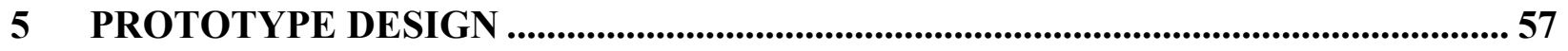

5.1 SHARK-FIN CAD DESIGN...................................................................................................58

5.2 SHARK-FIN OPTIMIZATION ..................................................................................................61

5.3 ASSEMBLY DESIGN ................................................................................................................... 


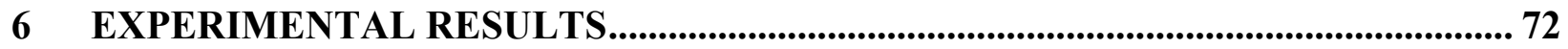

6.1 THEORETICAL SHARK-FIN MODEL.........................................................................72

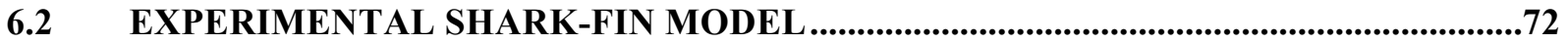

6.2.1 ROTARY POTENTIOMETER CALIBRATION ……………………………………...73

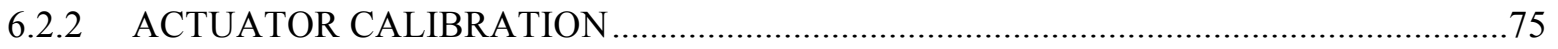

6.2.3 CONTROL SYSTEM FOR CANT-MECHANISM.........................................................79

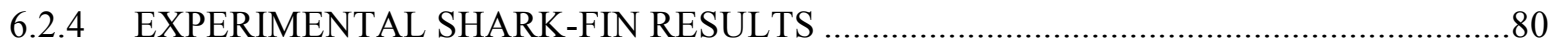

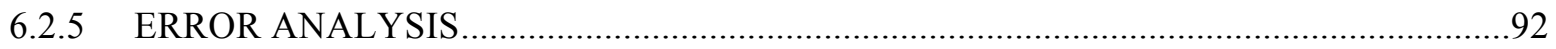

7 CONCLUSION

7.1 CONTRIBUTIONS ...................................................................................................................94

7.2 FUTURE WORK ………………………………………................................................................95

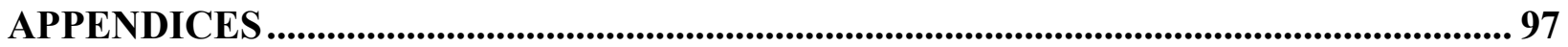

A. MATLAB CODE ……………………………………...........................................................97

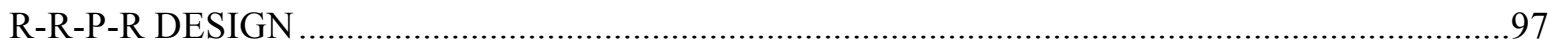

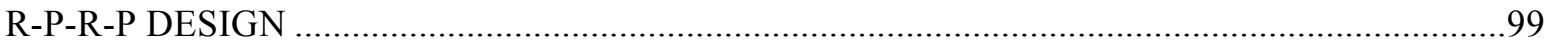

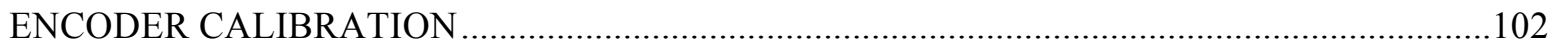

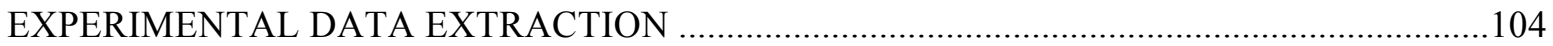

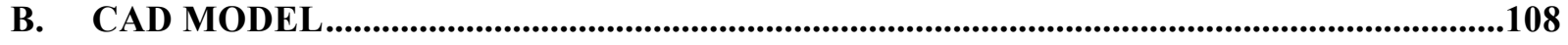

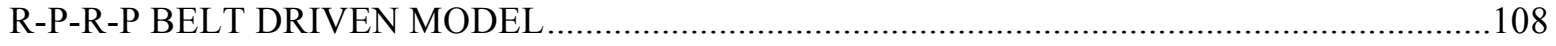

R-P-R-P ACTUATOR DRIVEN MODEL .............................................................................109

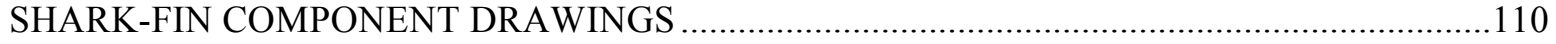

SHARK-FIN ASSEMBLY DRAWINGS............................................................................117

C. DERIVATION ..........................................................................................................................118

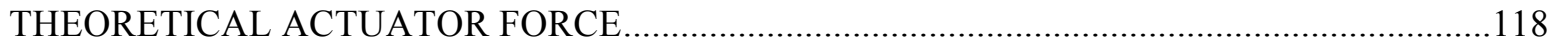

BIBLIOGRAPHY ……............................................................................................................... 125 


\section{LIST OF TABLES}

Table 3-1: Four bar mechanism enumeration assessment .................................................. 45

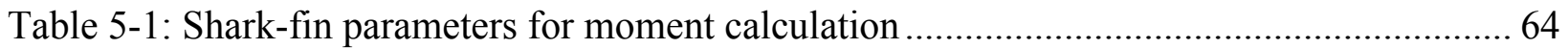

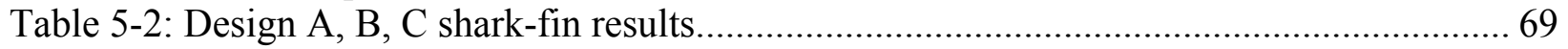

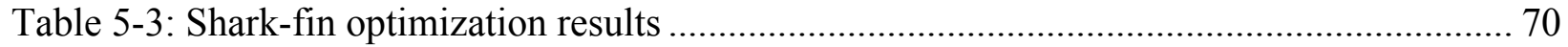

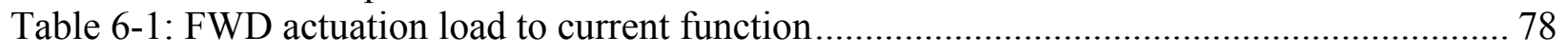

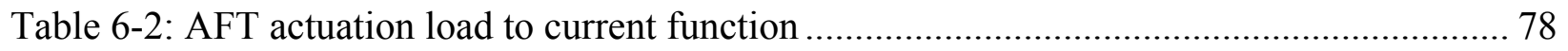




\section{LIST OF FIGURES}

Figure 1-1: Commercial airliner winglet designs [4] ................................................... 1

Figure 2-1: SARISTU ground static test setup [12] .................................................... 8

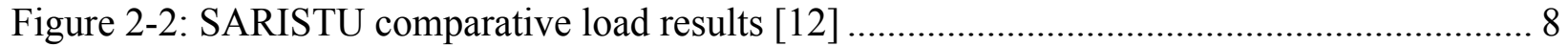

Figure 2-3: Wind tunnel test for variable cant angle winglet [13] .................................... 9

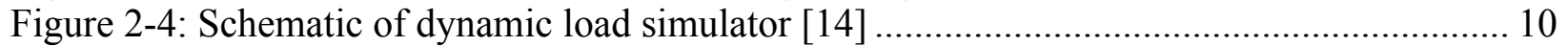

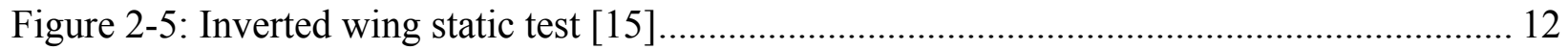

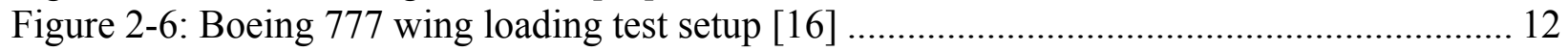

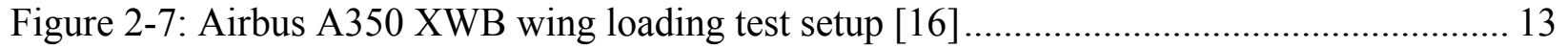

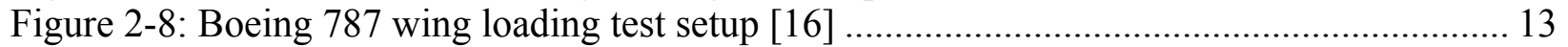

Figure 2-9: DG Flugzeugbau DG-800/1000 wing loading test setup [16] ............................... 13

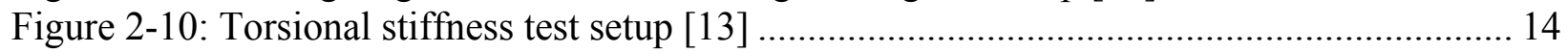

Figure 2-11: Ultimate static load test of an aileron [13] ............................................... 15

Figure 2-12: Structural diagram for the aileron endurance test setup [18] ............................. 16

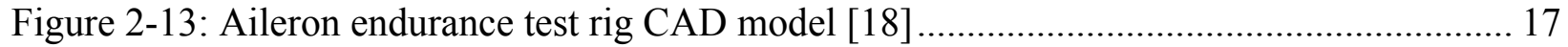

Figure 2-14: AEROSUD rudder static test [19] ................................................................ 18

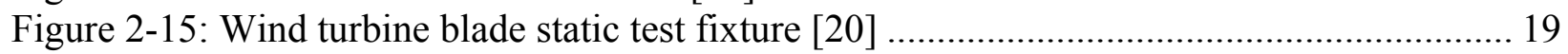

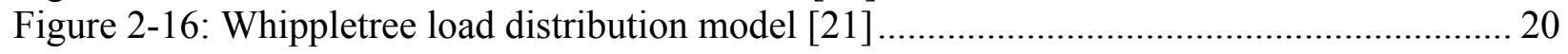

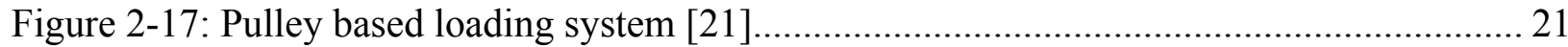

Figure 3-1: Load directional requirement - a) cant angle $=10^{\circ} \mathrm{b}$ ) cant angle $=80^{\circ} \ldots \ldots \ldots \ldots \ldots \ldots . . . \ldots \ldots$

Figure 3-2: Linkage designs: a) four bar mechanism b) slider crank mechanism [25] .............. 23

Figure 3-3: Winglet kinematic model ............................................................................... 24

Figure 3-4: Common R-R-R-R mechanism designs [24] ................................................... 25

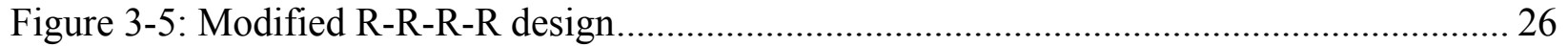

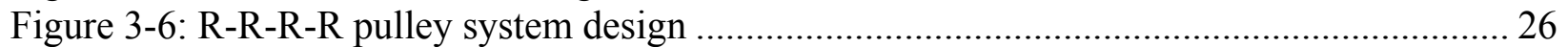

Figure 3-7: R-R-P-R model for iteration 1-a) Kinematic model b) CAD model........................ 27

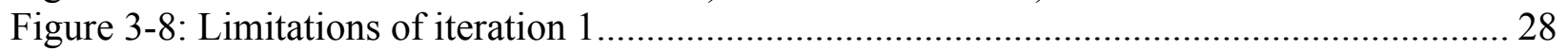

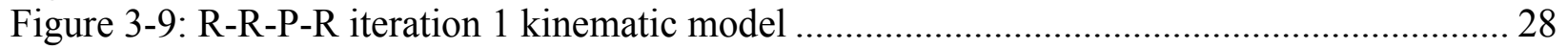

Figure 3-10: Cant angle vs slider displacement/load angle ................................................. 29

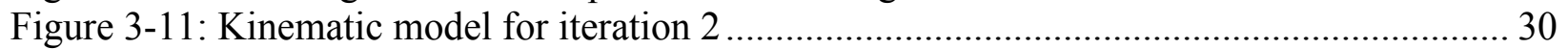

Figure 3-12: R-R-P-R geometry investigation................................................................... 32

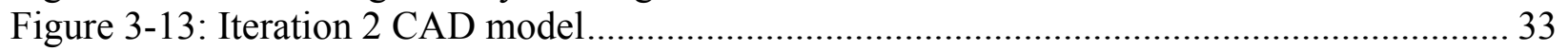

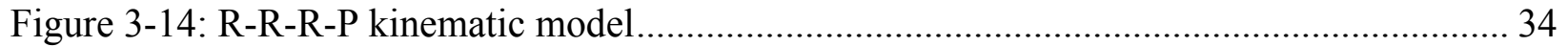

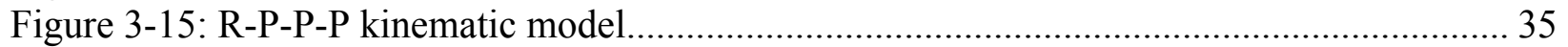

Figure 3-16: R-R-P-P kinematic model ............................................................................ 35

Figure 3-17: R-R-P-P CAD model - 10 degree and 80 degree configuration ............................ 36

Figure 3-18: Guide rod/rail interface .............................................................................. 36

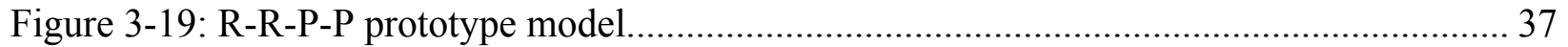

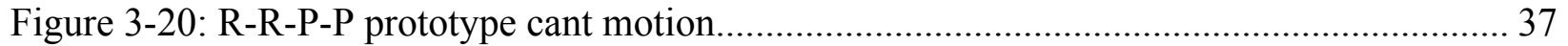

Figure 3-21: R-P-R-P kinematic model ............................................................................. 38

Figure 3-22: Dynamic loading active model ...................................................................... 39

Figure 3-23: Actuator displacement and distance weight traveled vs wing to actuator height .... 40

Figure 3-24: R-P-R-P belt drive CAD model ................................................................. 41

Figure 3-25: Double pulley system free body diagram ........................................................ 42

Figure 3-26: Belt driven active model ............................................................................ 42

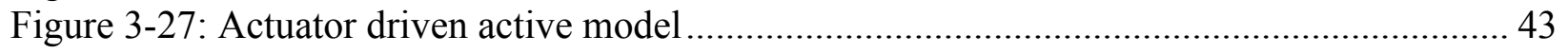


Figure 3-28: R-P-R-P actuator driver CAD model at 10 and 80 degree.................................... 43

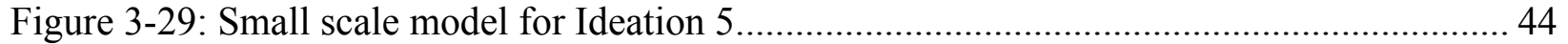

Figure 4-1: R-P-R-P detailed kinematic model .................................................................. 47

Figure 4-2: Kinematic model (position) for R-P-R-P design...................................................... 49

Figure 4-3: Actuator displacement model.............................................................................. 51

Figure 4-4: R-P-R-P kinematic model with loading actuator ..................................................... 52

Figure 4-5: R-P-R-P loading model a) Active design b) Passive design....................................... 53

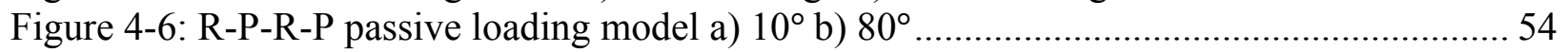

Figure 4-7: R-P-R-P position analysis schematic .................................................................. 55

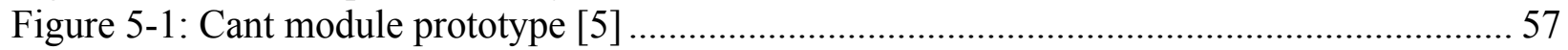

Figure 5-2: Exploded view of final prototype assembly ........................................................... 59

Figure 5-3: Exploded view of sub-assemblies - a) L bracket b) shark-fin c) winglet ...................59

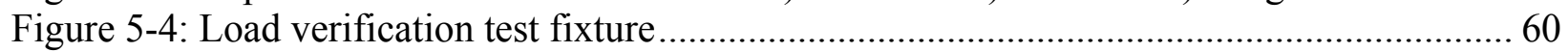

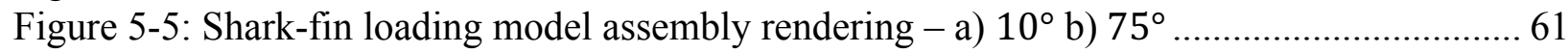

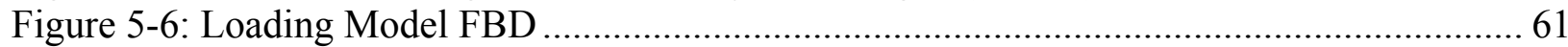

Figure 5-7: Shark-fin geometry a) Design A b) Design B c) Design C........................................ 64

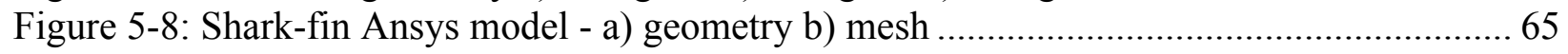

Figure 5-9: Ansys model a) BC 1 and 2 b) BC 3 c) Load 1 d) Load 2...................................... 66

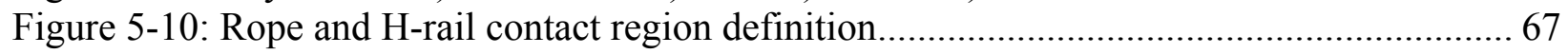

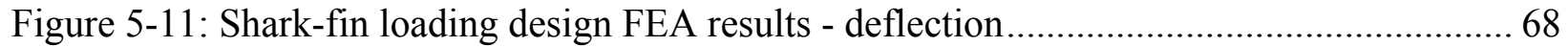

Figure 5-12: Shark-fin loading design FEA results - Max Principal Stress ................................. 69

Figure 5-13: Half size dynamic loading model - a) minimum position b) maximum position .... 71

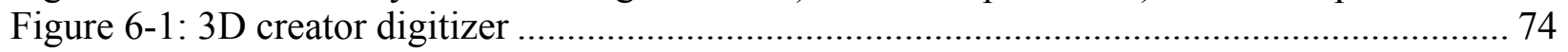

Figure 6-2: Actuator calibration test setup. a) tension test b) compression test ........................... 76

Figure 6-3: Actuator experimental calibration test-signal processing example............................. 77

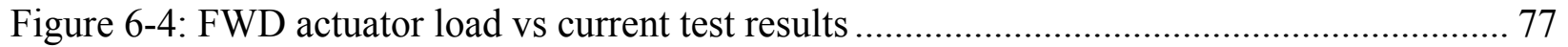

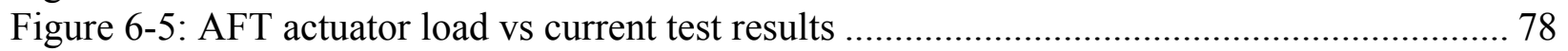

Figure 6-6: Block diagram for Simulink data acquisition [5] ................................................... 79

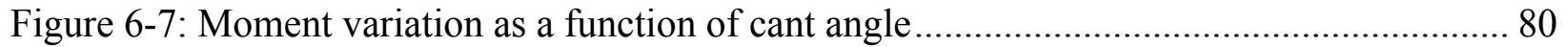

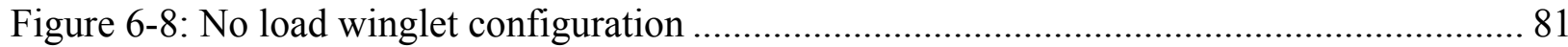

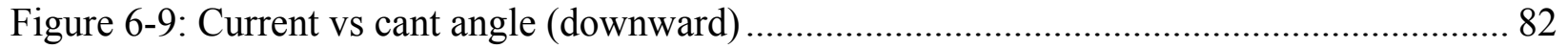

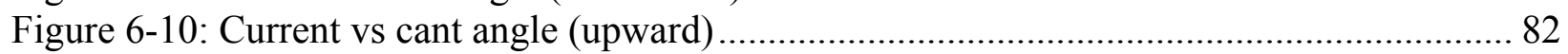

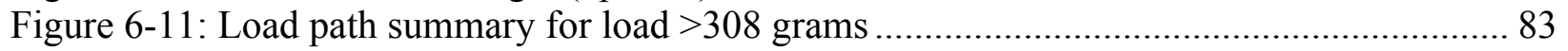

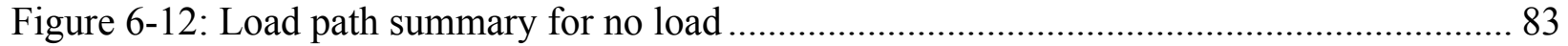

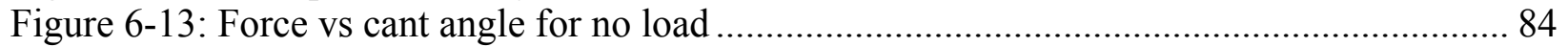

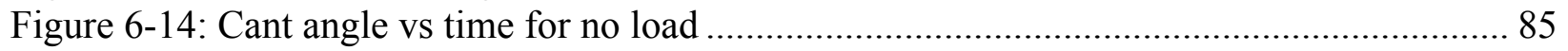

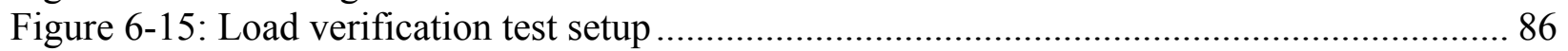

Figure 6-16: Load verification test - cant angle vs applied load.................................................. 87

Figure 6-17: Normalized actuator force vs cant angle for 700 gram load .................................... 88

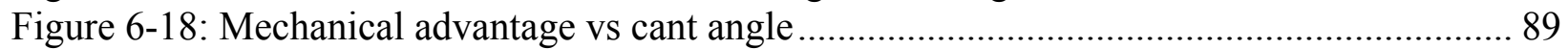

Figure 6-19: Normalized toggle load vs cant angle for 700 gram load ....................................... 89

Figure 6-20: Load distribution factor vs cant angle for 700 grams ........................................... 90

Figure 6-21: Experimental vs theoretical - normalized actuator load vs cant angle downward...91

Figure 6-22: Experimental vs theoretical - normalized actuator load vs cant angle upward........ 91

Figure 6-23: Theoretical vs experimental actuator load error - downward ................................... 92

Figure 6-24: Theoretical vs experimental actuator load error - upward ..................................... 92 


\section{NOMENCLATURE}

\begin{tabular}{|c|c|}
\hline$A$ & Amperes \\
\hline$B C$ & Boundary Condition \\
\hline$C A D$ & Computer Aided Design \\
\hline Cant Angle & Angle between wing span axis and winglet \\
\hline CFRP & Carbon Fiber Reinforced Polymer Composites \\
\hline$C G$ & Center of gravity \\
\hline$d$ & Distance traveled \\
\hline$D L S$ & Dynamic Loading Simulator \\
\hline$D O F$ & Degrees-of-Freedom \\
\hline ETR & Endurance Test Rig \\
\hline$f$ & Number of degrees of freedom for each joint \\
\hline$F$ & Number of degrees of freedom \\
\hline$F_{\text {out }}$ & Load Cell Output \\
\hline$F A A$ & Federal Aviation Administration \\
\hline$F B D$ & Free Body Diagram \\
\hline FEA & Finite Element Analysis \\
\hline$h$ & Distance between R1 and R4/P4 \\
\hline$i$ & Joint number \\
\hline$k-$ ratio & Proportion of loading in the forward toggle, with respect to the aft toggle \\
\hline$L$ & Lift force \\
\hline$L V D T$ & Linear Variable Displacement Transducers \\
\hline$M$ & Moment \\
\hline$M A$ & Mechanical Advantage \\
\hline$M A C$ & Mean Aerodynamic Center \\
\hline$M D F$ & Medium Density Fibreboard \\
\hline$n_{L}$ & Number of linkages \\
\hline$n_{j}$ & Number of joints \\
\hline$N$ & Reaction force \\
\hline
\end{tabular}




$\begin{array}{cl}\text { OEM } & \text { Original Equipment Manufacturer } \\ P & \text { Prismatic (joint) } \\ p & \text { Spatial point } \\ Q F T & \text { Quantitative Feedback Theory } \\ r & \text { Pulley radius } \\ R & \text { Revolute (joint) } \\ S & \text { Distance between axis of rotation and MAC (moment arm) } \\ \text { Shark fin } & \text { Developed linkage system } \\ T & \text { Tension in rope } \\ V & \text { Voltage } \\ W & \text { Weight } \\ x, y, z & \text { Distance } \\ \dot{x} & \text { Velocity } \\ X_{1}, X_{2} & \text { Variable objective function } \\ Z & \text { Total Objective Function } \\ \alpha, \beta, \psi, \theta & \text { Rotation Angle } \\ \dot{\theta} & \text { Angular Velocity }\end{array}$




\section{INTRODUCTION}

The efficiency and overall improvement of an aircraft's performance is a highly researched field of study. The introduction of winglets proved to advance an aircraft's efficiency by reducing the induced drag developed by wing tip vortices. As a result of the wing tip circulation generated by an aircraft's winglets, a sidewash is produced with a forward force component. This forward force acts in the same direction as the thrust, which counteracts the wing's drag [1]. During cruise conditions, induced drag accounts for roughly $40 \%$ of the total aircraft drag, and $80-90 \%$ during the second climb segment [2]. A study performed at the NASA Dryden Flight Research Center found that the use of winglets reduced the amount of fuel use by $6.5 \%$ [3]. The ability to improve an aircraft's efficiency is critical to modern aerodynamicists, which is why the study of various winglet designs has become a popular area of research. Current winglet design methodologies focus on a single flight segment's optimization. Some common winglet configurations used on commercial airliners are represented in Figure 1-1.

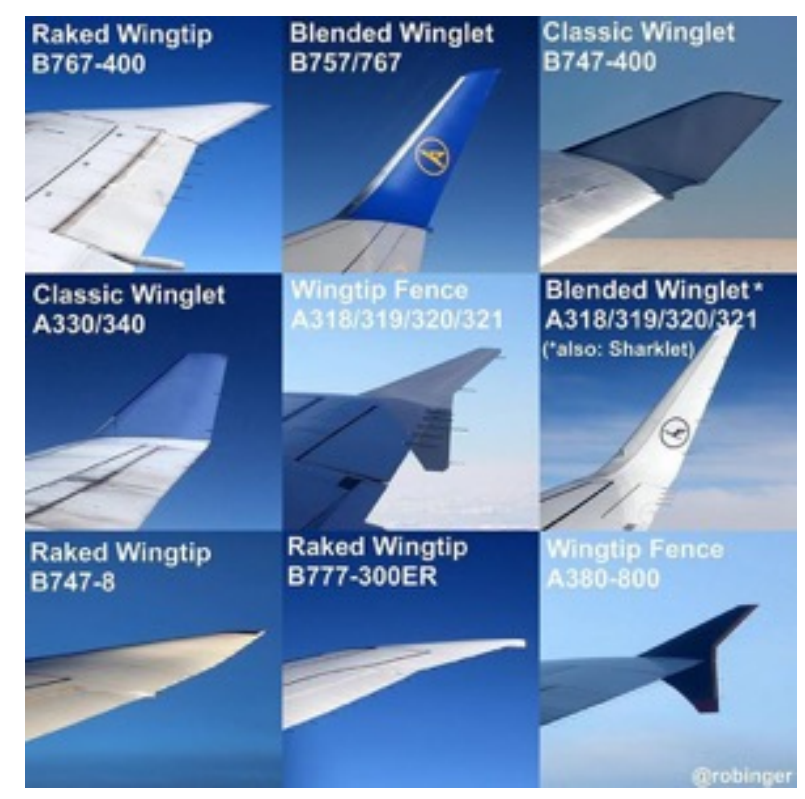

Figure 1-1: Commercial airliner winglet designs [4] 
The ability to optimize an aircraft's lift to drag ratio throughout the complete flight mission can lead to further improvements to aircraft efficiency. This resulted in the advancement of research in winglets capable of changing shape (morphing winglets). Having the capability of active shape change throughout various flight conditions can result in improved aerodynamic results, which would lead to improved fuel savings [4].

The three main geometric changes of a morphing winglet include a change in cant angle, toe angle and camber. The toe angle is the twist angle of the winglet, while the cant angle is the upward angle generated about the chord wise direction of the winglet. The change in camber can be achieved by extending the trailing edge or altering the width of the airfoil. Ryerson's Morphing Winglet Team, with support from Bombardier Aerospace has currently developed a cant module for a morphing winglet, with a range of $10^{\circ}$ to $80^{\circ}$. A half size model has also been produced in Ryerson's Intelligent Systems and Robotics Laboratory and has been illustrated in Figure 5-1. Additional details for the cant module can be found in [5].

In order to improve the efficiency of an aircraft, a morphing winglet allows for optimal winglet configurations at various flight segments. Although a large cant angle is beneficial during cruise conditions, a low cant angle during landing and take-off is desired to obtain the preferred lift characteristics of the wing [6]. A research study conducted at the Kumaraguru College of Technology revealed a decrease in lift to drag as the wing's angle of attack is increased, for both an aircraft flying with a constant cant angle of 30 degrees and 90 degrees [7]. Thus, a winglet with a constant cant angle configuration throughout a flight mission is not optimal.

One current research program that has begun analyzing a morphing winglet is an Airbus funded project at the University of Bristol in the United Kingdom called MORPHLET. The study has shown that the morphing winglet had a 5-6\% improvement in aerodynamic efficiency 
throughout the flight envelope, while a similar fixed winglet had a $3 \%$ improvement [8]. This additional 2-3\% improvement leads to significant fuel savings for airliners and leads to the reduction of carbon emissions. A similar study performed by a member of Ryerson's Morphing Winglet Team found a $1 \%$ improvement to the aerodynamic efficiency when using the proposed morphing winglet (cant module) for a flight mission defined by Bombardier. Additionally, the study found improvements to wing bending moments (2.4\%) and winglet bending moments (63\%) at a $2.5 \mathrm{~g}$ symmetric maneuver condition when comparing to an aircraft without winglets [9].

\subsection{SCOPE AND OUTLINE}

\subsubsection{PROBLEM STATEMENT AND OBJECTIVE}

To demonstrate the functionality of the morphing winglet developed by Ryerson's Morphing Winglet Team, a structural test would need to be completed. For flight application, the winglet is required to successfully adjust its cant angle through its complete range of $10^{\circ}$ to $80^{\circ}$ throughout the flight envelope. Bombardier Aerospace has provided the typical flight mission and the associated pressures acting on the winglet. It was found that a maximum of 1,700-pounds of lift force will act on the mean aerodynamic center (MAC) of the winglet. The purpose of the test is to verify the structural integrity of the complete winglet system and the synchronization between the cant module's dual linkage mechanisms under load. In order to reflect the flight conditions on the prototype without a wind tunnel, a load test fixture will be required with the following two requirements:

1. Apply a constant 1,700 -pound force at the MAC to simulate lift

2. Applied force must maintain perpendicularity (normal to winglet surface) throughout the cant-motion $\left(10^{\circ}-80^{\circ}\right)$

The above requirements are necessary to ensure the generated moment about the winglet's cant axis remains constant. In addition to the two requirements mentioned, the final design should 
aim to minimize the number of active joints to simplify the synchronization of the complete model and to minimize the required workspace to reduce cost and manufacturing complexities. To meet the above requirements and create a functional design, both passive and active mechanism designs were considered. A prototype loading fixture will be required to test on the existing half scale cant module [5] to verify the developed design meets the project requirements, which will serve as a proof of concept for the full scale model.

\subsubsection{THESIS OUTLINE}

The following section describes the organization of this thesis paper and a summary of each section. This paper is organized by the following:

\section{LITERATURE REVIEW}

3. DESIGN METHODOLOGY

4. FINAL DESIGN

5. PROTOTYPE DESIGN

6. EXPERIMENTAL RESULTS

\section{CONCLUSION}

The thesis paper begins with Section 2, which describes the current findings and technology developed for loading analysis. The literature review begins with a brief description of the structural regulations and the required tests to certify aircraft components, including winglets. Subsequently, the current methods used to perform load tests on aircraft components are outlined. While it is uncommon for original equipment manufacturers (OEMs) to publish their loading designs to the public, various sources were explored to obtain a survey of existing methods. Load testing designs were researched for the following aircraft components: wings, ailerons, rudders, winglets, and also for wind turbine blades. 
Section 3 describes the design methodology used to obtain various active and passive four bar morphing winglet loading designs. The design procedure required the analysis of all four bar mechanism combinations that could meet the defined design problem. Each enumeration was designed and analyzed to assess its validity and feasibility.

Following the design methodology, Section 4 describes in detail the final design for both an active and passive loading mechanism. For the active model, both a position and a velocity analysis were conducted. For the passive model, a geometric study was also conducted to describe the required dimensions to meet the design problem.

Section 5 outlines the prototype design for the final passive model. This section includes a geometry optimization section and the detailed design of the overall model. In order to increase the structural integrity of the fixture and improve the accuracy of test results, an optimization of the geometry was completed. Through the use of CAD and FEA, a geometrically accurate and optimized model was developed for the purpose of prototyping. With the use of a 3D printer, a laser cutter and "off the shelf" components, a half size prototype was manufactured.

In Section 6, the existing results from the kinematic analysis of the dual actuator mechanism on the cant module were compared to the experimental results obtained with the manufactured prototype. Through the cant mechanism's dynamic analysis, the theoretical loads in the forward and aft actuator were determined as a function of cant angle. Subsequently, with the half size loading model, the experimental actuator loads were obtained as a function of the cant angle. The theoretical and experimental results were compared to demonstrate the accuracy of the dynamic model for the cant module's mechanism.

Finally, the thesis concludes with Section 7, which summarizes the findings and potential work which can follow to further the research. 


\section{LITERATURE REVIEW}

\subsection{WING AND WINGLET STRUCTURAL REGULATIONS}

In order to ensure the structural integrity of an aircraft, various tests are required to be completed. According to the Federal Aviation Administration (FAA), the structure of an aircraft must be shown to comply with various strength and deformation requirements. This includes enduring ultimate and limit loads without failure or permanent deformation. Compliance for loading conditions can be shown through testing or through analysis supported by previously completed tests. While methods such as finite element modeling or analytical calculation are utilized in the design phase of a project, full scale tests are required to certify new aircraft structures [10].

A research group at the CIRA Italian Aerospace Research Council presented the design process of a morphing winglet for a regional aircraft. The study states that an adaptive winglet is a safety critical component, which requires the completion of a functional safety analysis [11]. Since a morphing winglet system is utilized to alleviate loads and assist in control functions, safety considerations will drive the structural design. While the failure of an adaptive winglet may have minor consequences on the safe operations of an aircraft and its occupants, a fault tree analysis can ensure the risk of failure is minimized. The paper suggests to utilize a redundant design through a dual command and monitoring lane with independent control units to minimize the probability of failure. Additionally, the use of linear variable displacement transducers (LVDTs) mounted to the designed critical joints would aid in the operational reliability of the active winglet [11]. 


\subsection{WINGLET LOADING}

A project funded by the European Union that has completed research in various topics related to advanced aircraft structures is called SARISTU (Smart Intelligent Aircraft Structures). Within the scope of the project, the study of the design, optimization, testing, verification, and validation of a wingtip active trailing edge was completed. While the design does not consider the change in cant angle, there are various concepts that can be applied to Ryerson's Morphing Winglet project. While there are various projects focused on a morphing winglet concept design, few have provided an engineering solution for a full-scale and close to flight-worthy model. The design developed and analyzed by the research group focuses on the application of an active winglet trailing edge, capable of a $-15^{\circ}$ to $15^{\circ}$ deflection, to be used on a short range aircraft. A full scale model was manufactured with the use of both carbon fiber reinforced polymer composites (CFRP) and metals, and assembled for testing. To validate the design and determine the ability to withstand loading, a ground static test was performed [12].

For the ground static test, the winglet was fixed to the test rig, with the active tab locked in positons based on the test case. The load was distributed through a whippletree capable of applying both a tension and compressive force. The load to be applied was based on aerodynamic data and FEA results. The first load case applied a downward bending load at $+10^{\circ}$ tab deflection and a second case applied an upward bending at $-15^{\circ}$ tab deflection. Through the use of three actuators with load cells, the whippletree was loaded to simulate the desired wing loading. The test fixture model has been illustrated in Figure 2-1 [12]. 

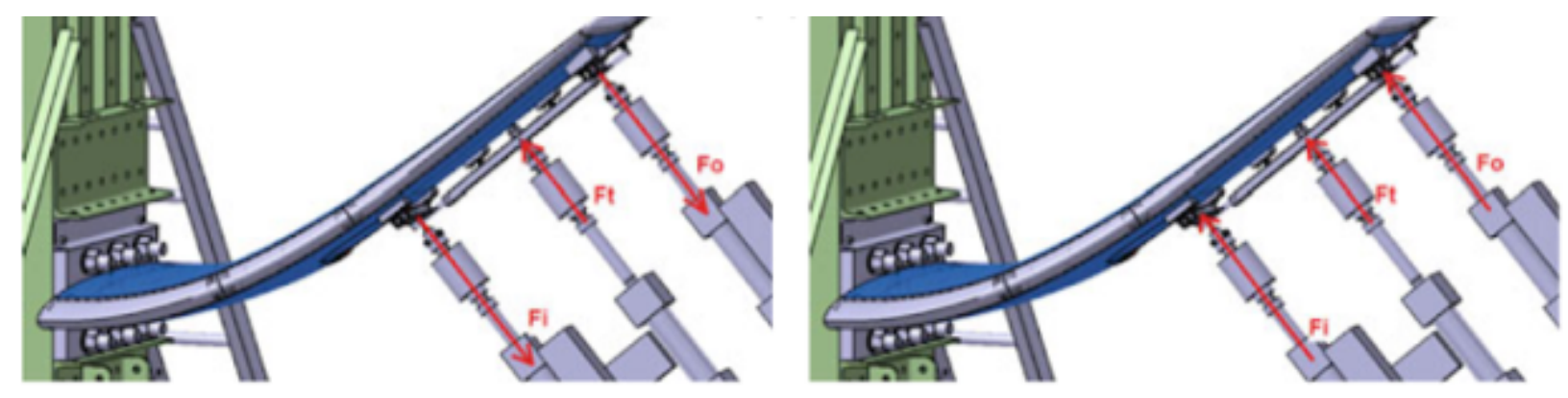

Figure 2-1: SARISTU ground static test setup [12]

Additionally, various strain gauges were used to measure the resultant strain, while the deflection was measured with the use of an optical system called PONTOS. The results from the ground static tests were compared to the FEA results, leading to a $20 \%$ overestimation in deformation by the FEA solution. The comparative results from the actual test to the finite model can be found in Figure 2-2 [12].

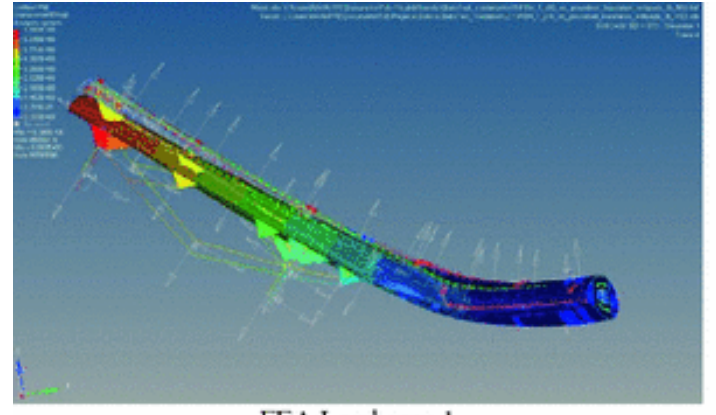

FEA Load case 1

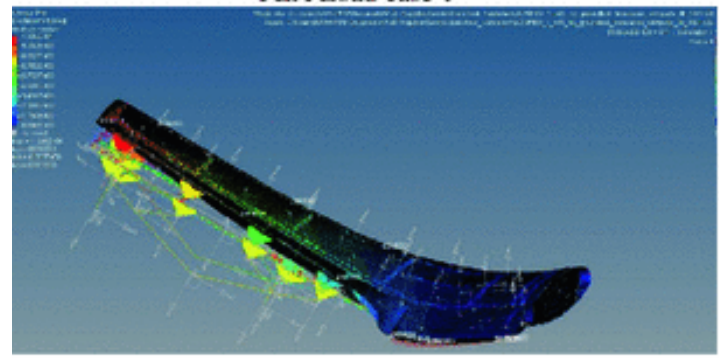

FEA Load case 2

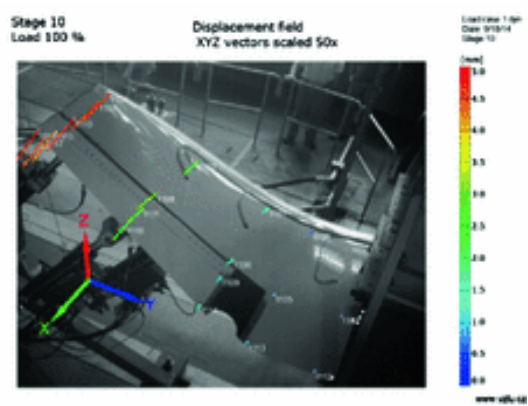

GST Load case 1

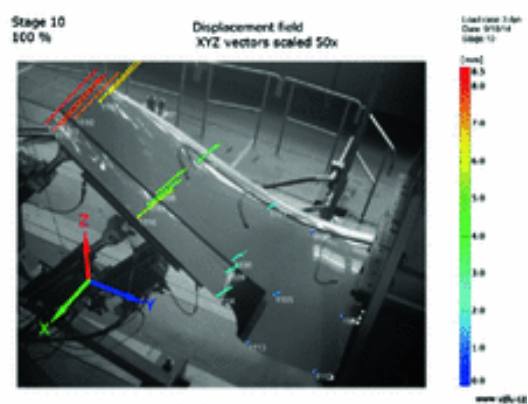

GST Load case 2

Figure 2-2: SARISTU comparative load results [12]

While a separate test was performed to determine the functionality of the adaptive winglet's trailing edge, the ground static test failed to test the motion under load. Rather, the model needed 
to be fixed in various positions prior to applying the load. To more accurately represent the loading conditions during operation, a dynamic loading model would need to be utilized.

A research paper by Bourdin, Gatto and Friswell [13] studied the aircraft controls of a variable cant angle winglet design. A model was developed to study the aerodynamic behavior of the wing design, capable of a $0^{\circ}$ to $90^{\circ}$ cant motion. Although the test was conducted with the use of a wind tunnel, the cant position was changed in the no-load condition. Figure 2-3 illustrates the wing model within the wind tunnel [13].
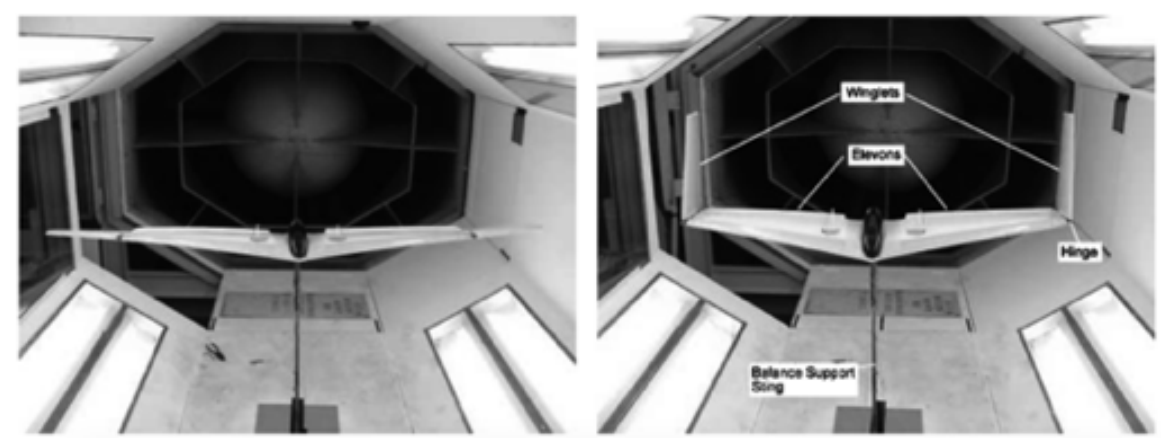

Figure 2-3: Wind tunnel test for variable cant angle winglet [13]

While the research conducted at the University of Bristol was not interested in the dynamic loading of the winglet in motion, the use of a wind tunnel could allow for a more accurate representation of the cant motion in flight.

\subsection{AIRCRAFT COMPONENT DYNAMIC LOADING}

Prior to an aircraft's first-flight and certification process, various on-ground tests are essential for the success of a new aircraft program. Testing control surfaces such as: ailerons, flaps, rudders and active winglet designs, requires a dynamic load test, which simulates the aerodynamic loads encountered throughout the flight envelope. In order to complete such testing, a dynamic load simulator (DLS) is often used. A DLS utilizes an actuation system to counteract the actuators 
used to alter the control surfaces. Thus, allowing the analysis of hinge moments and other critical features during motion [14].

In a paper by Nam and Hong, the importance and theory regarding dynamic load simulators is discussed in details. The paper discusses possible designs to test an active surface on an aircraft and also, a force controller design to replicate the wide spectrum of the resultant hinge moment variation. Figure 2-4 illustrates the load actuation system being incorporated in the pitch axis of the control surface. This allows for simpler control and accurate loading throughout the various load cases. Additionally, to more accurately generate the loads, the force controller designed in the paper utilized quantitative feedback theory (QFT). The efficiency of the QFT force controller, with the consideration of aircraft dynamics, control law and the hydraulic system was proven accurate by numerical solutions [14].

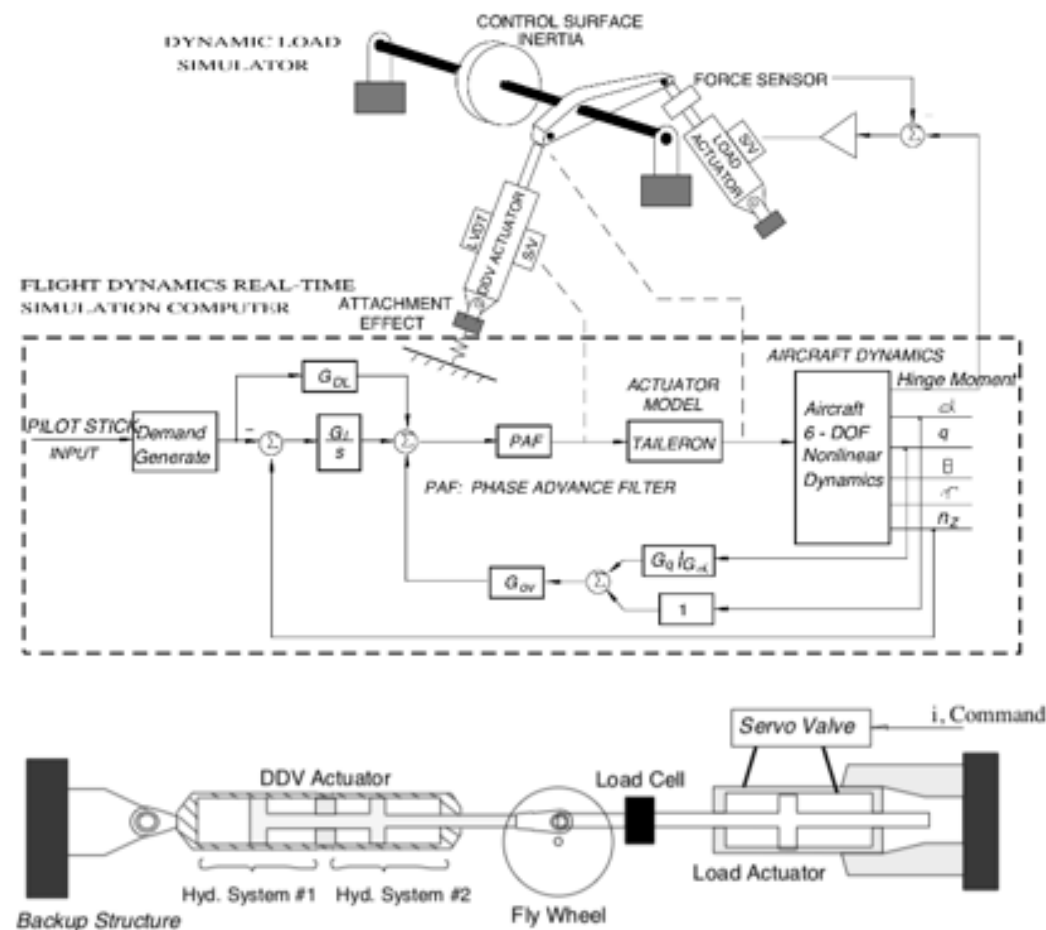

Figure 2-4: Schematic of dynamic load simulator [14] 


\subsection{WING LOADING}

To ensure the functionality of a morphing winglet structure and have the design certified, a load test is required. The load application should depict the ultimate and limit loads of the aircraft's flight envelope. While a full scale flight test is required to certify an aircraft, preliminary tests should be conducted to ensure a proof of concept and proof of functionality. These preliminary tests are often completed with the use of wind tunnels or test fixtures. While the use of a wind tunnel could more accurately represent the lift distribution on a wing, geometric constraints and economic challenges exist. A secondary solution is to utilize a load test fixture with an intricate design to best represent the loads. However, these designs that have been developed by OEMs are often classified under trade secrets. In order to research existing solutions to winglet loading methods, the bending test for an aircraft wing could be investigated.

A method that is used on smaller aircrafts, adapted from the 1960s is to flip the aircraft upside down, elevated at the fuselage and use gravity to apply a load. One method to load the wing is with the use of sandbags or weights. Figure 2-5 illustrates an inverted loading test that was utilized on a homebuilt aircraft. However, the use of hydraulic jacks and a whippletree system allows for a cleaner and safer solution. The use of hydraulics allows for a relief valve to remove the load in emergencies and also the ability to apply higher loads through larger actuators [15]. 

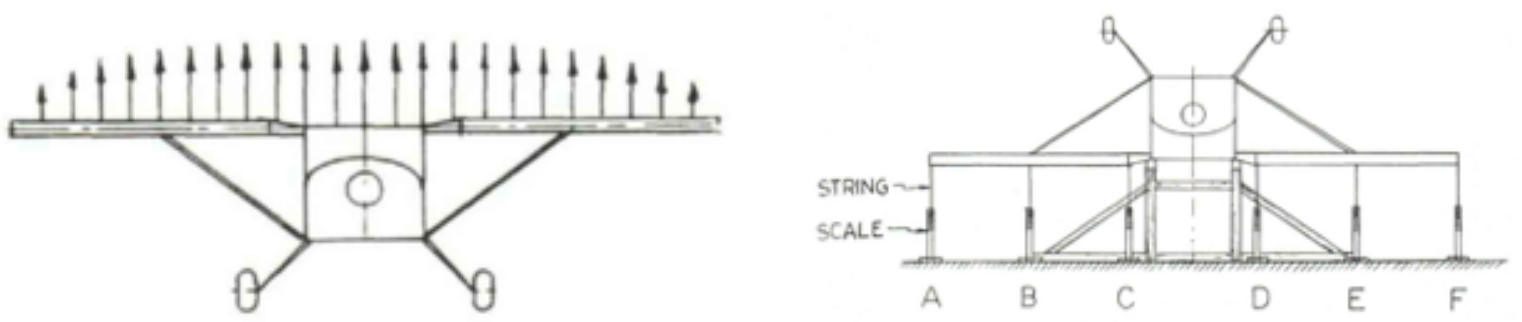

Figure 2-5: Inverted wing static test [15]

While the detailed designs of current wing loading methods are disclosed, the following illustrates four test setups that have been utilized by current OEMs. Many of the methods have a similar approach to loading the aircraft wing, through the use of multiple hydraulic actuators attached to a whippletree to distribute the load accordingly:

1. Figure 2-6 illustrates the wing load test for a Boeing 777.
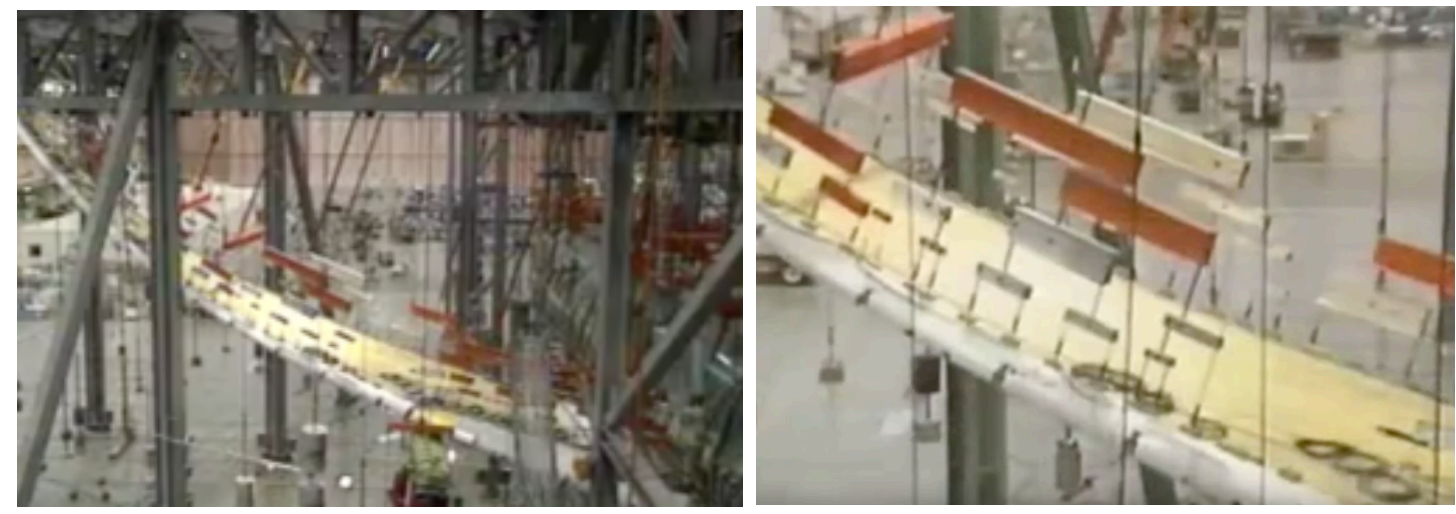

Figure 2-6: Boeing 777 wing loading test setup [16] 
2. Figure 2-7 illustrates the test setup for the Airbus A350 XWB.

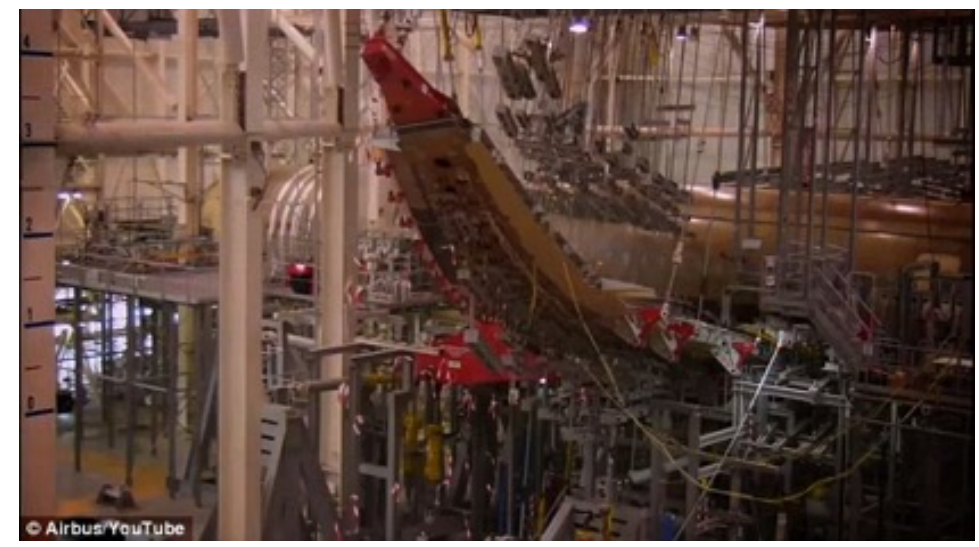

Figure 2-7: Airbus A350 XWB wing loading test setup [16]

3. Figure $2-8$ is the wing loading test setup for the Boeing 787
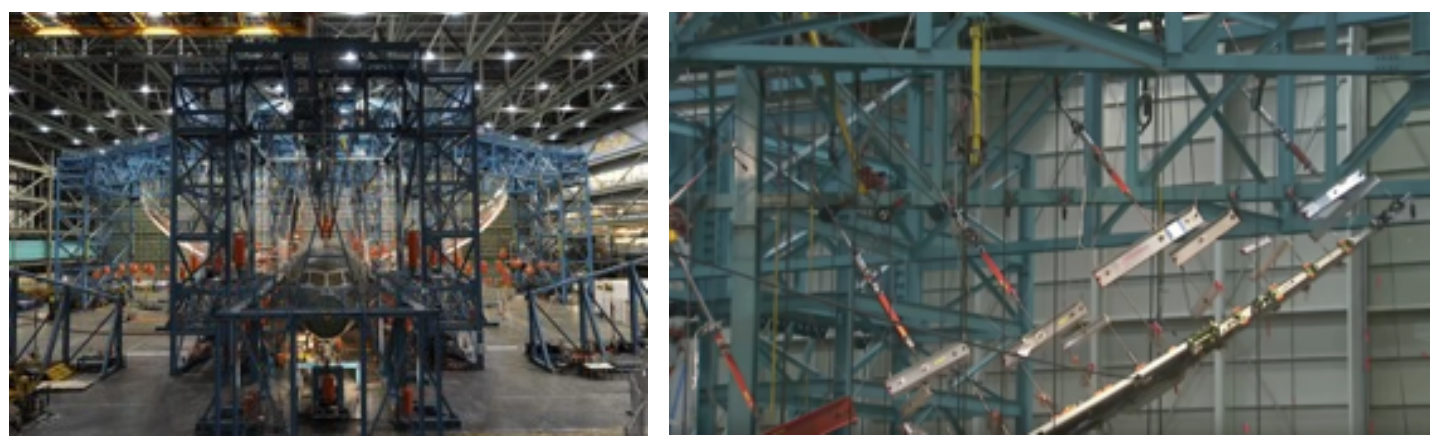

Figure 2-8: Boeing 787 wing loading test setup [16]

4. Figure 2-9 is a stress test on the wing of a DG Flugzeugbau DG-800/1000 (glider). The setup utilizes a design similar to a crane to apply the load.
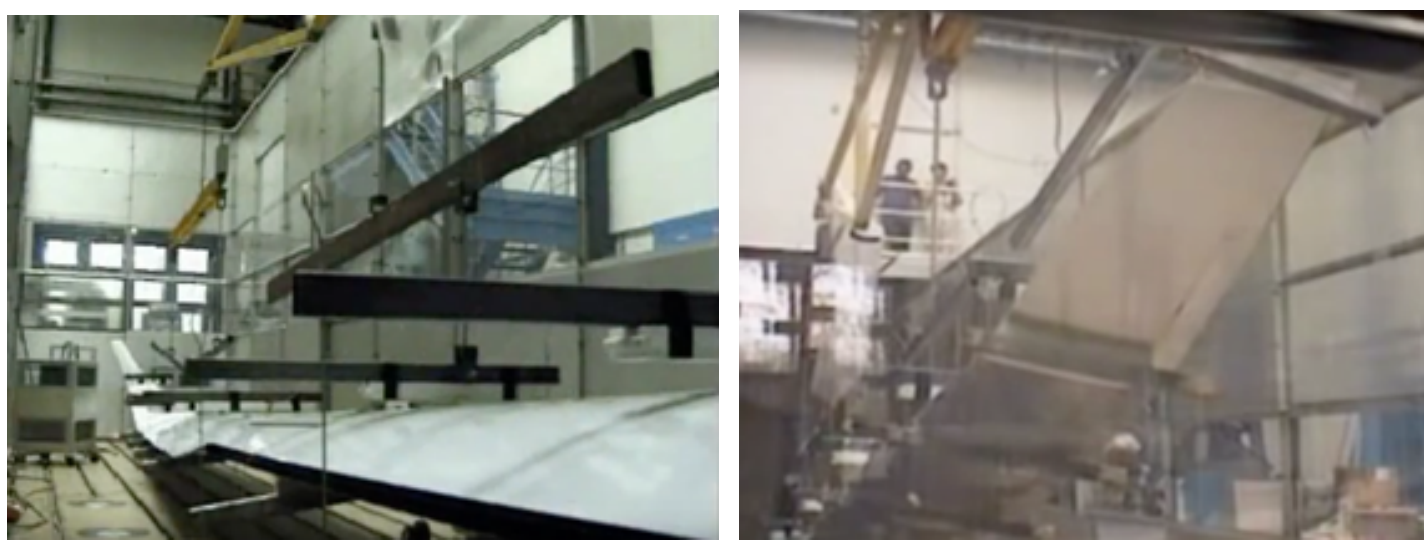

Figure 2-9: DG Flugzeugbau DG-800/1000 wing loading test setup [16] 


\subsection{AILERON LOADING}

Methods for the dynamic loading of an adaptive winglet could be explored through other control surfaces on an aircraft. Similar to a morphing winglet, an aircraft's aileron requires a change in angle throughout the flight. A research project called Vector for Innovative Sustainable Air Transportation (VITAS), has investigated the replacement of an aluminum aileron on the P180 Avanti with one made from CFRP. Determining its structural properties required the development of a full scale model for both a torsional stiffness test and an ultimate static load test. The deflections during both tests were obtained through 14 positon transducers placed in pairs (leading edge and trailing edge) in order to compute the torsional deformation. Fifteen strain gauges (rectangular rosettes) were also installed to measure the strain in all directions. During the torsional stiffness test, a dummy torque was applied about the ailerons axis of rotation. The test fixture for the torsional stiffness test has been illustrated in Figure 2-10. [17]

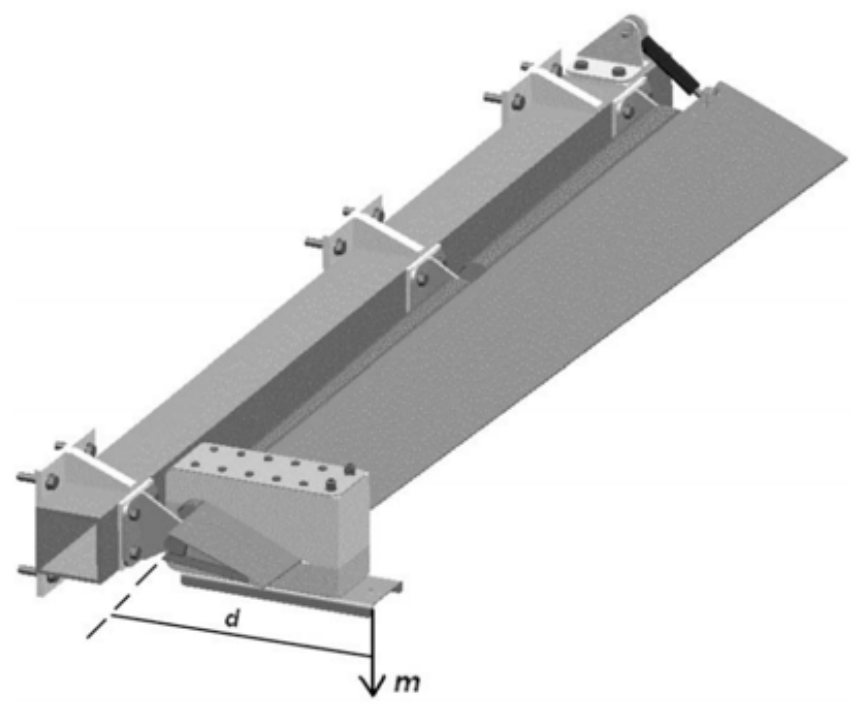

Figure 2-10: Torsional stiffness test setup [13]

For the ultimate static load test, a whippletree loaded by a hydraulic jack was connected to the upper surface of the aileron by means of eight rubber pads. The whippletree was designed to 
best represent the desired loading on the aileron. By analyzing the test setup in Figure 2-11 and results obtained from the research paper, an assumption can be made that the applied load was not adjusted to ensure perpendicularity during the aileron's motion. Therefore, it is likely that an undesired moment was present during the test [13].
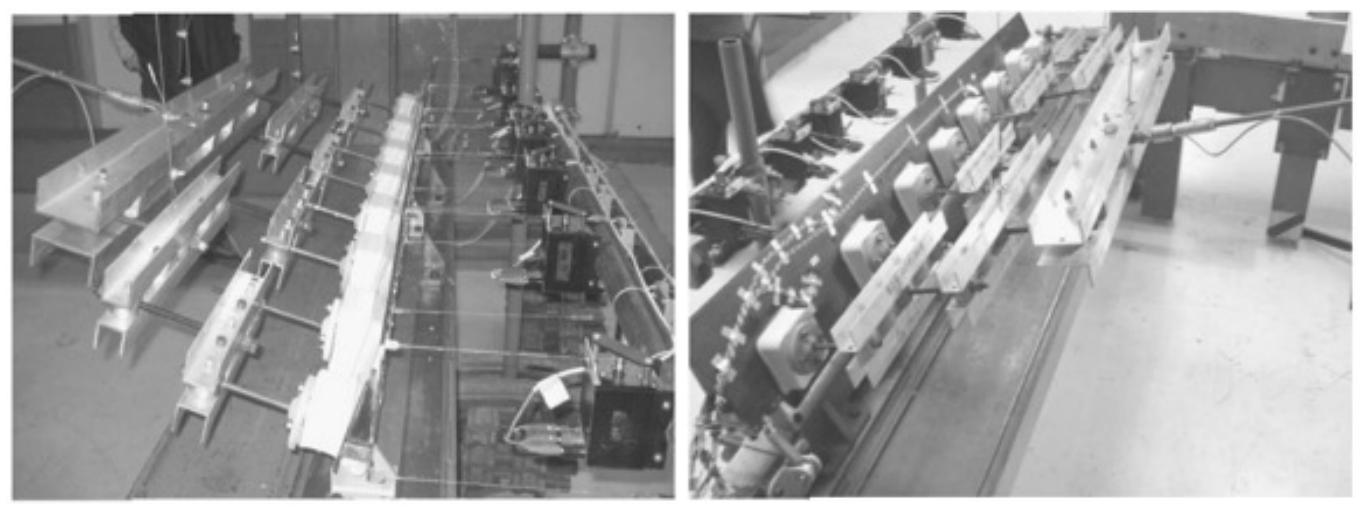

Figure 2-11: Ultimate static load test of an aileron [13]

In a paper by Prasal and Gangadharan, an aileron endurance test rig (ETR) was designed with a dynamic load simulator. The dynamic load simulator was used to simulate the aerodynamic load and ensure functionality, performance and stability of the aileron's actuators under load. Electro-hydraulic systems are often used to counteract aerodynamic loads acting on control surfaces. These systems allow for high power to weight ratios, optimal response rates and ability to withstand loading, which are all desired for the aerospace application. An ETR is used to test the fatigue and endurance characteristics for aircraft components. While the component being studied was controlled by its position, the load system was required to run in a force control loop. The loading design in the aileron's ETR system utilized a load actuator that was controlled by an electro-hydraulic servo valve. The applied load was acting on a lever that was also connected to the aileron. The schematic for the loading mechanism has been highlighted in Figure 2-12 [18]. 

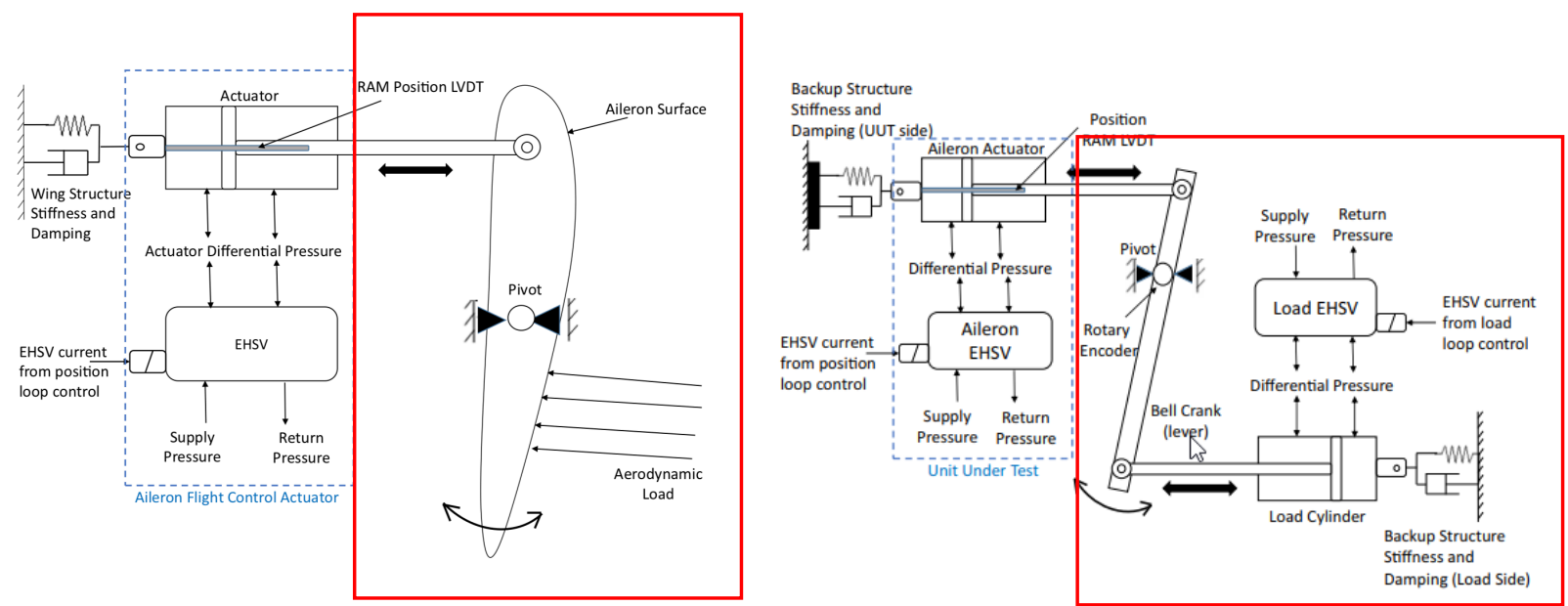

Figure 2-12: Structural diagram for the aileron endurance test setup [18]

Figure 2-12 illustrates the two systems (aileron actuation system and loading system) interacting and delivering equivalent aerodynamic loads about the aileron's hinge (pivot). The paper focused on the interaction between the load system and the control surface actuation system. As shown, the load cylinder applies a force onto the lever, producing a moment about the pivot. This generated moment is the applied loading, which must be counteracted by the force of the aileron actuator.

A physical test rig was developed to verify and validate the theoretical results from the paper. Figure 2-13 shows the CAD model developed to aid in the design and fabrication of the aileron endurance test rig. The aerodynamic load data was based on a typical flight spectrum obtained from an aircraft manufacturer [18]. 


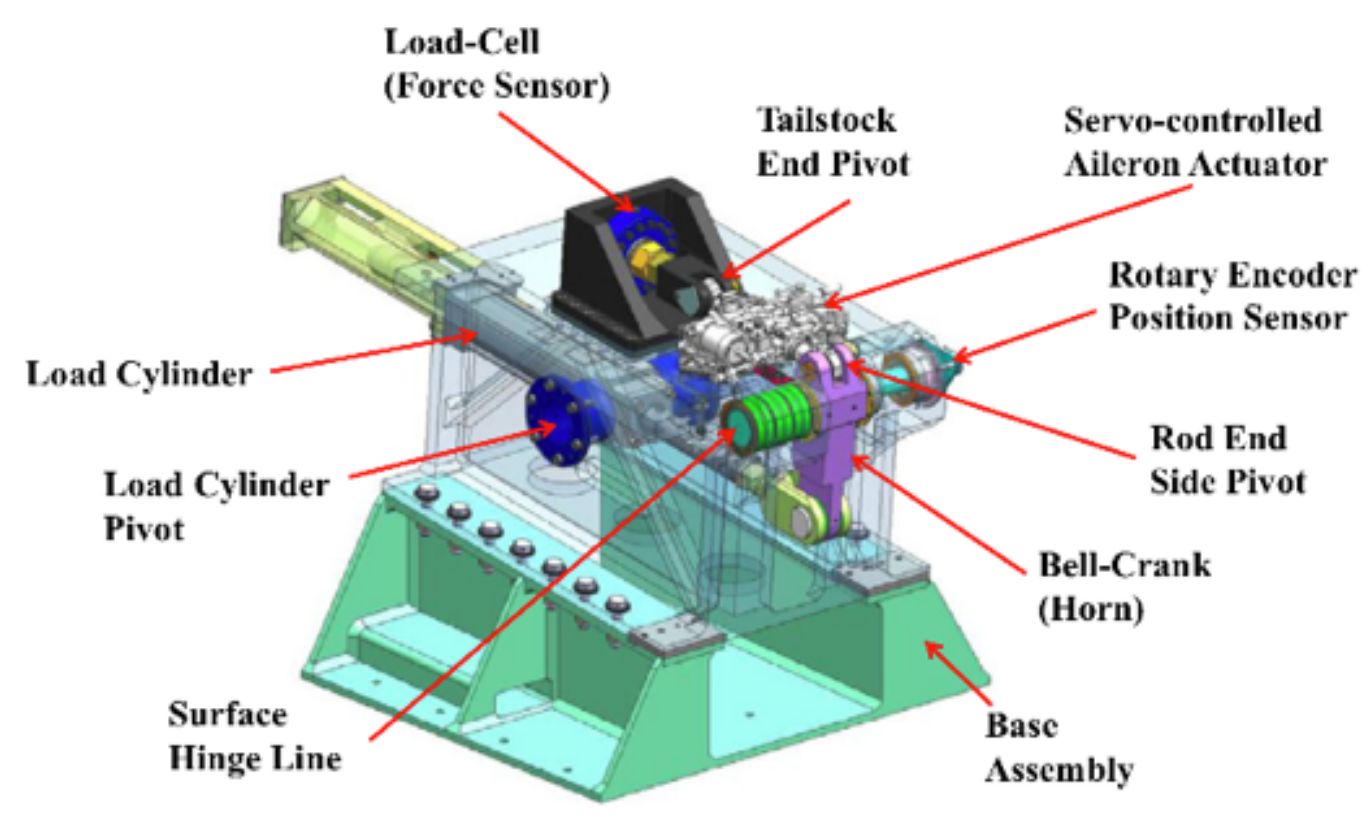

Figure 2-13: Aileron endurance test rig CAD model [18]

The paper presents a method to apply a moment about the control surfaces axis of rotation, through a common lever arm. However, as the aileron is actuated, the angle between the moment arm and the applied load does not remain perpendicular. Failing to apply a perpendicular load introduces an undesired side load on the actuator's hinge point. 


\subsection{RUDDER LOADING}

The static load testing of an aircraft rudder was conducted by AEROSUD, an established leader in the South African aviation industry. In March of 2016, a CFRP rudder was manufactured and tested using a test jig illustrated in Figure 2-14 consisting of an actuator, load cell and whippletree system to apply the load.
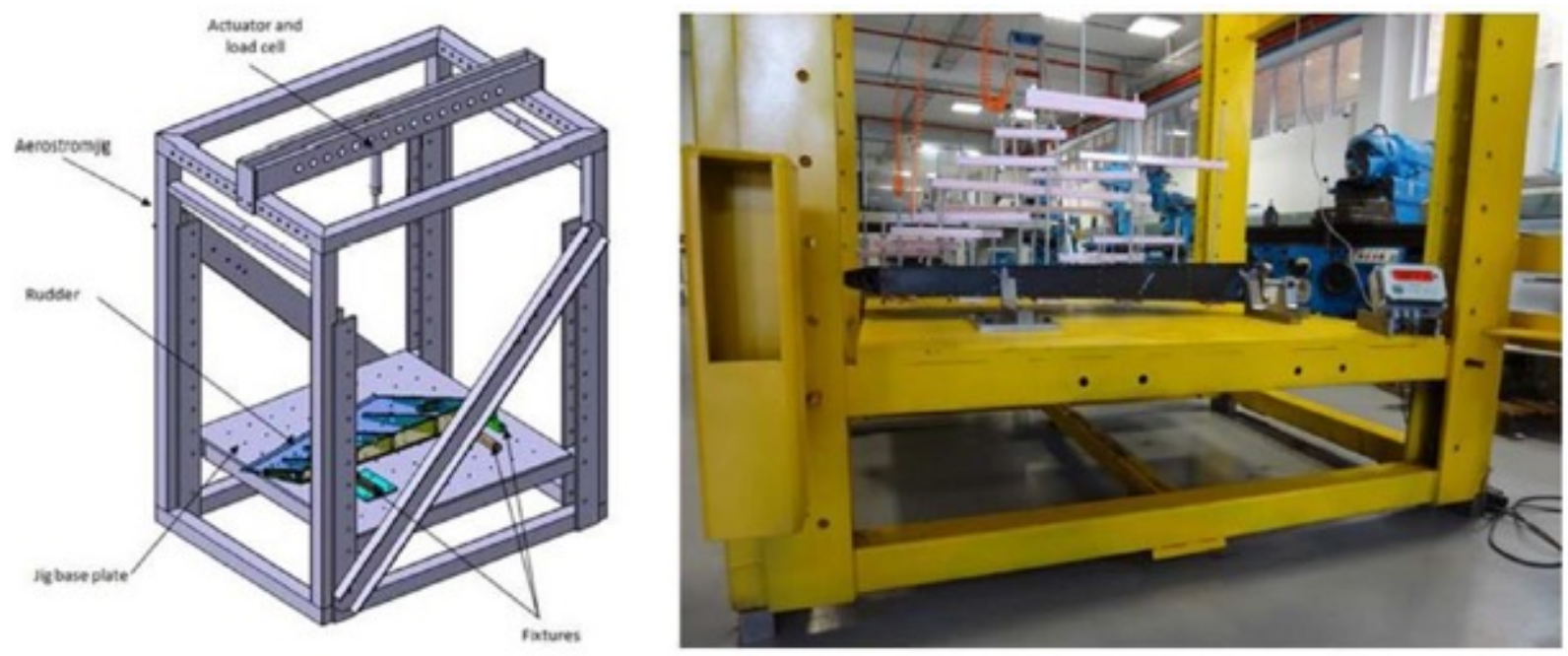

Figure 2-14: AEROSUD rudder static test [19]

The test requirement was to apply a $304 \mathrm{~kg}$ load on the static winglet for 3 seconds without failure. While the model passed the test, it fails to test the rudder in dynamic conditions (yaw motion) [19]. Although the static testing of a rudder will ensure the structural integrity of its design, a dynamic load simulator would ensure the functionality and integrity of the control mechanism used to adjust the rudder's deflection [19]. The above model provides insight into test fixture designs and the types of supports and reinforcements that would be required. 


\subsection{WIND TURBINE LOADING}

Loading mechanisms can also be found for the testing of large wind turbine blades. Similar to aircraft wings and winglets, the wind turbine blade produces a lift force and must undergo a static strength test. At the National Renewable Energy Center (NREC) in the United Kingdom, the static testing of a turbine blade is performed through the use of electric winches which drive cables attached to non-critical points on the blade. The tests utilize strain gauges to measure stresses and lasers to measure the deflections along the blade [20].

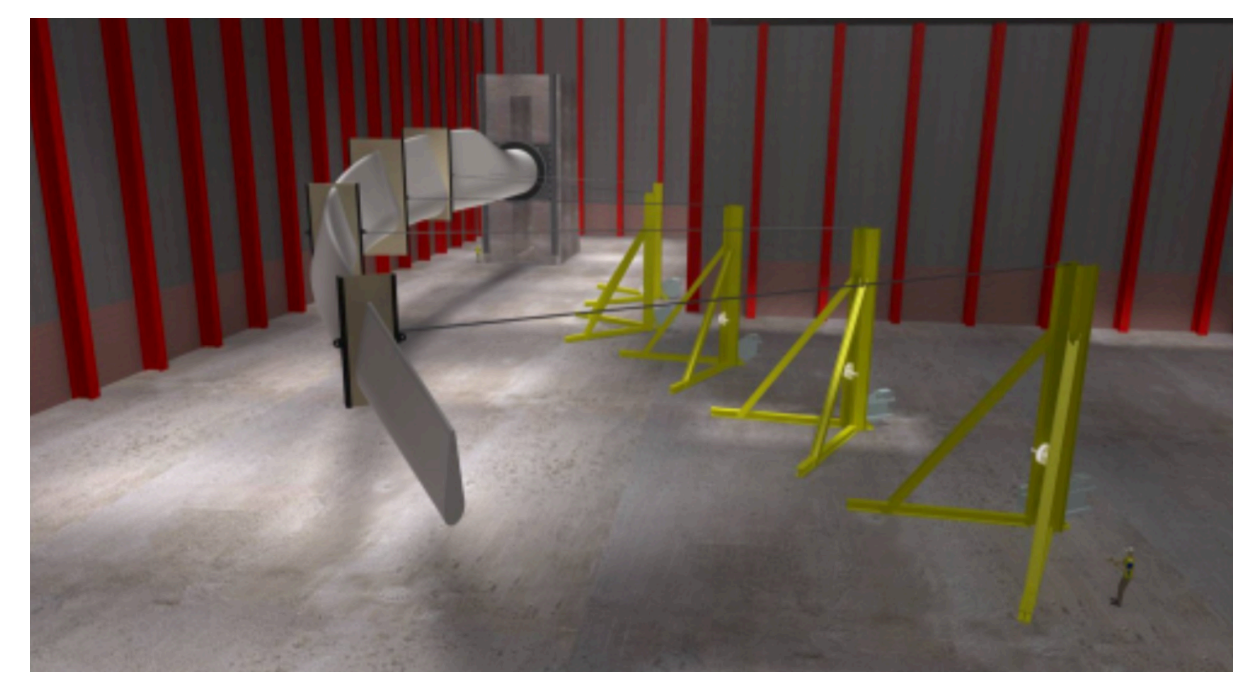

Figure 2-15: Wind turbine blade static test fixture [20]

Figure 2-15 illustrates a typical wind turbine static test setup used at the NREC. As illustrated, the applied loading acts in one direction along the span of the blade. As the blade bends during the test, the resultant moment at the root varies and a side loading is present since the applied loading on the blade does not maintain perpendicularity. 


\subsection{DISTRIBUTED LOAD VS POINT LOAD}

As summarized in the literature review, the loading fixtures on various aircraft control surfaces utilize either a point load about the mean aerodynamic center or a distributed load system. The resultant moment from both loading systems about the point of interest are identical. However, the use of a distributed load will best represent the lift profile acting on the control surface.

Two common methods to simulate a distributed load include pressure loading and a system of closely spaced discrete loads. Pressure loading utilizes the force of gravity acting on sand and/or water bags [21]. Commonly performed in the aerospace industry at smaller scales, sandbags are used to represent the load distributed along a wing, as shown in Figure 2-5 [22]. The second method utilizes a series of discrete loads to accurately simulate the distributed load. A whippletree system which is illustrated in Figure 2-16 is a commonly used model to represent a distributed load. Through a series of linkages, a whippletree mechanism distributes the force evenly and can be utilized in both tension and compression [23]. While effective, the whippletree system would require sufficient stiffness when utilizing large loads [21].

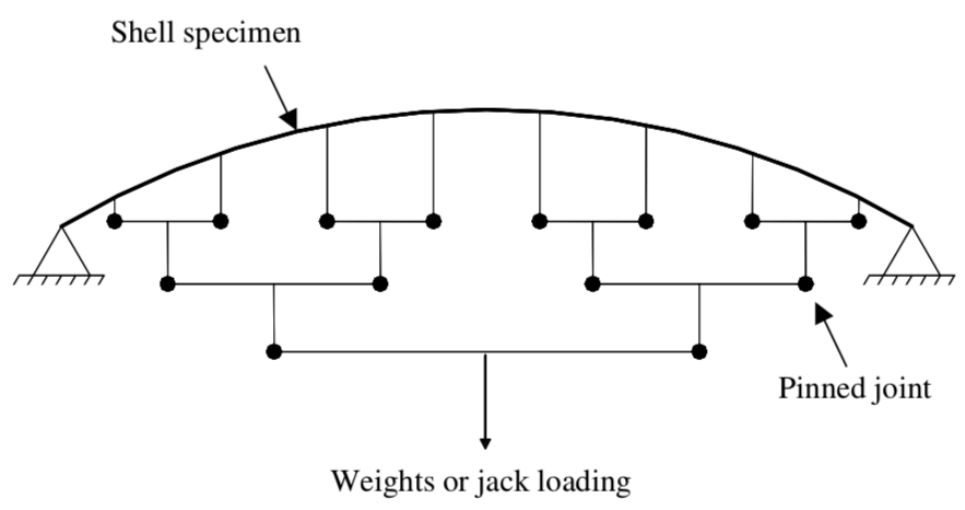

Figure 2-16: Whippletree load distribution model [21] 
A method proposed by Wong, Teng and Wang [21] utilized an intricate pulley system to distribute the loading. The ability to change the load direction, amplify a load and convert a force into a number of equal forces through a pulley system is proposed to be a simpler solution to simulating a distributed load. Figure 2-17 illustrates the proposed method [21].

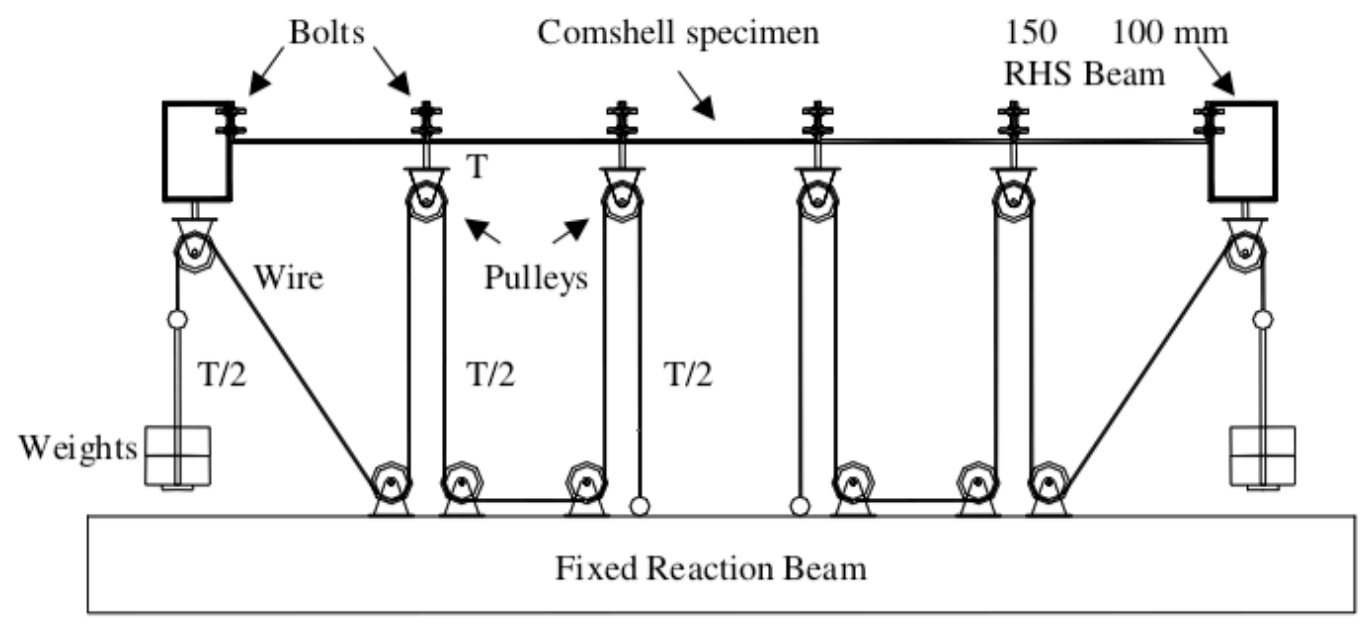

Figure 2-17: Pulley based loading system [21]

For the purpose of analyzing the resultant moment about an axis of interest, where the structure of the surface is not of interest, a point load would be adequate. By obtaining the resultant force, a point load about the mean aerodynamic center will produce the equivalent moment as a distributed load, simplifying the fixture design. 


\section{DESIGN METHODOLOGY}

The following section outlines the methodology used to develop the final loading model to assess the structural integrity of the morphing winglet's cant module. To perform a structural strength test on a dynamic surface such as a winglet, the use of a mechanism based loading system was required. Since the loading models currently used in industry focus on static testing (see Section 2), the direction of the applied load remains constant. As the winglet travels through the cant motion, the direction of the applied load needed to vary to ensure the resultant moment about the winglet's axis of rotation remained constant. The lower and upper limits of the winglet's cant motion have been illustrated in Figure 3-1a and Figure 3-1b respectively, with the load direction illustrated.
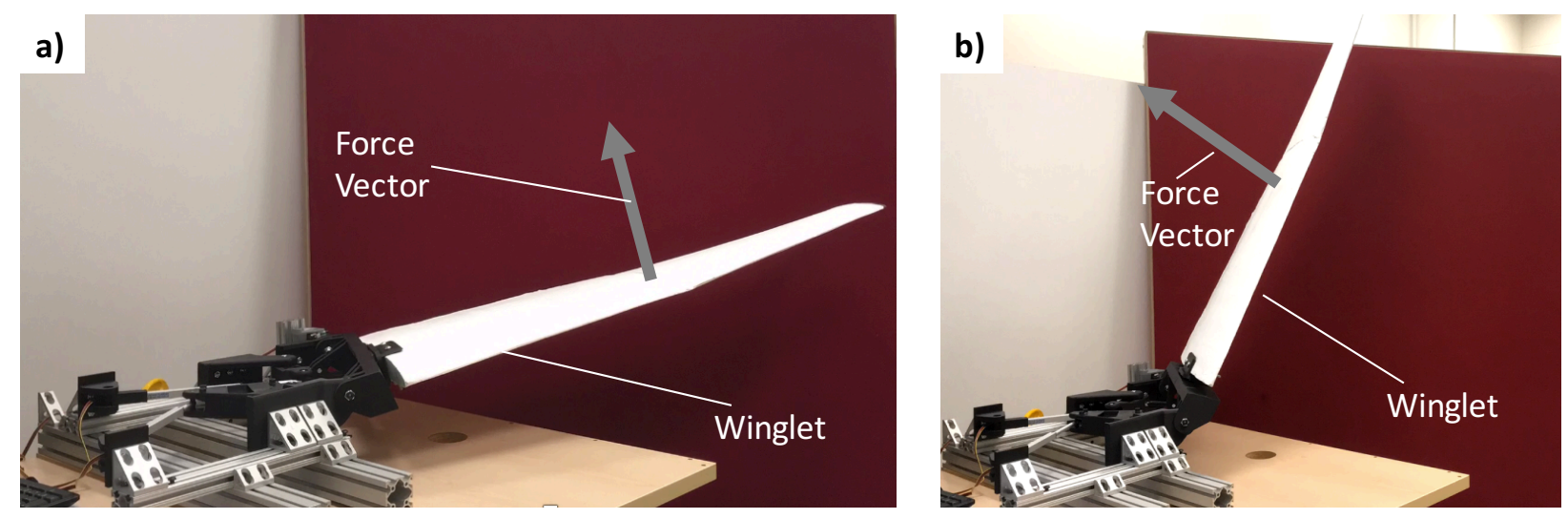

Figure 3-1: Load directional requirement - a) cant angle $=10^{\circ}$ b) cant angle $=80^{\circ}$

An enumerative design procedure was implemented to determine a functioning dynamic loading model for the morphing winglet. Focusing on the use of a closed planar four bar mechanism to meet the requirements, all combinations of both prismatic $(\mathrm{P})$ and revolute $(\mathrm{R})$ joints were studied [24]. A four bar linkage design consists of the following elements: a fixed link called the frame, the input link called the crank, the output link known as the rocker or follower link and finally, the coupler which transfers the motion from the input to the output link [25]. The most 
common four bar linkage consists of four revolute joints, illustrated in Figure 3-2a. By replacing one of the linkages with a prismatic joint, the linkage system becomes a slider-crank mechanism, illustrated in Figure 3-2b. This linkage design can be found in various applications, such as a single piston engine. Finally, if two of the turning pairs are replaced by prismatic joints, the resulting mechanism converts to a double slider-crank mechanism, which has been illustrated in Figure 3-2c [25].

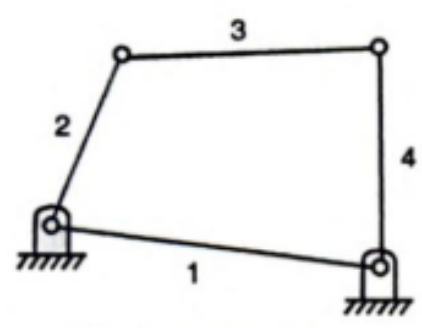

a)

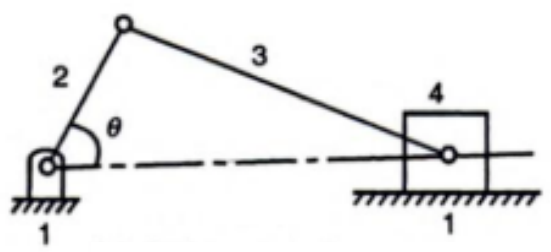

b)

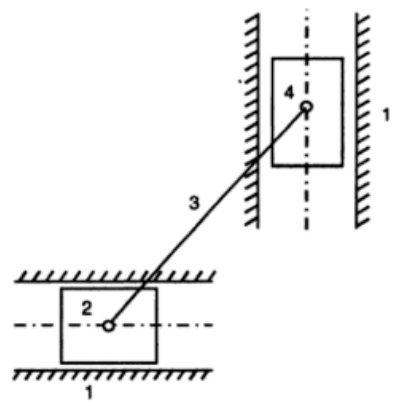

c)

Figure 3-2: Linkage designs: a) four bar mechanism b) slider crank mechanism [25]

Given the unique loading requirements for the morphing winglet, uncommon linkage designs were also analyzed. By selecting a different link on the four bar chain to become the reference or frame, a unique kinematic chain could be derived. This transformation is called kinematic inversion [26]. Furthermore, by varying the lengths of the linkages, restrictions can be placed on the input and output angles, resulting in a desired motion [27].

Given the first joint for the winglet system (Link 1) is revolute as illustrated in Figure 3-3, only the following combinations of revolute and prismatic joints were necessary for analysis:

- R-R-R-R

- $\quad$ R-R-P-R

- R-P-R-R

- R-P-P-R 
- R-R-R-P

- R-P-P-P

- $\quad$ R-R-P-P

- R-P-R-P

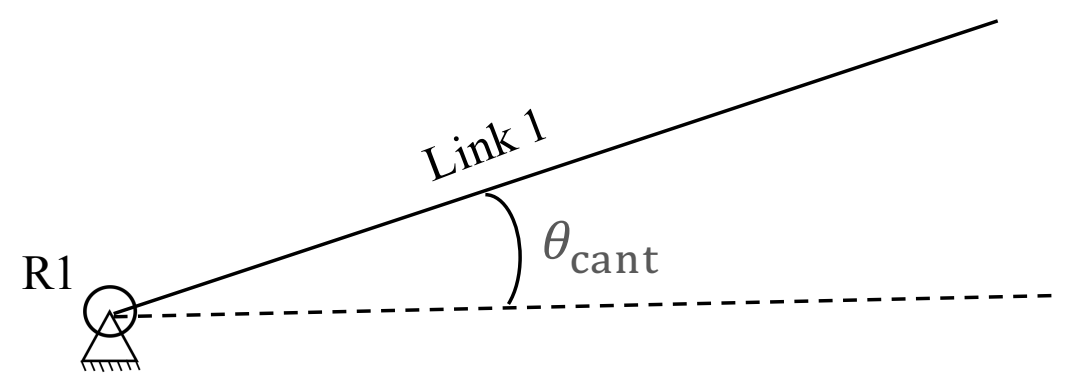

Figure 3-3: Winglet kinematic model

The acceptability criteria for each design was based on the two requirements for the dynamic loading model, which would ensure a constant moment about the cant module's axis of rotation:

1. Ability to apply a constant force at the MAC to simulate lift

2. Ability to maintain perpendicularity between the load and the winglet throughout the cantmotion $\left(10^{\circ}-80^{\circ}\right)$ to produce a constant moment about the cant module's axis of rotation

To reduce the complexities associated with the synchronization of multiple active joints and to minimize the challenges associated with manufacturing, the following objectives were also considered when proceeding through each enumeration design:

1. Minimizing the number of active joints

2. Minimizing the loading mechanism's workspace

Upon completion of the analysis of each four bar linkage enumeration, a table was produced to summarize which designs were admissible and not-admissible. 


\subsection{R-R-R-R DESIGN}

The first dynamic loading model utilized a common four-bar linkage system with four revolute joints. Figure 3-4 illustrates four conventional planar R-R-R-R mechanism designs which produce unique path trajectories depending on the length of the linkages. Given the required motion of the input link must travel from $10^{\circ}$ to $80^{\circ}$, the "Crank-rocker" and "Parallelogram linkage" $\left(2^{\text {nd }}\right.$ and $4^{\text {th }}$ image $)$ were used as potential kinematic loading designs for the morphing winglet.
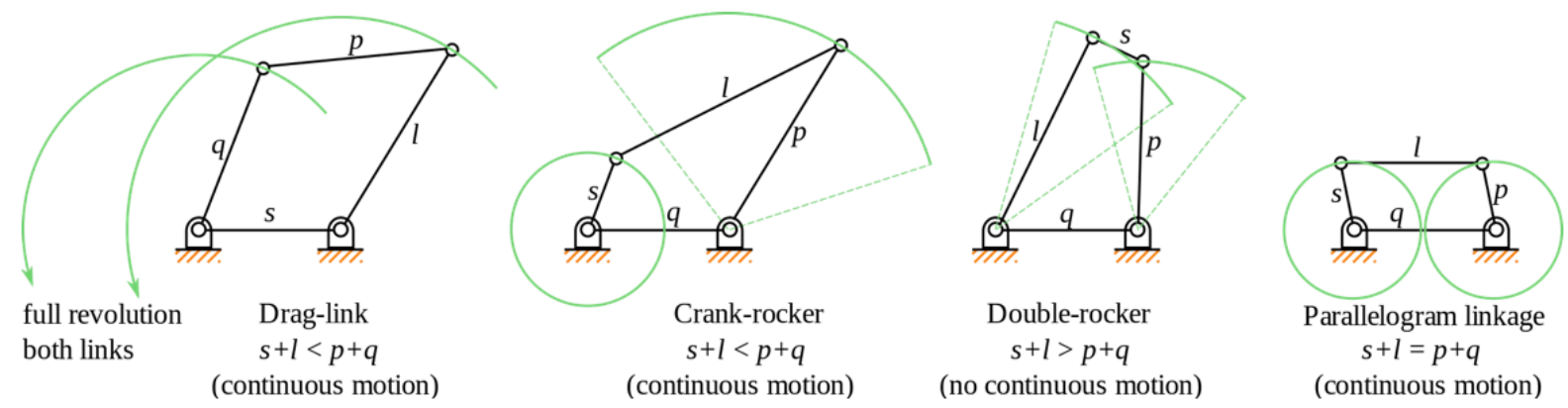

Figure 3-4: Common R-R-R-R mechanism designs [24]

The second requirement stated that the applied loading must remain constant throughout the winglet's cant motion. Therefore, Link 2 would need to be perpendicular to Link 1 as the input angle varies from $10^{\circ}$ to $80^{\circ}$. To ensure the loading acts perpendicular to the winglet throughout the motion, Link 1 was modified to become an "L" shaped link. Figure 3-5 illustrates the complete R-R-R-R kinematic design which attempts to ensure the applied loading remains perpendicular throughout the cant motion. The proposed R-R-R-R mechanism did not require additional active joints, which simplifies the synchronization and control of the loading model. 


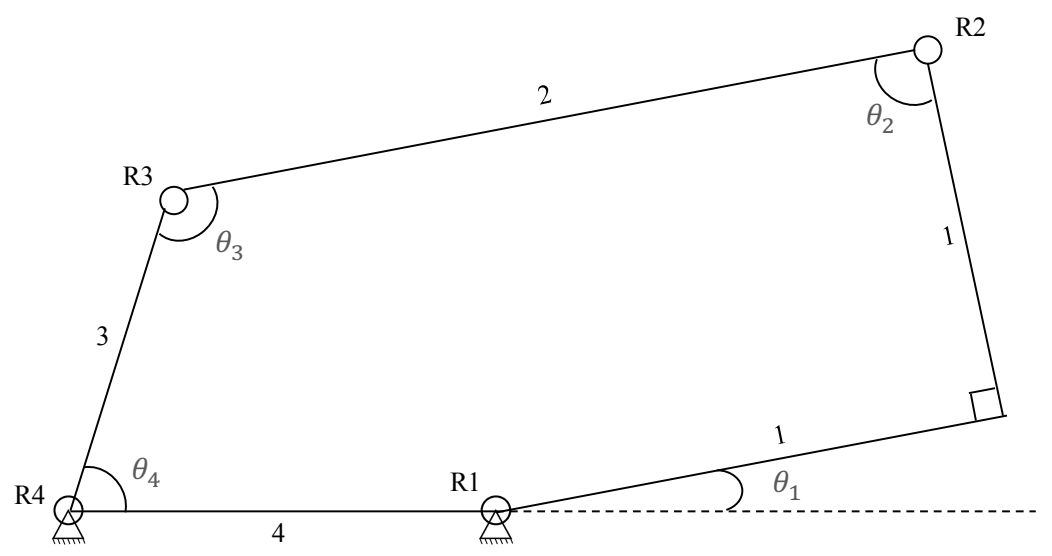

Figure 3-5: Modified R-R-R-R design

The load in this design would need to be applied on the vertical portion of Link 1. Through the use of a pulley system, the applied load can be guided through the revolute joints and attached to the load point. This has been illustrated in Figure 3-6.

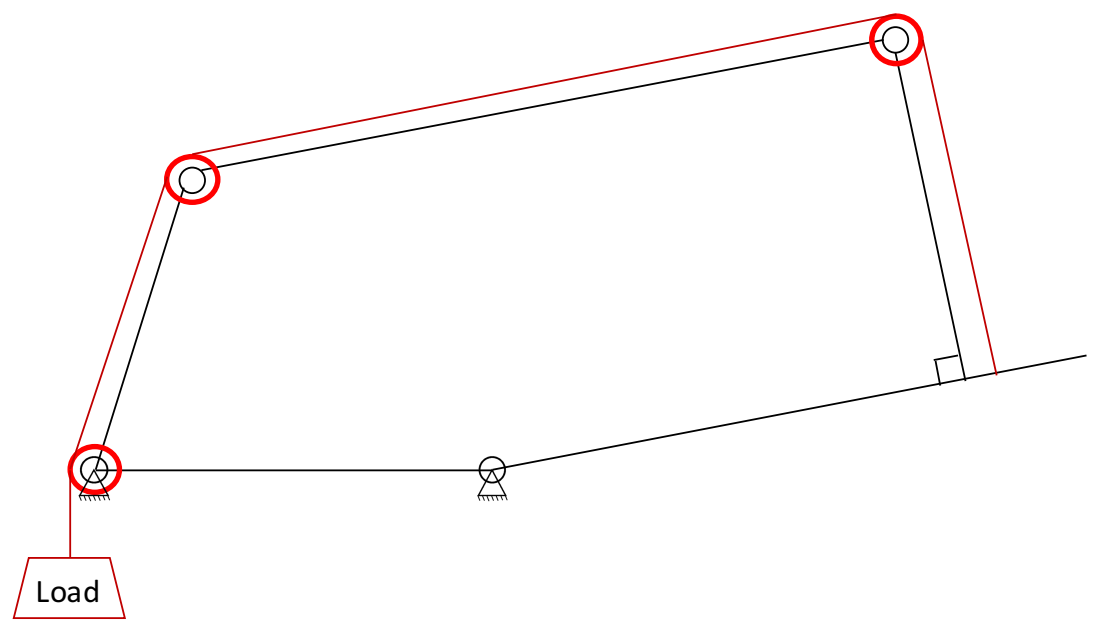

Figure 3-6: $R-R-R-R$ pulley system design

Figure 3-5 shows the limitation of utilizing an R-R-R-R mechanism to apply a constant perpendicular load through the full cant motion of the winglet. As the input angle $\left(\theta_{1}\right)$ changes, $\theta_{2}$ also varies. Therefore, the angle at which the load is transferred onto the second revolute joint varies and produces an undesired loading at R1. This leads to a non-uniform moment about the winglets axis of rotation. Since the second requirement could not be met, the R-R-R-R mechanism was eliminated from the list of potential design solutions. 


\subsection{R-R-P-R DESIGN}

A second kinematic dynamic loading model for the morphing winglet utilized a passive RR-P-R mechanism, which had a revolute joint at the winglet's connection point and a fixed, perpendicular slider/guide connection. However, this required the upper rail to rotate in the same planar direction as the winglet. The second revolute joint at the loading point was necessary to create the necessary degree of freedom. The first iteration for the loading design was modeled in Figure 3-7 without the pulley system for simplicity.

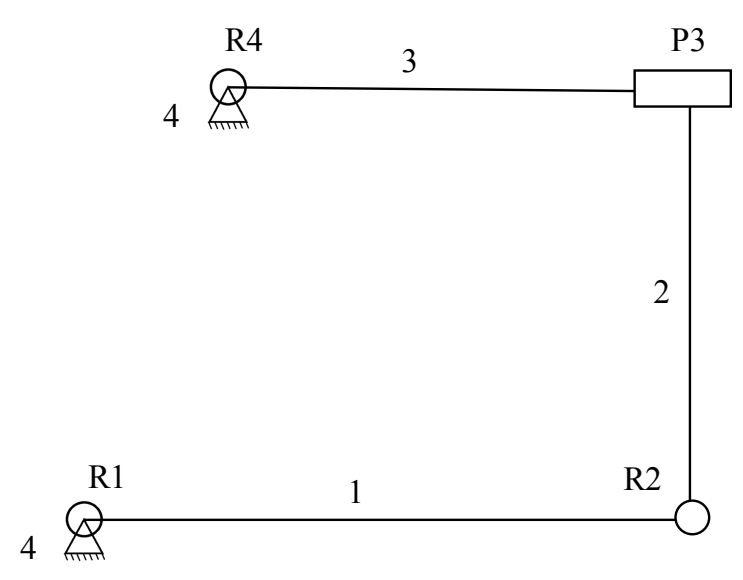

a)

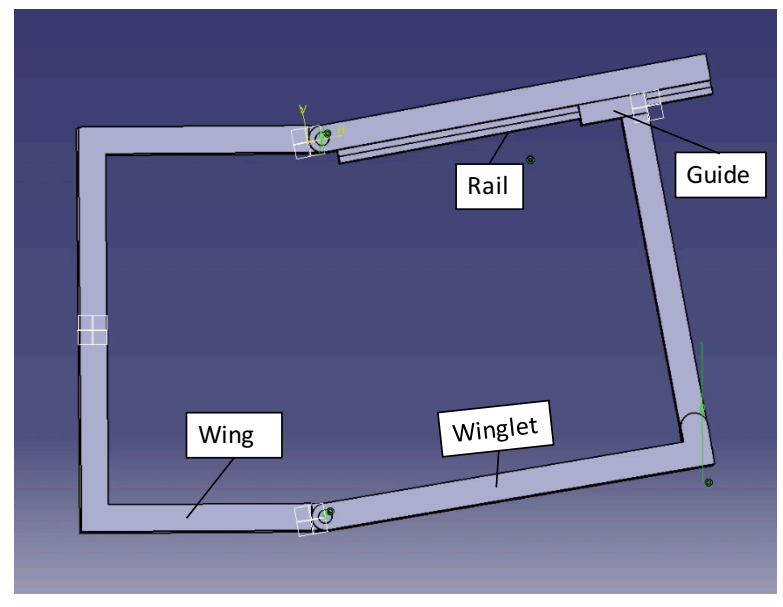

b)

Figure 3-7: R-R-P-R model for iteration 1-a) Kinematic model b) CAD model

Since the connection point at the winglet end and slider bar was a revolute joint (R2), the beam was free to rotate. With the current model that was arbitrarily dimensioned, the design failed to achieve the complete cant motion. The design also produced an undesired side loading since R2 significantly deviated from $90^{\circ}$. This limitation was highlighted in Figure 3-8. 


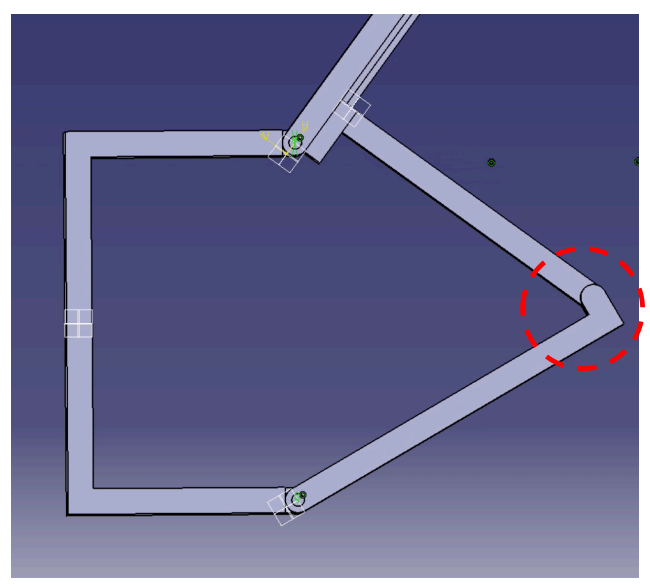

Figure 3-8: Limitations of iteration 1

The above limitation was also analyzed with the use of the following kinematic model and equations, where ' $S$ ' represents the applied load's moment arm:

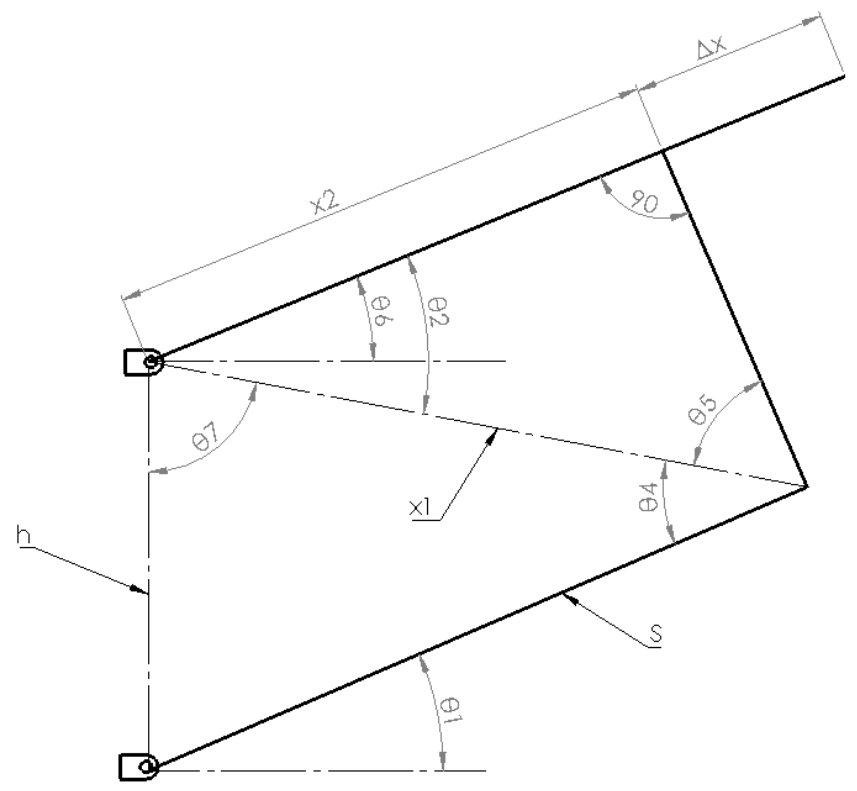

Figure 3-9: R-R-P-R iteration 1 kinematic model

$$
\begin{gathered}
x_{1}=\sqrt{S^{2}+h^{2}-2(S)(h) \cos \left(90^{\circ}-\theta_{1}\right)} \\
\theta_{4}=\sin ^{-1}\left(\frac{h * \sin \left(90^{\circ}-\theta_{1}\right)}{x_{1}}\right) \\
x_{2}=\sqrt{x_{1}^{2}-h^{2}}
\end{gathered}
$$




$$
\begin{gathered}
\theta_{2}=\sin ^{-1}\left(\frac{h}{x_{1}}\right) \\
\theta_{7}=\sin ^{-1}\left(\frac{S * \sin \left(90^{\circ}-\theta_{1}\right)}{x_{1}}\right) \\
\theta_{6}=\theta_{2}+\theta_{7}-90^{\circ}
\end{gathered}
$$

With the above model, the only variable that could be optimized was the ratio between the vertical distance $(h)$ between R1 and R4 and the moment arm $(S)$ :

$$
h-\text { ratio }=\frac{h}{S}
$$

By varying the height with a constant moment arm of 20 -inches $(S)$, which was initially provided by the Ryerson Morphing Winglet Team, and studying the load angle being generated $\left(\theta_{4}+\theta_{5}\right)$ and the actuator displacement throughout the cant motion, the relationships in Figure 3-10 were found.
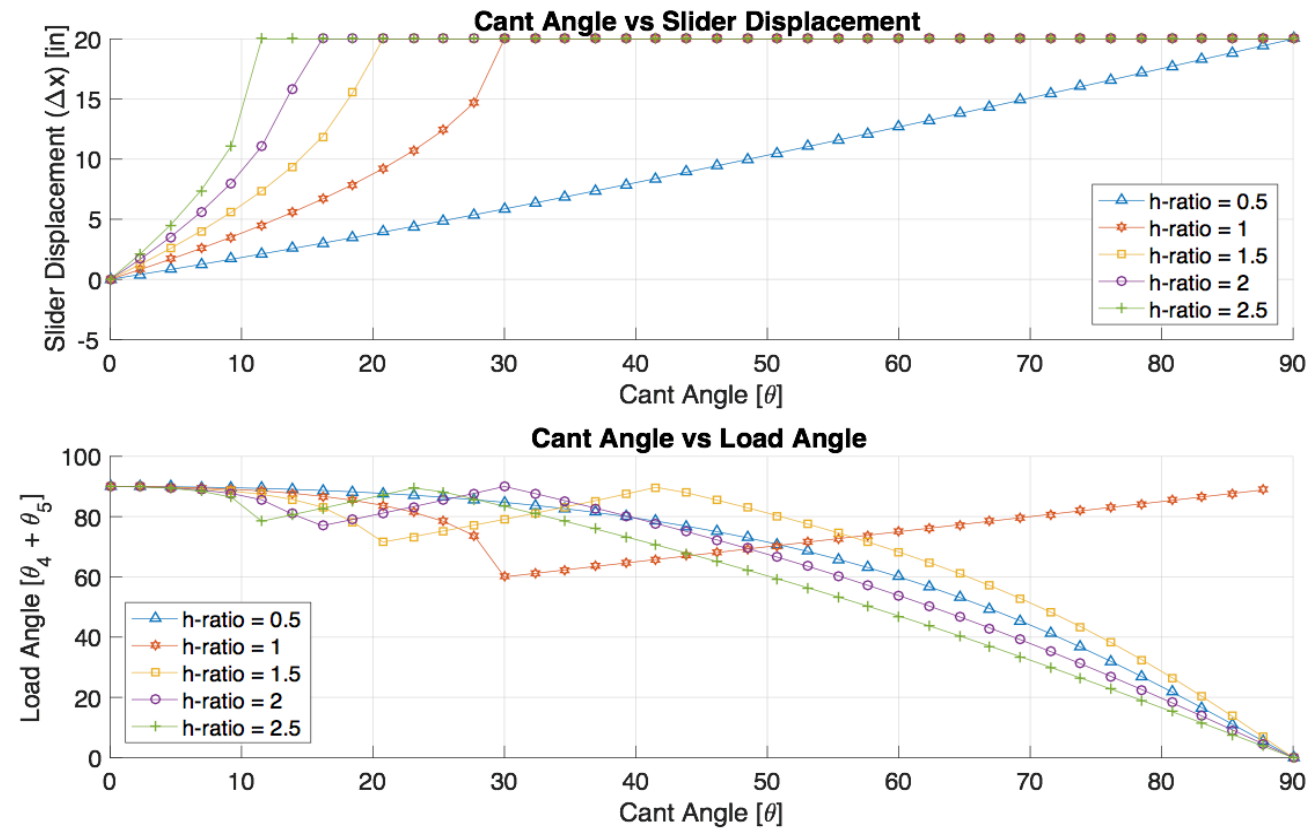

Figure 3-10: Cant angle vs slider displacement/load angle 
The inflection points in the first plot represents the limitation for the slider displacement. Although a ratio smaller than 0.5 will eliminate this constraint, the second plot highlights the significant variation in load angle as the cant angle increases. As a result, the first R-R-P-R iteration for the loading mechanism was limited by its geometry.

In order to eliminate the geometric constraint and minimize the load angle, a second variable was introduced to the design, $\Delta x$ (See Figure 3-11).

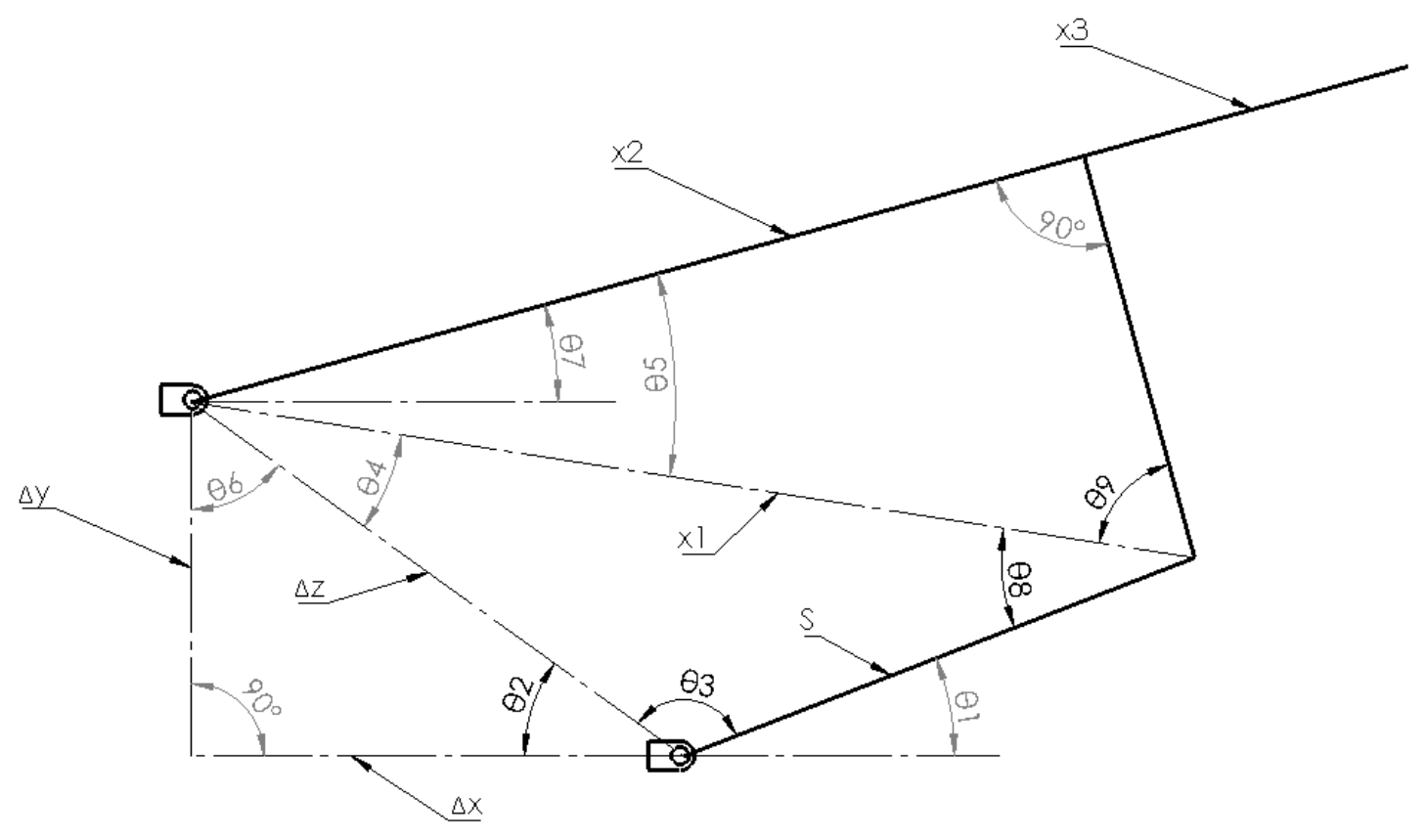

Figure 3-11: Kinematic model for iteration 2

The following equations were used to study the kinematic model for the second iteration:

$$
\begin{gathered}
\Delta z=\sqrt{\Delta x^{2}+\Delta y^{2}} \\
\theta_{2}=\tan ^{-1}\left(\frac{\Delta y}{\Delta x}\right) \\
\theta_{6}=\tan ^{-1}\left(\frac{\Delta x}{\Delta y}\right) \\
\theta_{3}=180^{\circ}-\theta_{1}-\theta_{2}
\end{gathered}
$$




$$
\begin{gathered}
x_{1}=\sqrt{S^{2}+\Delta z^{2}-2(S)(\Delta z) \cos \theta_{3}} \\
\theta_{4}=\sin ^{-1}\left(\frac{S * \sin \left(\theta_{3}\right)}{x_{1}}\right) \\
x_{2}=\sqrt{x_{1}^{2}-h^{2}} \\
\theta_{5}=\tan ^{-1}\left(\frac{h}{x_{1}}\right) \\
\theta_{7}=\theta_{4}+\theta_{5}+\theta_{6}-90^{\circ} \\
\theta_{8}=\sin ^{-1}\left(\frac{\Delta z * \sin \left(\theta_{3}\right)}{x_{1}}\right) \\
\theta_{9}=\cos ^{-1}\left(\frac{h}{x_{1}}\right) \\
\theta_{10}=\theta_{8}+\theta_{9}
\end{gathered}
$$

With the above relationships and the use of MATLAB, a graphical approach was used to iterate to a final model. By setting a constant y-ratio and iterating through various $\mathrm{x}$-ratios, an improved R-R-P-R design was developed. By using a constant 20-inch moment arm and a $h_{\text {ratio }}\left(\frac{\Delta y}{s}\right)$ of 0.4 the plots in Figure 3-12 were generated to study various $x_{\text {ratio }}\left(\frac{\Delta x}{s}\right)$. 

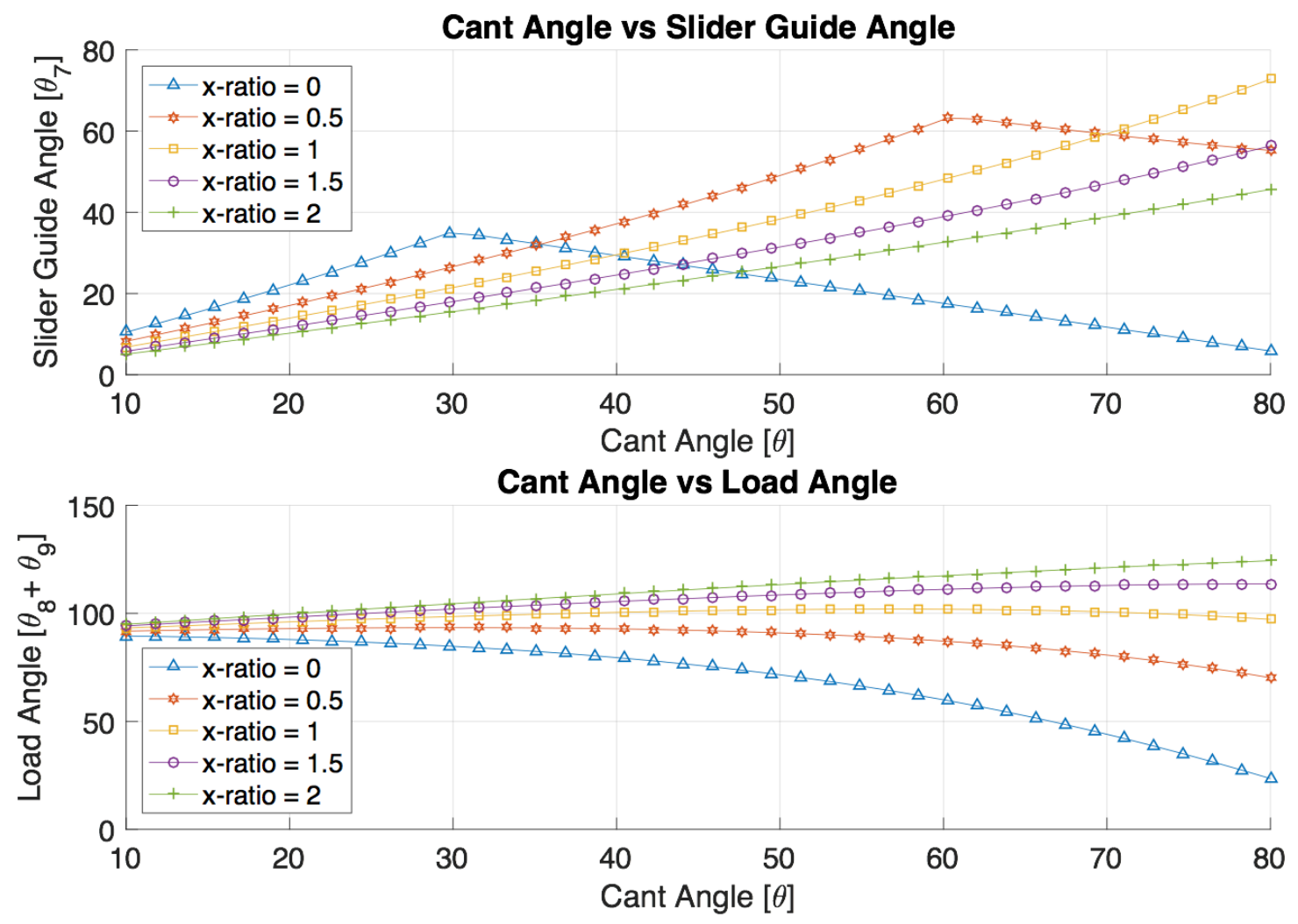

Figure 3-12: R-R-P-R geometry investigation

Figure 3-12 illustrates the relationship between the slider guide angle, slider displacement and load angle, as a function of the cant angle. From the first and third plot, a conclusion could be made as to which $\mathrm{x}$-ratio would provide optimal results. By avoiding inflection points in the first plot, and aiming for a $90^{\circ}$ load angle throughout the cant motion in the third plot, a x-ratio of 1.0 was chosen for iteration 2. This design produced a maximum load angle of $99.5^{\circ}$ when the winglet is in the $54.5^{\circ}$ cant position. Therefore, the applied load deviates from perpendicularity, failing to meet the requirements for the winglet loading design. However, since the resultant side load was minimal, the Morphing Winglet Team decided to further investigate the design. By utilizing the above results, the following model was developed on CAD: 


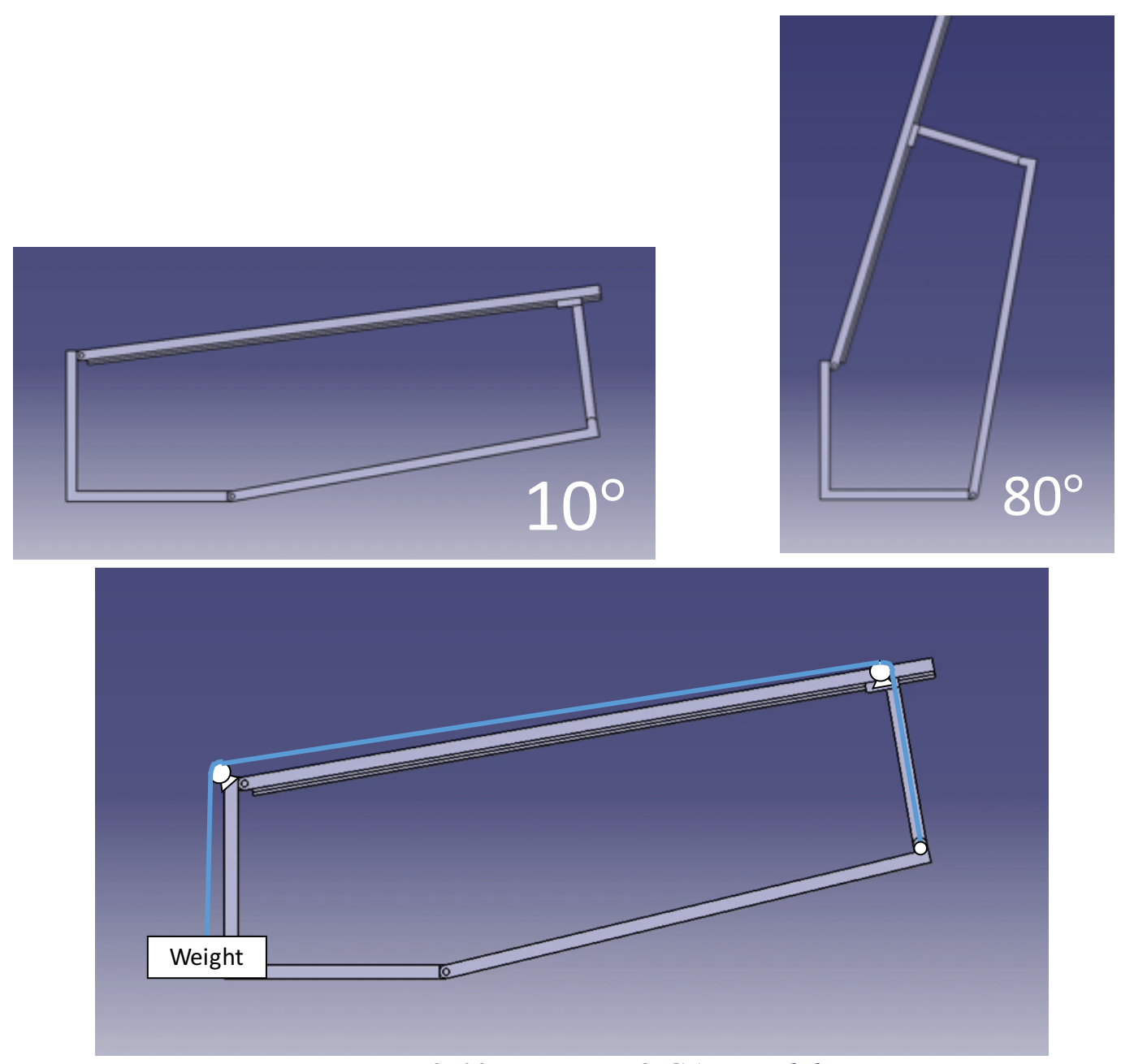

Figure 3-13: Iteration 2 CAD model

Apart from the side loading present in iteration 2, the joints and slider system would need to be reinforced to ensure structural stability under load. Additionally, minimizing friction between the slider and the rail is essential for the functionality of the model. The above model also required a large workspace (vertical), due to the final revolute joint (R4), which fails one of the problem's objectives. Thus, the R-R-P-R model was deemed impractical and was decided by Ryerson's Morphing Winglet Team to focus only on designs which utilize a prismatic joint at the R4 location to minimize the system's workspace. This decision led to the elimination of the R-P-R-R and RP-P-R potential four bar linkage designs. 


\subsection{R-R-R-P DESIGN}

The following section outlines an R-R-R-P four bar mechanism design for the purpose of dynamically loading the winglet. Figure 3-14 illustrates a kinematic model with the joints and linkages labeled for two different cant angle configurations.
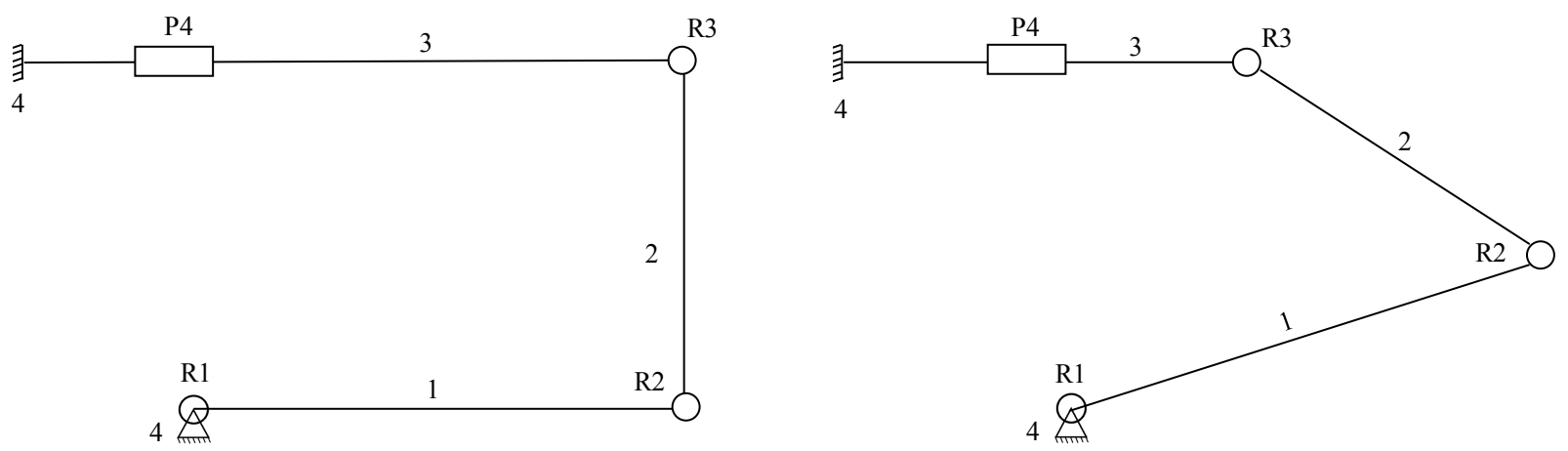

Figure 3-14: R-R-R-P kinematic model

As the cant angle varies, it can be seen from Figure 3-14 that the angle between Link 1 and Link 2 deviated from the desired $90^{\circ}$. This would result in an undesired side loading onto the winglet's root. In order to avoid this condition, the loading mechanism would require the removal of R2 at the tip of the winglet and create a fixed right angled linkage. This would ensure the load being guided to the loading point on the winglet would be perpendicular throughout the cant motion. Based on the inability to maintain a perpendicular load onto the winglet as the winglet travels, the defined R-R-R-P mechanism was deemed inadmissible for the purpose of a dynamic loading model.

\subsection{R-P-P-P DESIGN}

The R-P-P-P planar four bar linkage enumeration design illustrated in Figure 3-15 was also found to not be feasible for the dynamic loading model. Upon completion of the literature review, a closed planar R-P-P-P mechanisms was found to produce an over constraint linkage system. 
Given the use of three prismatic joints results in a locked linkage system, the R-P-P-P design was deemed an invalid solution for the loading model.

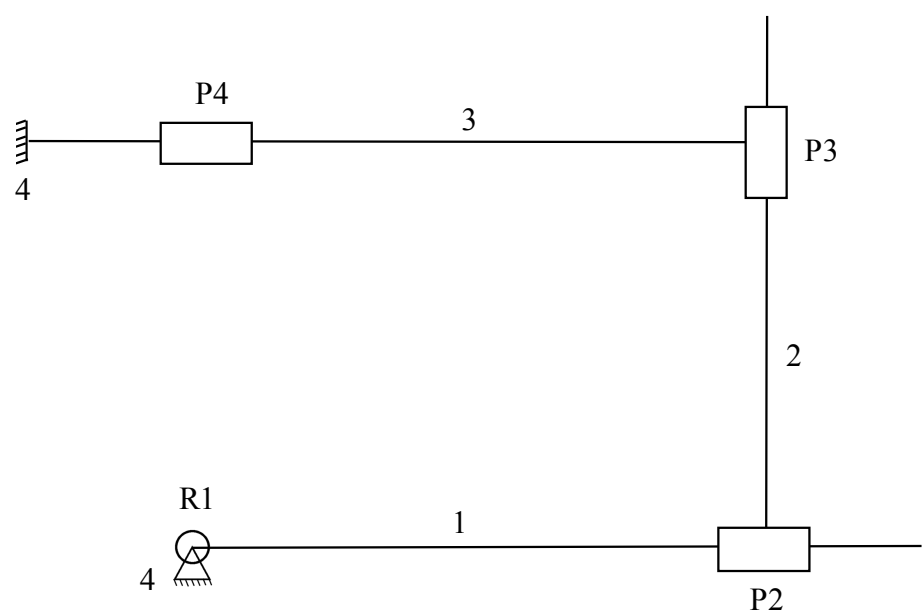

Figure 3-15: R-P-P-P kinematic model

\subsection{R-R-P-P DESIGN}

The four bar mechanism loading design illustrated in Figure 3-16 utilizes a passive, R-RP-P model to meet both project requirements. Maintaining perpendicularity at the loading point (MAC) required a fixed 90-degree link, similar to the R-R-R-R design.

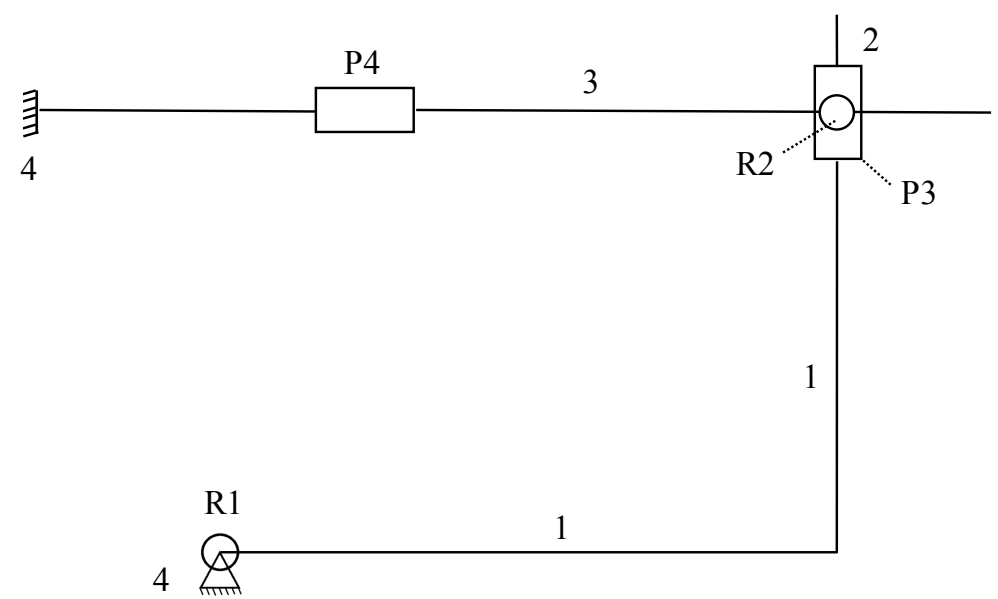

Figure 3-16: R-R-P-P kinematic model

As the cant angle is increased, the resultant side force acting through Link 1 passively causes the prismatic joint to move along the rail to maintain perpendicularity. To ensure the feasibility of the model, a kinematic CAD model was created with the use of a guide rod (P3) and 
a slider (P4). Figure 3-17 demonstrates the CAD model of the winglet in the lower and upper limits of the cant motion.
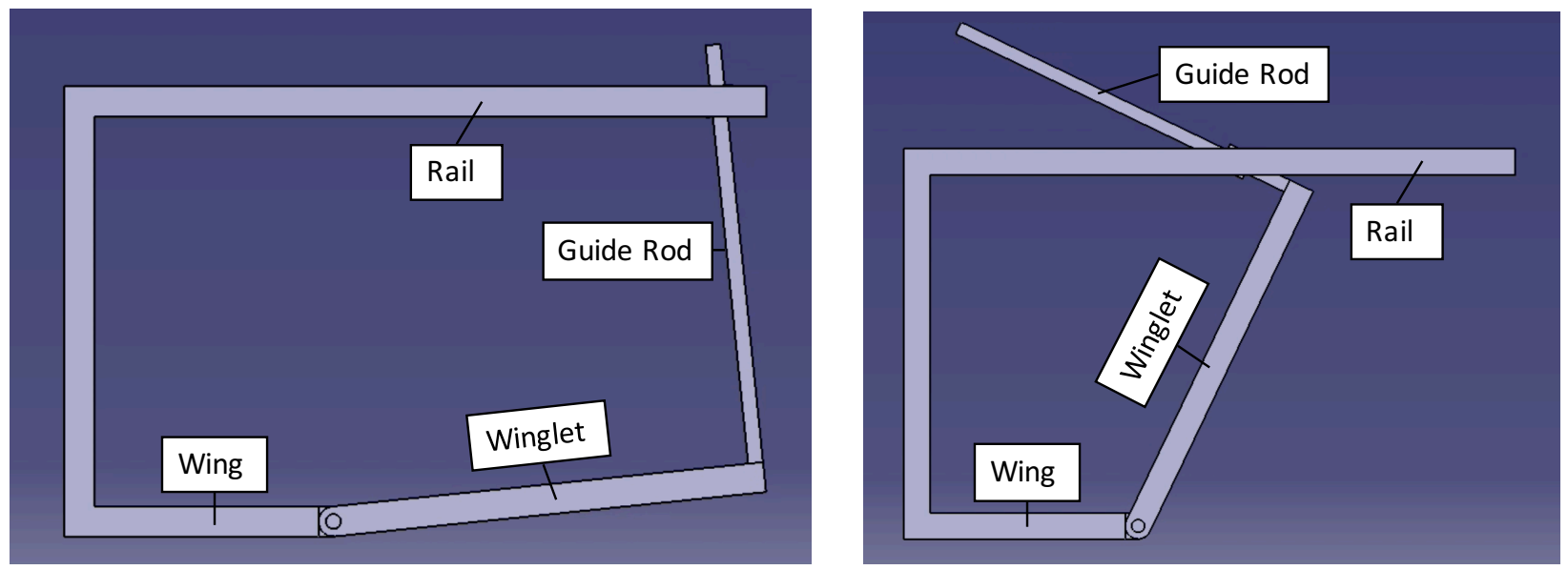

Figure 3-17: R-R-P-P CAD model - 10 degree and 80 degree configuration

Figure 3-18 illustrates the details at the guide rod and rail system's interface. Using a revolute joint that allows for the guide rod to slide through, the perpindicularity was maintained at the winglet.

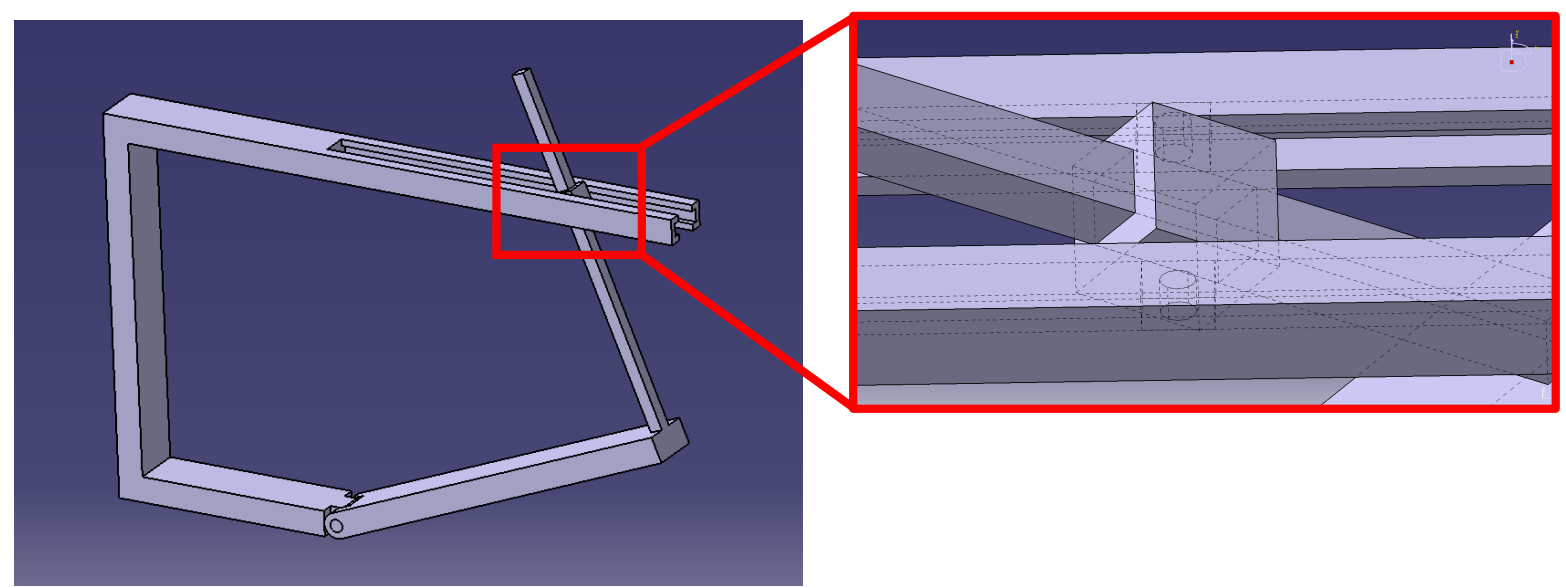

Figure 3-18: Guide rod/rail interface

In order to further demonstrate the functionality of the design with the incorpriated pulley system, a small prototype was built and illustrated in Figure 3-19. 


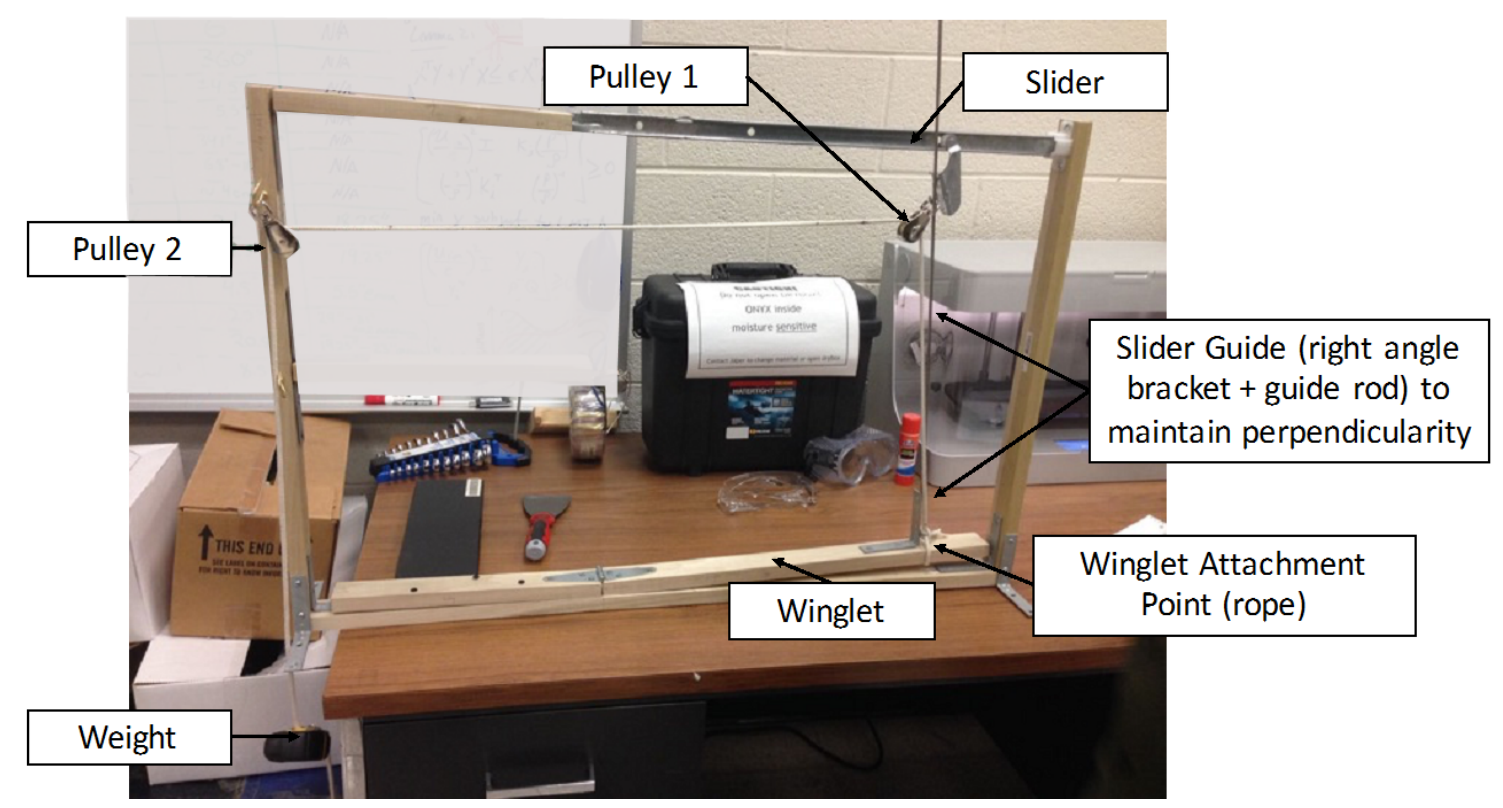

Figure 3-19: R-R-P-P prototype model
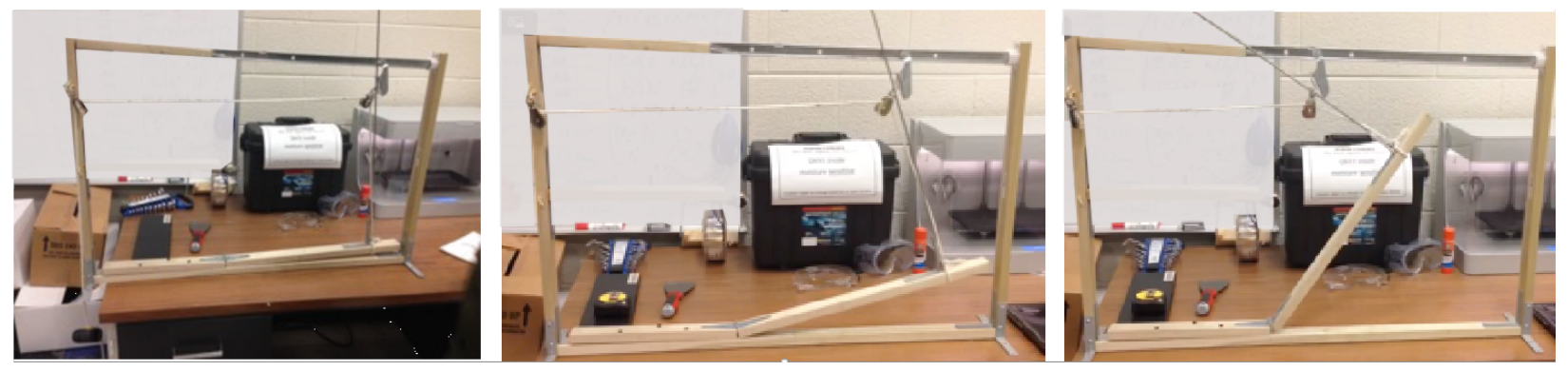

Figure 3-20: R-R-P-P prototype cant motion

After the addition of the pulley system, the design was able to meet both problem requriements, as demonstrated in Figure 3-20. While this prototype proved its functionality, there were various challenges associated with the design. Firstly, the slider/pulley connection would need to resist high structural loads when converting to the full scale model. These loads would also translate to large bending moments on the guide rods, resulting in undesired loading on the winglet. Additionally, the loading mechanism has a low mechanical advantage at the initial and final positions of the winglet. Consequently, as the winglet approaches the two limits of its cant motion, the side force that leads to the slider's motion reduces, producing undesired compressive loads on Link 1. 


\subsection{R-P-R-P DESIGN}

The following section illustrates an active dynamic loading design for the morphing winglet. Through the use of an R-P-R-P mechanism design demonstrated in Figure 3-21, the two requirements of the problem are satisfied, while meeting the workspace constraint. However, the model is not passive and required an active $\mathrm{P} 4$ joint.

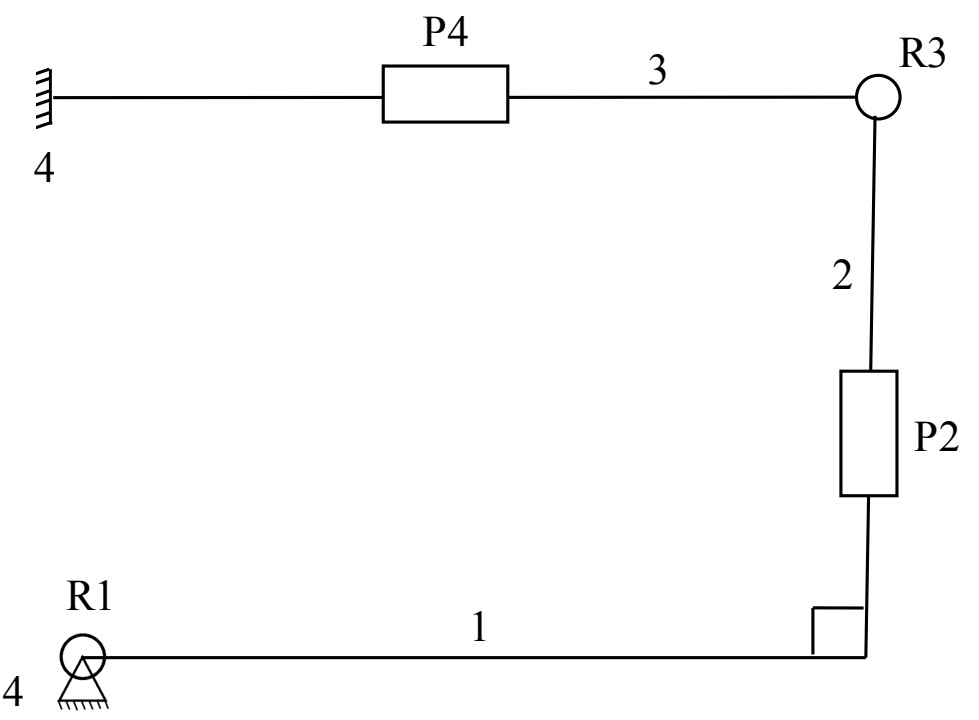

Figure 3-21: R-P-R-P kinematic model

By analyzing the kinematic model outlined in Figure 3-21, the overall system's degrees of freedom/mobility $(F)$ can be calculated by using (Eq. 3-20).

$$
F=\lambda\left(n_{L}-n_{j}-1\right)+\sum_{i=1}^{n_{j}} f_{i}
$$

where, $\lambda$ is equal to 3 (planar mechanism), $n_{L}$ is the number of links, $n_{j}$ is the number of joints and $f$ represents the degrees of freedom of each joint [28]. The R-P-R-P kinematic model has a mobility of one, requiring only a single active joint. However, both R1 and P4 are active joints, making the loading model an actuation-redundant system.

The ability to adjust the location of R3, illustrated in Figure 3-22, with the use of an actuator or belt drive allowed the loading to be redirected, ensuring the two requirements were met. Figure 
3-22 demonstrates both the kinematic model which ensures the perpendicularity was maintained, and the pulley system used to apply the load on the winglet.

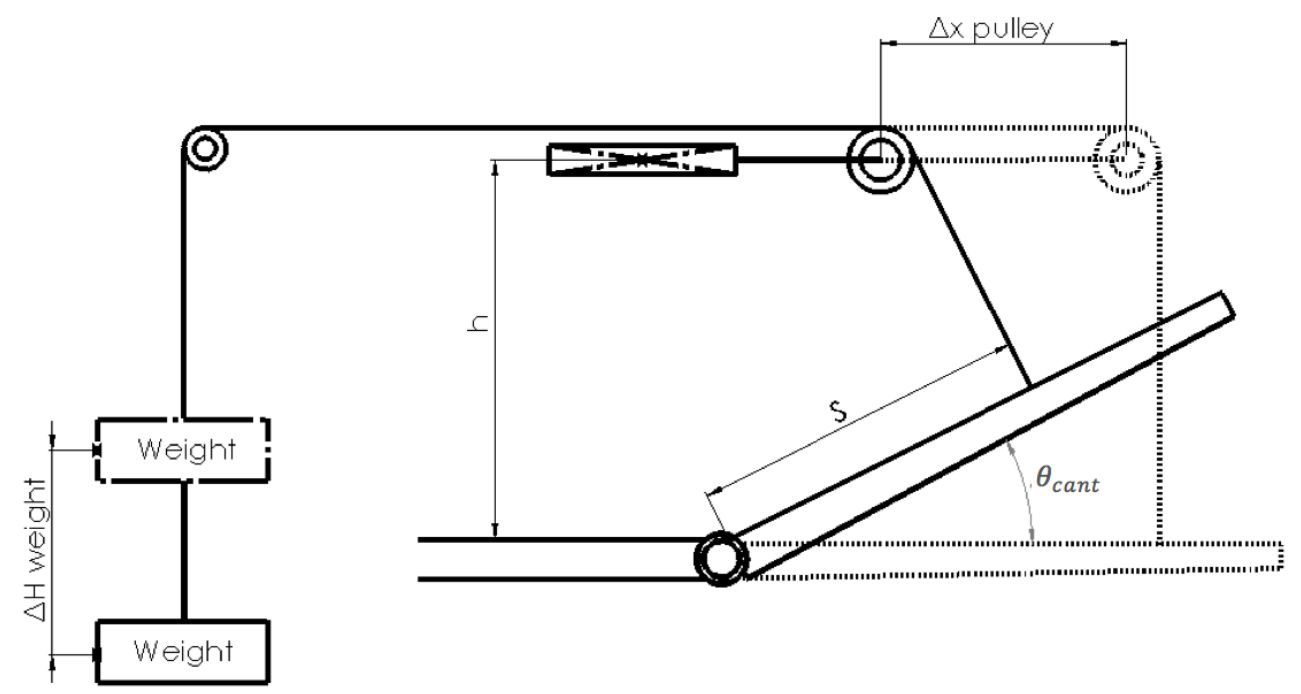

Figure 3-22: Dynamic loading active model

By referring to Figure 3-22, Link 2 and P2 from Figure 3-21 are represented by a rope, which simplified the overall model. As the winglet begins to rotate upwards in the cant direction, the horizontal actuator retracts to ensure the load direction is continuously perpendicular to the winglet surface. Furthermore, since the load direction along Link 3 remains parallel to the wing throughout the cant motion, the resultant moment applied on the loading fixture remains constant.

The current model utilizes a static weight to apply the loading. The model can be altered to utilize a second actuator to apply a load throughout the motion of the winglet. The simplified relations in (Eq. 3-21) and (Eq. 3-22) represent the required actuator displacement and the distance the weight will travel as a function of the winglet's cant angle (assuming the pulley is a single point with no rope engagement):

$$
\begin{gathered}
\Delta x_{\text {pulley }}(\theta)=S *(1-\cos \theta)+(h-S * \sin \theta) \tan \theta \\
\Delta H_{\text {weight }}(\theta)=\Delta x_{\text {pulley }}+\frac{h-S * \sin \theta}{\cos \theta}
\end{gathered}
$$


To determine the maximum stroke of the actuator $(\mathrm{P} 4)$ and the distance the weight will travel, the following equations were derived:

$$
\begin{gathered}
\text { Total Actuator Dispalcement }=\Delta x_{\text {pulley }}\left(80^{\circ}\right)-\Delta x_{\text {pulley }}\left(10^{\circ}\right) \\
\text { Total Weight Travel }=\Delta H_{\text {weight }}\left(80^{\circ}\right)-\Delta H_{\text {weight }}\left(10^{\circ}\right)
\end{gathered}
$$

By setting the moment arm (S) constant in (Eq. 3-21) and (Eq. 3-22), the actuator's stroke requirements to achieve a $10^{\circ}-80^{\circ}$ motion becomes a function of the distance between $\mathrm{R} 1$ and P4. By using the provided moment arm of 20-inches, the plots in Figure 3-23 were obtained.
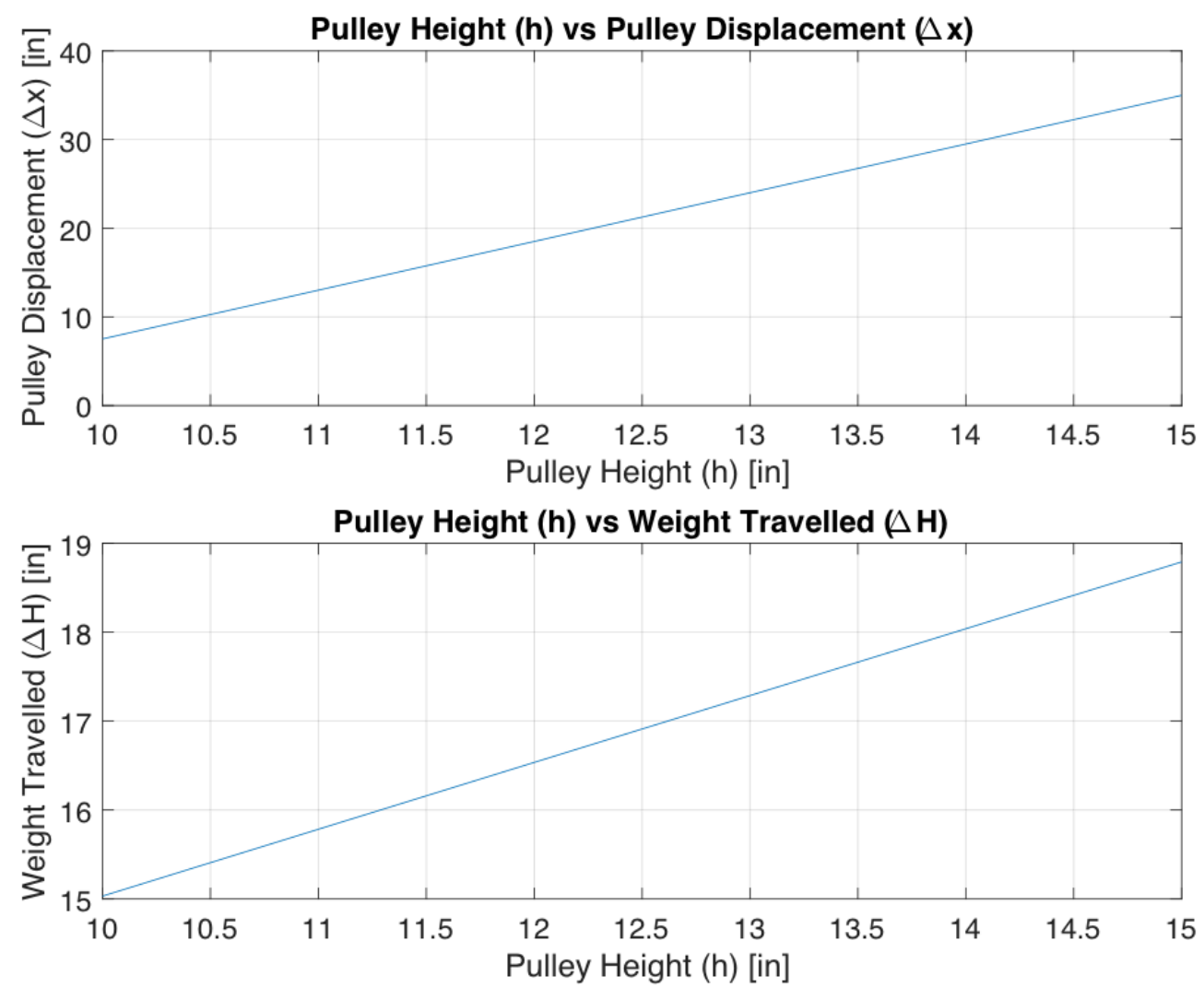

Figure 3-23: Actuator displacement and distance weight traveled vs wing to actuator height

As shown in Figure 3-23, the required actuator displacement increases as the height is increased. However, a minimum height will be required to ensure the winglet does not interfere 
with the loading fixture. Two possible methods to move the pulley in the horizontal direction (P4) are with the use of a belt drive or a linear actuator.

\subsubsection{BELT DRIVEN MODEL}

Figure 3-24 demonstrates a belt drive being used for P4, to provide the required movement of the pulley. The use of a belt drive allows for a larger pulley displacement, however, the ability to withstand large loading is sacrificed. Additional images for the CAD model can be found within Appendix B.

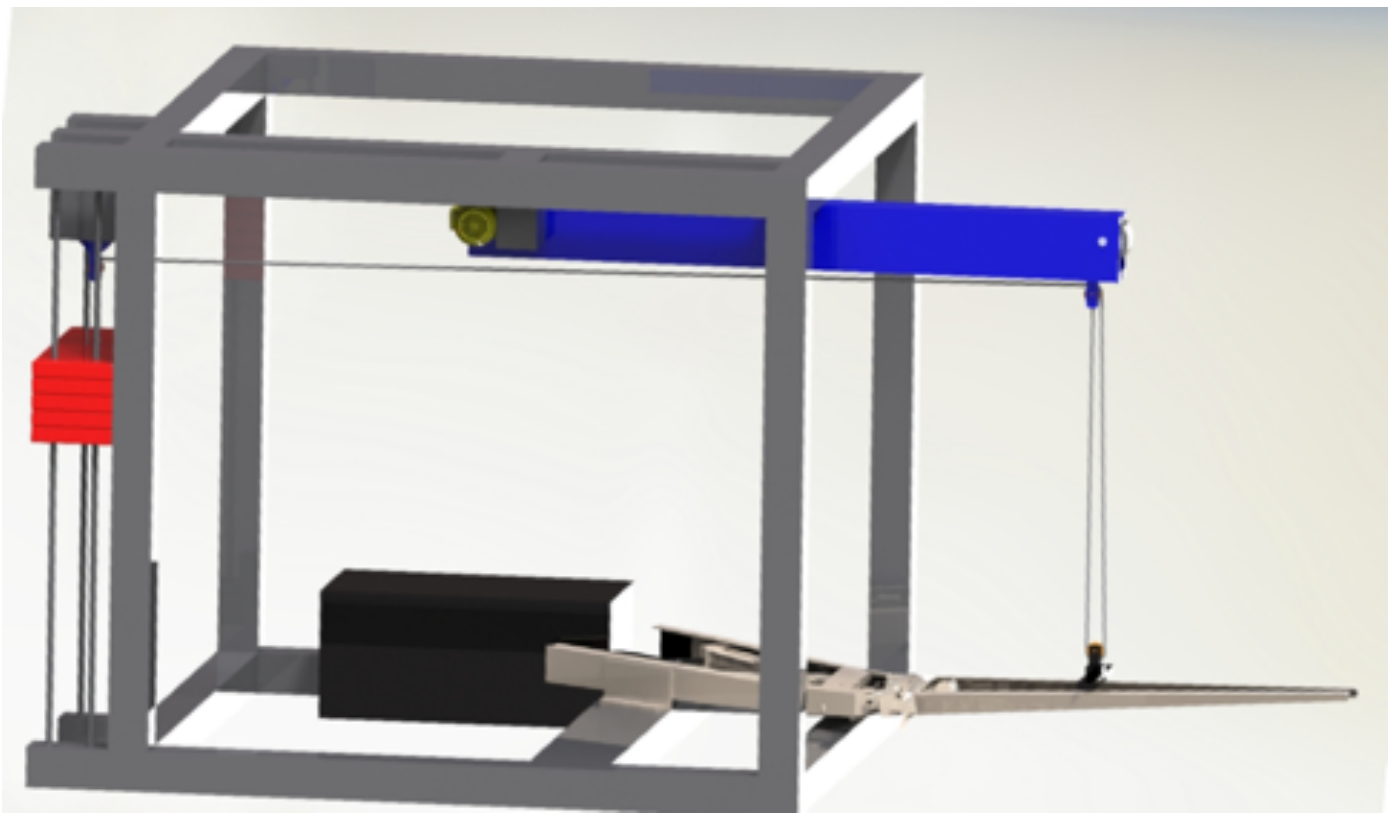

Figure 3-24: R-P-R-P belt drive CAD model

Furthermore, to minimize the required weight to complete the dynamic load test, a double pulley system could be utilized [29]. A double pulley system reduces the required load by two, but doubles the distance travelled by the weights, as a result of conservation of mass (see Figure 3-25 and (Eq. 3-25)). 


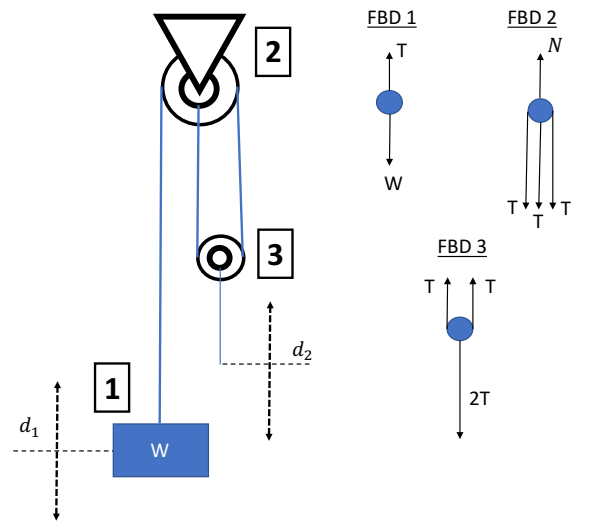

Figure 3-25: Double pulley system free body diagram

$$
T * d_{1}=2 T * d_{2} \quad d_{1}=2 * d_{2}
$$

Figure 3-26 illustrates the detailed features of the belt drive loading model, where $T$ represents the tension in the rope, $W$ represents the weight, $N$ represents the reaction force and $d$ represents the distance travelled. The CAD model utilizes a double pulley system with a stepper motor driven belt drive. The developed test fixture would be capable of providing a constant load on the winglet throughout the complete cant motion.

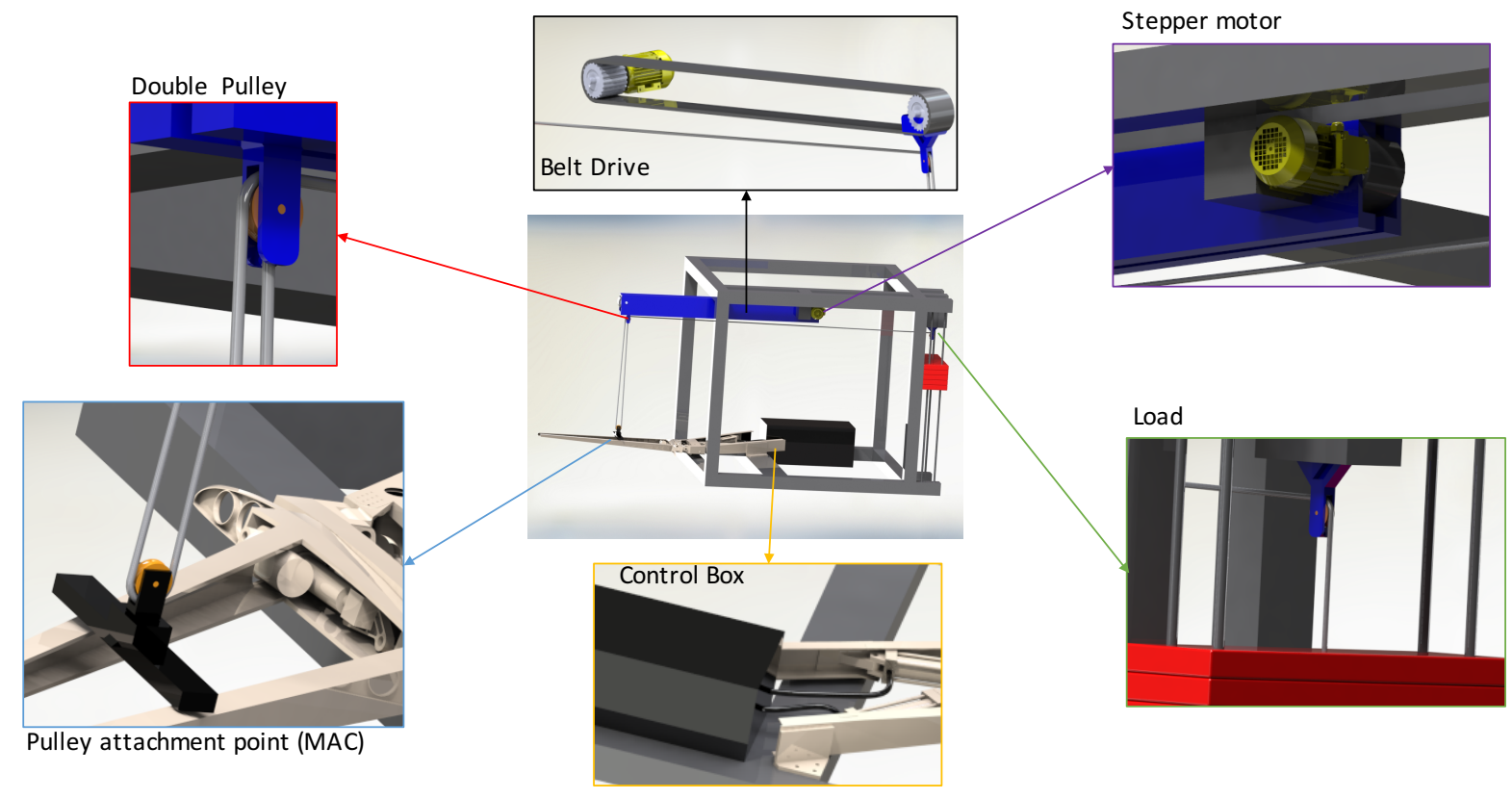

Figure 3-26: Belt driven active model 


\subsubsection{ACTUATOR DRIVEN MODEL}

The following design utilized many of the features illustrated in Figure 3-26, however, a linear actuator was used to represent P4. In addition, a linear actuator was modeled to apply the required loading, rather than the static weights which had been modeled for the belt driven design. Figure 3-27 shows a detailed CAD rendering of the actuator driver loading model.

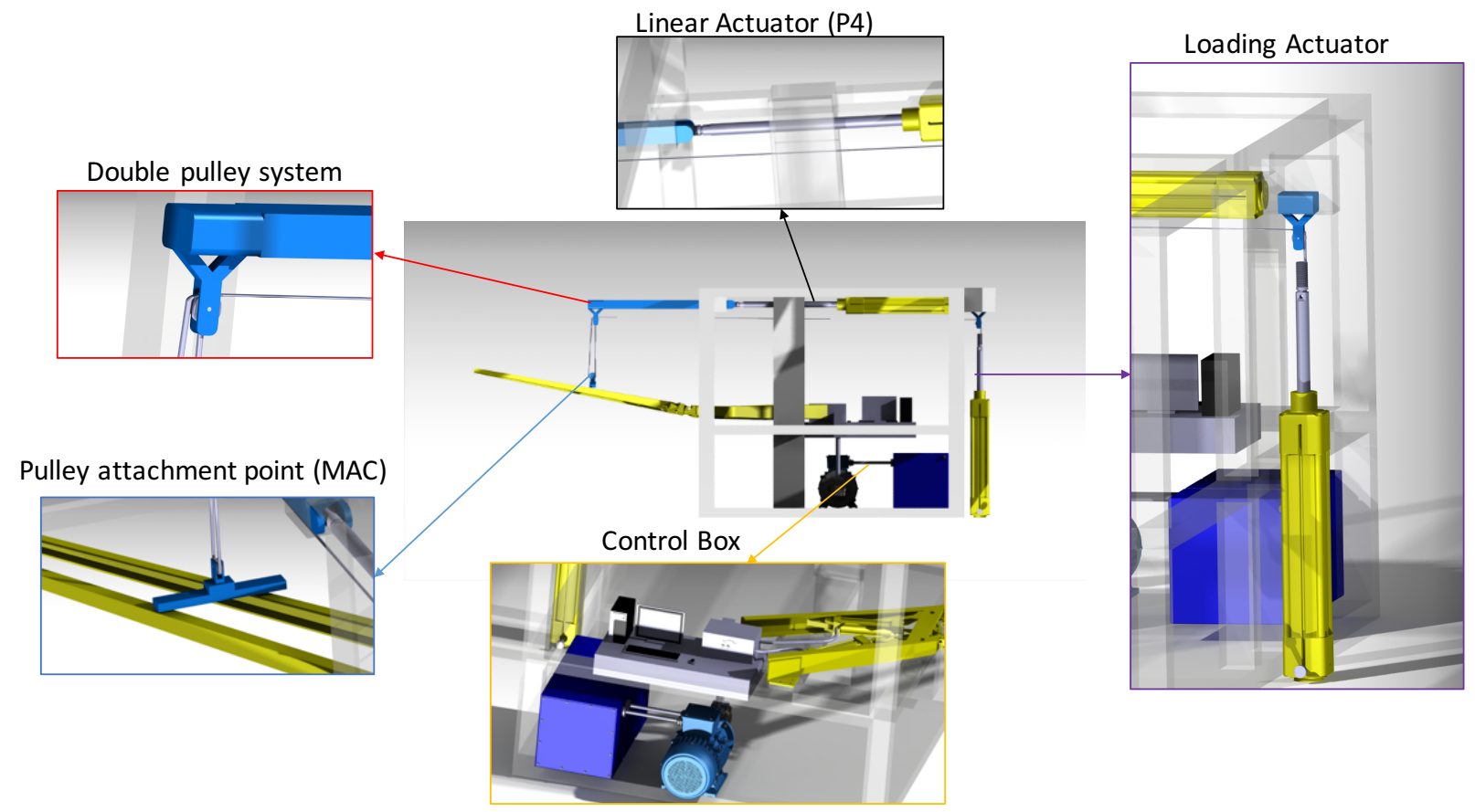

Figure 3-27: Actuator driven active model
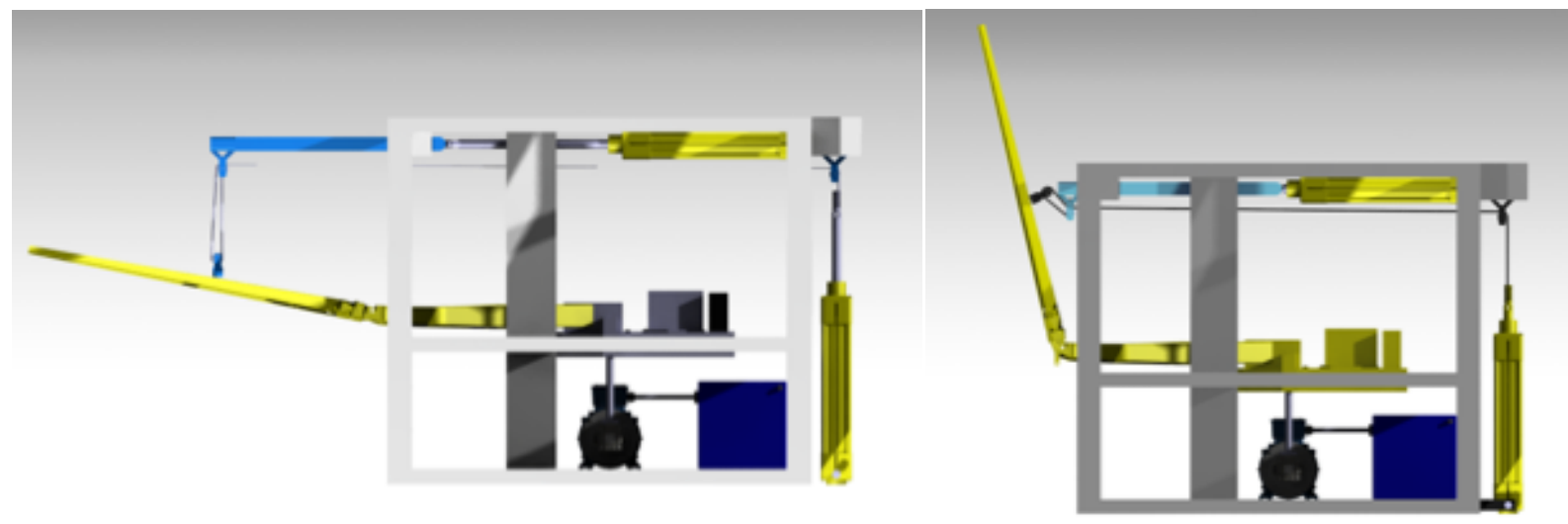

Figure 3-28: R-P-R-P actuator driver CAD model at 10 and 80 degree 
(Eq. 3-21) and (Eq. 3-22) apply directly to the model within Figure 3-28. By analyzing the cant angle, the horizontal actuator would adjust to ensure the loading direction remains perpendicular, as demonstrated in Figure 3-28. In addition to the improved load resistance by a linear actuator, the rail could be retracted completely within the loading fixture, ensuring the winglet would not interfere with the test rig. By utilizing a linear actuator to apply a load, a synchronization with the cant module's kinematics would be required to ensure constant loading throughout the cant motion of the winglet. Additional multi-view renderings of the actuator driven model can be found within Appendix B.

To demonstrate the functionality of the R-P-R-P kinematic loading model, a small-scale fixture was developed. The model was used to validate the use of the double pulley system and to ensure constant, perpendicular loading would be maintained throughout the winglet motion.

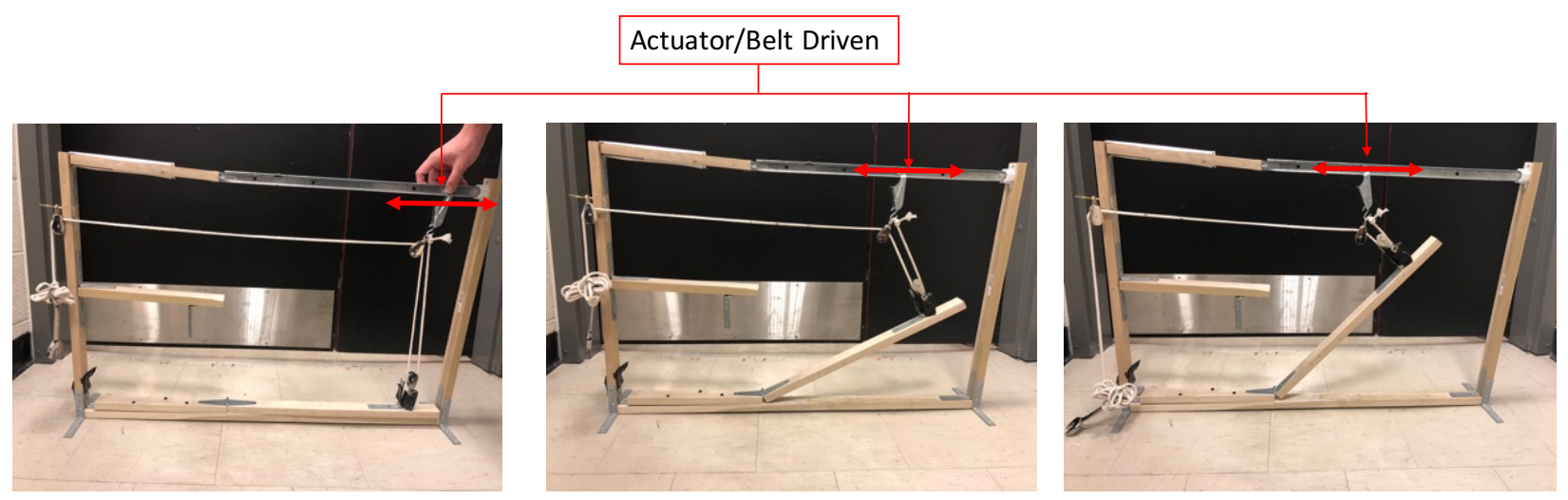

Figure 3-29: Small scale model for Ideation 5

Note: The model was not built with the use of an actuator; rather manual repositioning of $\mathrm{R} 3$ was required. It was concluded that the R-P-R-P design would successfully meet the problem's requirements. However, the design solution would require the use of an additional active joint, which would require synchronization between the two active joints: R1 and P4. 


\subsection{DESIGN METHODOLOGY SUMMARY}

The following section summarizes the findings from each four bar mechanism enumeration. Table 3-1 summarized whether each enumeration was admissible or not admissible as a dynamic loading design for the morphing winglet's cant module.

Table 3-1: Four bar mechanism enumeration assessment

\begin{tabular}{|c|c|c|}
\hline Enumeration & Admissible / Not-Admissible & Reason \\
\hline R-R-R-R & Not-Admissible & Fails to generate a constant moment \\
\hline R-R-P-R & Not-Admissible & $\begin{array}{c}\text { Fails to generate a constant moment } \\
\text { Requires large workspace }\end{array}$ \\
\hline R-P-R-R & Not-Admissible & $\begin{array}{c}\text { Similar to R-R-P-R } \\
\text { Requires large workspace }\end{array}$ \\
\hline R-P-P-R & Not-Admissible & $\begin{array}{c}\text { Similar to R-R-P-R } \\
\text { Requires large workspace }\end{array}$ \\
\hline R-R-R-P & Not-Admissible & Fails to maintain perpendicularity \\
\hline R-P-P-P & Not-Admissible & Over constraint linkage system \\
\hline R-R-P-P & Admissible & Meets design requirements \\
\hline R-P-R-P & Admissible & Meets design requirements \\
\hline
\end{tabular}

Through the enumeration study of four bar linkage systems consisting of revolute (R) and prismatic $(\mathrm{P})$ joints, two kinematic models were found to be admissible design solutions for the winglet loading model: R-R-P-P and R-P-R-P. 


\section{FINAL DESIGN}

As a result of the enumeration study of all potential four bar linkage solutions, it was found that both the R-R-P-P and R-P-R-P kinematic models successfully met the two problem requirements. However, the R-R-P-P model required the force transfer from the first link to the second to ensure perpendicularity is maintained. Additionally, at the limits of the cant motion, the kinematic model had a low mechanical advantage, resulting in large stresses at the R2-P3 joint and low force transmissibility. Thus, the R-P-R-P design solution was found to have a higher probability of success over the R-R-P-P design. The following section provides further analysis of the R-P-R-P design that was proposed in Section 3.6.

\subsection{R-P-R-P ACTIVE LOADING DESIGN}

The following section will outline the position analysis and velocity analysis for the R-P-RP design in Figure 3-24 and Figure 3-26.

\subsubsection{POSITION ANALYSIS}

\subsubsection{METHOD 1}

To utilize the finalized design, a detailed kinematic model was required to improve the accuracy of the location of R3 in Figure 3-21. By having an accurate location of R3, the active P4 joint could be synchronized to ensure perpendicularity is maintained between Link 1 and Link 2 . Additionally, the model would aid in the pulley sizing and the measurement of rope engagement throughout the cant motion. Figure 4-1 was utilized to produce the positon and velocity analysis for $\mathrm{P} 4$ for a given pulley radius. 


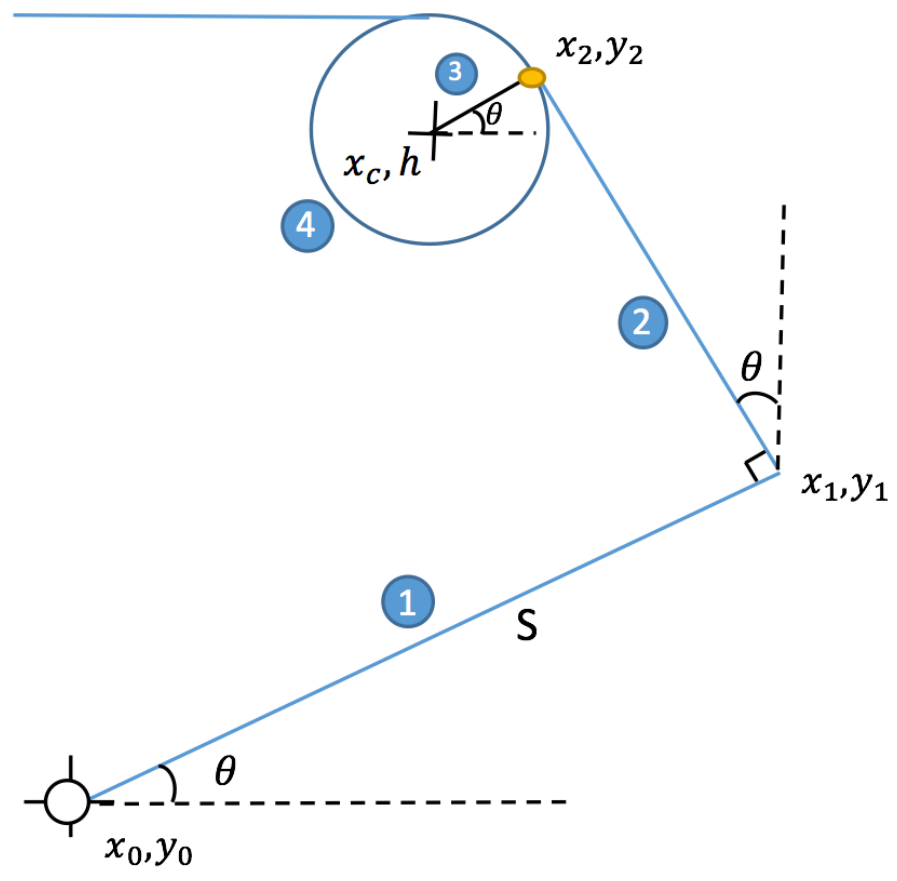

Figure 4-1: R-P-R-P detailed kinematic model

In Figure 4-1, the initial engagement point, which ensured tangency between Line 2 and the circle is marked in yellow. By ensuring Line 2 is tangent to the circle throughout the cant motion, the precise positon of the center of the circle can be determined for the purpose of P4's position and velocity analysis. With a known origin $(0,0)$ and height between the pulley center and winglet root $(h)$, there are three remaining unknowns of interest: $x_{2}, y_{2}$ and $x_{c}$. Therefore, three equations were required: the equation for Line 2, the equation of Line 3 and the equation of Circle 4. The following equation was used to define Line 1:

$$
y=x * \tan \theta
$$

In order to determine the equation for Line 2, the negative reciprocal of Line 1 was required. Using the point of intersection as $x_{1}$ and $y_{1}(S * \cos \theta, S * \sin \theta)$, the following equation was obtained:

$$
y=-x * \cot (\theta)+\left(\frac{s}{\sin \theta}\right)
$$


The equation of Line 3 was determined by using the slope of Line 1 since they are collinear, and the coordinates of the center of the circle.

$$
y=\tan (\theta) * x+\left(h-\tan \theta * x_{c}\right)
$$

Finally, the equation of Circle 4 was defined as the following:

$$
\left(x-x_{c}\right)^{2}+(y-h)^{2}=r^{2}
$$

where $r$ is the radius of the pulley (circle). With the given three equations (Line 2, Line 3 and Circle 4) and common point of intersection, the points $x_{2}, y_{2}$ and $x_{c}$ could be determined.. While there are two possible solutions where the line is tangent to the circle (on the inside or outside of line 2), only one solution is of interest (see Figure 4-1). With the three equations, three unknowns and the help of Matlab's computation ability, the following equation was derived to determine the location of the center of the circle as a function of the cant angle:

$$
x_{c}=\frac{2 * S * \cos (\theta)-h * \sin (2 \theta)-4 * \cos (\theta)}{2 * \cos ^{2}(\theta)}=\frac{S-2-h * \sin (\theta)}{\cos (\theta)}
$$

Additionally, the point of intersection $\left(x_{3}\right.$ and $\left.y_{3}\right)$ can be determined with the following expressions:

$$
\begin{gathered}
x_{2}=-\frac{\frac{h}{2} * \sin (2 \theta)-S * \cos (\theta)+r * \cos ^{3}(\theta)-r * \cos (\theta)}{\cos ^{2}(\theta)} \\
y_{2}=h+r * \sin (\theta)
\end{gathered}
$$

To validate the above expressions, a kinematic model was created on MATLAB, which resulted in the plot in Figure 4-2. 


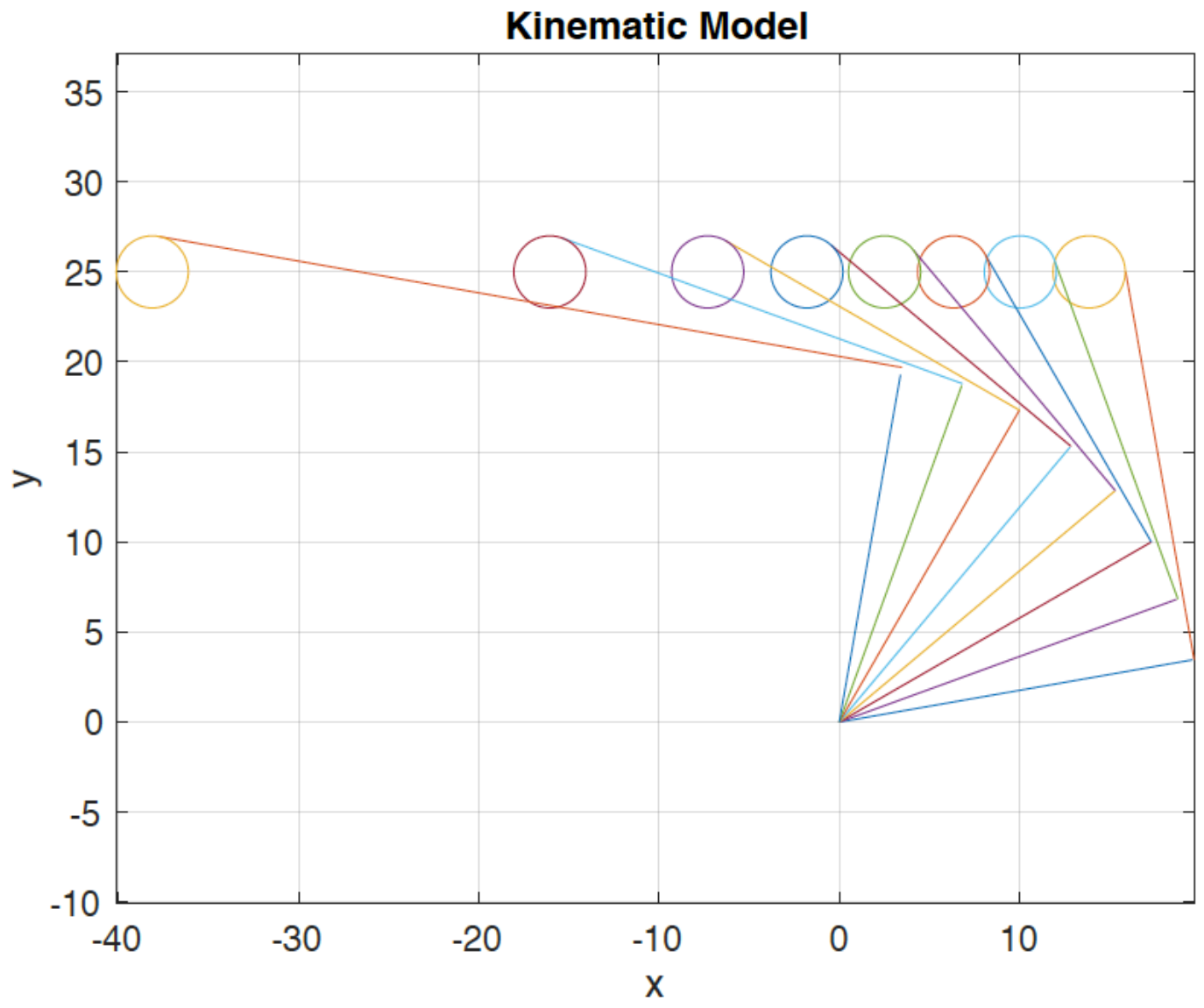

Figure 4-2: Kinematic model (position) for R-P-R-P design

\subsubsection{METHOD 2}

A second method to determine the position of $x_{2}, y_{2}$ and $x_{c}$ was completed by utilizing the equations of Line 2 and Circle 4. The instance where (Eq. 4-2) is tangent to (Eq. 4-4), the load direction on the winglet would be perpendicular. In order to simplify the derivation, the following substitution was utilized:

$$
y=-\cot (\theta) * x+\left(\frac{s}{\sin \theta}\right)=a x+b
$$

where,

$$
a=-\cot (\theta) \quad \text { and } \quad b=\left(\frac{s}{\sin \theta}\right)
$$


First, by substituting (Eq. 4-8) into (Eq. 4-4), the following expression was obtained:

$$
\left(x-x_{c}\right)^{2}+(a x+b-h)^{2}=r^{2}
$$

After expanding and simplifying, (Eq. 4-10) could be re-written in the following form:

$$
\left(1+a^{2}\right) x^{2}+\left(-2 x_{c}+2 a b-2 a h\right) x+\left(x_{c}^{2}+b^{2}-2 b h+h^{2}-r^{2}\right)=0
$$

Next, to determine $x_{c}$ where tangency occurs, the discriminant of the above expression was set to zero:

$$
b^{2}=4 a c
$$

The following quadratic expression was obtained:

$$
\left(-4 a^{2}\right) x_{c}^{2}+(8 a h-8 a b) x_{c}+\left(8 b h-4 b^{2}-4 h^{2}+4 r^{2}+4 a^{2} r^{2}\right)=0
$$

Similarly to Method 1 , the above expression resulted in two $x_{c}$ locations where tangency occurred. By utilizing the horizontal positon that led to the circle positioned on the left hand side, $x_{2}$ and $y_{2}$ were evaluated in order to validate the results. By producing an identical plot as Figure $4-2$, it was found that the two methods used in the position analysis produced identical results. 


\subsubsection{VELOCITY ANALYSIS}

In addition to the positon analysis, a velocity analysis was completed. To control the linear actuator (P4), the velocity of the end effector would be required. As highlighted in Figure 4-3 in yellow, the velocity of the actuator as a function of the angular rate of the winglet would ensure perpendicularity throughout the winglet's cant motion.

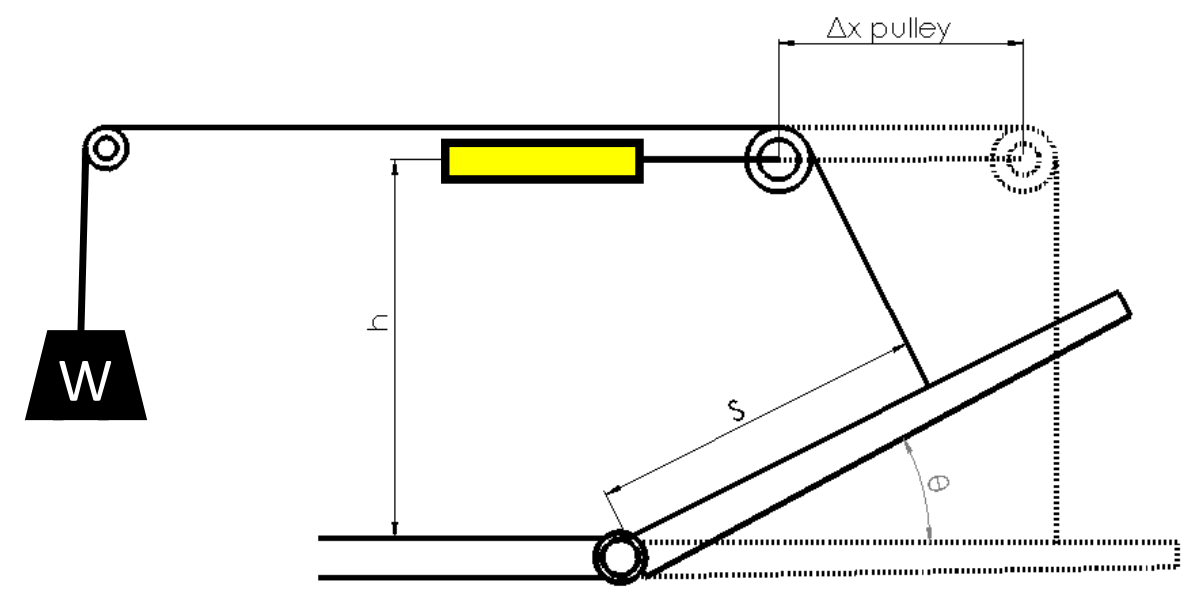

Figure 4-3: Actuator displacement model

To determine the speed as a function of the winglet's cant angle, the derivative of (Eq. 4-5) was taken with respect to time. The following equation represents the velocity of the actuator's end effector:

$$
\dot{x}_{c}=\frac{(S-2) * \sin (\theta)-h}{\cos ^{2}(\theta)} * \dot{\theta}
$$

where, $\dot{\theta}$ represents the angular rate of the winglet. The velocity of the actuator is non-linear, making the synchronization of the system challenging. To mitigate this challenge, further investigations were completed to convert the active loading model to a passive system. 


\subsubsection{LOAD APPLICATION SYSTEM}

The R-P-R-P linkage system defined in Figure 3-21 ensures perpendicularity throughout the cant motion through an actuation-redundant kinematic system. While P4 is used to ensure the load direction remains normal to the winglet, a parallel actuation system is required to apply the load. The complete loading kinematic model is illustrated in Figure 4-4.

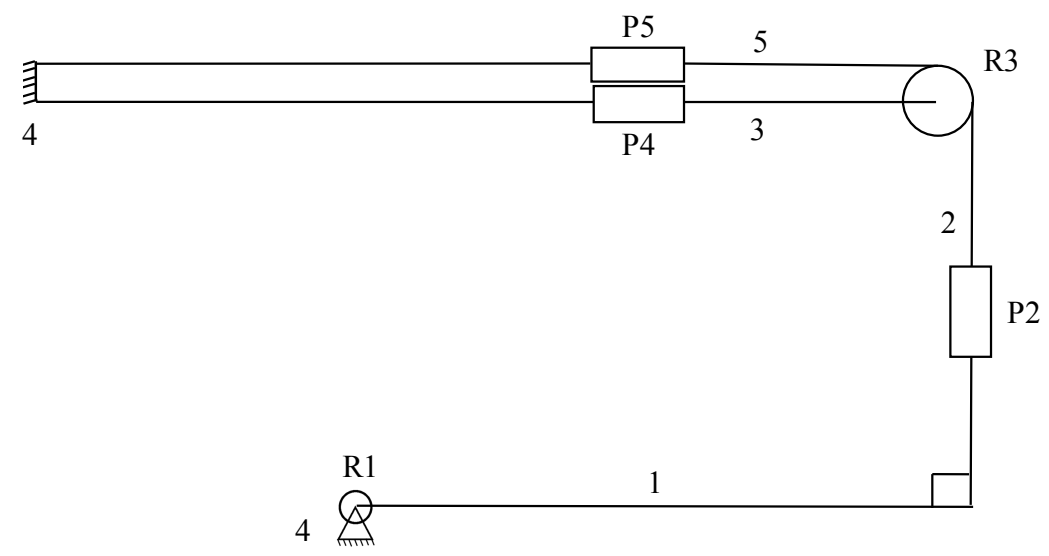

Figure 4-4: R-P-R-P kinematic model with loading actuator

In Figure 4-4, P5 is used to apply the load onto the winglet throughout the cant motion through a pulley system. Through the use of an independent force control, P5 can be synchronized with the active joints, $\mathrm{R} 1$ and $\mathrm{P} 4$, to meet the design requirement of applying a constant loading. By incorporating the load application system, the kinematic system becomes a 5-bar linkage with 5 joints, which results in a mobility of 2 . Given the system has three active joints, it remains an actuation redundant design, failing to minimize the number of active joints.

Upon analysis of the R-P-R-P active model, a redesign was required to reduce the complexity of the system. Having three active joints, with two being codependent, a high degree of controllability would be required to ensure the load remained constant and perpendicular. Additionally, given the velocity analysis of P4 resulted in a non-linear equation, synchronization of R1 and P4 becomes challenging. To mitigate this challenge, The R-P-R-P linkage system in Figure 4-4 was re-evaluated to produce a passive system. 


\subsection{R-P-R-P PASSIVE LOADING DESIGN}

By utilizing a circular linkage system to combine the P2, R3 and P4 joints, the active loading design in Figure 4-5a was transformed to a passive design illustrated in Figure 4-5b.

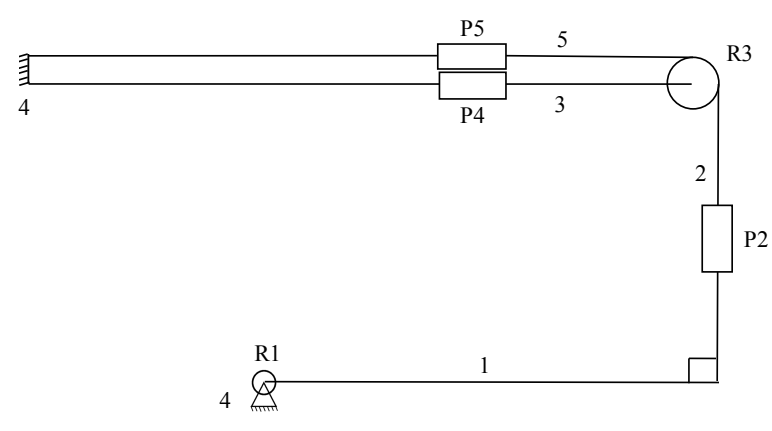

a)

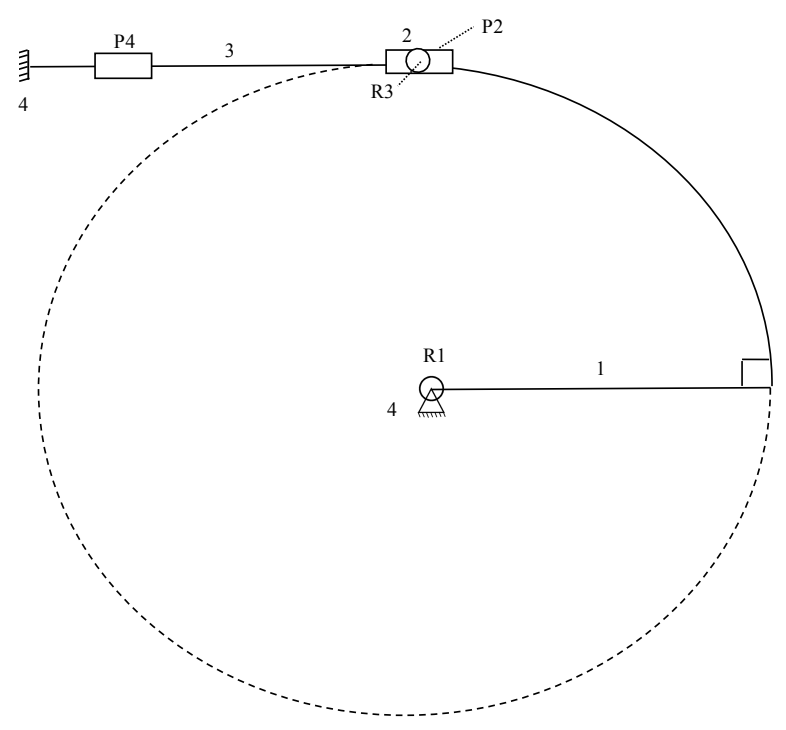

b)

Figure 4-5: R-P-R-P loading model a) Active design b) Passive design

In Figure 4-5b, P4 is the active joint used to apply the loading on the winglet, similar to P5 in Figure 4-5a. Through the use of a combined P2-R3 joint at the end of the circular linkage, P4 remains parallel to the base and tangent to Link 2 throughout the cant motion. To better demonstrate the passive R-P-R-P model, the illustration in Figure 4-6 was created. In this model, the curved linkage which consists of P2 and R3 will be referred to as the "shark-fin" linkage, given its resemblance to a shark's dorsal fin. 


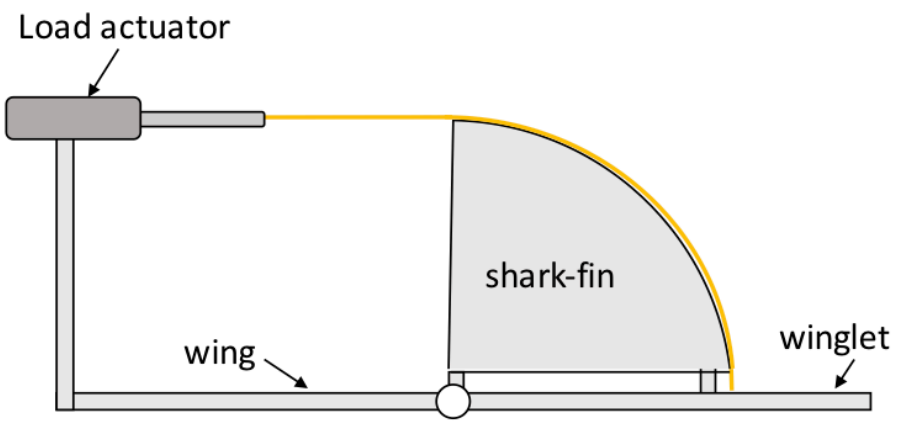

a)

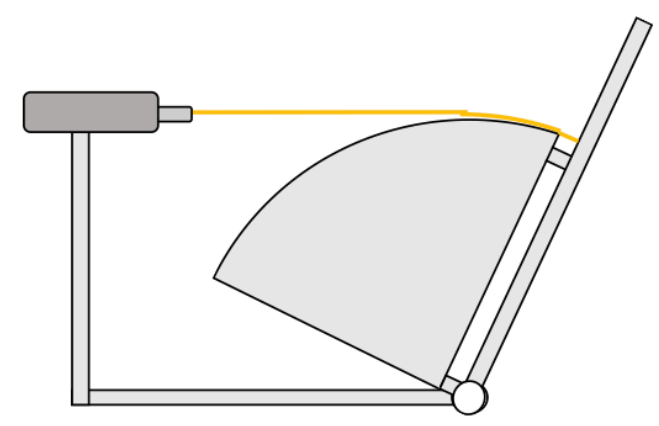

b)

Figure 4-6: R-P-R-P passive loading model a) $10^{\circ}$ b) $80^{\circ}$

In the passive R-P-R-P model, the shark-fin radius is centered about the axis of rotation. Additionally, the radius is equal to the span from the root of the winglet to the loading point. This ensures the release angle of the rope at Link 3 remained parallel to the wing and tangent to the shark-fin throughout the cant motion, similar to the active model.

By converting the active joint, P4, in Figure 4-5a with the shark-fin, the number of active joints is reduced. Given the system in Figure 4-5b becomes a 4-bar linkage system with 4 joints, the mobility of the system becomes 1 . While the model remains an actuation redundant system, as a result of the active $\mathrm{R} 1$ and $\mathrm{P} 4$ joints, the synchronization challenge is reduced. Since the sharkfin rotates with the winglet structure, the applied loading direction passively maintains perpendicularity throughout the cant motion. Additionally, the load application system can be simplified by utilizing a force control feedback system between P4 and an installed load cell at the loading point. This would ensure the applied load remains constant throughout the motion and simplifies the controllability by making the two active joints independent from each other. Furthermore, the loading model can be converted to a completely passive system through the use of static loads, rather than an actuator at $\mathrm{P} 4$. 


\subsubsection{POSITION ANALYSIS}

When utilizing a linear actuator to apply the load, a position analysis is required to calibrate the loading actuator with the cant module. The schematic in Figure 4-7 was utilized to understand the positon analysis of the R-P-R-P model.

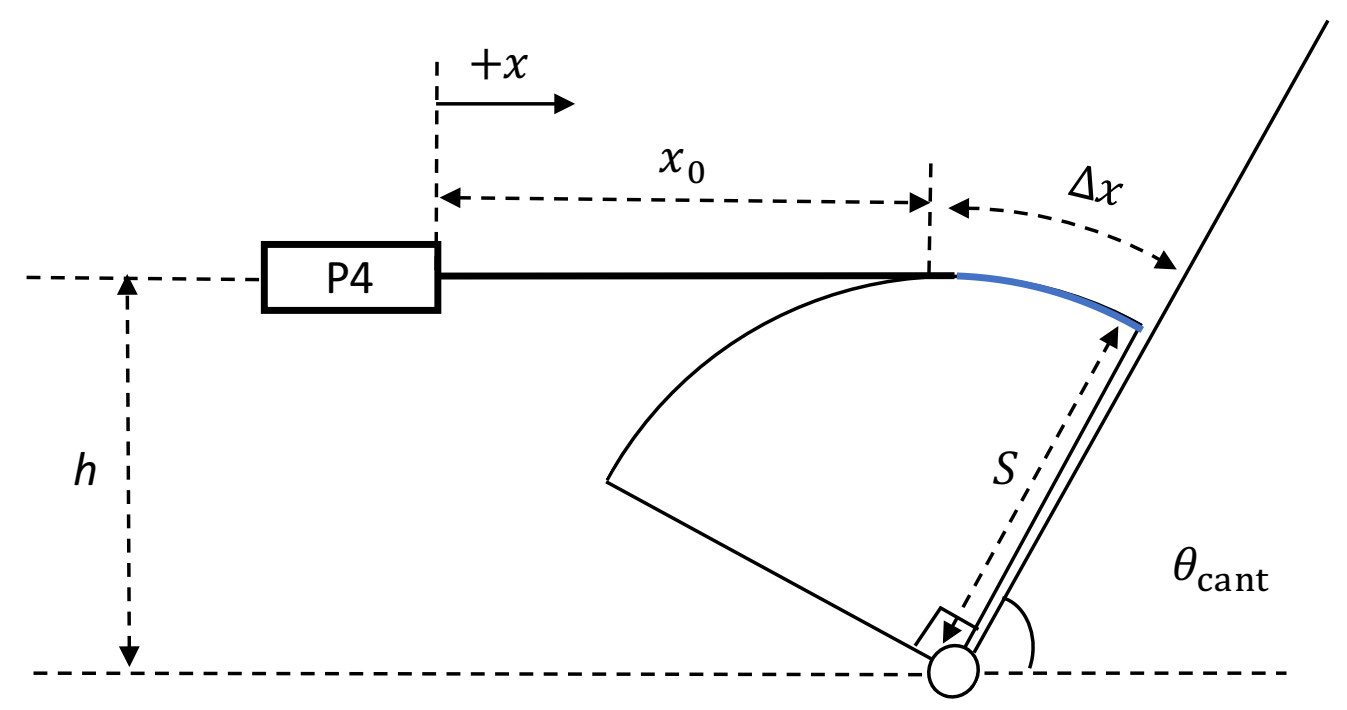

Figure 4-7: R-P-R-P position analysis schematic

The location of the loading actuator $(\mathrm{P} 4)$ with respect to the axis of rotation is required to compute the position analysis of the actuator. This parameter is dependent on the location of the mean aerodynamic center, where the load will be applied. The required height $(h)$ of the actuator to ensure it remains parallel to the wing and tangent to the shark-fin throughout the cant motion is equal to the distance to the loading location on the winglet. Additionally, this parameter is equal to the diameter of the shark-fin.

To obtain an expression to describe the position of the linear actuator, an equation for $\Delta x$ is required, which is based on the arc length of the shark-fin:

$$
\Delta x=S *\left(90^{\circ}-\theta_{\text {cant }}\right) * \frac{\pi}{180}
$$


Thus, the stroke of the actuator with respect to the cant angle can be represented by the following expression:

$$
x_{\text {act }}=x_{0}+S *\left(90^{\circ}-\theta_{\text {cant }}\right) * \frac{\pi}{180}
$$

\subsubsection{VELOCITY ANALYSIS}

Similar to Section 4.1.2, the velocity for the actuator's (P4) end effector can be derived to synchronize the loading model with the cant module to ensure constant perpendicular loading throughout the cant motion. The first derivative of (Eq. 4-16) with respect to time was evaluated.

$$
\dot{x}_{a c t}=-S * \dot{\theta}_{c a n t}
$$

where $\dot{\theta}_{\text {cant }}$ is the angular rate of change of the cant module in radians per second. From the above expression, it is clear that the velocity analysis leads to a linear relationship, making the synchronization of the loading fixture with the cant module only a function of the angular rate of change. 


\section{PROTOTYPE DESIGN}

To validate the final dynamic loading design, a prototype was required to study the actuator loads to compare with theoretical findings, and to ensure the problem's requirements were met. Since a half size model of the cant module was developed by Ryerson's Morphing Winglet Team, it was decided to scale the loading fixture to fit the existing structure. The cant module prototype which was used for testing has been illustrated in Figure 5-1.

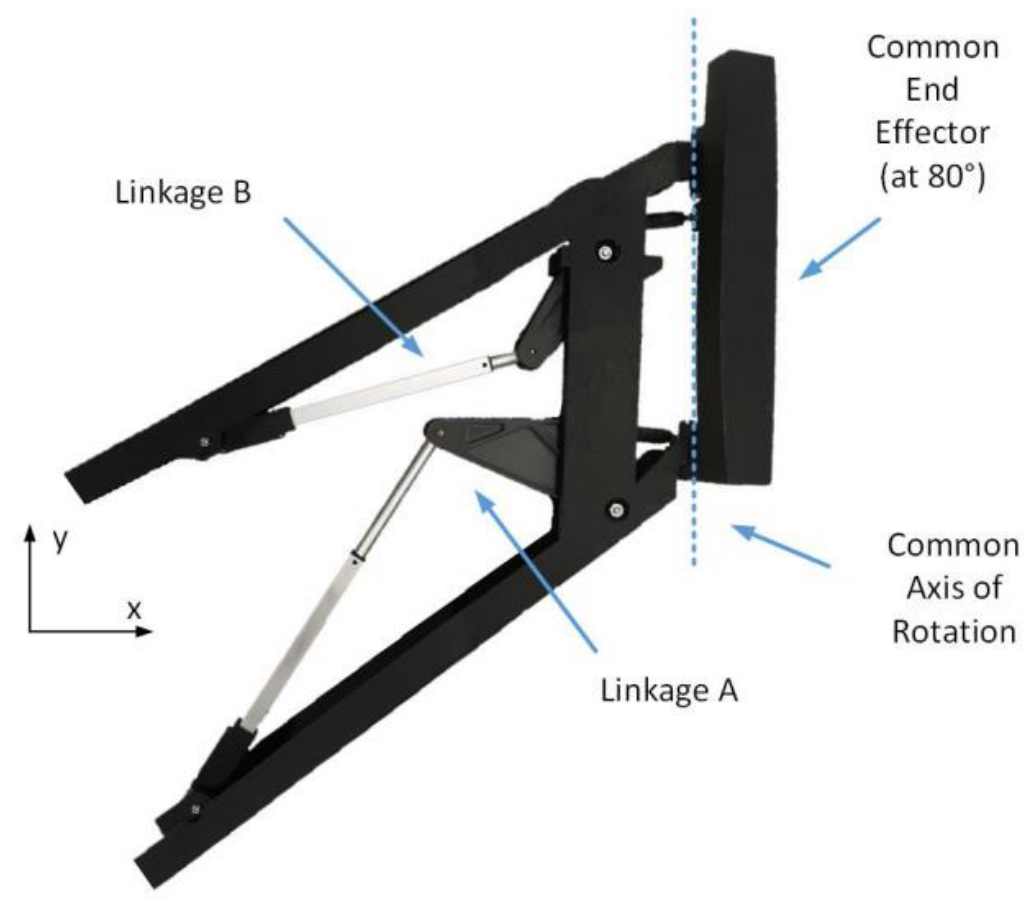

Figure 5-1: Cant module prototype [5]

Optimization of the shark-fin design was required to ensure the results from experimental findings best matched the full scale loading rig. To ensure the compatibility of the shark-fin model with the existing structure, a final CAD model was also required. 


\subsection{SHARK-FIN CAD DESIGN}

The components used to develop the Shark-fin model were designed and assembled using CATIA. Producing a geometrically accurate model in CATIA enabled the use of both a 3D printer and a laser cutter to develop a majority of the components for the prototype. Ryerson's Intelligent Systems and Robotics Laboratory is equipped with a Markforged Mark Two 3D printer which has a build volume of $320 \mathrm{~mm} \times 132 \mathrm{~mm} \times 154 \mathrm{~mm}$. This build volume needed to be considered during the design stage to ensure all required components would fit within the 3D printer's workspace. Off the shelf components were also required, and were included in the final CAD model.

Figure 5-2 and Figure 5-3 illustrate the exploded views of the required components to produce the final prototype. The detailed drafts for each component can be found in Appendix B. The shark-fin geometry represented in the CATIA models were a result of an optimization study conducted in Section 5.2. 


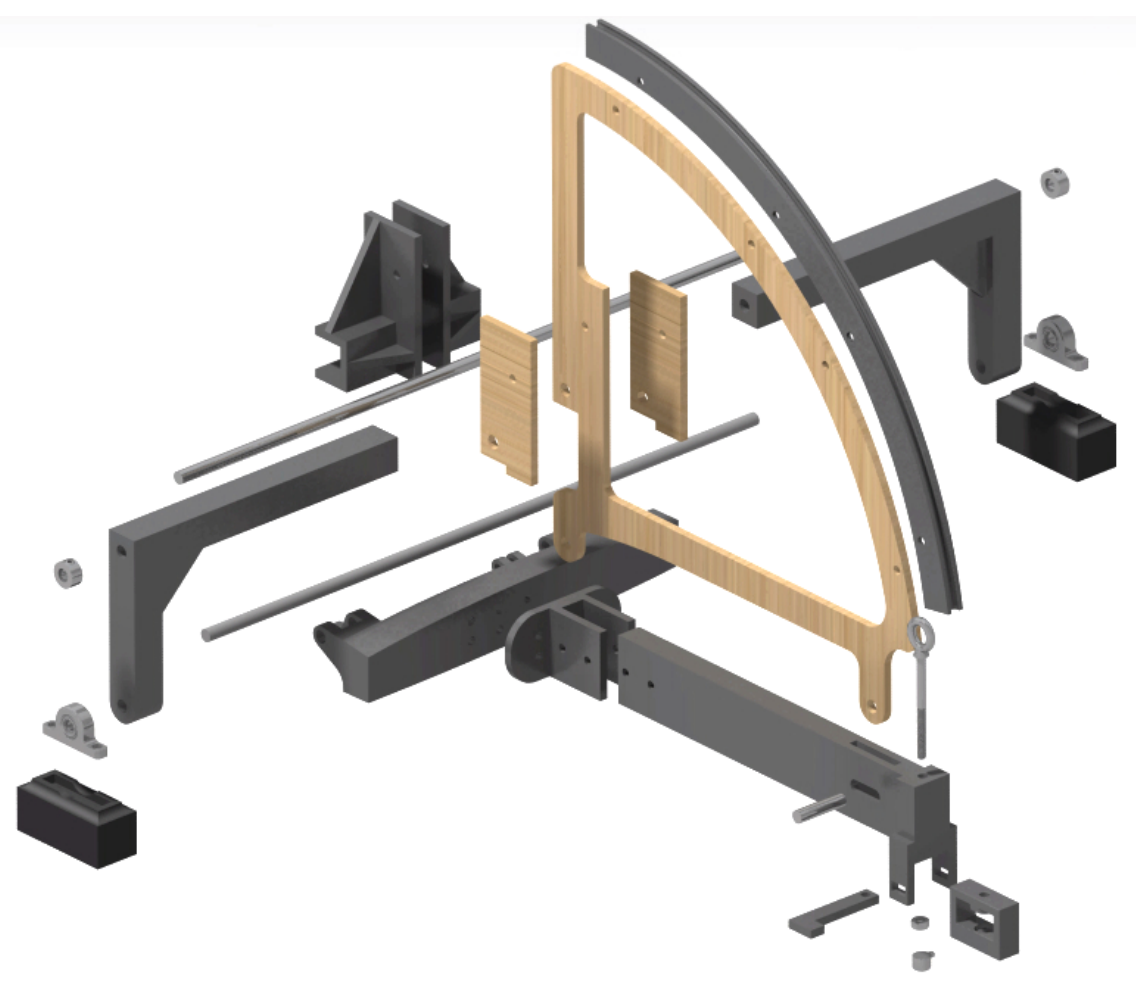

Figure 5-2: Exploded view of final prototype assembly

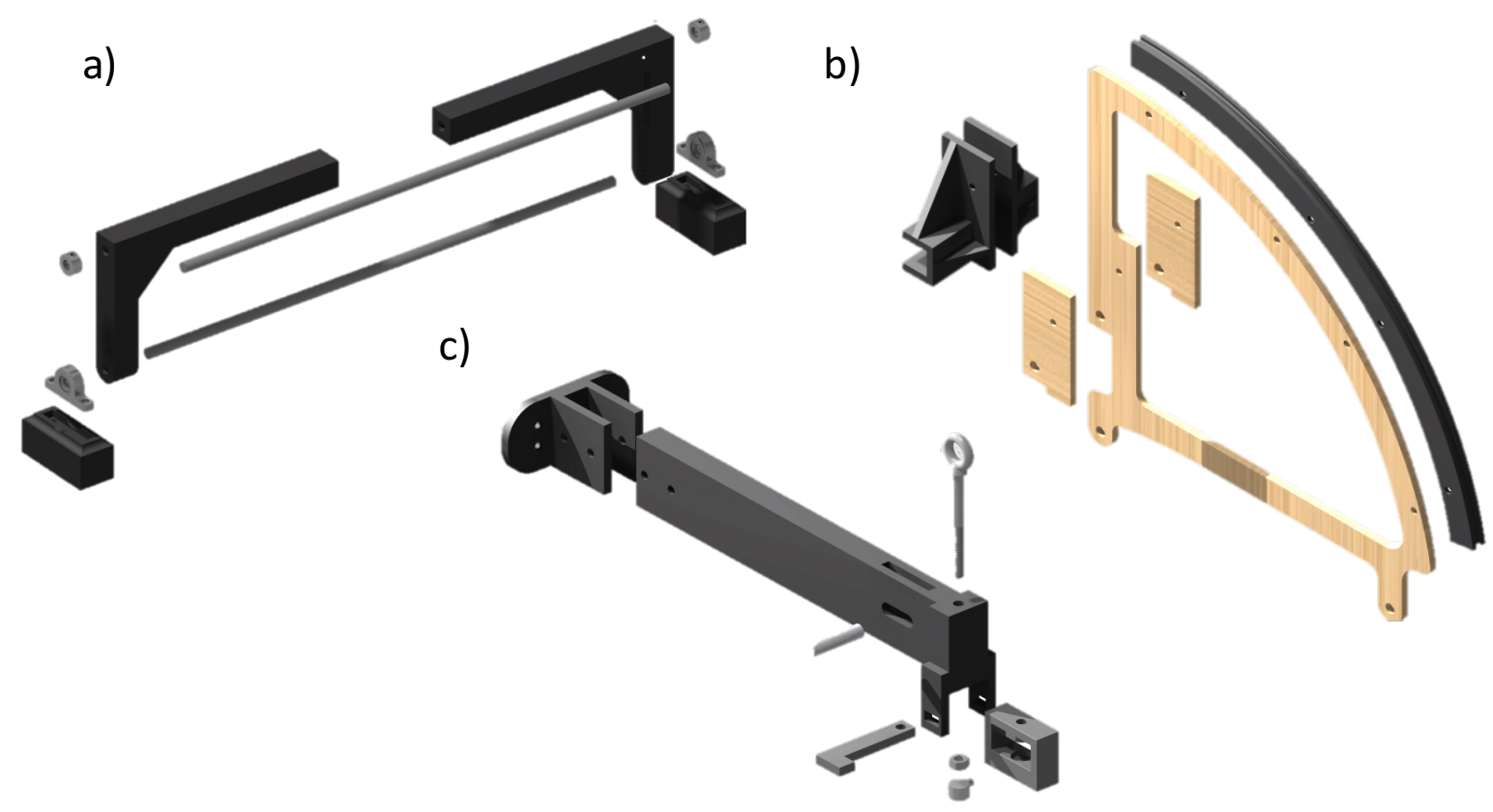

Figure 5-3: Exploded view of sub-assemblies - a) L bracket b) shark-fin c) winglet 
In addition to the loading model, a test fixture was required to ensure the applied loading on the winglet remained constant throughout the cant motion. The test fixture has been illustrated in Figure 5-4. The hole in the winglet for the eye-bolt to pass through is a loose fit to allow the load to be transferred. By applying an upward force on the eye-bolt through the pulley system, the load cell holder is raised by the installed nut. As the load cell holder is raised under load, it becomes constraint by the L-tab. The resultant reaction force acting on the load cell by the L-tab was used to ensure the load on the winglet remained constant throughout the winglet's motion and equal to the weight being used at the end of the pulley system.

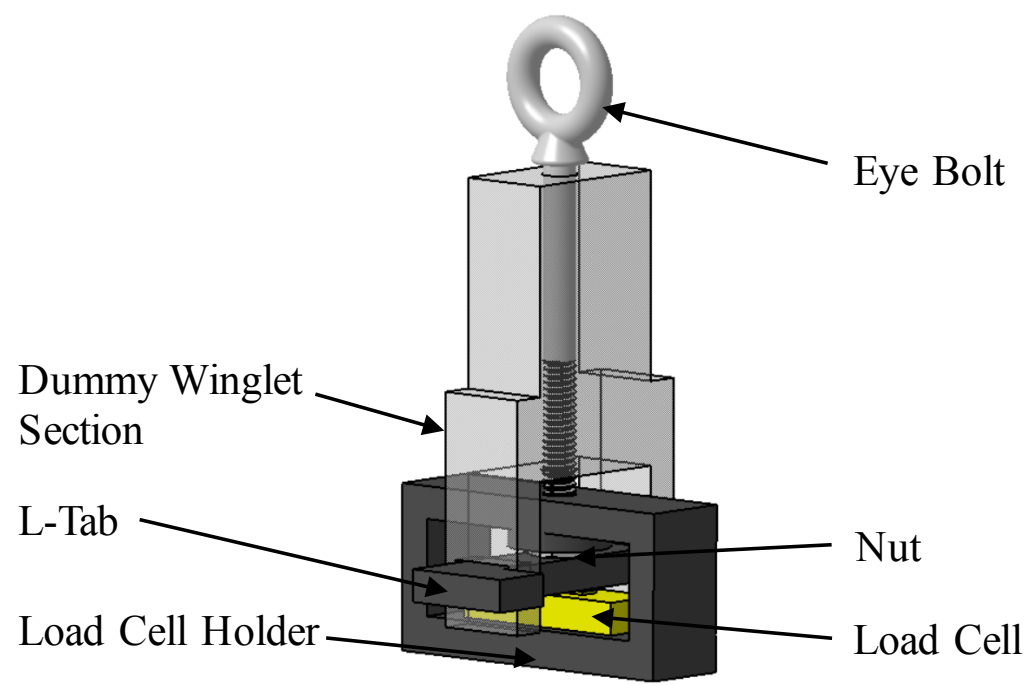

Figure 5-4: Load verification test fixture

Through the use of CATIA's assembly toolbox, the half size shark-fin loading system's assembly models were developed. The required frame to load the winglet through the use of a pulley system was designed using Aluminum extrusions and was included in the complete assembly. Figure 5-5a and Figure 5-5b illustrate renderings for the shark-fin assembly CAD at the cant angle's lower and upper limits respectively, with additional illustrations in Appendix B. 

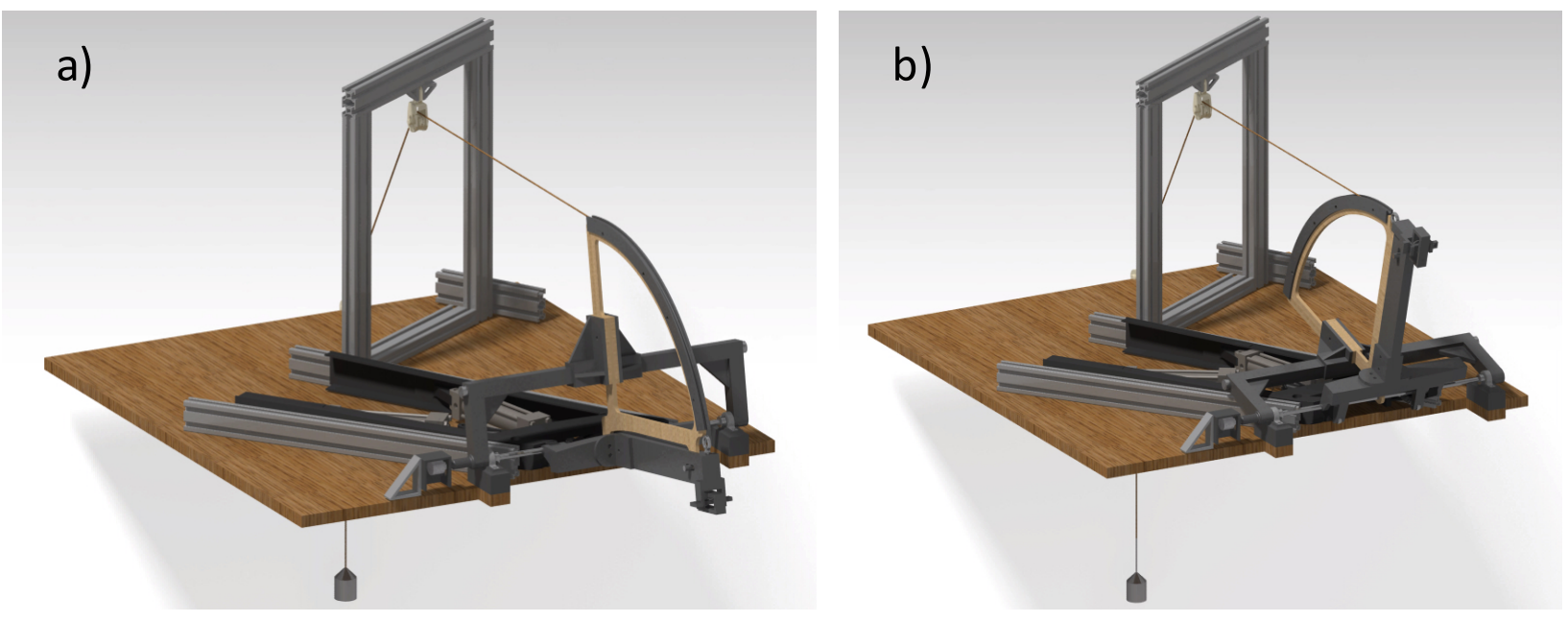

Figure 5-5: Shark-fin loading model assembly rendering - a) $10^{\circ}$ b) $75^{\circ}$

\subsection{SHARK-FIN OPTIMIZATION}

Given the applied loading on the prototype model will be limited due to its structural stiffness, the weight of the loading structure will have a large impact on the total moment at the winglet's axis of rotation. For the purpose of the prototype test, the moment being generated by the applied loading should be greater than the moment generated by the weight of the structure throughout the cant motion. In order to determine the minimum applied load to maintain the desired moment direction, equation (Eq. 5-1) was derived from the free-body-diagram (FBD) presented in Figure 5-6.

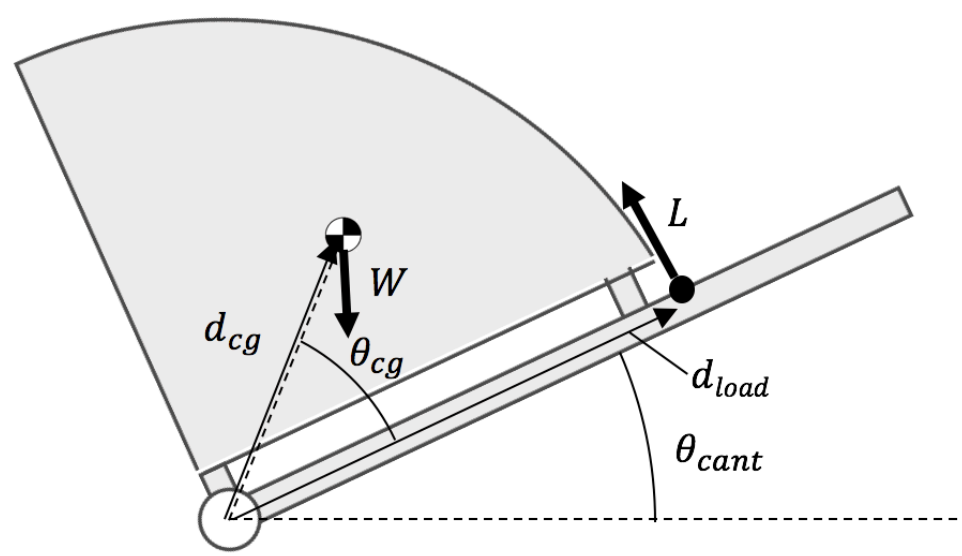

Figure 5-6: Loading Model FBD 


$$
M_{E}=L d_{\text {load }}-W d_{c g} \cos \left(\theta_{c g}+\theta_{\text {cant }}\right)=0
$$

In (Eq. 5-1), $L$ represents the applied load (lift), $\mathrm{d}_{\text {load }}$ is the moment arm for the lift force, $\mathrm{W}$ is the weight of the loading system, $\mathrm{d}_{\mathrm{cg}}$ is the distance between the rotation axis and the center of gravity of the loading system, $\theta_{c g}$ is the angle to the shark-fin's center of gravity and $\theta_{\text {cant }}$ is the cant angle. To ensure the desired moment direction about the axis of rotation is maintained throughout the cant motion, equation (Eq. 5-2) must hold true.

$$
L d_{\text {load }}>W d_{c g} \cos \left(\theta_{c g}+\min \left(\theta_{\text {cant }}\right)\right)
$$

Since the half scale model will generate a significant moment variation throughout the cant motion as a result of the shark-fin system's weight and the limited allowable loading, the test will fail to meet the project requirement. By applying larger applied loads ( $L$ ), the left side of (Eq. 5-2) increases, while the right side remains constant, causing the percent variation in moment to reduce. Therefore, the full scale test is expected to display a small percent variation in moment, given the cant module will utilize high strength metals designed to withstand the stresses associated with the required 1,700 pound applied load. Ryerson's Morphing Winglet Team has set a 1\% moment variation limit to mitigate the effects of the loading system's weight.

To best represent the full scale loading model, the moment being produced by the weight of the half size shark-fin assembly will need to be minimized, while considering the stresses under loading conditions. An optimization process was used to determine the dimensioning of the loading fixture to best match the expected full scale model results. While a majority of the components being used on the shark-fin loading model were pre-defined or developed for the purpose of assembly, the internal geometry of the shark-fin was not constraint. Given the sharkfin will have a significant impact on the moment variation and require stiffness to withstand the 
reaction loads as a result of the applied loading, an optimization of its geometry was performed. The following two objectives were defined for the optimization problem:

Objective 1: Minimize moment generated by the weight of the loading fixture

$$
M=W_{\text {shark-fin }} d_{c g} \cos \left(\theta_{c g}+10^{\circ}\right)
$$

Objective 2: Minimize the maximum principal stress on the shark-fin assembly The geometries of the shark-fin designs were also subject to the following constraints:

Constraint 1: $\theta_{c g}>0^{\circ}$

Constraint 2: $d_{c g}>0$

Constraint 3: Shark-fin Radius $=d_{M A C}$

Given the full scale winglet being used by Bombardier would be approximately 68.75inches, the MAC location was defined as 27.5 inches from the cant interface. For the half scale model, the loading point was placed 13.75 -inches from the cant interface $\left(d_{M A C}\right)$. Therefore, given the required distance to the MAC, the shark-fin radius was defined as 13.75-inches. Additionally, upon aerodynamic simulations performed by Bombardier Aerospace on the supercritical airfoil, the chord-wise distance for the center of pressure was found to be approximately $50 \%$ its chord.

With the defined radius of the shark-fin, three distinct designs were developed for the purpose of the optimization study, which have been illustrated in Figure 5-7. The three different models were produced by removing material about the shark-fin's center of gravity, inherently changing the perimeter's wall thickness. Design A was used as the base-line geometry, Design C was the upper limit with adequate material at the perimeter of the shark-fin and Design B was an intermediate geometry. Each design was modeled using CATIA to determine the variables required for the moment calculation (Table 5-1) and to perform a finite element analysis (FEA). 
Table 5-1: Shark-fin parameters for moment calculation

\begin{tabular}{|c|c|c|c|}
\hline Shark-Fin Design & Weight (lb) & $\boldsymbol{d}_{\boldsymbol{c g}}$ (in) & $\boldsymbol{\theta}_{\boldsymbol{c g}}(\mathbf{d e g})$ \\
\hline Design A & $4.502 \mathrm{lb}$ & 5.290 in & 42.789 \\
\hline Design B & $4.337 \mathrm{lb}$ & 5.176 in & 42.384 \\
\hline Design C & $3.884 \mathrm{lb}$ & 4.735 in & 41.034 \\
\hline
\end{tabular}

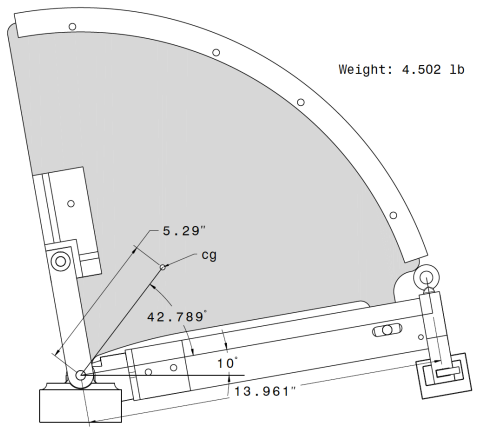

a)

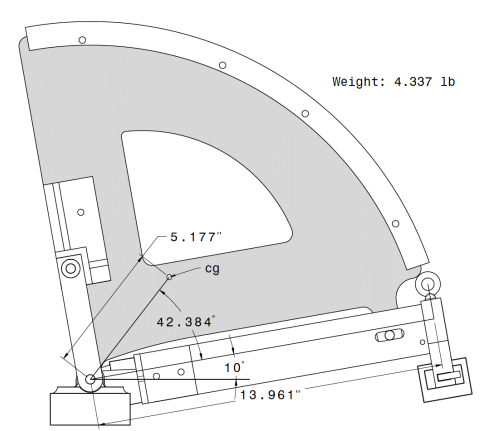

b)

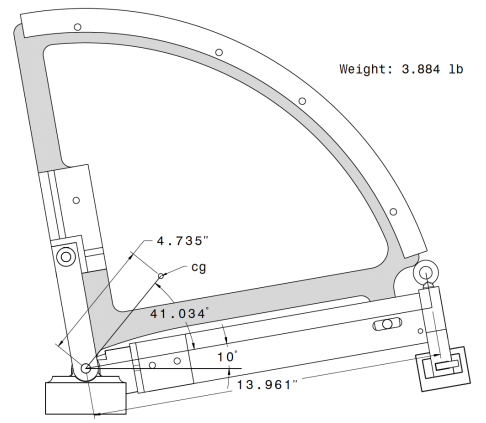

c)

Figure 5-7: Shark-fin geometry a) Design A b) Design B c) Design C

Given the complex geometries of the shark-fin designs, a medium-density fibreboard (MDF) material was selected, given its manufacturability with a laser cutter, sufficient stiffness and low weight. To complete the finite element analysis of the shark-fin designs, a rope was added to the geometry to accurately represent the load being transferred to the shark-fin. By utilizing Ansys Workbench, the deflection and stress plots were obtained for the three shark-fin designs. Given the highest stresses and maximum undesired moment would occur at the minimum cant angle, a static analysis of the shark-fin assembly was analyzed in its $10^{\circ}$ cant configuration.

The Ansys model and mesh used to evaluate the three geometries with the rope have been illustrated in Figure 5-8a and Figure 5-8b respectively (only Design C shown). The boundary 
conditions (BC) and loads applied in the Workbench model have been illustrated in Figure 5-9. In Figure 5-9a, BC 1 is a fixed support (all DOF) where the toggle joints attach to the cant interface and $\mathrm{BC} 2$ in Figure 5-9b is a second fixed support (all DOF) where the rod ends are fixed by the two pillow bearings. In Figure 5-9c and Figure 5-9d, load 1 represents the applied force of gravity on the system and load 2 defines the applied load by the pulley system respectively. A 2.2046pound $(1 \mathrm{~kg})$ force was used for the optimization section, which was the maximum load used on the half size prototype test.

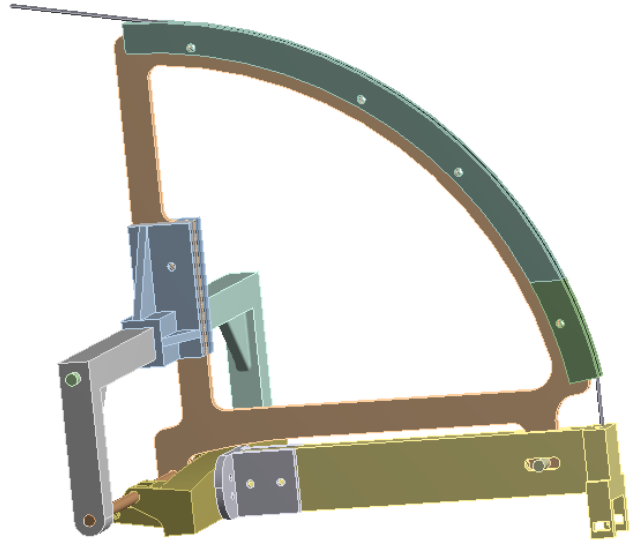

a)

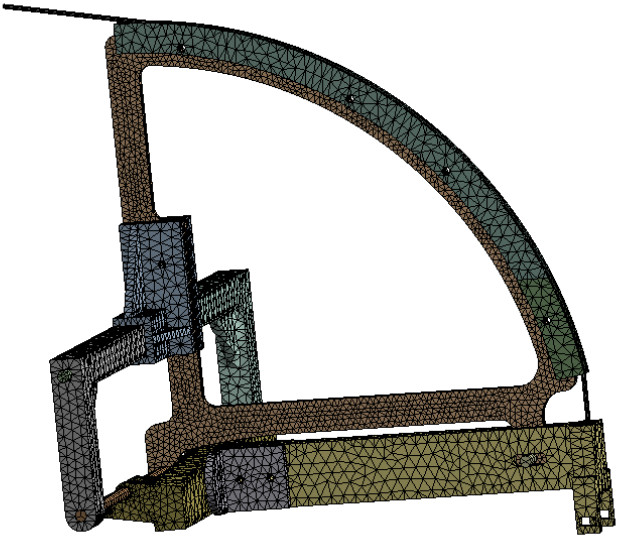

b)

Figure 5-8: Shark-fin Ansys model - a) geometry b) mesh 


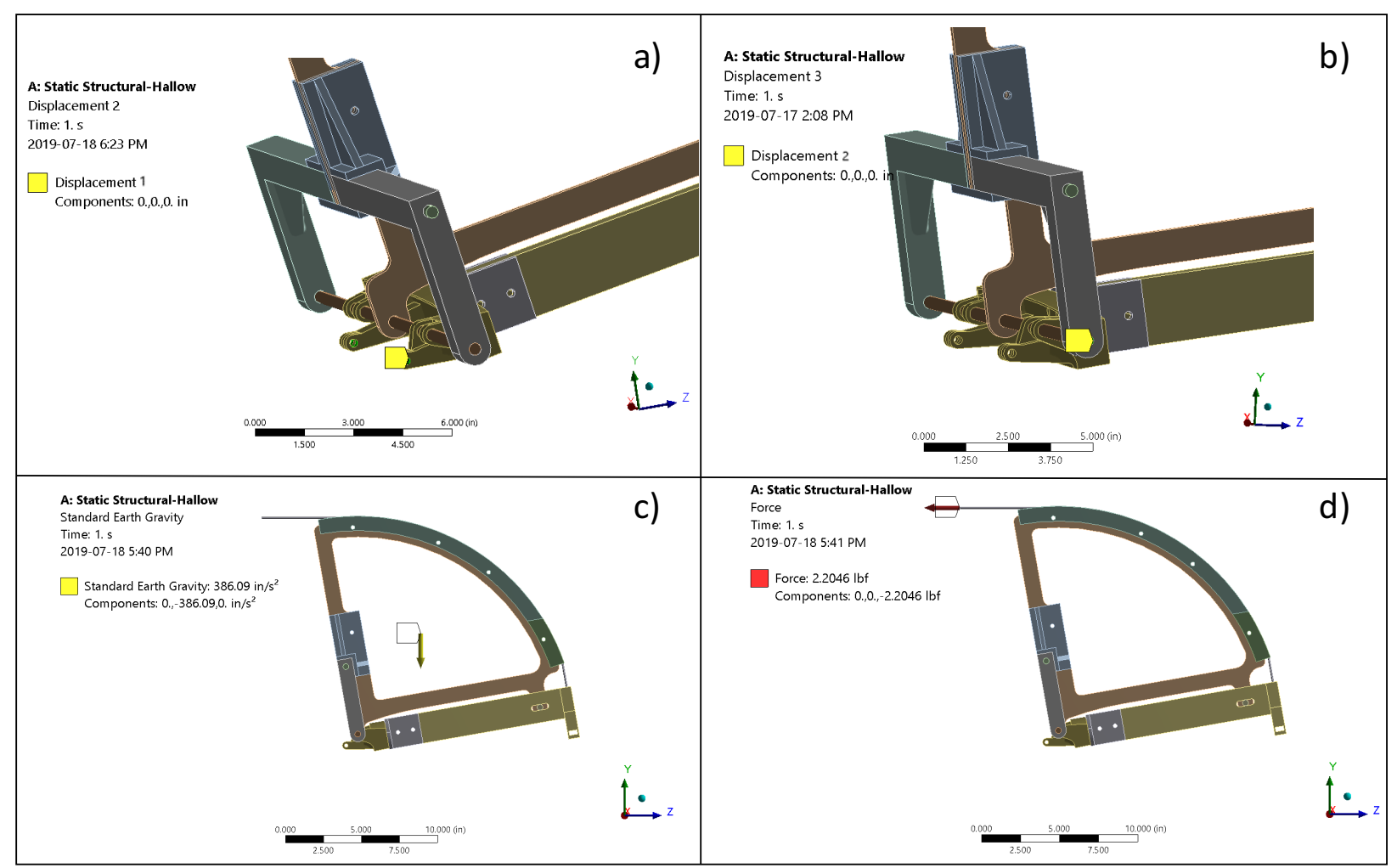

Figure 5-9: Ansys model a) BC 1 and 2 b) BC 3 c) Load 1 d) Load 2

To ensure the load from the string onto the shark-fin was being transferred, a "noseparation" contact region was defined between the rope and the H-rail, which has been illustrated in Figure 5-10. Additionally, the interfaces along the bottom rod and the pin at the winglet end were defined as frictionless contacts, while the remaining connection points were represented as bonded contacts, to best match the physical model [30]. 


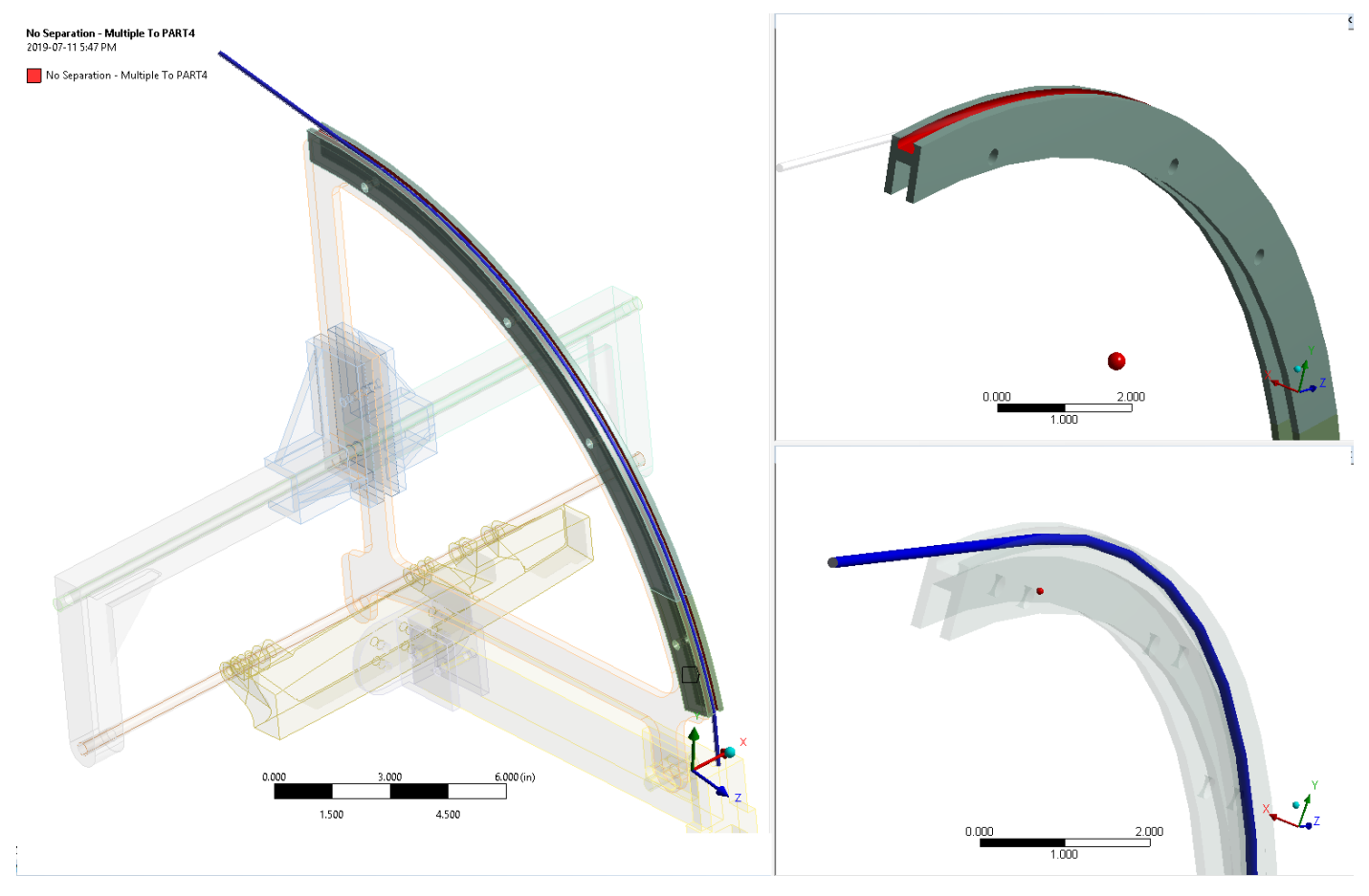

Figure 5-10: Rope and H-rail contact region definition

With the material properties of the Onyx filament [31], the MDF wood [32], the steel rod (Ansys built-in material) and the polypropylene rope [33] defined, the static structural analysis was completed on the three designs. Figure 5-11 illustrates the total deflection of the loading model and the isolated shark-fin deflections for the three designs. This demonstrates that the defined boundary conditions, loads and contacts in Ansys successfully emulate the expected deflections of the shark-fin loading model under load. To obtain results for the second objective function, the maximum principal stress for the shark-fin assembly was evaluated and illustrated in Figure 5-12. The results indicate that the critical stress location occur on the lower bar, at the fixed pillow bearing location. Given the shark-fin loading system was designed to transfer the loads to the pillow bearings, the results from the analysis match with the theoretical expectation. 


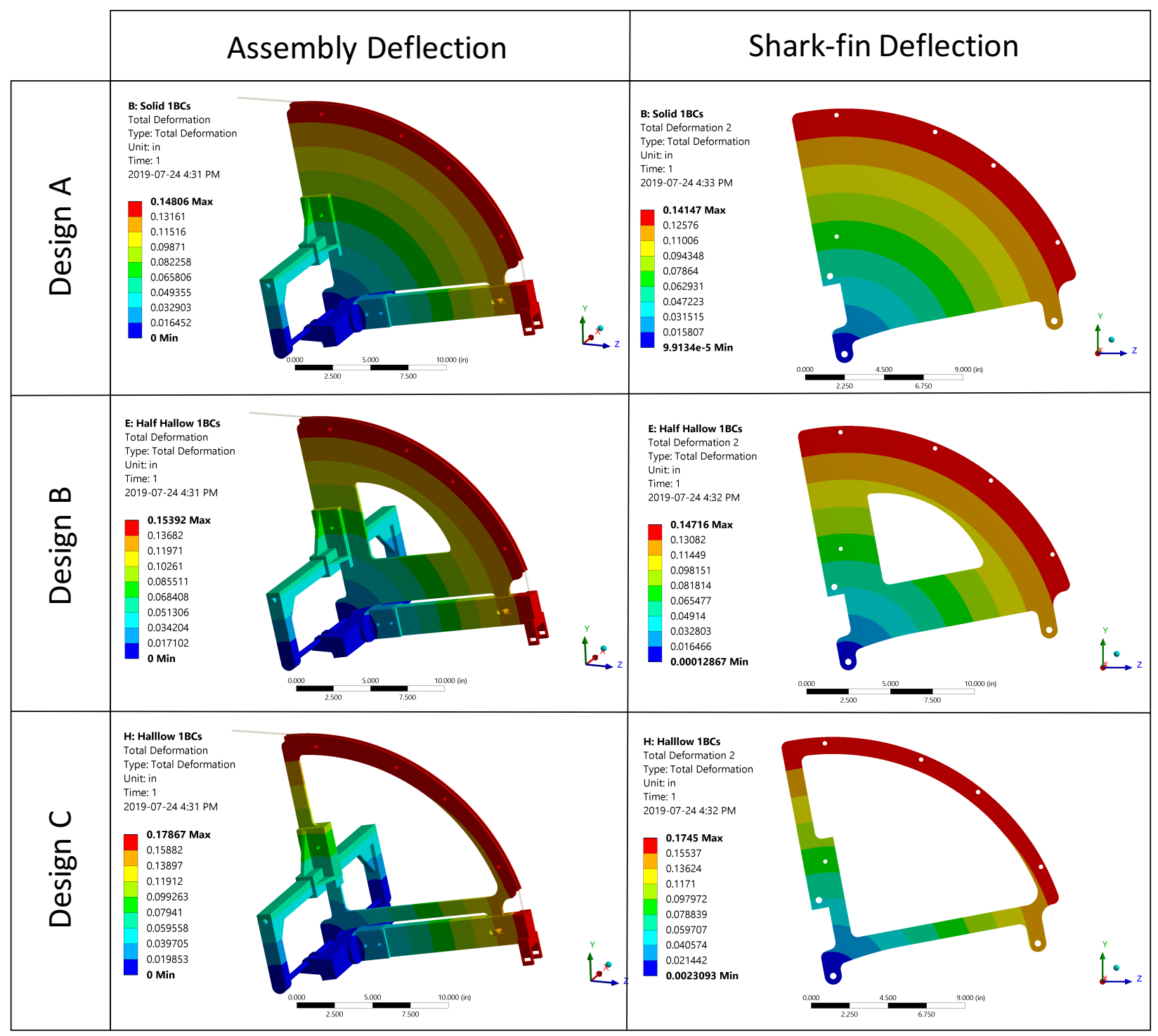

Figure 5-11: Shark-fin loading design FEA results - deflection 


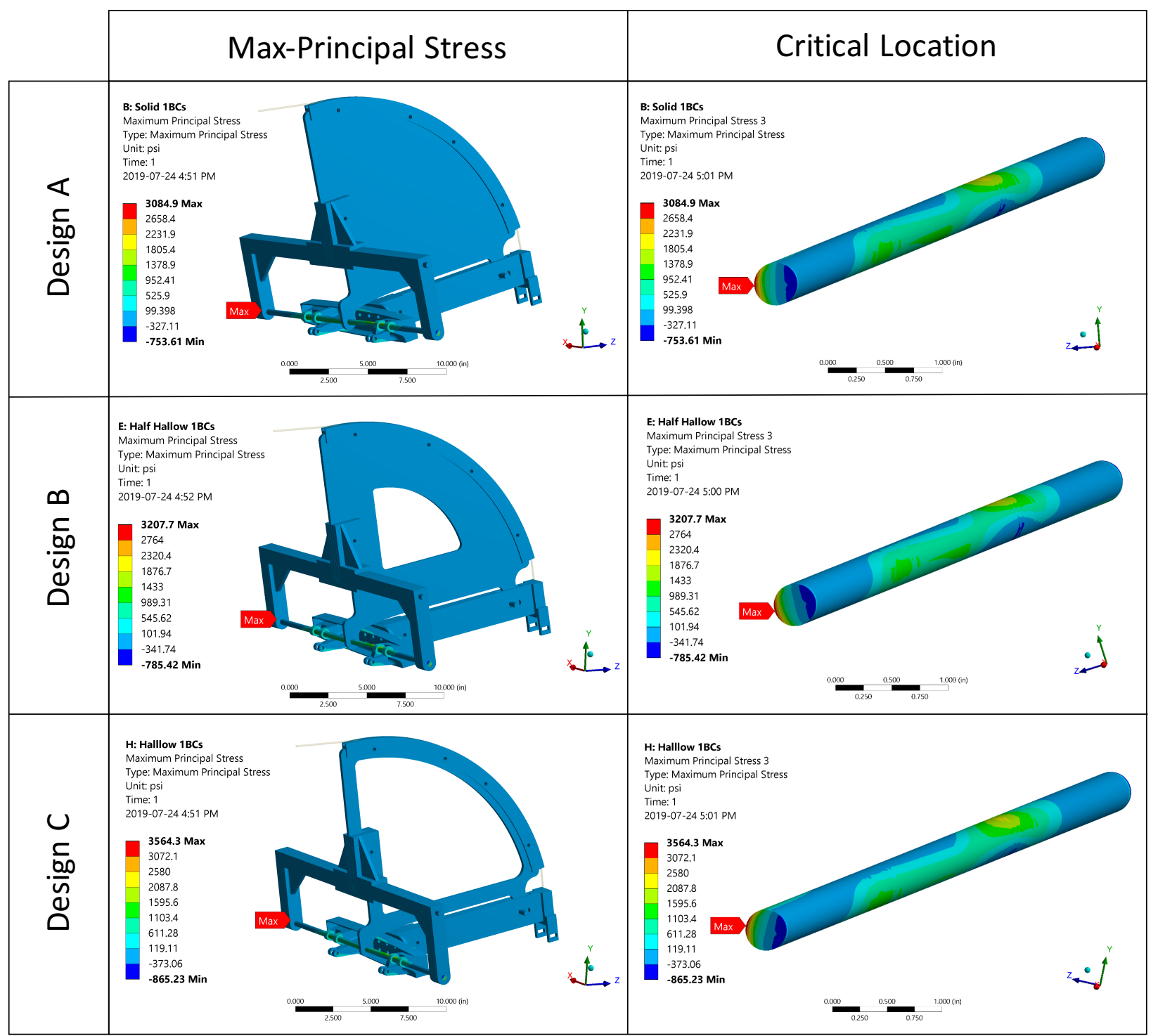

Figure 5-12: Shark-fin loading design FEA results - Max Principal Stress

Table 5-2 summarizes the evaluated results for the objectives and constraints defined for the optimization of the shark-fin model.

Table 5-2: Design A, B, C shark-fin results

\begin{tabular}{|l|c|c|c|}
\hline Parameter & Design A & Design B & Design C \\
\hline Objective 1 - Moment (lb*in) & 14.404 & 13.701 & 11.56 \\
\hline Objective 2 - Max Principal Stress (psi) & 3084.9 & 3207.7 & 3564.3 \\
\hline Constraint 1 - $\theta_{c g}$ & met & met & met \\
\hline Constraint 2 $-d_{C G}$ & met & met & met \\
\hline Constraint 3 $-d_{M A C}$ & met & met & met \\
\hline
\end{tabular}


Given the design problem consists of two objectives of varying units, the parameters were first normalized to the maximum of the three designs. An optimization function was required to weigh the importance of each objective. Through discussions with Ryerson's Morphing Winglet Team, the importance of the two objectives: limiting unwanted moment about the cant's axis of rotation $\left(X_{1}\right)$ and ensuring structural integrity $\left(X_{2}\right)$ were concluded to being equally important. Therefore, an objective function with coefficients of 0.5 was derived:

$$
\min Z=0.5 * X_{1}+0.5 * X_{2}
$$

where $X_{1}$ represents the maximum normalized moment generated by the system's weight and $X_{2}$ represents the maximum normalized stress on the shark-fin assembly [34]. Table 5-3 summarizes the normalized results for the objective functions and the resultant score for each design.

Table 5-3: Shark-fin optimization results

\begin{tabular}{|c|c|c|c|}
\hline Parameter & Design A & Design B & Design C \\
\hline $\boldsymbol{X}_{\mathbf{1}}$ & 1 & 0.951 & 0.802 \\
\hline $\boldsymbol{X}_{\mathbf{2}}$ & 0.865 & 0.899 & 1 \\
\hline Optimization Function $(\mathbf{Z})$ & $\mathbf{0 . 9 3 2}$ & $\mathbf{0 . 9 2 5}$ & $\mathbf{0 . 9 0 1}$ \\
\hline
\end{tabular}

Given all three designs meet the optimization problem's constraints, the calculated results in the final row of Table 5-3 indicates Design C to be the optimal shark-fin geometry. 


\subsection{ASSEMBLY DESIGN}

After selecting the optimal shark-fin design and ensuring the dimensional accuracy of the manufactured components, the shark-fin loading fixture was assembled at Ryerson's Intelligent Systems and Robotics Laboratory. Figure 5-13a demonstrates the winglet in the lowest positon at $10^{\circ}$ and Figure $5-13 \mathrm{~b}$ shows the winglet at its maximum positon at $75^{\circ}$.
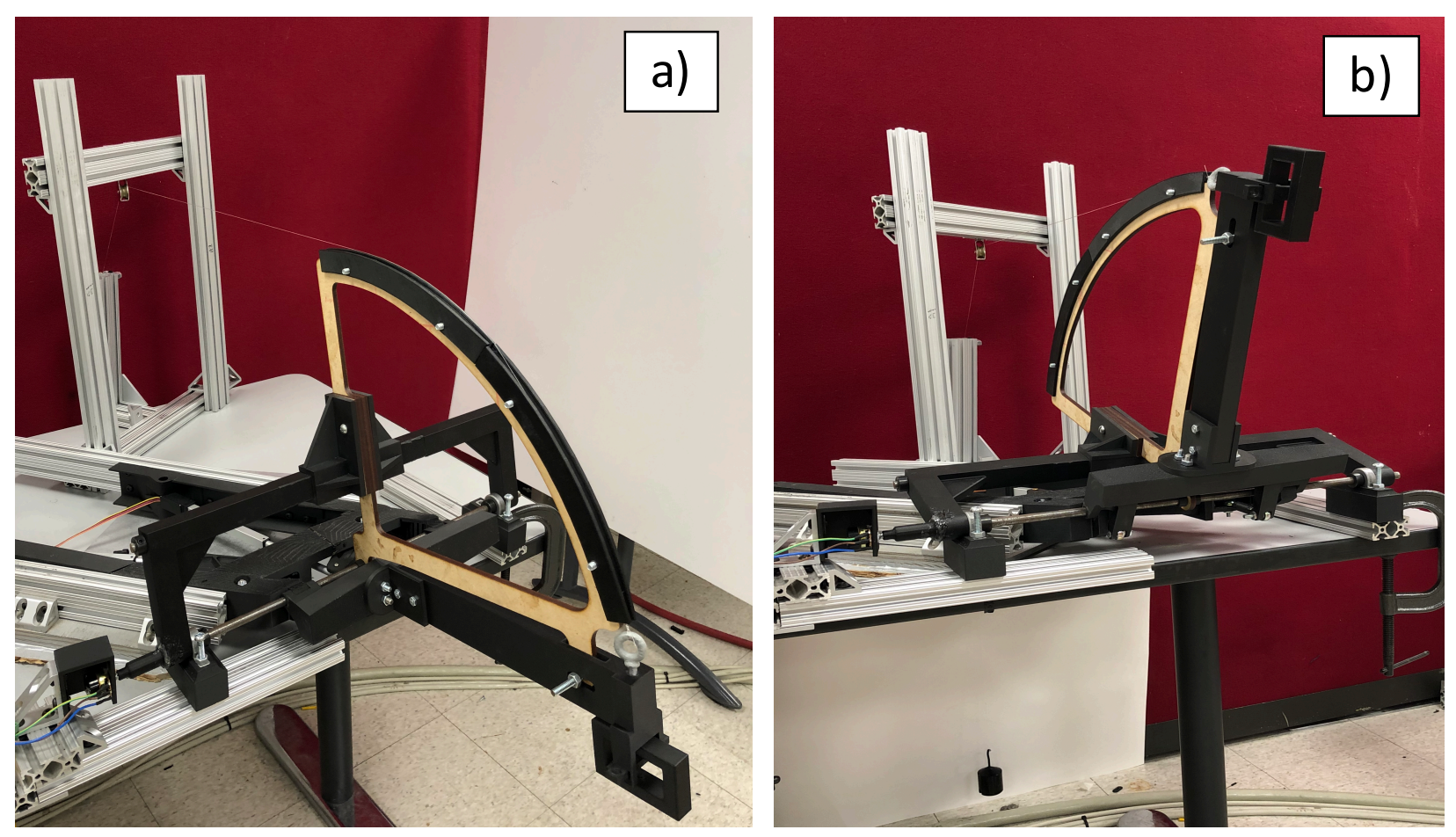

Figure 5-13: Half size dynamic loading model - a) minimum position b) maximum position

The winglet was limited to a maximum cant angle of $75^{\circ}$ due to the $3 \mathrm{D}$ printer's maximum print size constraint. Since the full scale loading fixture will utilize machined components, the winglet will be free to travel the complete motion up to $80^{\circ}$. For the purpose of validating the loading model, the half size model's limitation was deemed acceptable at this stage of the project. 


\section{EXPERIMENTAL RESULTS}

Validating the final loading model required the comparison of theoretical and experimental data. The purpose of the loading mechanism was to analyze the forward and aft actuators' force characteristics under an applied load during the cant motion. By utilizing a kinematic model, the theoretical actuator load readings were derived as a function of the cant angle. Following the derivation, the dynamic loading prototype was used to obtain experimental data for comparison.

\subsection{THEORETICAL SHARK-FIN MODEL}

Prior to the development of a dynamic loading model presented in this paper, the design, analysis and production of the cant module was completed by Ryerson's Morphing Winglet Team [35]. To determine the theoretical loading on the forward and aft actuators, the cant module's kinematic analysis was required. The derivation for the dynamic analysis is provided in Appendix C. The resultant actuator force equation (Eq. C-0-24) was utilized in the following sections to compare with the experimental findings [35]. However, given (Eq. C-0-24) does not consider the moment generated by the weight of the winglet or loading fixture, (Eq. C-0-23) was replaced by (Eq. 5-1). This ensures the theoretical results would account for the center of gravity variation which would be experienced during the experimental tests.

\subsection{EXPERIMENTAL SHARK-FIN MODEL}

By utilizing the half size shark-fin loading model developed for the morphing winglet load test, experimental results were obtained for the actuator loads as a function of cant angle. To obtain an experimental plot of the load versus cant angle, the raw data extracted from the encoder and the actuators required calibration and transformation. Additionally, the Simulink model used to actuate the winglet required additional modules to obtain the necessary data. 


\subsubsection{ROTARY POTENTIOMETER CALIBRATION}

The Simulink model developed for the cant module's kinematic study acquires the winglet's cant angle from the dual four bar linkage system's forward kinematics [35]. However, the reading is theoretical and does not account for manufacturing inaccuracies or material deformation which occurs when the system is under load. A rotary potentiometer was installed on the axis of rotation, to accurately measure the system's cant angle. The rotary potentiometer consists of a variable resistor which is used to create an adjustable voltage divider. The potentiometer consists of a mechanical knob (wiper) which is used to divide the defined $10 \mathrm{k} \Omega$ resistor into two. By providing an input voltage with a known ratio between the two resistors in series, there exists a varying voltage output at the wiper as a function of the knobs angular position. [36] To obtain the cant angle, the knob of the potentiometer was bonded to the (L bracket), to ensure coaxial rotation with the winglet. Therefore, as the winglet is actuated, the potentiometer's knob will simultaneously rotate, resulting in a varying voltage measurement.

Obtaining an accurate model for the cant angle as a function of the potentiometer's voltage required the use of a digitizer. By utilizing the 3D Creator Precision Optical Digitizer developed by Boulders Innovators Group, with the Encoder Calibration Matlab Code (Appendix A), the winglet's cant angle was verified. The digitizer utilizes a camera and a portable probe, illustrated in Figure 6-1, to measure the 3D coordinates of any point in space to an accuracy of $0.001 \mathrm{~mm}$. 


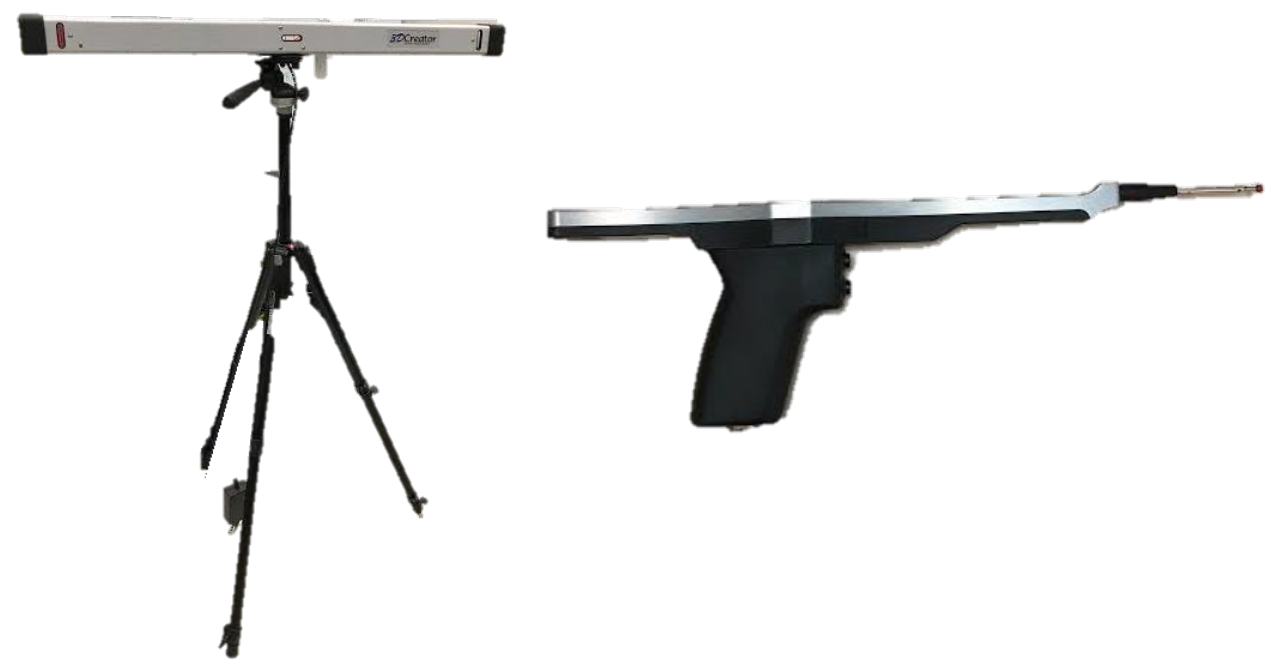

Figure 6-1: 3D creator digitizer

To obtain accurate and consistent cant angle measurements from the digitizer, 3D printed markers were placed onto varying locations on the winglet. Three markers were required on the wing to represent the zero-degree reference plane, two markers were placed about the axis of rotation and the final marker was placed at the tip of the winglet.

Utilizing the $\mathrm{X}, \mathrm{Y}$ and $\mathrm{Z}$ coordinates of the defined markers and the MATLAB script provided in Appendix A, the cant angle range was measured and validated. By setting the winglet at varying positions and obtaining the cant angle and voltage reading, (Eq. 6-1) was obtained.

$$
\theta_{\text {cant }}=7.7817 * V+75
$$

where, the input voltage $(V)$ is in volts and the resultant cant angle is in degrees. 


\subsubsection{ACTUATOR CALIBRATION}

Obtaining the load from the cant module's linear actuators required an additional module in the Simulink design. First, the raw current outputted by the forward and aft actuator in amperes required filtering to minimize the noise in the signal. The following first order low pass filter was

utilized to filter the current readings: $\left(\frac{20}{s+20}\right)$. The low pass filter was used to eliminate the high frequency noise being produced by the Quanser box. The cutoff frequency for the filter was determined through trial and error by Ryerson's Morphing Winglet Team [37]. Second, a conversion function was required to transform the current to a force reading. To obtain an accurate model, experimental calibration tests were conducted on each actuator.

During the experimental calibration, multiple test conditions were required, due to the operation and nature of the cant module's linear actuators. It was found that the actuators had different responses when they were operating under tension and compression, and when the load was in the direction of motion and against the direction motion. Therefore, the following four tests were performed on both the forward and aft actuator:

1. Tension Test:

a) Load in Direction of Motion

b) Load Against Direction of Motion

2. Compression Test:

c) Load in Direction of Motion

d) Load Against Direction of Motion

The test setups used for the experiment under tension and compression have been illustrated in Figure 6-2. By applying a static load at the actuator's end effector (for tension and compression), and actuating for the complete stroke range, the required test data for the four conditions were obtained. 


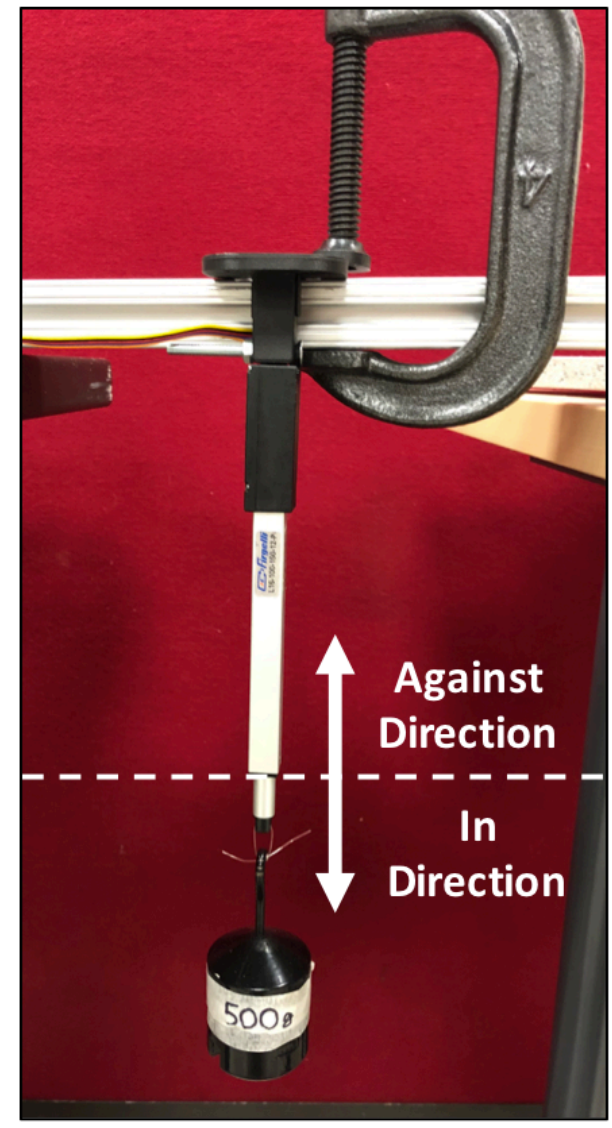

a)

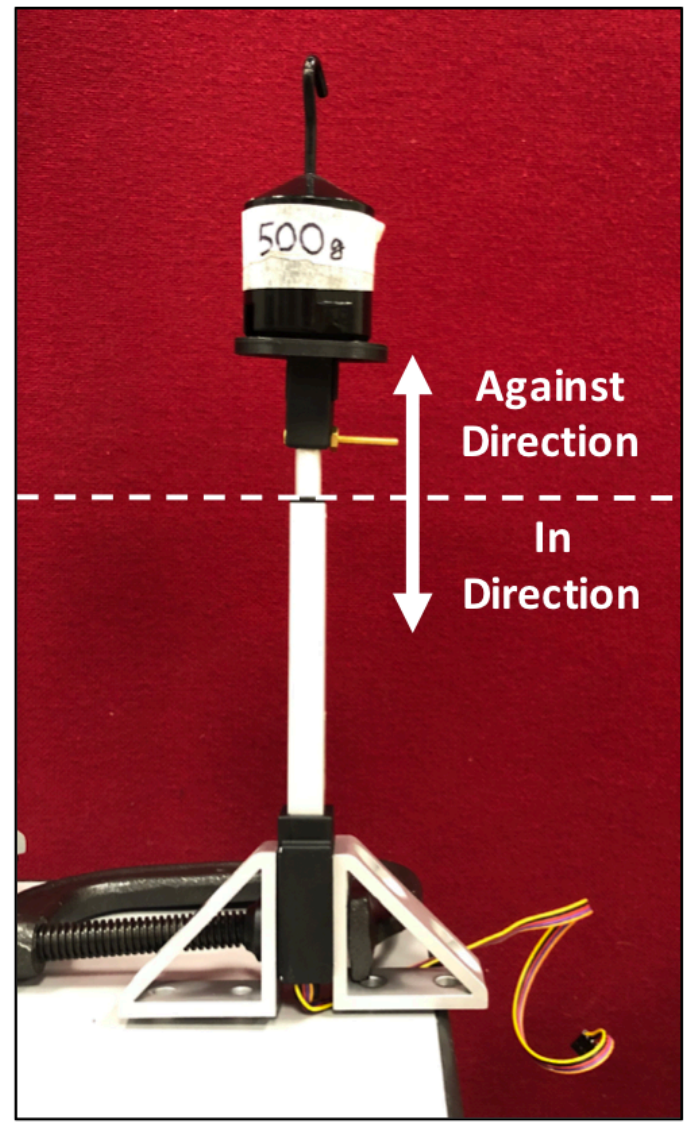

b)

Figure 6-2: Actuator calibration test setup. a) tension test b) compression test

For each test condition, varying controlled weights were loaded and the current versus theoretical cant angles, based on the cant module's forward kinematics were recorded. Figure 6-3 illustrates the raw data outputted from the actuators, the moving average over 50 readings and the mean current reading over the complete cant motion for one of the required tests. The mean current value from the filtered signal was extracted and used as a data point for each load test to determine the current versus load function. 


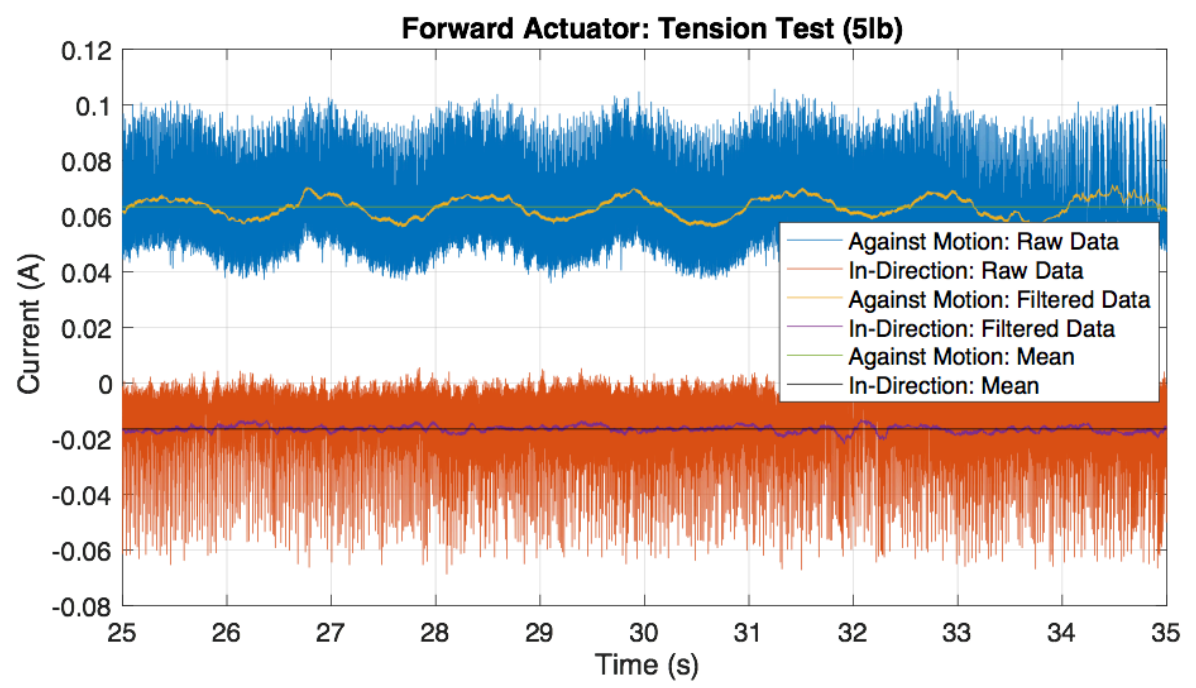

Figure 6-3: Actuator experimental calibration test-signal processing example

By performing all the test conditions at varying loads, a precise current to load conversion was obtained for both the forward and aft actuators. The test results have been plotted in Figure 6-4 and Figure 6-5. In Figure 6-4 and Figure 6-5, a negative current represents the actuator retracting and a positive current represents the actuator extending, while a positive force represents the applied load causing tension while a negative force represents a compressive force.

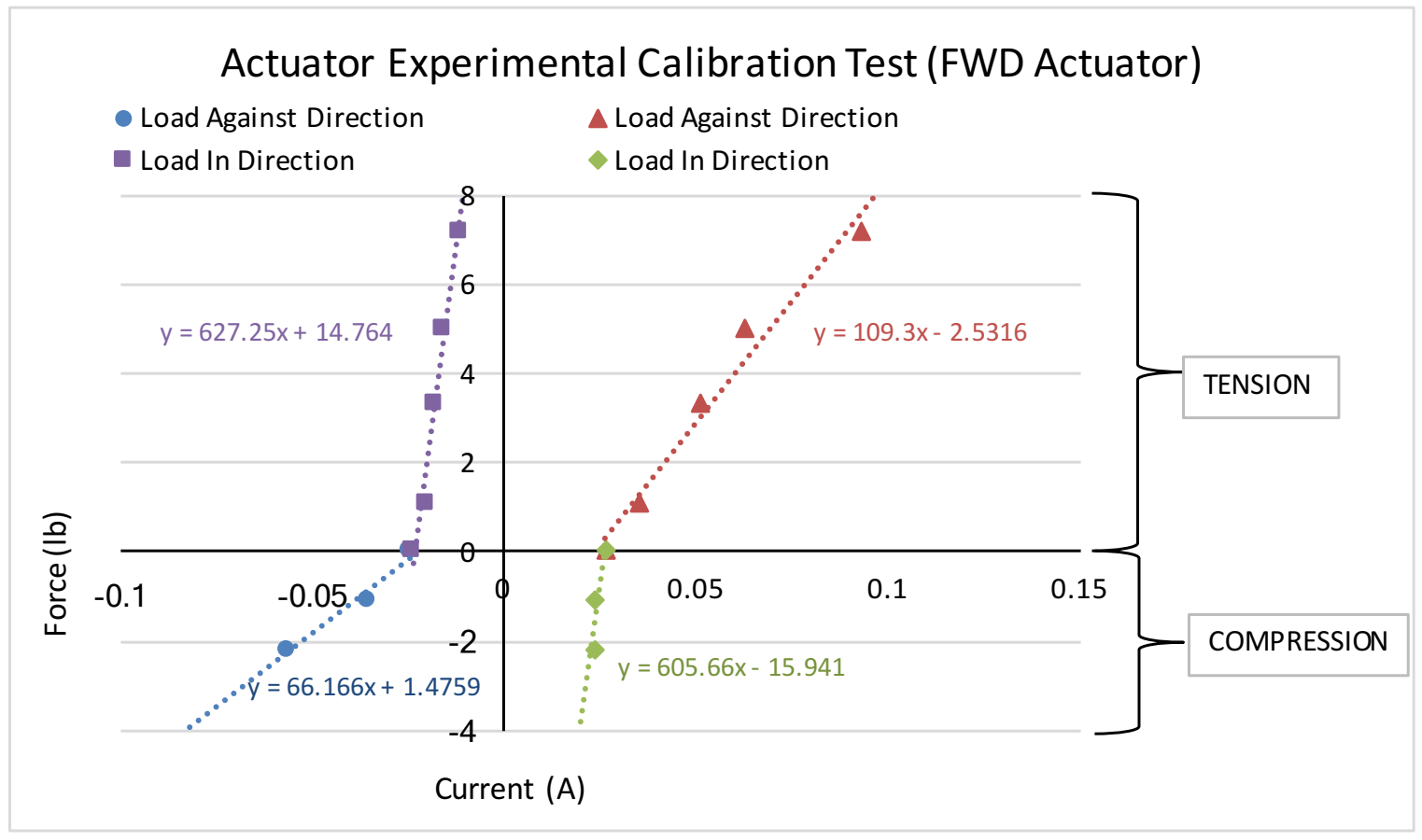

Figure 6-4: FWD actuator load vs current test results 


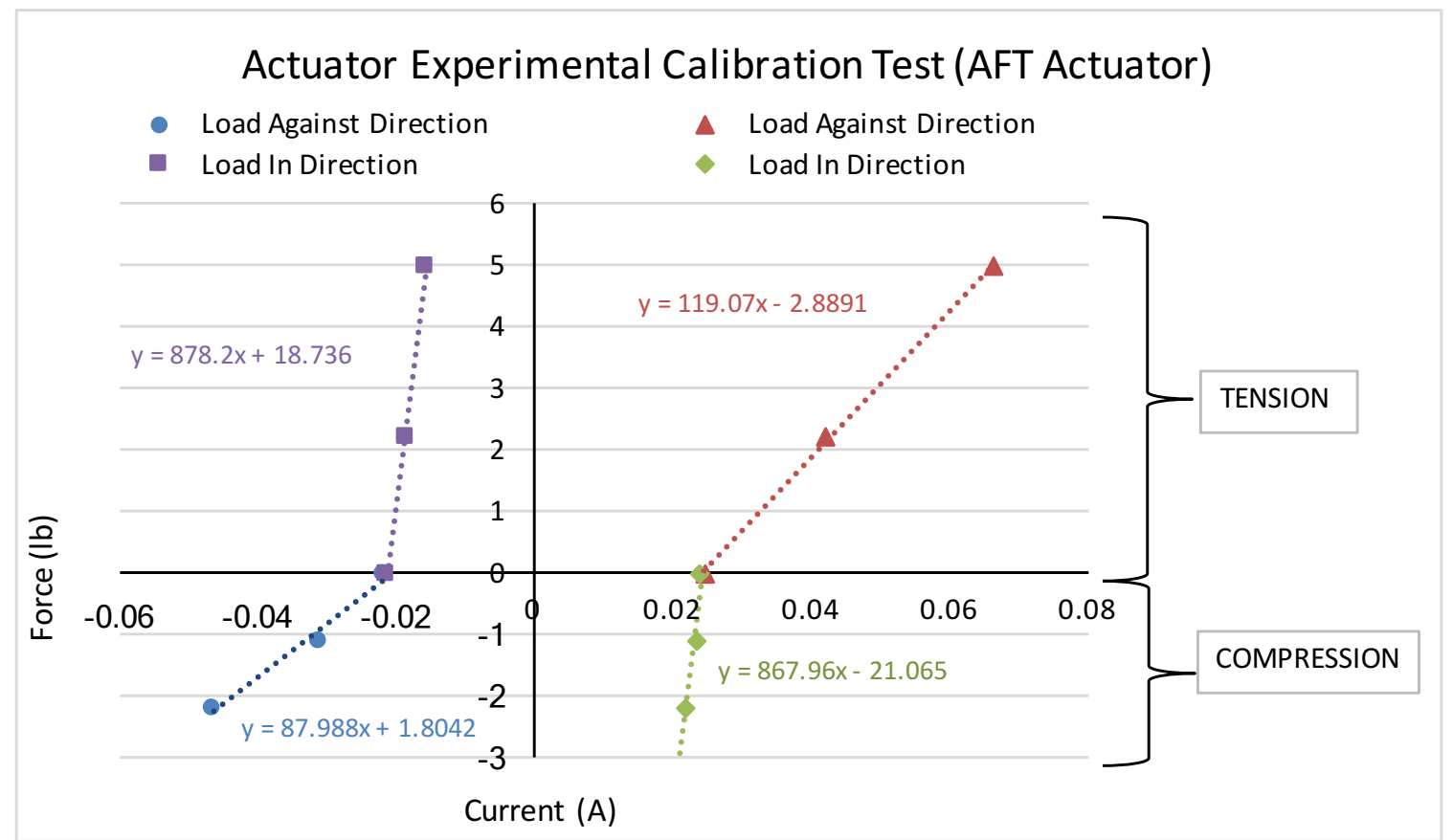

Figure 6-5: AFT actuator load vs current test results

The current to force functions have been summarized in Table 6-1 and Table 6-2. These functions were utilized to convert the recorded current reading from the Simulink model to a force in Section 6.2.4.

Table 6-1: FWD actuation load to current function

\begin{tabular}{|c|c|c|}
\hline \multirow{2}{*}{ Test Condition } & \multicolumn{2}{|c|}{ Forward Actuator } \\
\cline { 2 - 3 } & Tension & Compression \\
\hline $\begin{array}{c}\text { Load In Direction of } \\
\text { Motion }\end{array}$ & $F=627.25 A+14.764$ & $F=605.66 A-15.941$ \\
\hline $\begin{array}{c}\text { Load Against } \\
\text { Direction of Motion }\end{array}$ & $F=109.3 A-2.5316$ & $F=66.166 A+1.4759$ \\
\hline
\end{tabular}

Table 6-2: AFT actuation load to current function

\begin{tabular}{|c|c|c|}
\hline \multirow{2}{*}{ Test Condition } & \multicolumn{2}{|c|}{ Aft Actuator } \\
\cline { 2 - 3 } & Tension & Compression \\
\hline $\begin{array}{c}\text { Load In Direction of } \\
\text { Motion }\end{array}$ & $F=878.2 A+18.736$ & $F=867.96 A-21.065$ \\
\hline $\begin{array}{c}\text { Load Against } \\
\text { Direction of Motion }\end{array}$ & $F=119.07 A-2.8891$ & $F 7.988 A+1.8042$ \\
\hline
\end{tabular}

In Table 6-1 and Table 6-2, $A$ is the current in amperes and $F$ is the load in pounds. 


\subsubsection{CONTROL SYSTEM FOR CANT-MECHANISM}

In order to obtain the desired experimental results, the installed rotary potentiometer and the developed transformation functions were incorporated into the existing cant module's Simulink model, which had been developed by Gabriel Campos and Upasana Choudhuri [5]. The block diagram used for the data acquisition for the shark-fin loading model has been illustrated in Figure $6-6$.

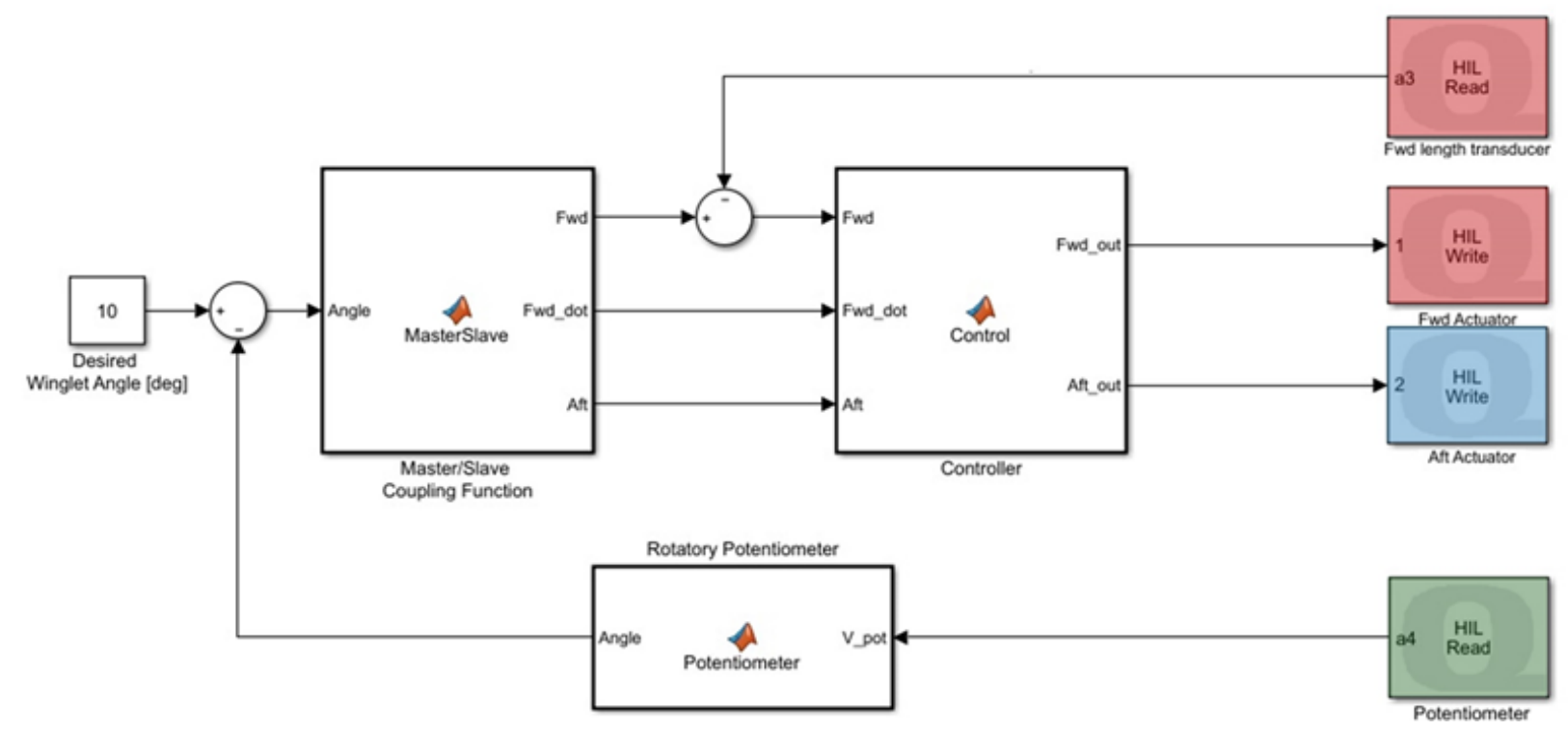

Figure 6-6: Block diagram for Simulink data acquisition [5]

The controller utilizes a 'master-slave' relationship to synchronize the dual linkage mechanism. The feedback system in the forward linkage is required to ensure the actuators remain synchronized throughout the cant motion and to prevent fighting between the two linkage systems. Further detail for the cant module's control system can be found in [5]. 


\subsubsection{EXPERIMENTAL SHARK-FIN RESULTS}

To determine the minimum load to apply at the end of the pulley system to eliminate the influence of the moment generated by the weight of the shark-fin fixture, the results for Design C in Table 5-1 were required. By entering the obtained measurements into (Eq. 5-2), a minimum load of 308 grams ( 0.679 pound) was calculated to ensure the desired moment throughout the cant motion. By ensuring the applied load remains greater than the critical load, the direction of the moment remains constant and the nature of the force (compression or tension) acting on the actuators remain constant. This ensures the actuators are not damaged during the test. Figure 6-7 illustrates the variation in moment (quadratic) about the axis of rotation as the cant angle is increased for various loading conditions.

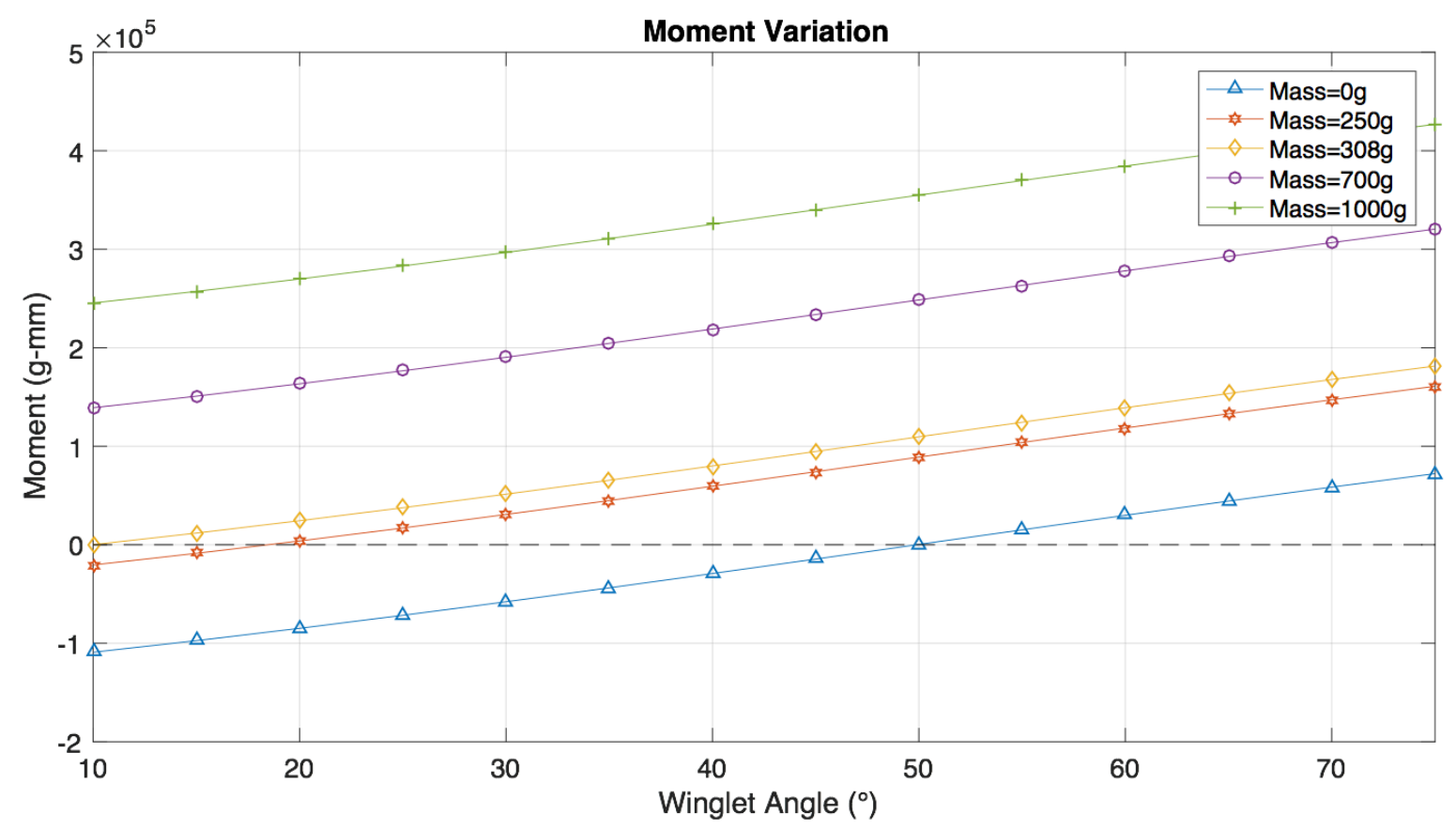

Figure 6-7: Moment variation as a function of cant angle

Analyzing a no load condition can verify the accuracy of the loading model and data analysis methodology. Theoretically under a no load condition, as the loading fixture's center of gravity aligns with the axis of rotation, the forward and aft actuators should produce a zero force 
reading. As demonstrated in Figure 6-8, the cant angle at which the center of gravity aligns with the axis of rotation is $48.96^{\circ}$. To validate the loading model, a test will be conducted with no applied load to ensure a zero force reading on each actuator or a large drop in force at the center of gravity crossing.

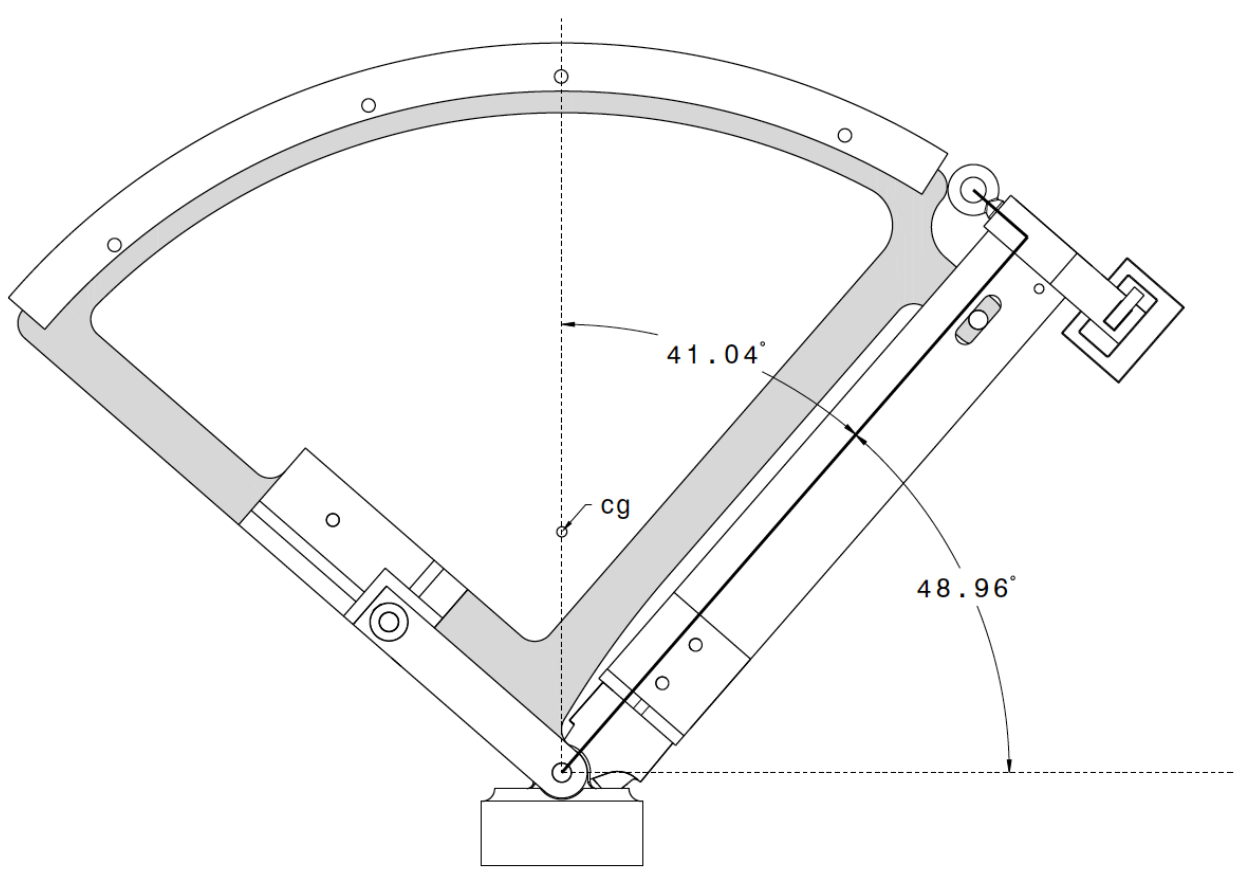

Figure 6-8: No load winglet configuration

Through the developed Simulink model for the shark-fin loading fixture, various tests were conducted with multiple loads for both the winglet traveling from $10^{\circ}-80^{\circ}$ and $80^{\circ}-10^{\circ}$ at $1^{\circ}$ per second. The developed Simulink model extracted the measured cant angle and current from each actuator simultaneously as a function of time. The data files extracted from each test were analyzed and plotted using the Matlab script included in Appendix A. Figure 6-9 and Figure 6-10 illustrate the current from each actuator as a function of the cant angle for varying loads, as the winglet travels downward and upward respectively. 


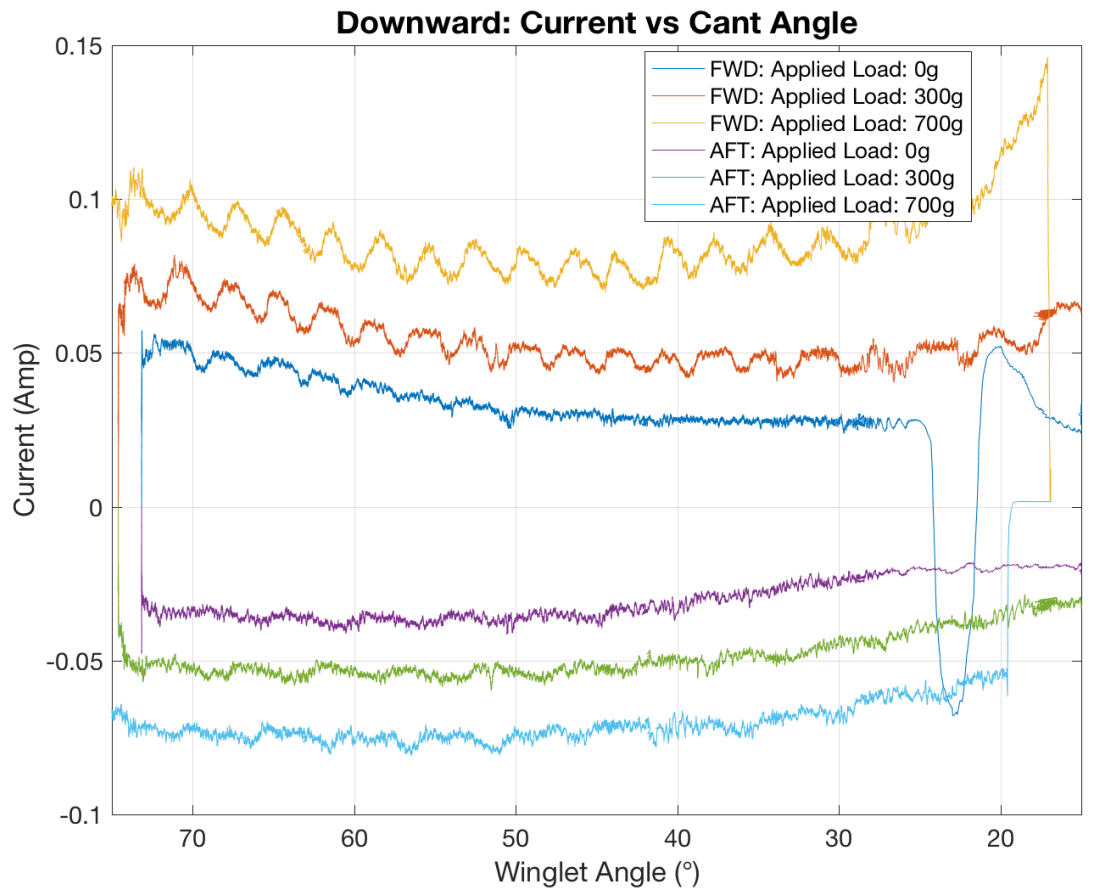

Figure 6-9: Current vs cant angle (downward)

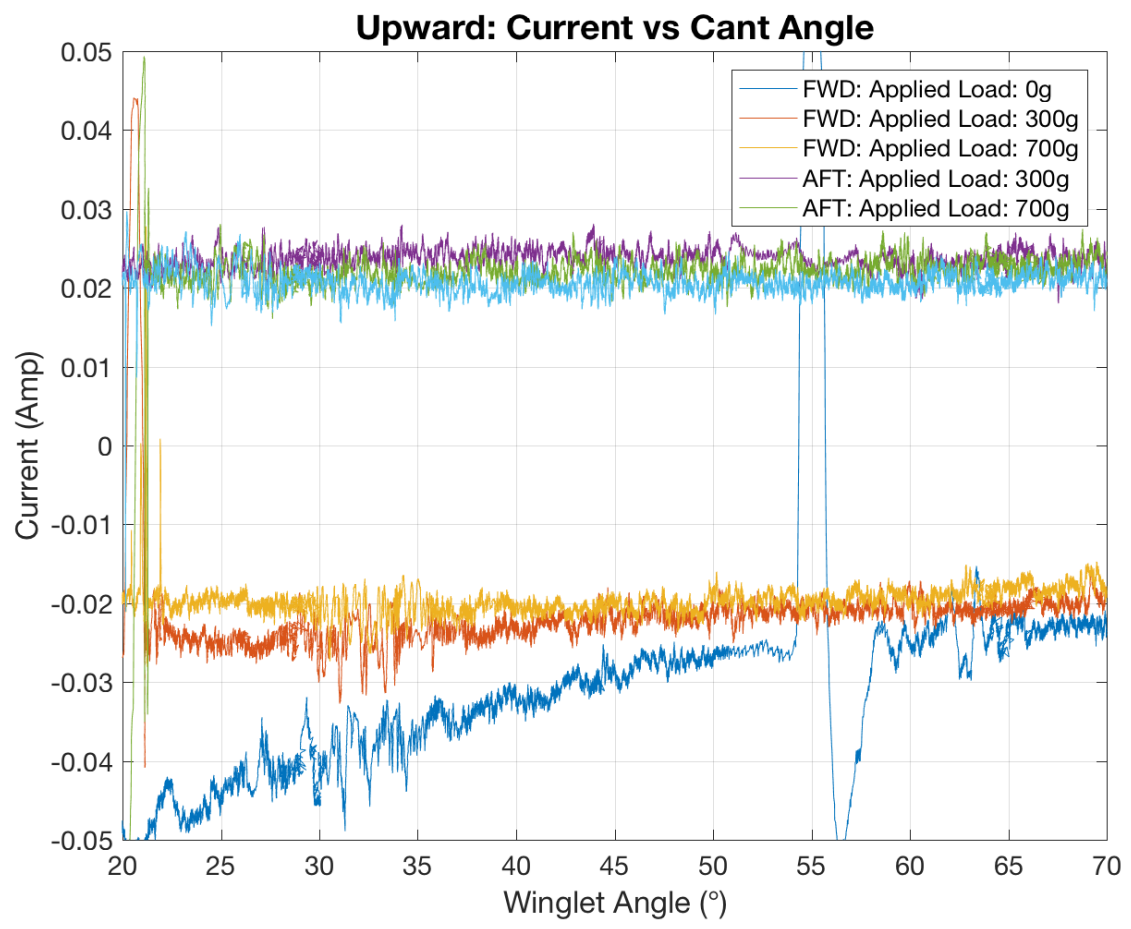

Figure 6-10: Current vs cant angle (upward) 
Converting the current in Figure 6-9 and Figure 6-10 to a load value required the appropriate conversion factor from Table 6-1 and Table 6-2. These conversion factors are dependent on the amount of load applied during the test, the direction of the cant motion and the linkage system being monitored. To determine the actuator's load direction and the direction of motion, a load path analysis was conducted. A flow chart was developed to organize the findings from this study for loads greater than 308 grams ( 0.679 pounds) and has been presented in Figure 6-11. Additionally, a load path study was required for the no load condition, in order to verify the accuracy of the loading model being used. Due to the change in moment direction as the center of gravity crosses the axis of rotation, a piecewise load function would need to be utilized. Figure 6-12 illustrates the actuator properties for the various test conditions.

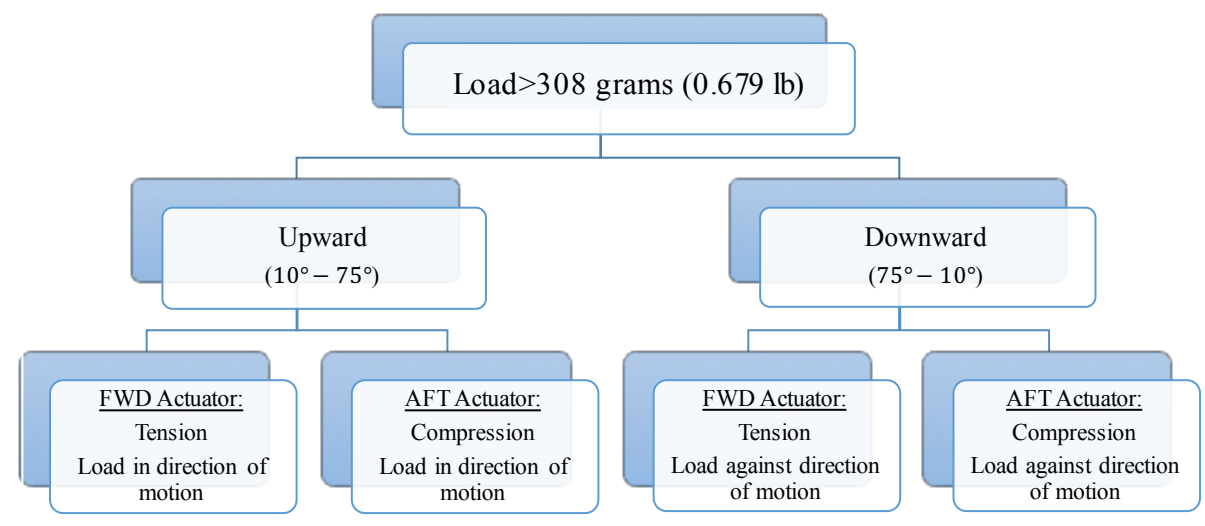

Figure 6-11: Load path summary for load $>308$ grams

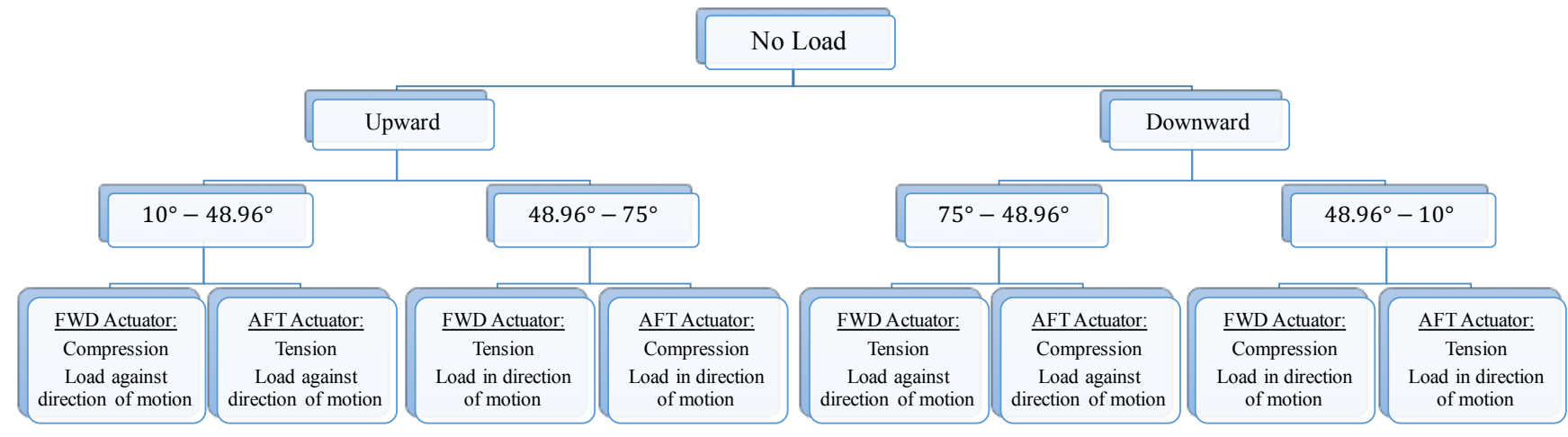

Figure 6-12: Load path summary for no load 
By corresponding Figure 6-11 and Figure 6-12, with Table 6-1 and Table 6-2, the required load versus cant angle plots were determined. First, the no load condition was analyzed to ensure the loading system was modeled and calibrated accurately. Figure 6-13 illustrates the force reading on the forward and aft actuator for the no load test throughout the cant motion. The experimental data was reduced at the winglet's upper and lower bounds, due to a high degree of signal variation caused by the slack in the system, which will be discussed in Section 6.2.5. For the purpose of the experimental analysis, only the results from a cant angle range of $25^{\circ}$ to $70^{\circ}$ were utilized. By analyzing the no load experimental results, it was apparent that there existed an inflection point at approximately $50^{\circ}$ which corresponded well with the theoretical result of $48.96^{\circ}$. Therefore, the developed dynamic loading model correlated well with the theoretical findings.

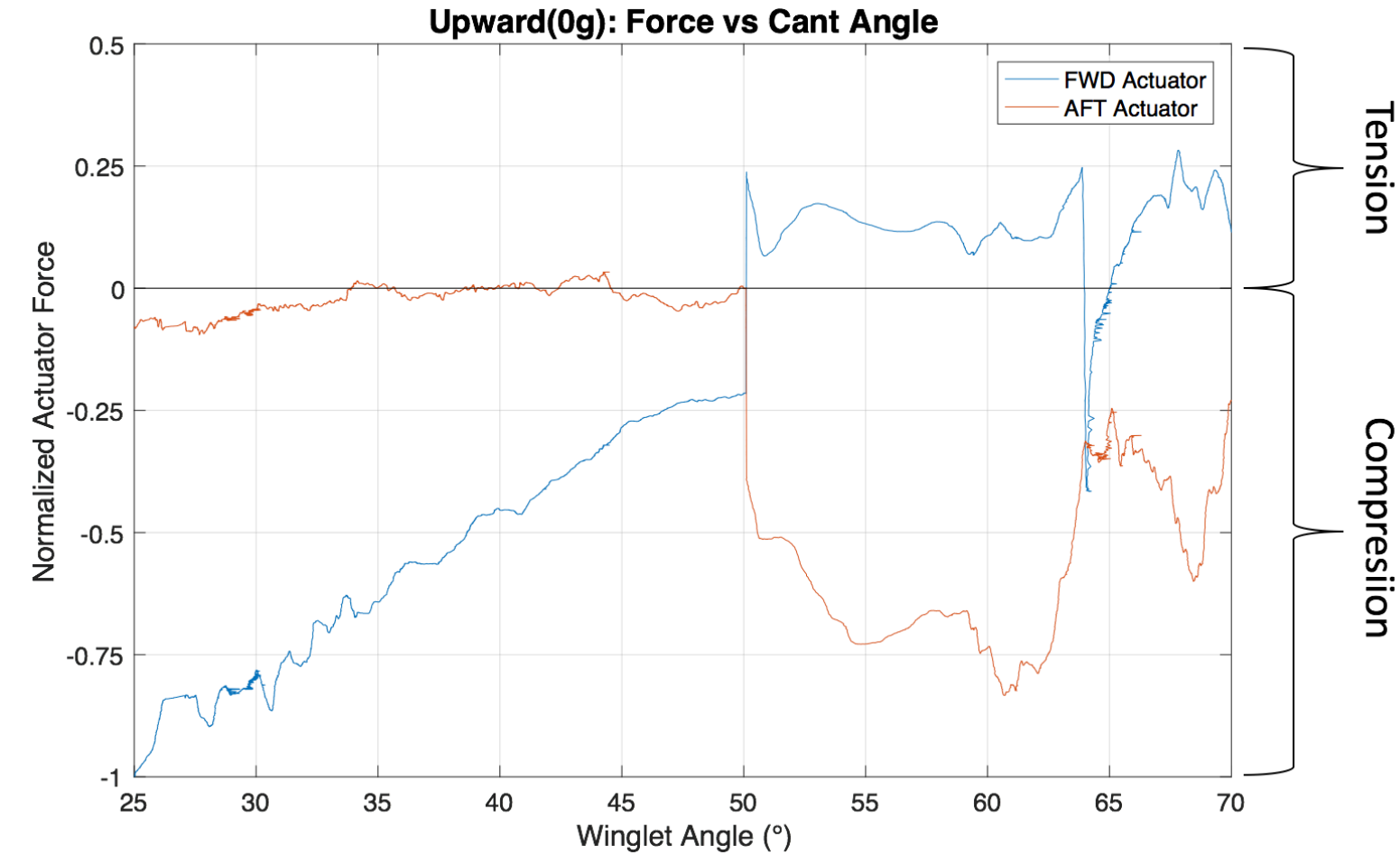

Figure 6-13: Force vs cant angle for no load

The large variance in load readings past the inflection point was a result of the nature of the loading changing on the actuators. As the center of gravity passes the axis of rotation, the 
actuator's would experience a sudden change from an applied tension load to a compression load or vice versa. This required the use of a piecewise function to plot the force, which contributes to the large fluctuation past the inflection point. In Figure 6-13, this change in load direction is demonstrated as the load curve changes signs. Additionally, from $50^{\circ}-59^{\circ}$, the actuators are not counteracting any load. Due to the limitation of the linear actuators and manufacturing inaccuracies, the inflection point causes the winglet to experience a sudden rate increase in cant angle, which fails to meet the cant module's defined design requirement [5]. This can be demonstrated by plotting the cant angle versus time in Figure 6-14 and analyzing the unexpected change in slope.

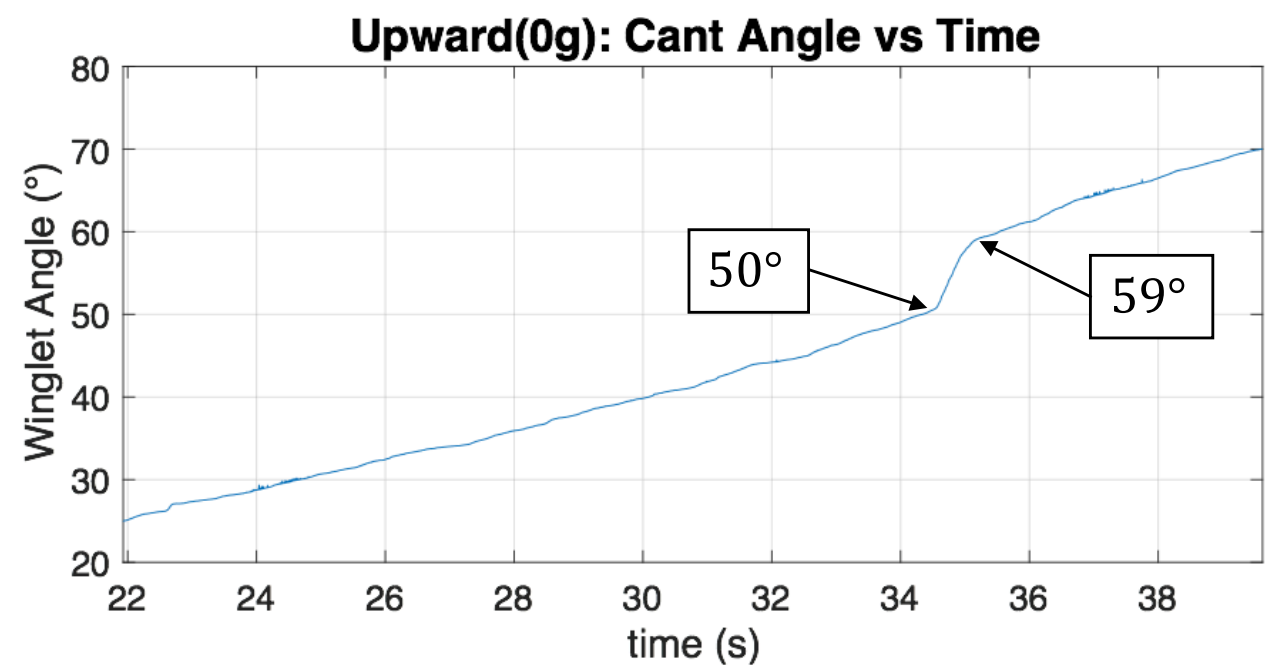

Figure 6-14: Cant angle vs time for no load

By proving the accuracy of the loading model with the no load condition, higher loads can be analyzed to compare with theoretical results. A set of controlled weights based on SI units were used for the experimental tests. Therefore, the results in the following section will be presented in SI units.

First, to validate that the shark-fin loading mechanism successfully applied a constant load throughout the cant motion, a load verification test was completed. The load test fixture illustrated 
in Figure 6-15 was used to extract the applied load as a function of the winglet's cant angle. To confirm the theory, the winglet was actuated from its minimum to maximum cant angle at three different load conditions: 300 grams, 500 grams and 1000 grams. The load cell utilized for the experiment required a calibration test, which resulted in the following function:

$$
L=\left(4.5 * F_{\text {out }}-1.0508\right) * 101.97
$$

where, $\mathrm{L}$ represents the load in grams and $F_{\text {out }}$ represents the output from the load cell in Newtons.

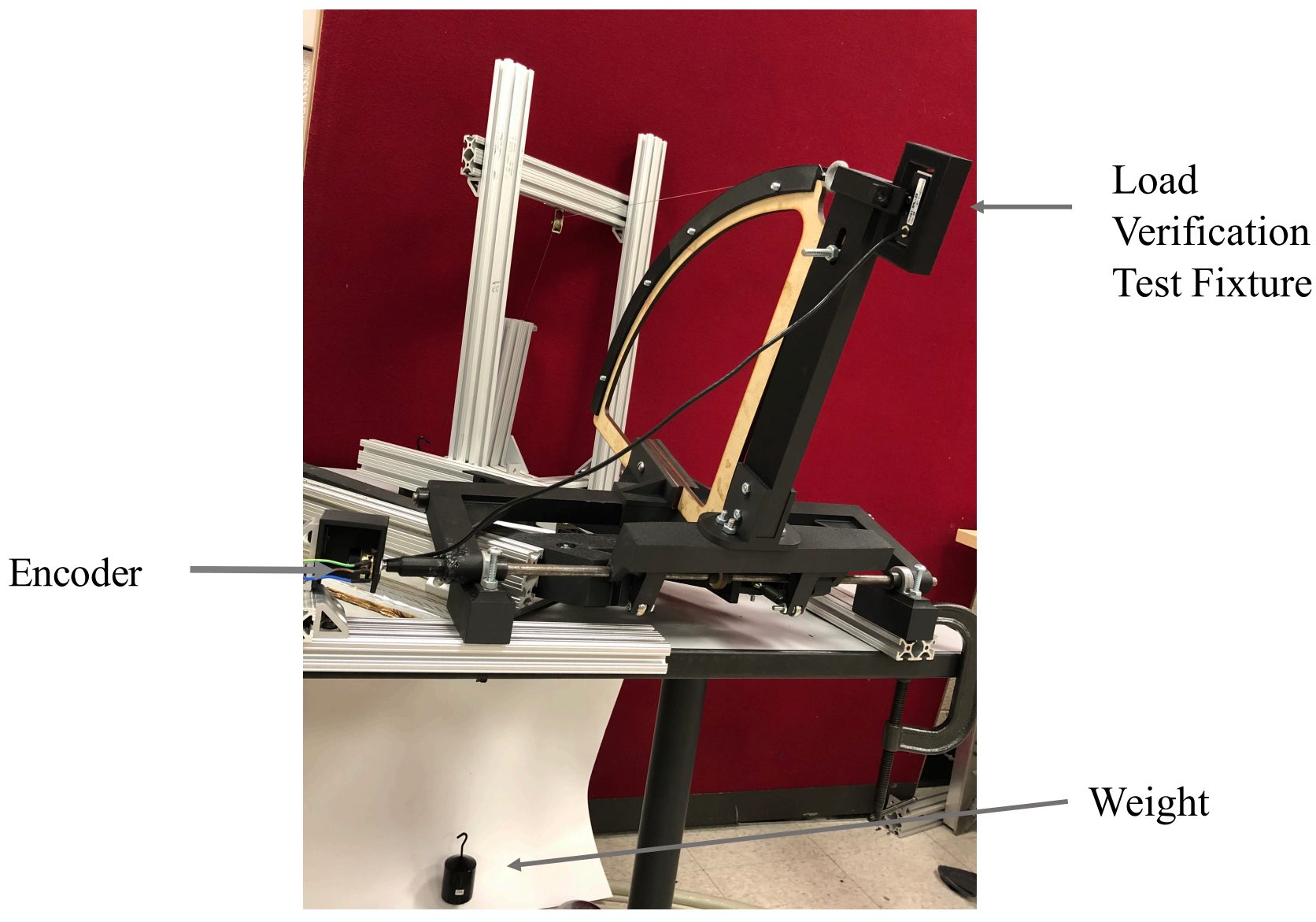

Figure 6-15: Load verification test setup 


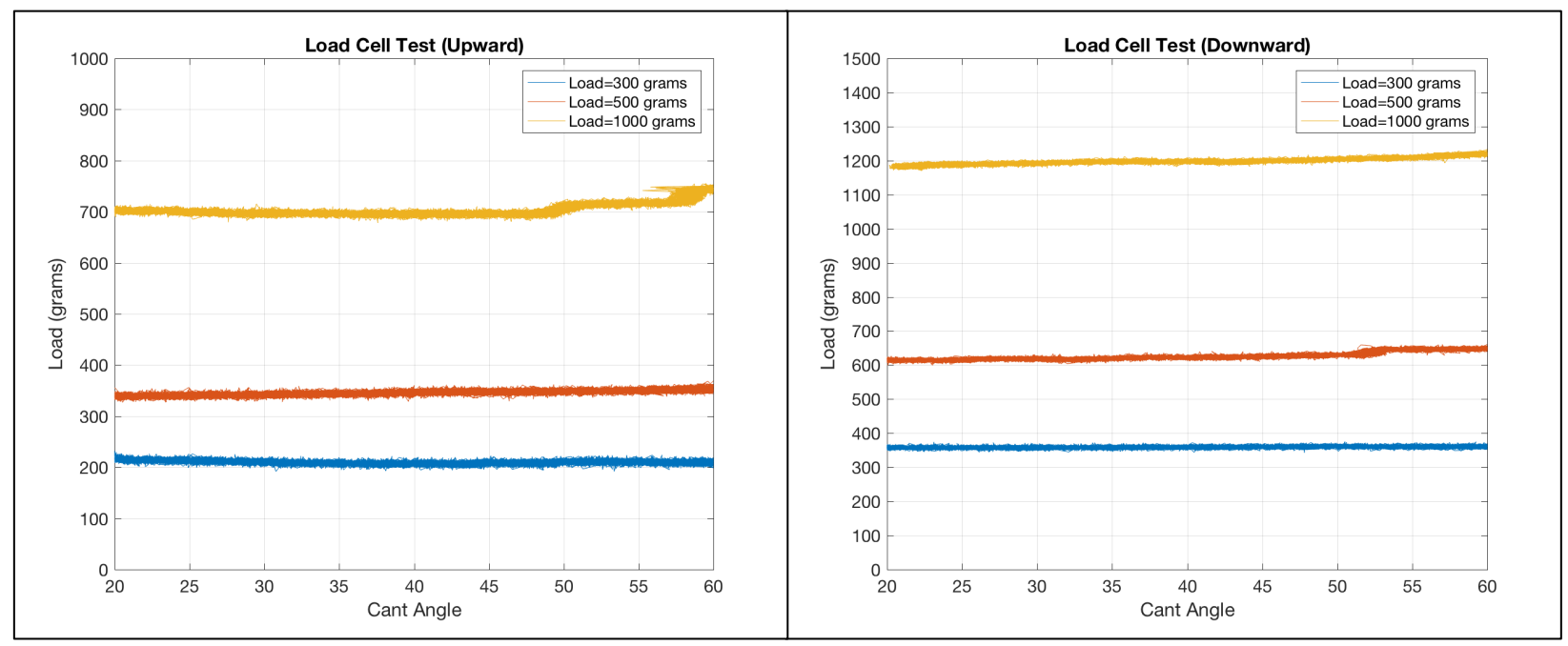

Figure 6-16: Load verification test - cant angle vs applied load

The results from the load verification test were summarized in Figure 6-16 and demonstrated that the load remained constant throughout the cant angle range, for both the upward and downward motion. However, there was a discrepancy between the load cell reading and the applied load. Additionally, the upward and downward motion for the same load resulted in different load readings. Since the upward motion has the weight traveling in the same direction as the winglet, it results in a smaller force reading than the downward motion. Furthermore, the load verification test fixture relied on the eye bolt to travel freely through the winglet. If the applied load does not maintain perpendicularity with the winglet surface as a result of manufacturing inaccuracies or material deformation, the load cell readings would vary, due to frictional loss. This friction loss remains constant throughout the cant motion, resulting in a constant delta between the applied load and the load cell reading. To compensate for this error, normalized forces would be utilized when comparing the theoretical to experimental results

Although various tests were conducted by incrementally increasing the applied load, for the purposes of this paper, a single load of 700 grams was chosen to be analyzed. By utilizing Table 6-1 and Table 6-2 to convert the current in Figure 6-9 to a load reading, Figure 6-17 was 
obtained. The blue line (positive axis) represents the forward actuator, showing a positive quadratic relation, and the orange line (negative axis) represents the aft actuator, which shows a reduction in load with cant angle. Due to manufacturing inaccuracies and low stiffness components, the slack in the overall system resulted in

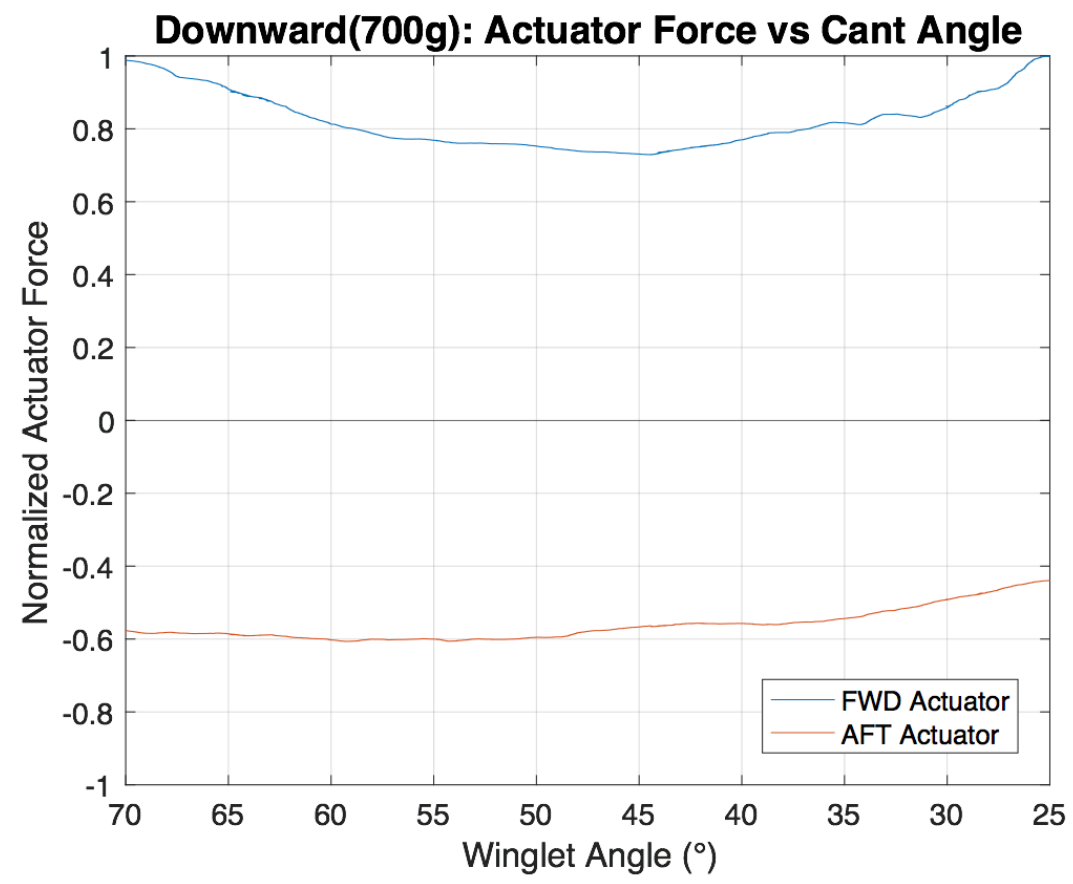

Figure 6-17: Normalized actuator force vs cant angle for 700 gram load

To produce an accurate theoretical load vs cant angle plot, the experimental distribution factor $(k)$ referenced in Appendix C was utilized in (Eq. C-0-24). This required the ratio of force in the toggle of Linkage A with respect to the force in the Linkage B toggle. Multiplying the load within the actuators by the mechanical advantage of each linkage mechanism provides the load in each toggle. The mechanical advantage as a function of the cant angle was determined through the CAD model and plotted in Figure 6-18. A second order equation of best fit for both Linkage A and B was also included. 


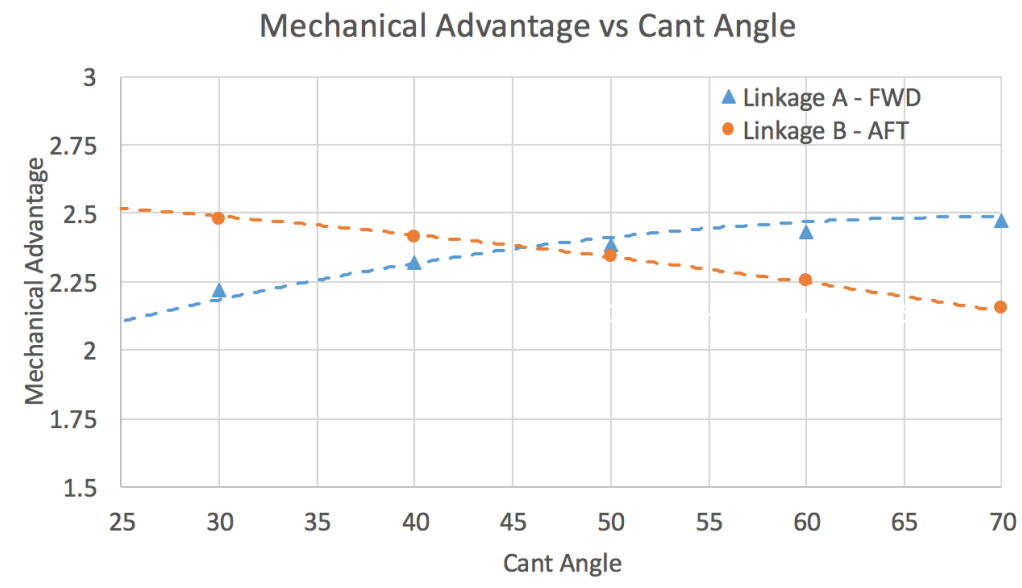

Figure 6-18: Mechanical advantage vs cant angle

The equation for the mechanical advantage for Linkage A and Linkage B as a function of the cant angle have been included in (Eq. 6-3) and (Eq. 6-4) respectively.

$$
\begin{aligned}
& M A_{f w d}=-0.0002 * \theta_{\text {cant }}^{2}+0.0266 * \theta_{\text {cant }}+1.5585 \\
& M A_{\text {aft }}=-6 * 10^{-5} * \theta_{\text {cant }}^{2}-0.0024 * \theta_{\text {cant }}+2.6174
\end{aligned}
$$

By utilizing the mechanical advantage equations in accordance with Figure 6-17, the toggle loads can be extracted as a function of cant angle, shown in Figure 6-19.

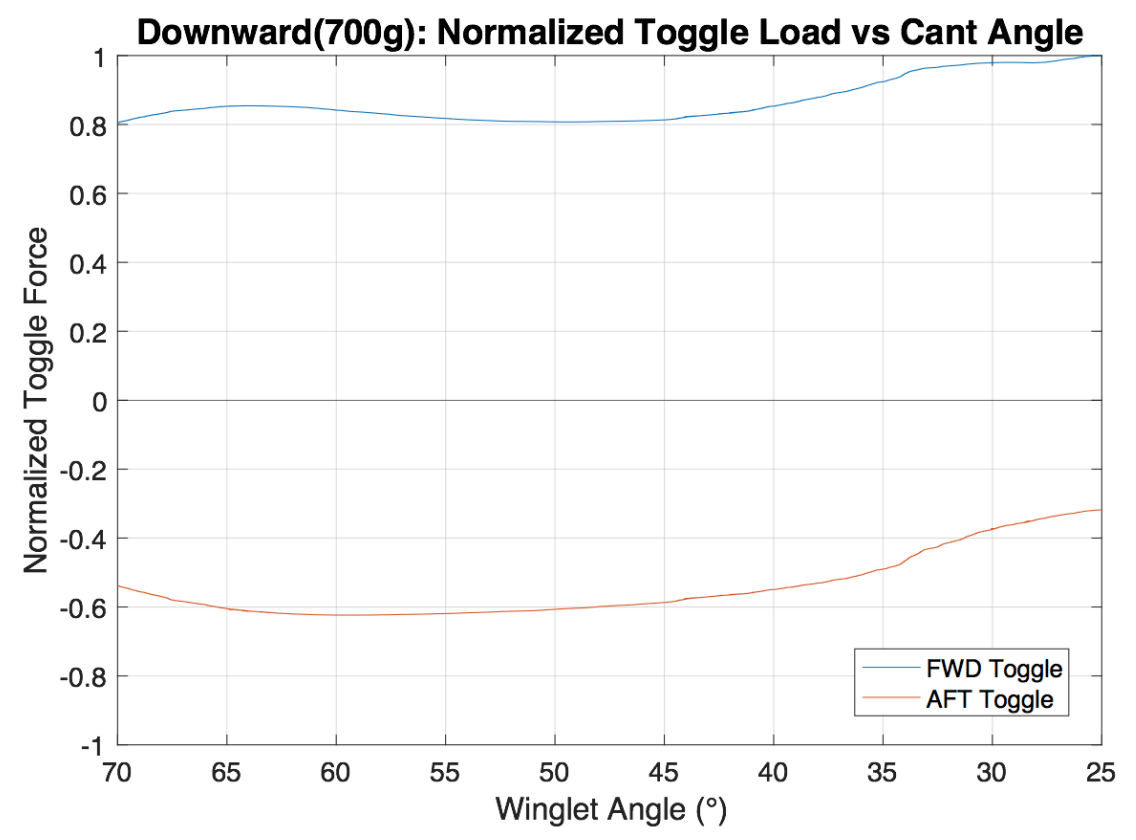

Figure 6-19: Normalized toggle load vs cant angle for 700 gram load 
Finally, by plotting the proportion of loading in the forward toggle, with respect to the aft toggle (Eq. 6-5), the $k$ ratio as a function of cant angle was obtained. This procedure was performed for both the winglet traveling upward $\left(75^{\circ}-10^{\circ}\right)$ and downward $\left(10^{\circ}-75^{\circ}\right)$ and was plotted in Figure 6-20.

$$
k=\frac{a b s\left(\text { Force }_{f w d} * M A_{f w d}\right)}{a b s\left(\left(\text { Force }_{a f t} * M A_{a f t}\right)+\left(\text { Force }_{f w d} * M A_{f w d}\right)\right)}
$$
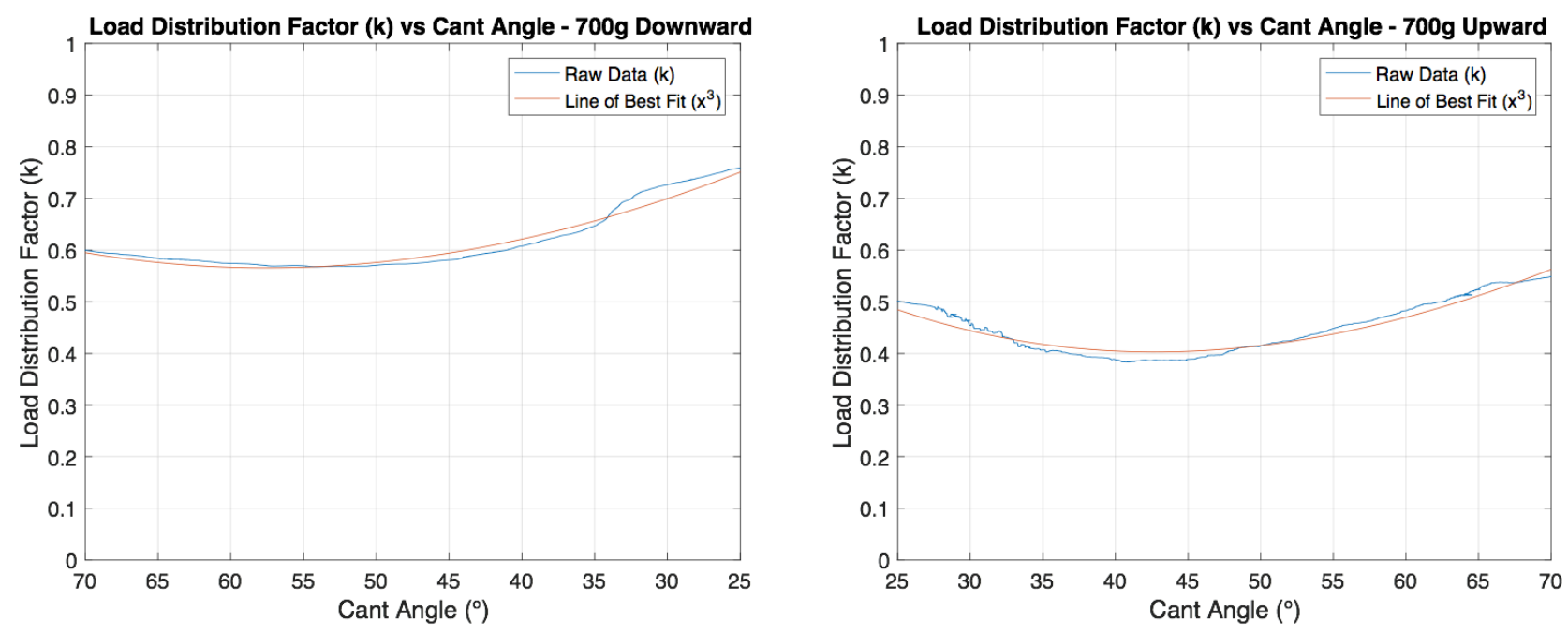

Figure 6-20: Load distribution factor vs cant angle for 700 grams

The experimental function for $\mathrm{k}(\theta)$ was approximated by a third order line of best fit and then incorporated into the theoretical model. To compare the theoretical and experimental results, the load values were normalized to unity and overlaid in Figure 6-21 and Figure 6-22 for the winglet traveling in both the downward and upward directions respectively. 


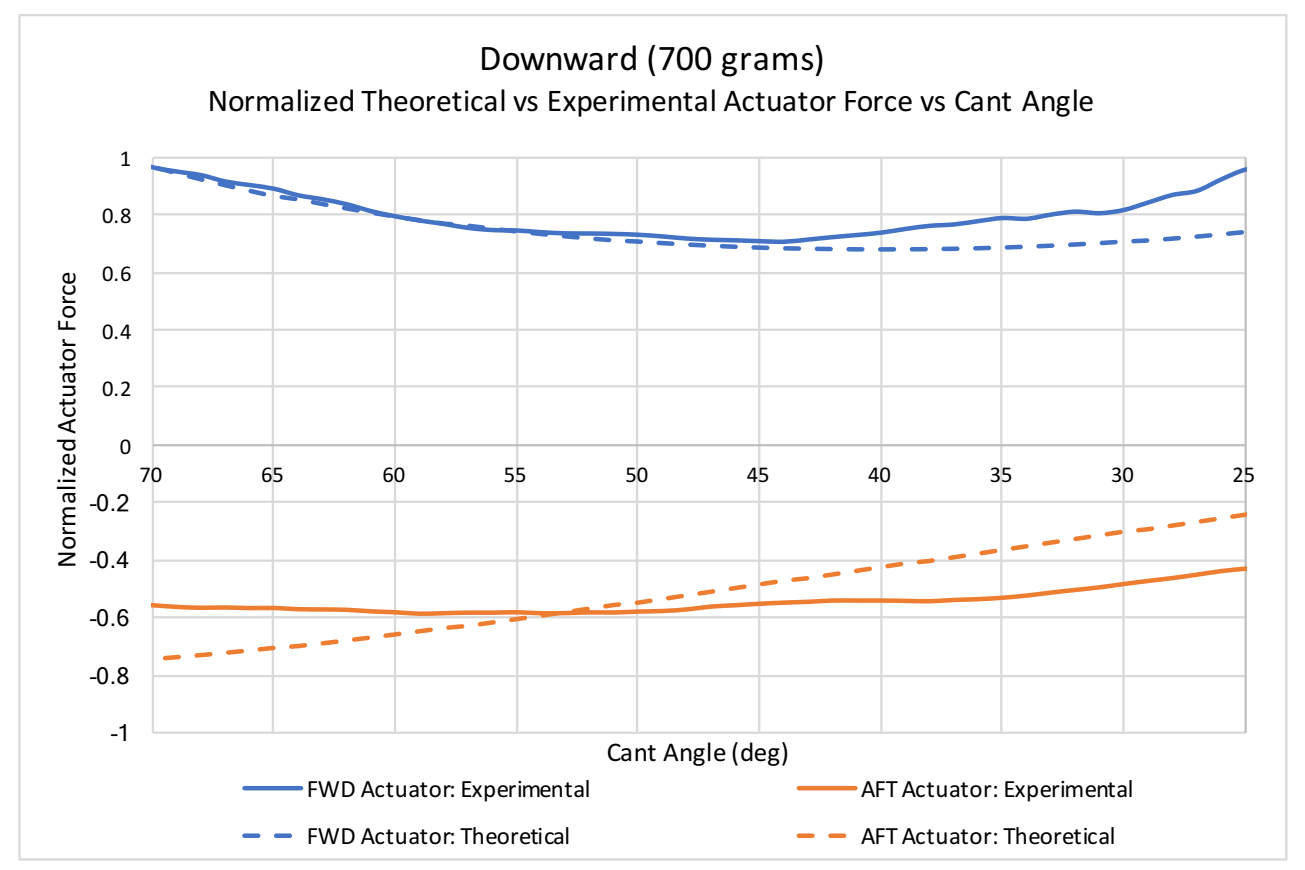

Figure 6-21: Experimental vs theoretical - normalized actuator load vs cant angle downward

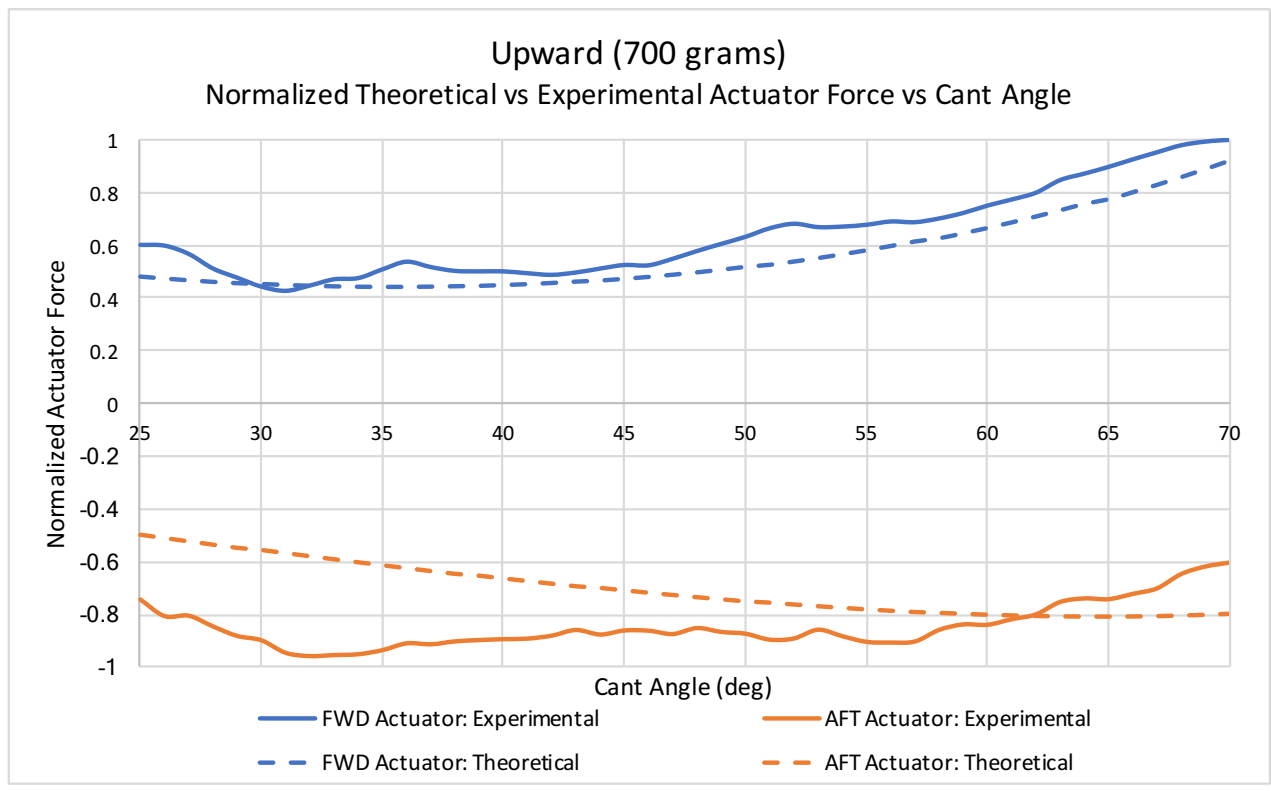

Figure 6-22: Experimental vs theoretical-normalized actuator load vs cant angle upward

As observed from Figure 6-21 and Figure 6-22, the theoretical and the experimental results show a good correlation for the forward actuator, while the aft actuator seemed to deviate at the systems limits. 


\subsubsection{ERROR ANALYSIS}

To quantify the discrepancy in results, the percent error was determined through (Eq. 6-6) and plotted as a function of the cant angle in Figure 6-23 and Figure 6-24.

$$
\% \text { Error }=\left|\frac{\text { Experimental Load }- \text { Theoretical Load }}{\text { Theoretical Load }}\right| * 100 \%
$$

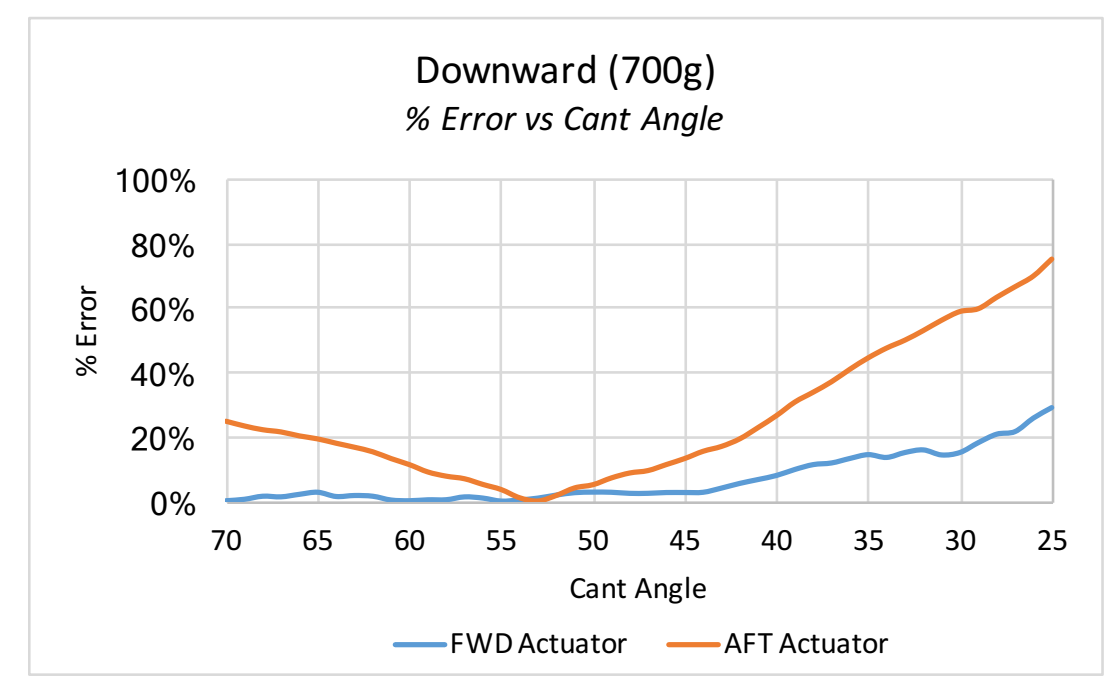

Figure 6-23: Theoretical vs experimental actuator load error - downward

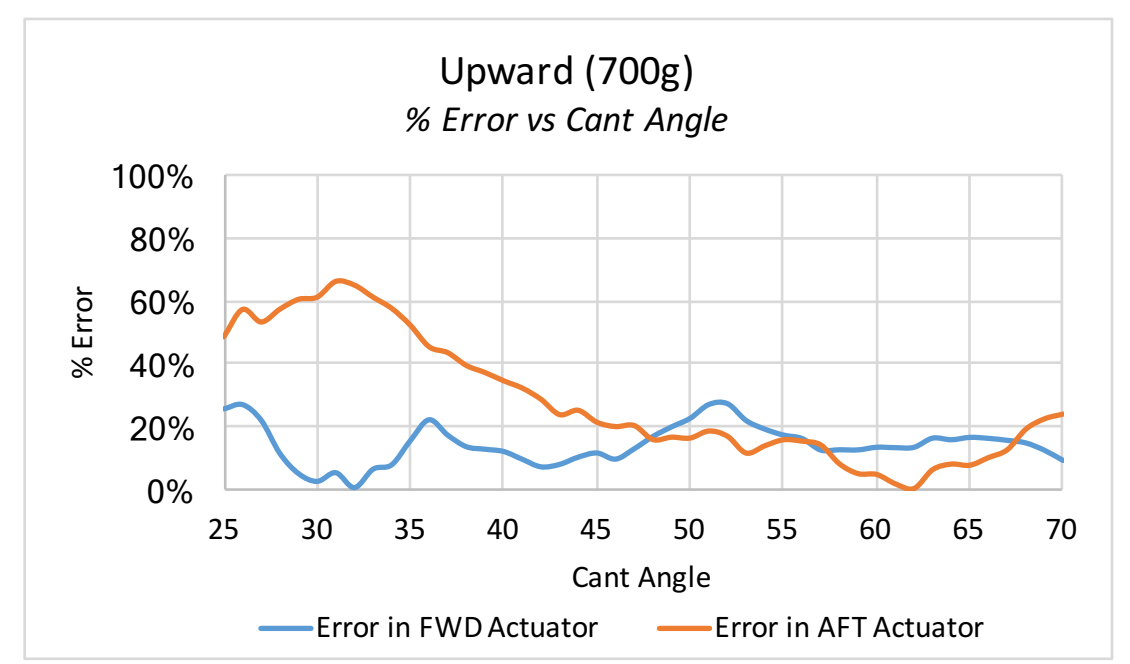

Figure 6-24: Theoretical vs experimental actuator load error - upward

For the downward motion of the winglet, the average percent error in the experimental load curve for the forward and aft actuators were found to be $7 \%$ and $26 \%$ respectively. For the upward motion, the error for the forward and aft actuators was found to be $14 \%$ and $28 \%$ respectively. 
The load in the forward actuator showed a stronger correlation to the theoretical results in comparison to the aft actuator. This can be attributed to the cant module's control system which utilized a master-slave control strategy. The master-slave system compensates for any discrepancies in position and velocity by monitoring the error in the forward actuator and adjusting the aft actuator accordingly. Given the forward actuator was defined as the master, it more closely matched the theoretical results.

An additional source of error can be attributed to the prototype's cant system experiencing deformation during the load test. As a result of manufacturing inaccuracies and the use of low stiffness components on the half size model, the forward and aft linkage system's workspace would deform throughout the motion. As a result, the forward and inverse kinematics become inaccurate, leading to erroneous output results which have been plotted in Figure 6-23 and Figure 6-24.

Furthermore, given the cant mechanism's control system was designed to experience a constant moment about the winglet's axis of rotation throughout the cant motion, a large variation in resultant moment would lead to an additional source of error in the experimental findings. As illustrated in Figure 6-7, a large variation in moment was present for the experimental findings, due to the structural limitations of the half size prototype limiting the applied load. This variation leads to non-optimal controls for the cant module's dual 6-bar mechanism, causing the experimental values to deviate from the theoretical results.

Lastly, when comparing the error between Figure 6-23 and Figure 6-24, a larger error was present during the upward motion. This can be a result of the upward motion's applied load reading having a larger deviation to the theoretical applied load, as illustrated in Figure 6-16. Given the full scale load fixture will utilize a linear actuator with a feedback system to apply a constant load, the force reading on the winglet's loading point will be equal to the theoretical load set by the user. 


\section{CONCLUSION}

\subsection{CONTRIBUTIONS}

This thesis provided a design solution to validate the structural integrity of Ryerson's Morphing Winglet Team's cant mechanism system. In order to reproduce the aerodynamic loads that a morphing winglet would encounter throughout the flight envelop, a dynamic loading system was required to apply a constant, perpendicular load throughout the cant motion. An enumeration study was completed, analyzing various planar four bar linkage mechanisms consisting of prismatic and revolute joints to meet the design problem. The study found that an R-P-R-P sharkfin linkage design met both the design requirements stated in Section 1.1.1.

The finalized dynamic loading system for the morphing winglet was modeled using CATIA, while the geometry of the shark-fin was developed through a multi-objective study. To validate the loading fixture, a half size model was manufactured, which integrated with an existing half scale cant module. By developing the required loading fixture, the structural integrity of the winglet was successfully tested with an applied load and the control system for the cant module's dual actuator system was validated with the theoretical results. As a result of a successful proof of concept on the half scale model, the developed shark-fin loading system is being implemented on the full scale winglet being developed by Bombardier Aerospace and Ryerson University.

To ensure the success of the full scale test, (Eq. 5-2) should be utilized to determine the minimum applied load necessary to eliminate the effects of the center of gravity. From the half scale testing, the inflection point resulted in the over extension of the cant module's linkages, resulting in a large variation in actuator loads. By avoiding sudden changes in actuator load, the probability of failure in the actuators or linkages is minimized. Furthermore, Section 7.2 outlines the lessons learnt from the experiments conducted on the half size cant module and various methods to improve results and obtain data which minimizes the percent error. 


\subsection{FUTURE WORK}

While the developed shark-fin loading fixture was successfully implemented on the half size cant module, design improvements can be incorporated for the full scale test. Given the required loading for the full scale model would be significantly larger, the structural integrity of each component becomes critical. The use of high strength materials, while optimizing for weight and stiffness would be necessary to eliminate the risk of component deformation or fractures. Although a FEA model was developed for the optimization of the shark-fin, a more detailed stress analysis would be required for the full scale loading fixture components.

Second, improvements could be made to better correlate the theoretical findings with the experimental results. The provided half scale cant module did not utilize high precision joints, which resulted in slack in the dual six bar linkage system. Also, by improving the filtering functions and the quality of the sensors used to extract the current from the actuators, the amount of fluctuation in load reading could be reduced. To better isolate for the desired signal frequencies, other filters can be investigated, such as a narrow bandpass filter [37]. Also, the potential source of error produced by the cant module's master-slave system can be validated by reprograming the controls to change the master from Linkage A (forward) to Linkage B (aft), as shown in Figure $5-1$.

Third, the developed control system used for the cant module was calibrated for a single loading condition. To improve the cant system's controls, calibration tests would need to be conducted for various loading conditions to account for the applied load and inertial effects. Next, a feedback system would be required to determine the actual loading condition and to adjust the forward and inverse kinematics accordingly. 
Finally, for the full scale load test, the method of load application becomes a challenge. Given significantly larger loads would need to be applied, a linear actuator would need to be incorporated, as modeled in Section 4.2. This would result in the full scale test requiring synchronization between the load application joint (P4) and the winglet's base joint (R1). This synchronization can be simplified by utilizing a force feedback system for P4. By incorporating a feedback system through the use of a load cell at the loading point on the winglet, the applied load can be adjusted to ensure the loading throughout the cant motion remains constant and accurate. Also, the full scale model will aim to produce a moment variation that is less than $1 \%$. By achieving this target, the effects of the loading system's center of gravity become minimized and the generated moment about the axis of rotation is close to being constant, which improves the cant module's controls during motion.

By implementing the above recommended improvements for the full scale loading test, the theoretical results are expected to show a stronger correlation to the experimental results. 
APPENDICES

\section{A. MATLAB CODE \\ R-R-P-R DESIGN}

$\underline{\text { h-ratio }}$

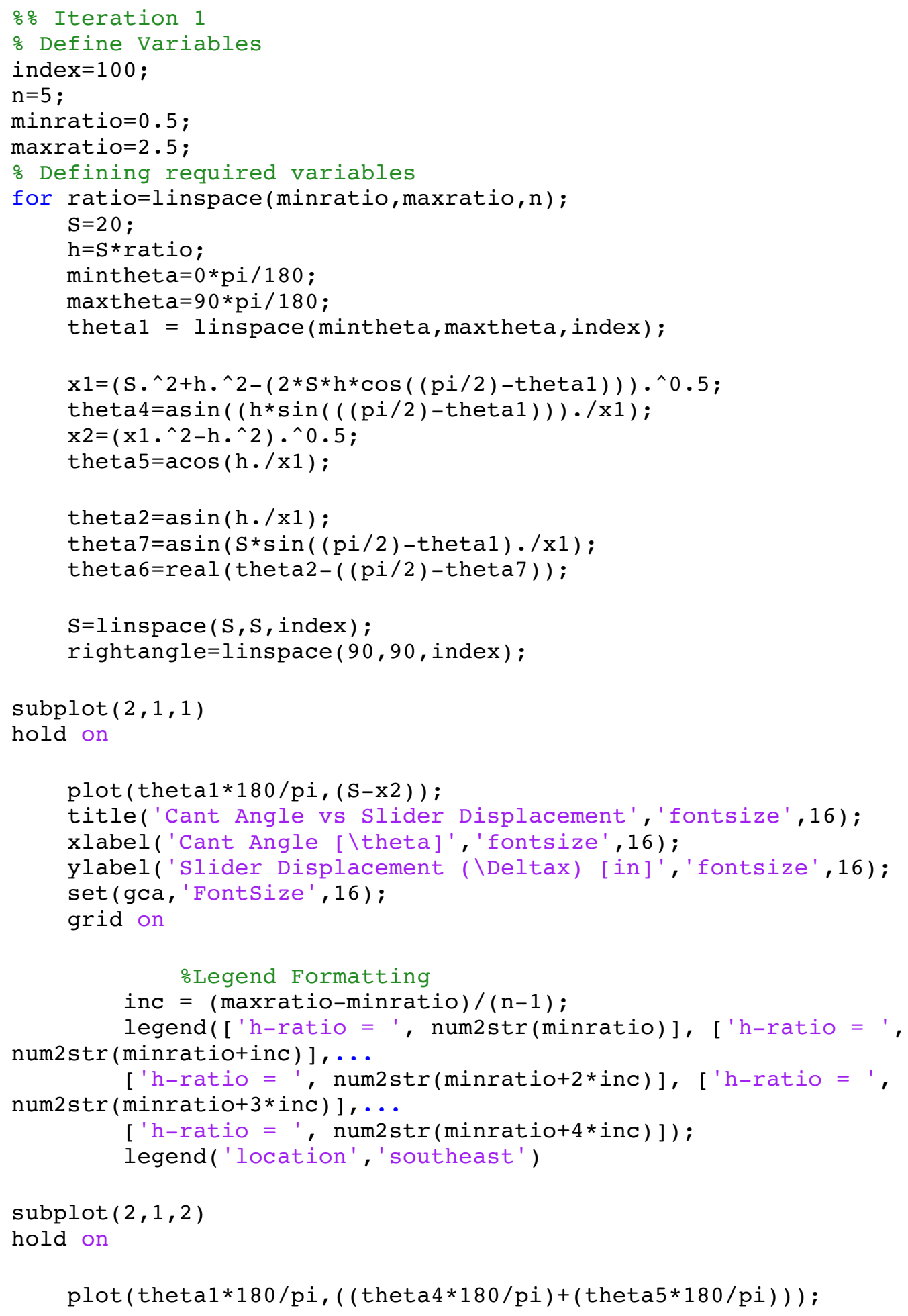




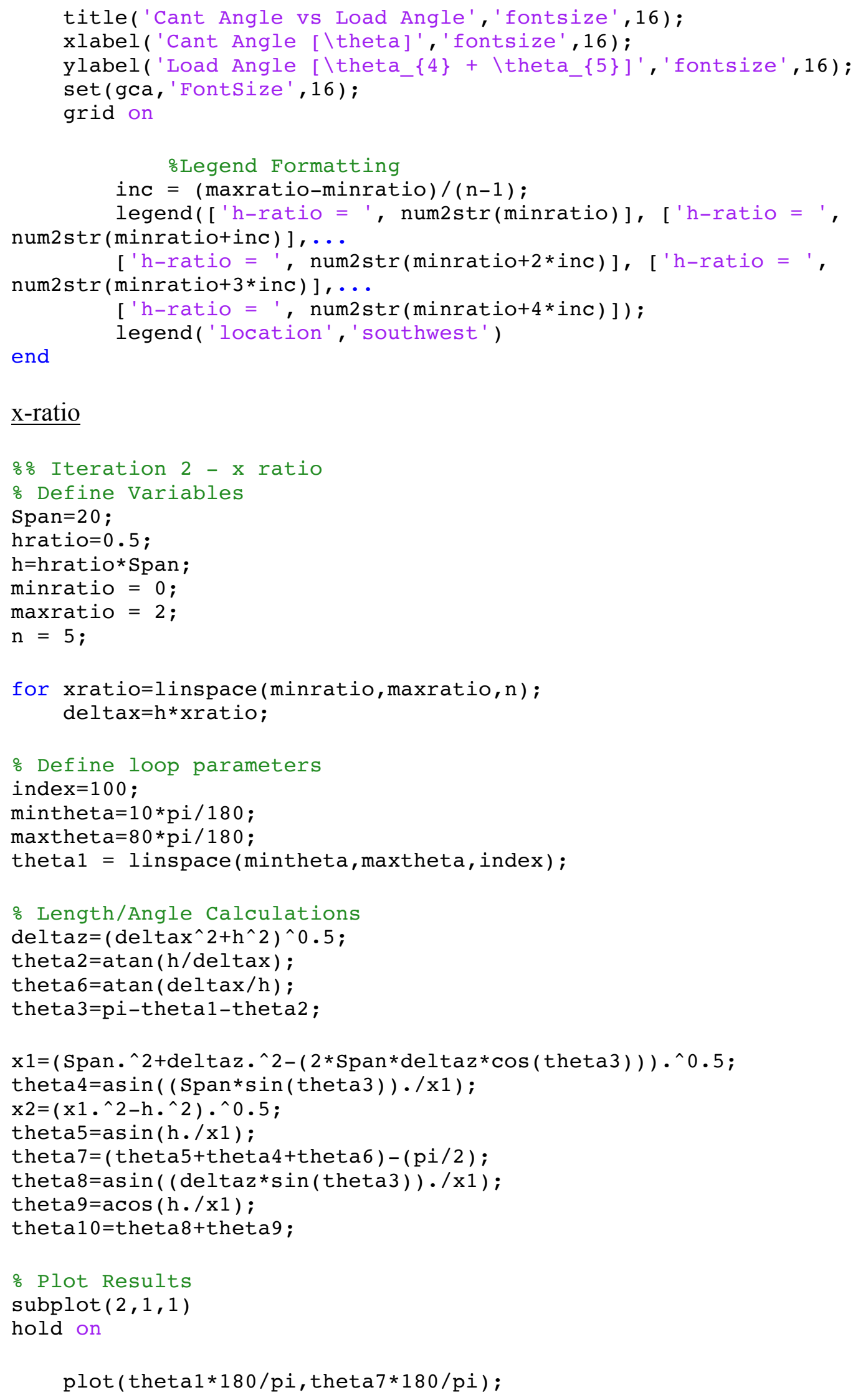




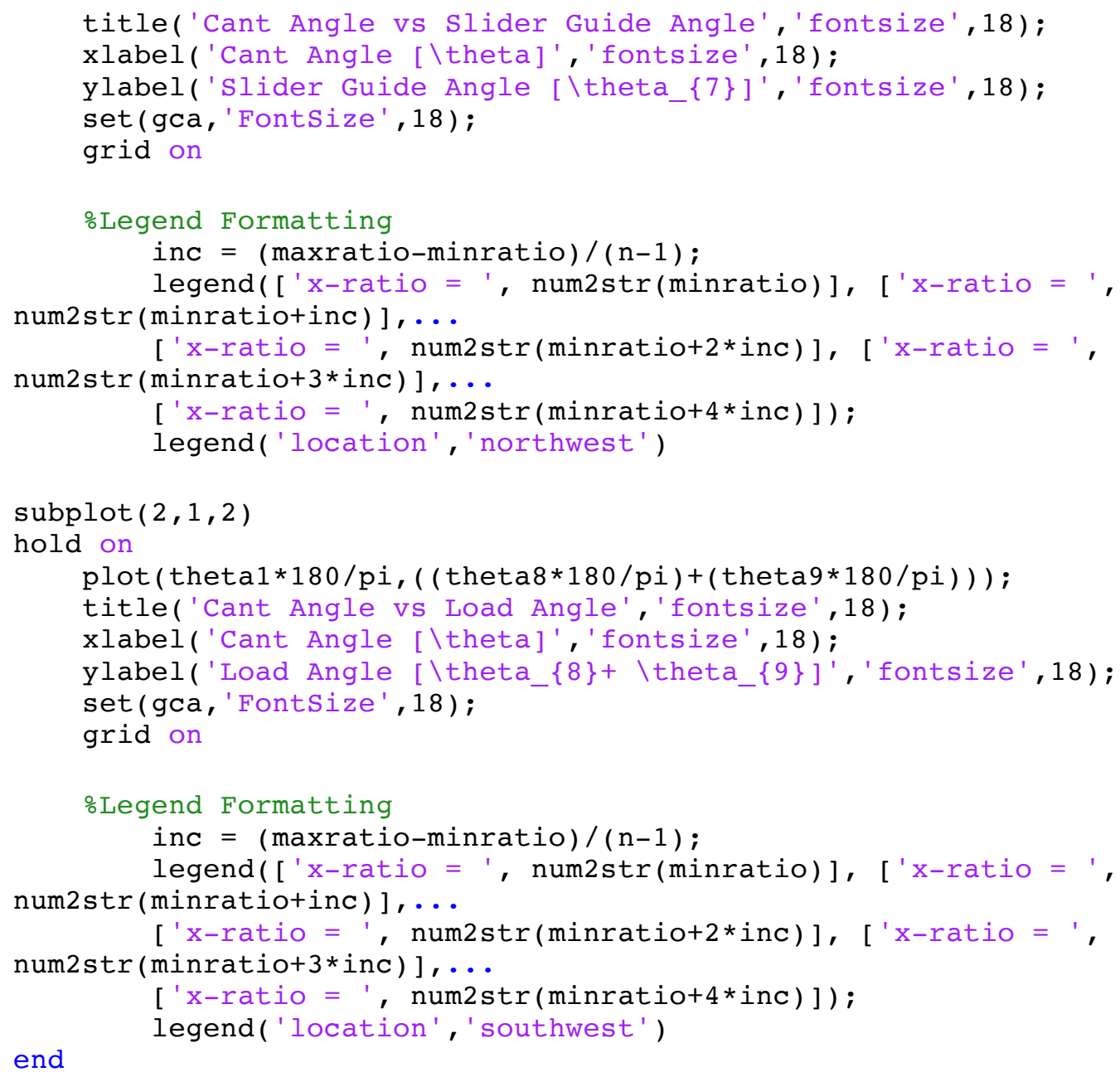

\section{R-P-R-P DESIGN}

Actuator to Winglet Height Study

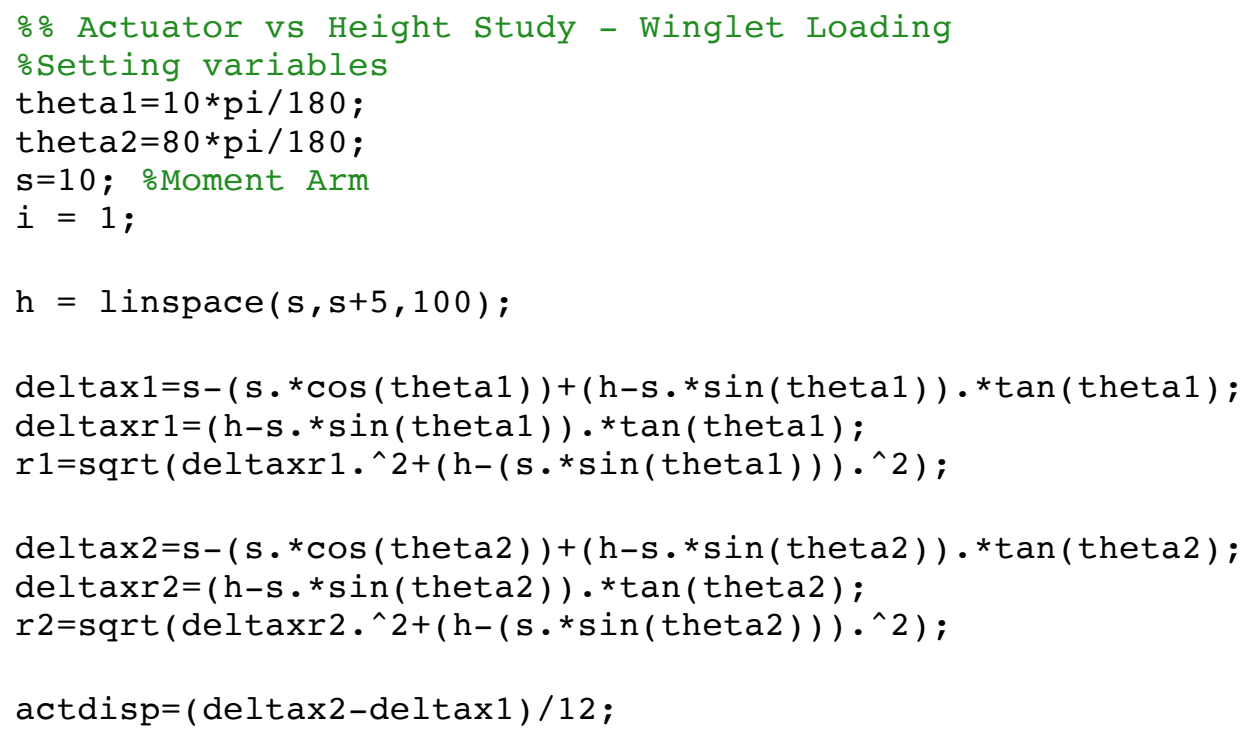




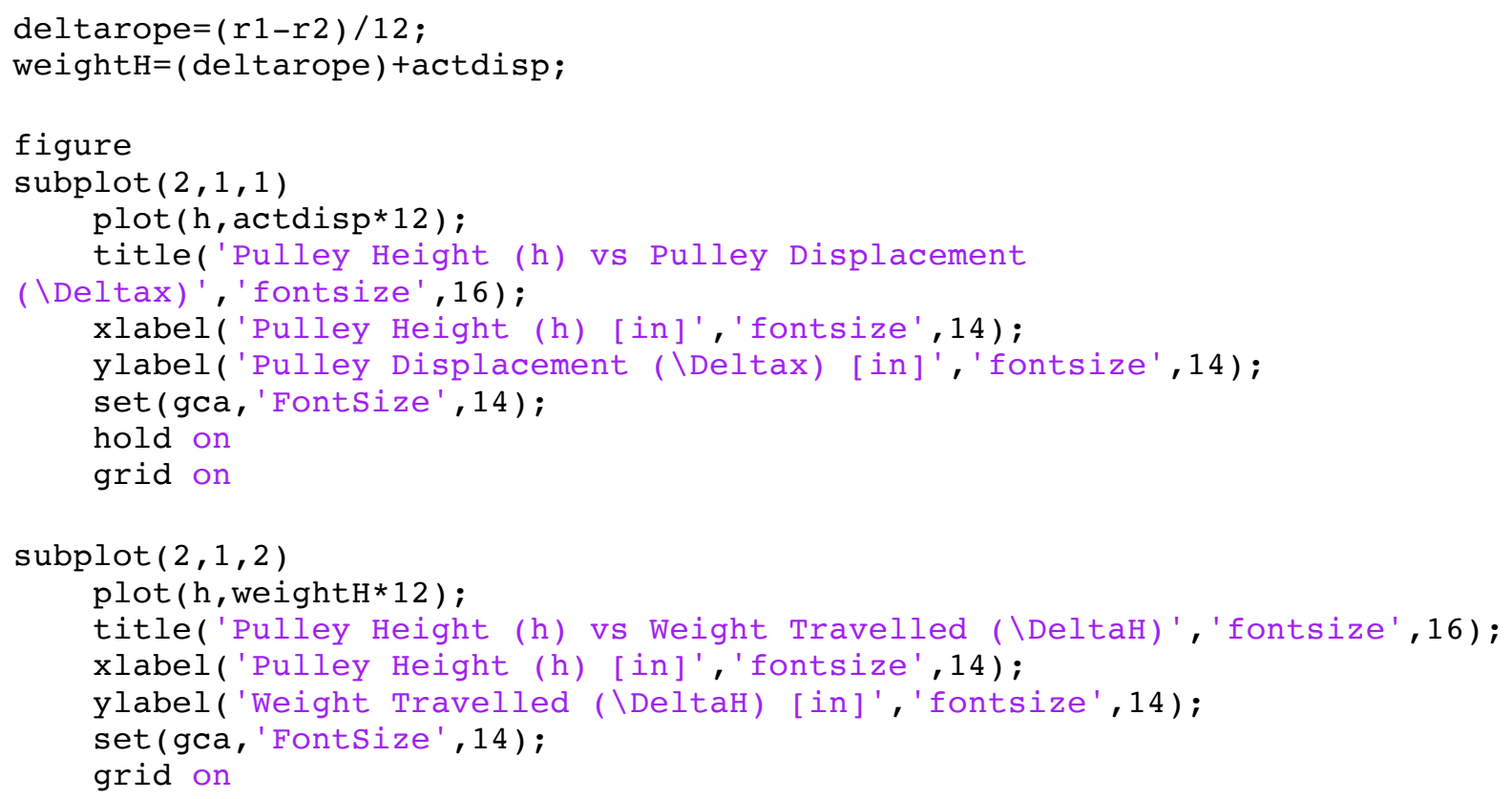

$\underline{\text { Position Analysis Method } 1}$

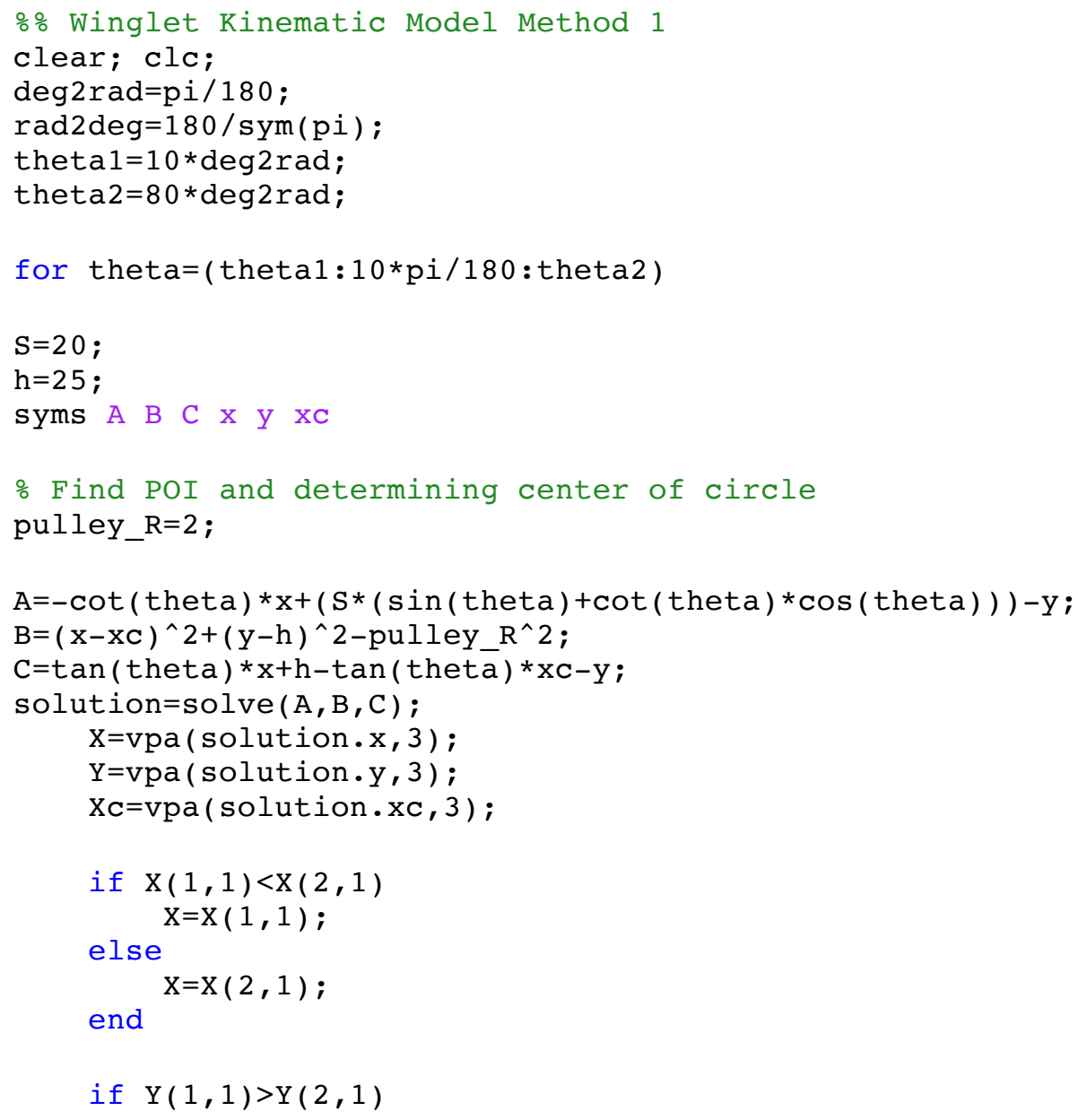




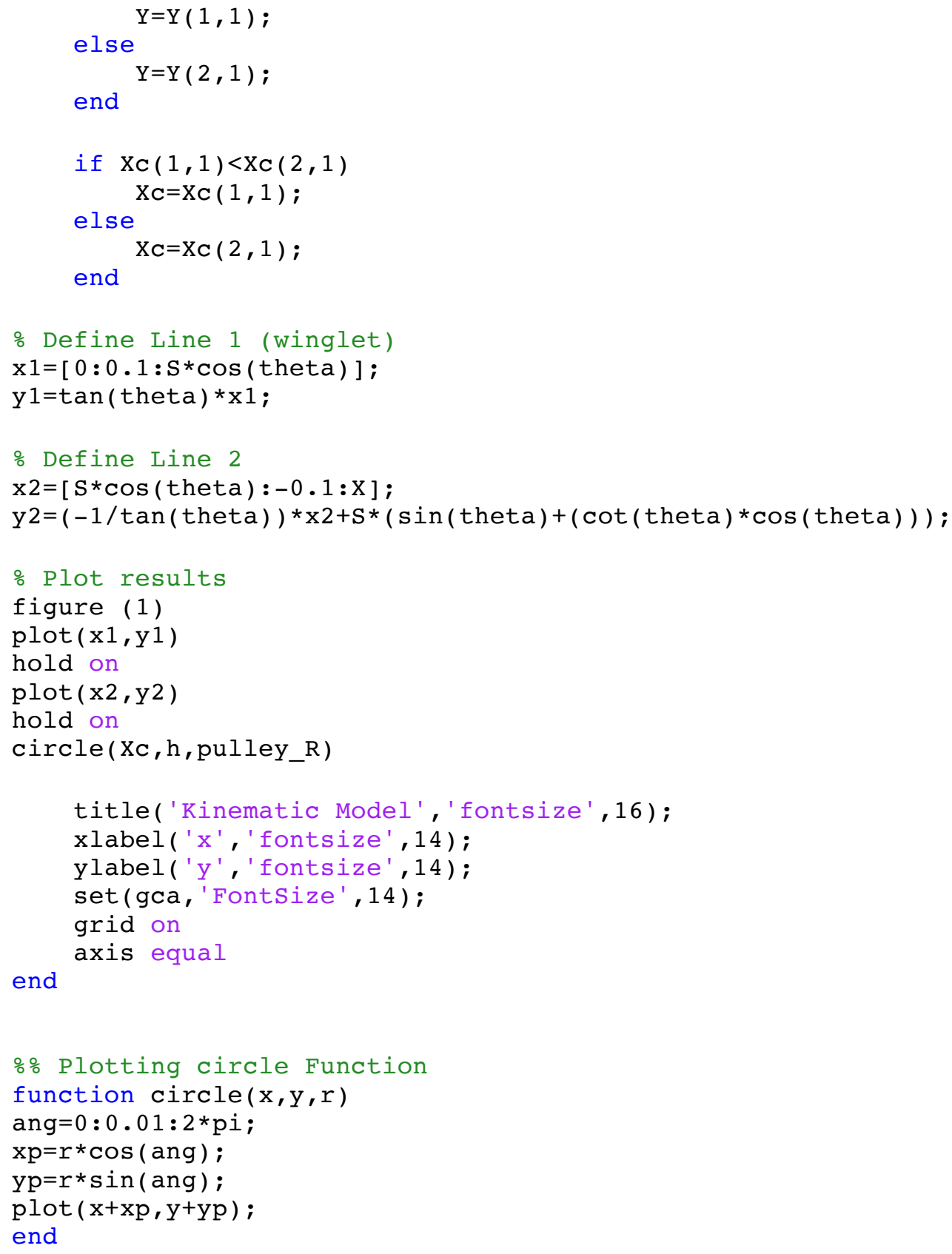

Position Analysis Method 2

\% Winglet Kinematic Model Method 2 


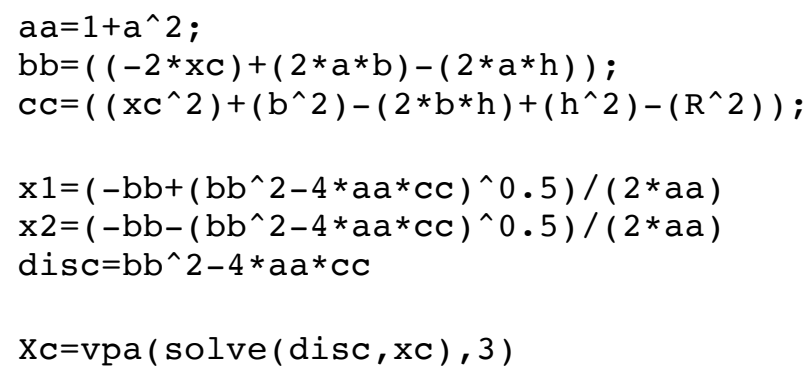

\section{ENCODER CALIBRATION}

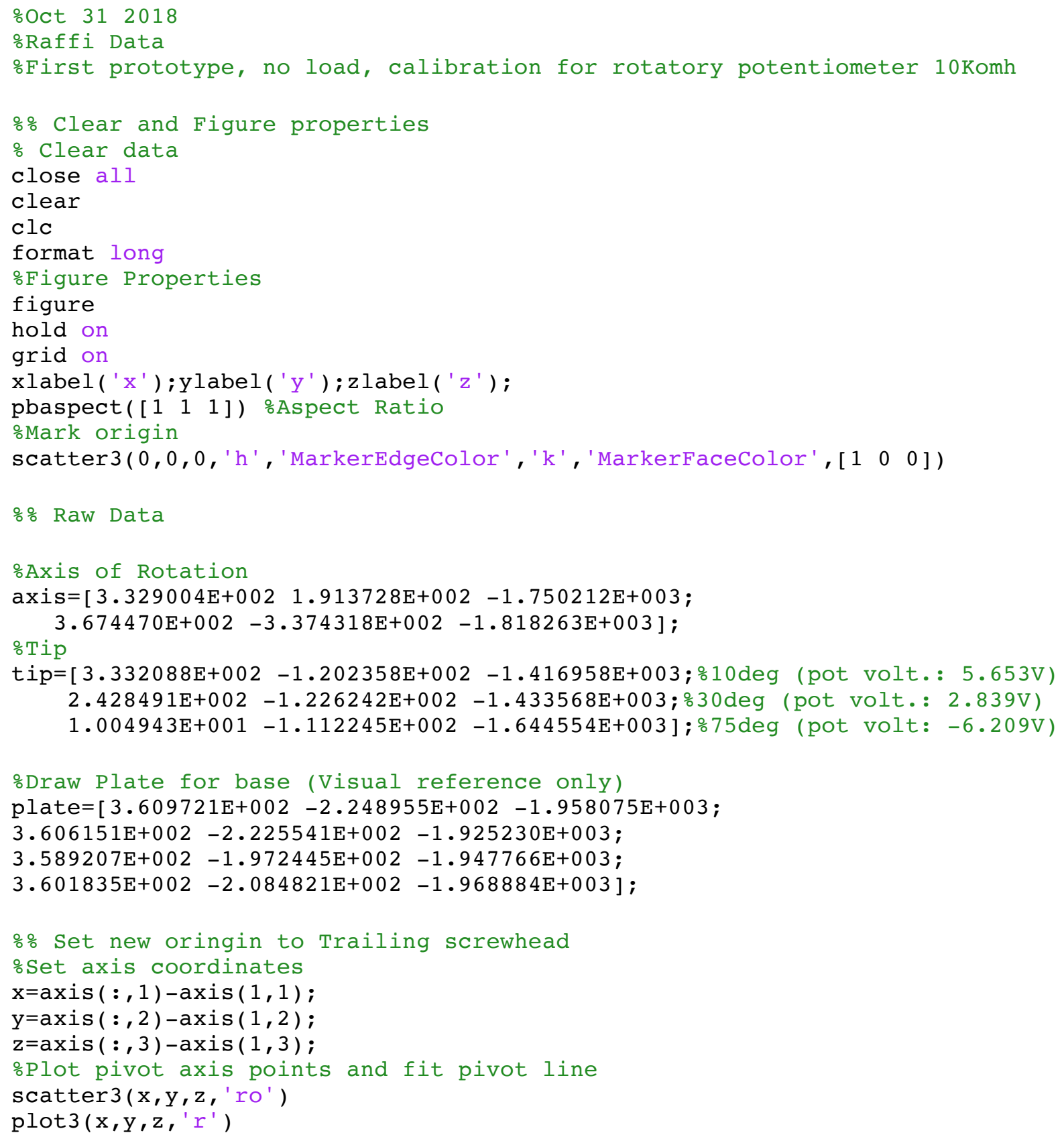




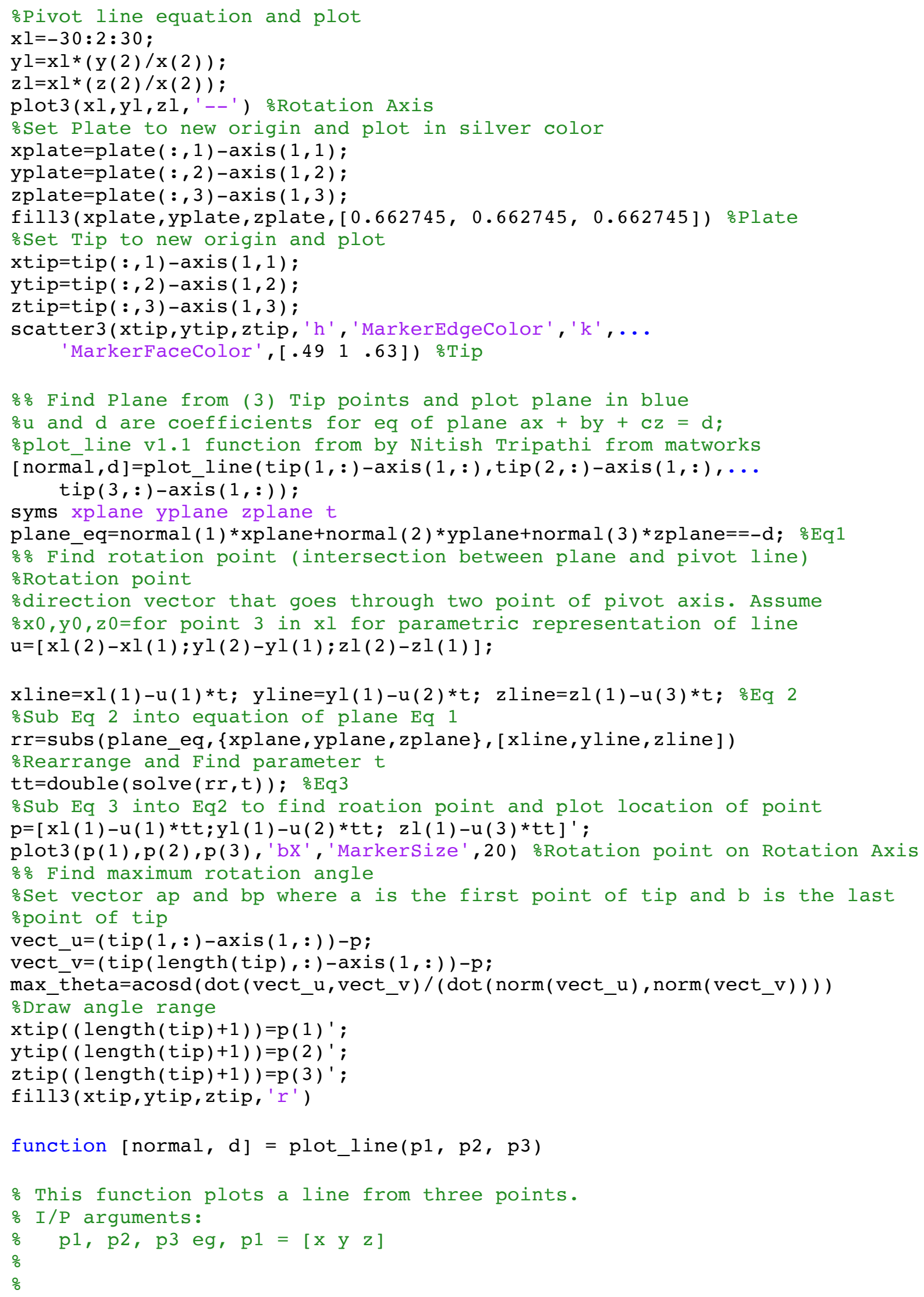




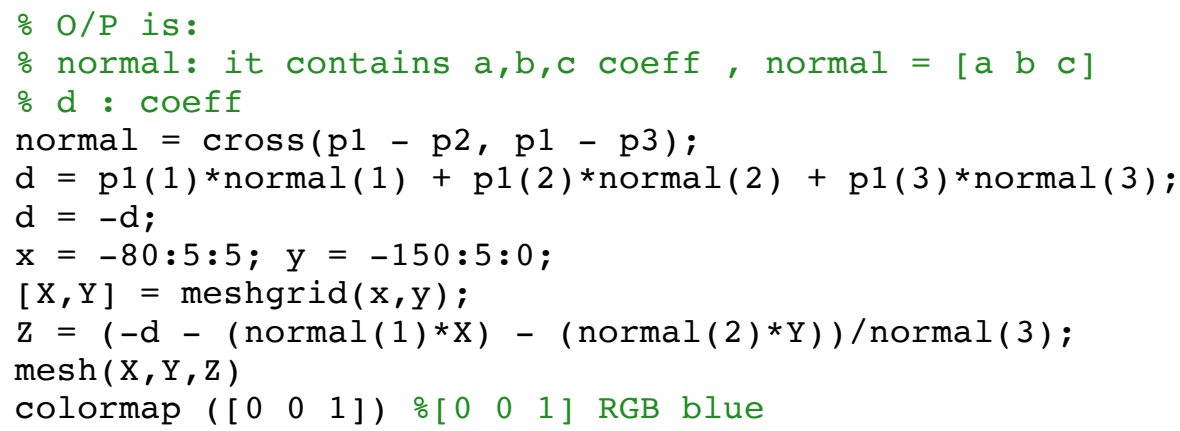

\section{EXPERIMENTAL DATA EXTRACTION}

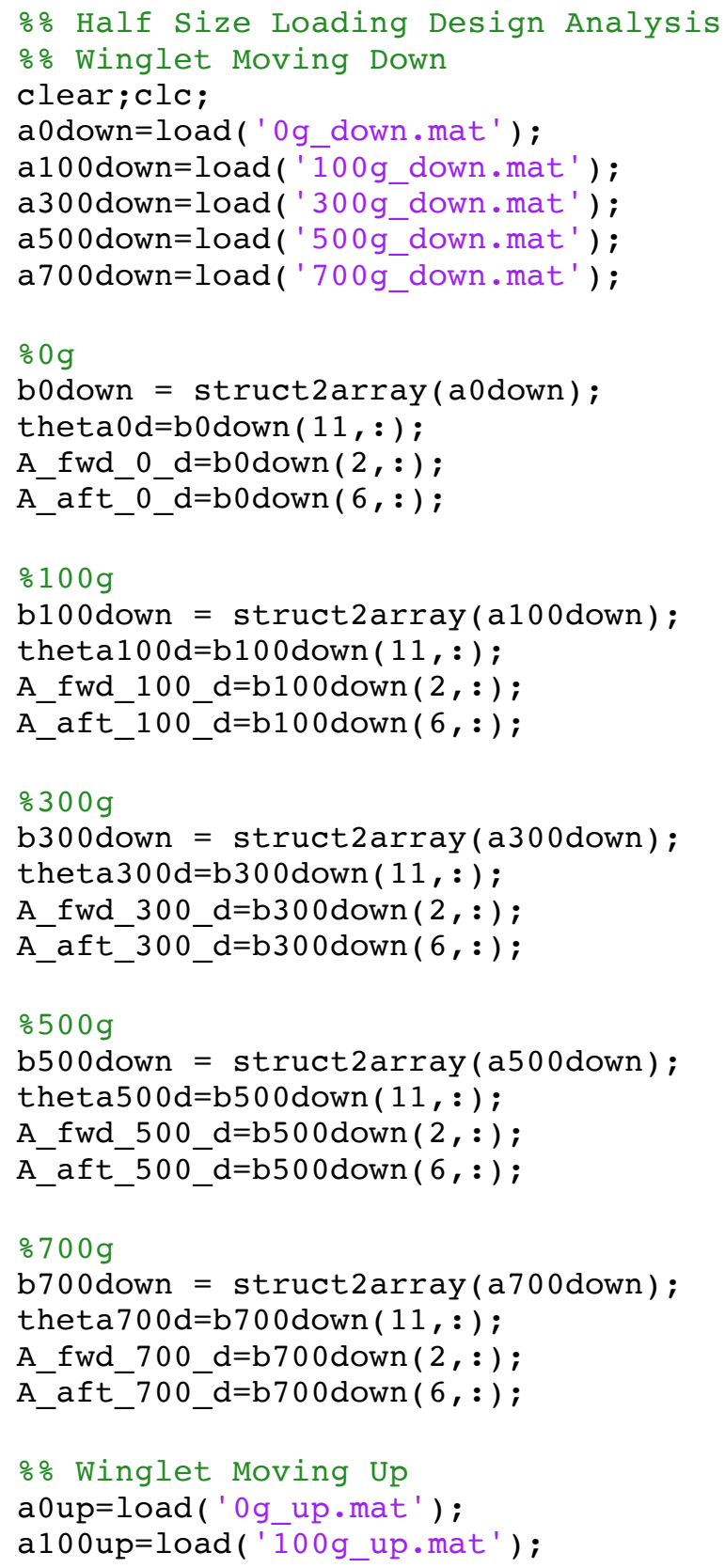




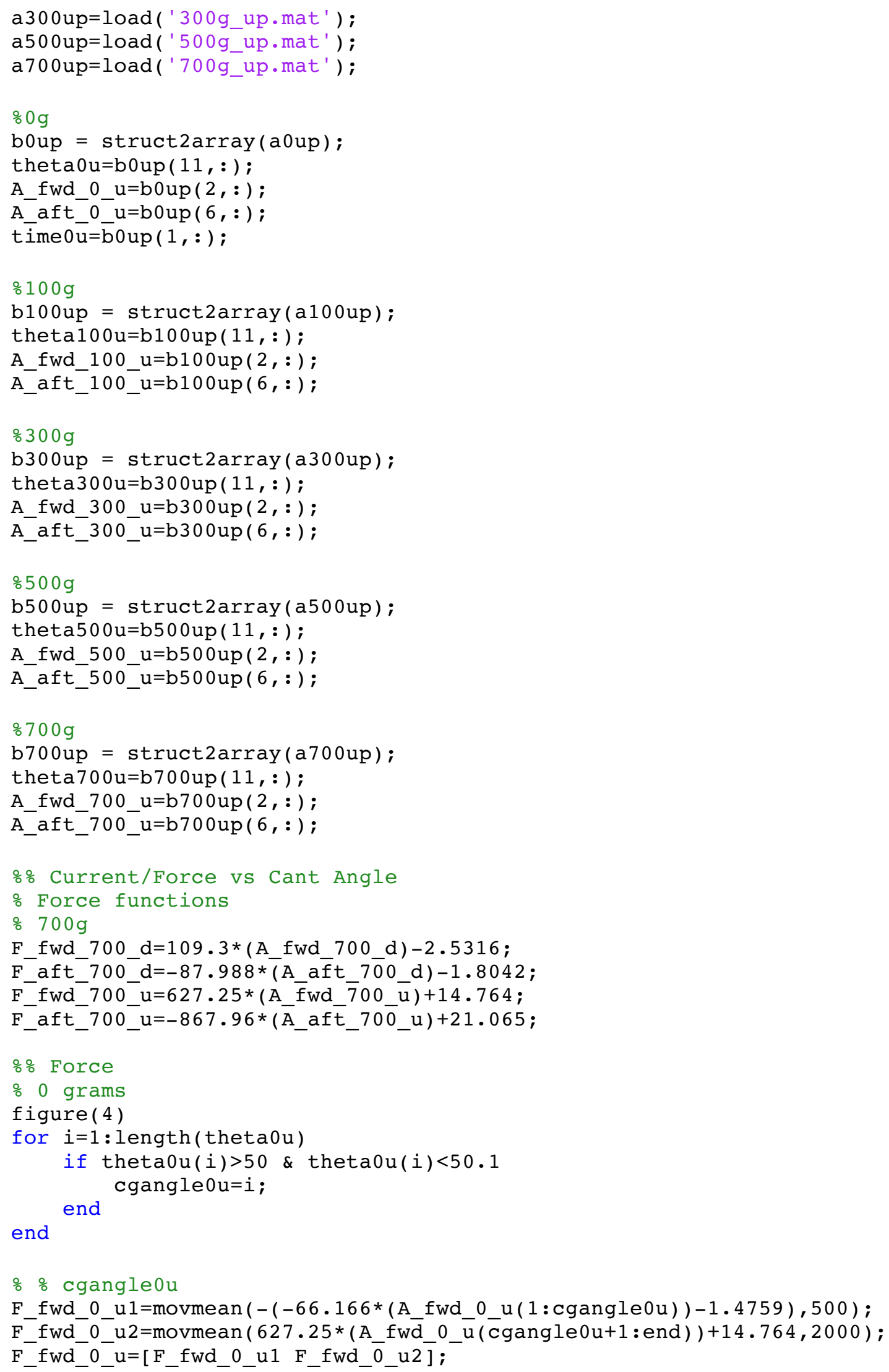




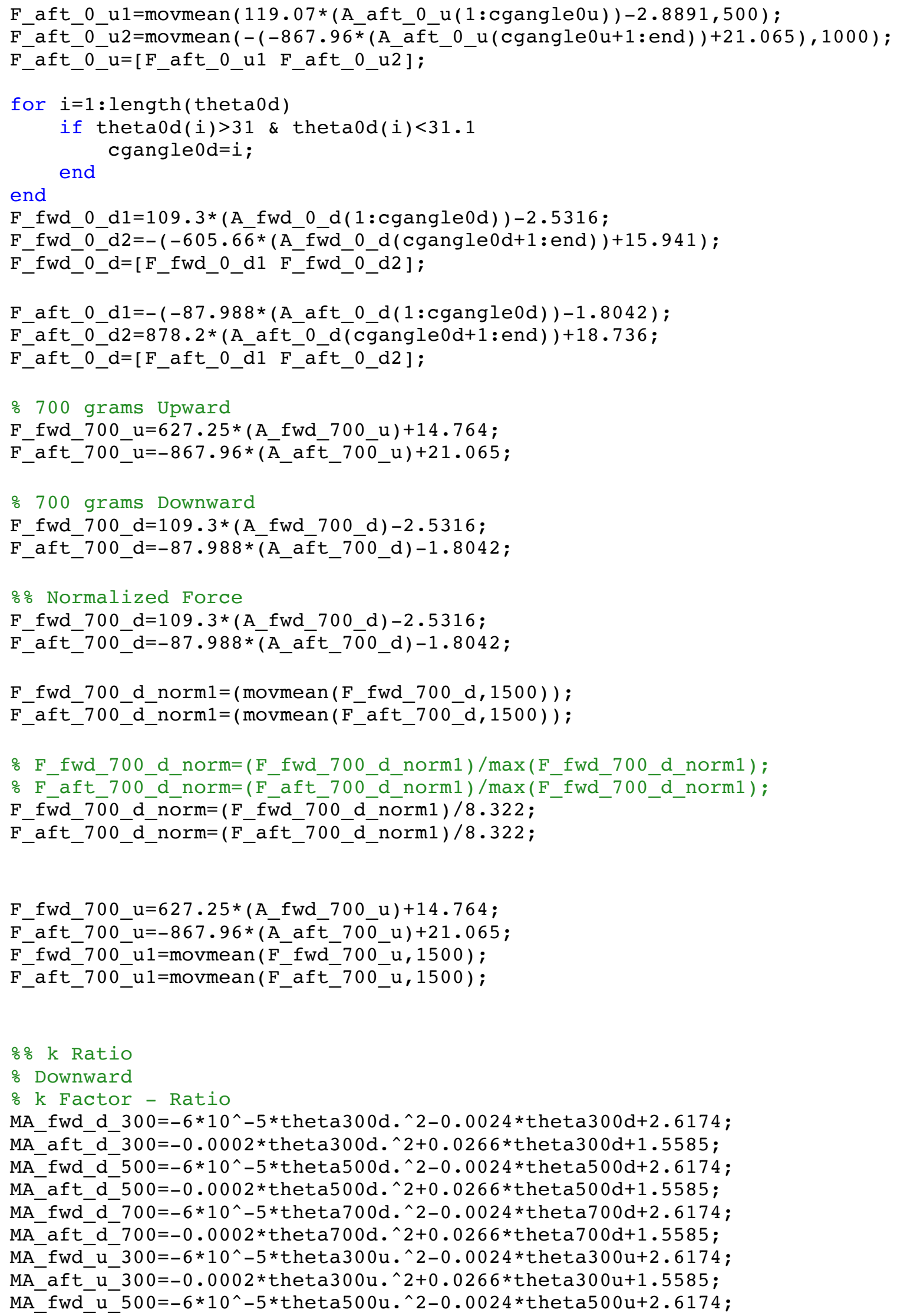


MA_aft_u_500=-0.0002*theta500u.^^2+0.0266*theta500u+1.5585;

MA_fwd_u_700=-6*10^-5*theta700u.^2-0.0024*theta700u+2.6174;

MA_aft_u_700=-0.0002*theta $700 \mathrm{u} .{ }^{\wedge} 2+0.0266 *$ theta $700 \mathrm{u}+1.5585$;

MA_fwd_u_700=-6*10^-5*theta700u.^2-0.0024*theta700u+2.6174;

MA_aft_u_700=-0.0002*theta $700 u \cdot{ }^{\wedge} 2+0.0266 *$ theta $700 u+1.5585$;

F_fwd_300_d=movmean (109.3* (A_fwd_300_d ) -2.5316,8000);

F_aft_300_d=movmean $(-87.988 * \overline{-}$ (A_aft_300_d $)-1.8042,8000)$;

F_fwd_500_d=movmean (109.3*(A_fwd_500_d) $-2.5316,8000)$;

F_aft_500_d=movmean (-87.988*(A_aft_500_d) $-1.8042,8000)$;

F_fwd_700_d=movmean (109.3* (A_f $\overline{-}$ d_ $\left.7 \overline{0} 0 \_d \overline{)}-2.5316,8000\right)$;

F_aft_700_d=movmean $(-87.988 * \overline{-}$ (A_aft_700_d $)-1.8042,8000)$;

F_fwd_300_u=movmean (627.25*(A_fwd_300_u ) +14.764,8000);

F_aft_300_u=movmean $\left(-867.96 *\left(\bar{A} \_a f t \_30 \bar{t} \_u\right)+21.065,8000\right)$;

F_fwd_500_u=movmean $(627.25 *($ A_fwd_500_u $)+14.764,8000)$;

F_aft_500_u=movmean $\left(-867.96 *\left(\bar{A} \_\right.\right.$aft_50 $\left.\left.50 \_u\right)+21.065,8000\right)$;

$\mathrm{F}^{-} \mathrm{fwd}$-700 u $1=$ movmean $\left(627.25 *\left(\mathrm{~A}^{-} \mathrm{fwd}-700^{-} \mathrm{u}\right)+14.764,8000\right)$;

F_aft_700_u1=movmean $\left(-867.96 *\left(\bar{A} \_\right.\right.$aft $\left.\left.\bar{t} \_70 \overline{0} \_u\right)+21.065,8000\right)$;

F_fwd_300_d_k=MA_fwd_d_300.*F_fwd_300_d;

F_aft_300_d_k=MA_aft_d_300.*F_aft_300_d;

$\mathrm{F}^{-}$fwd_500_d_k=MA_fwd_d_500.*F_fwd_500_d;

F_aft_500_d_k=MA_aft_d_500.*F_aft_500_d;

$\mathrm{F}^{-}$fwd_700_d_k=MA_fwd_d_700.*F_fwd_700_d;

F_aft_700_d_k=MA_aft_d_700.*F_aft_700_d;

F_fwd_300_u_k=MA_fwd_u_300.*F_fwd_300_u;

F_aft_300_u_k=MA_aft_u_300.*F_aft_300_u;

$\mathrm{F}^{-}$fwd 500_u_k=MA fwd_u_500.*F_fwd_500_u;

F_aft 500_u k=MA aft u_500.*F aft 500 u;

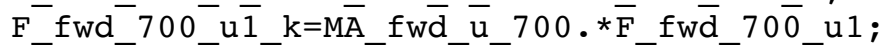

F_aft_700_u1_k=MA_aft_u_700.*F_aft_700_u1;

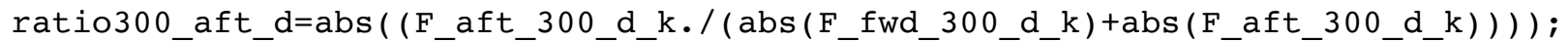

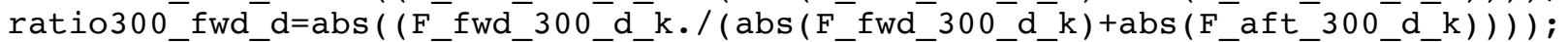

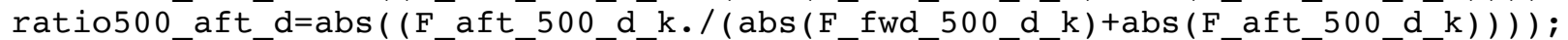
ratio500_fwd_d=abs ( (F_fwd_500_d_k./( abs (F_fwd_500_d_k ) +abs (F_aft_500_d_k ) ) ) ;

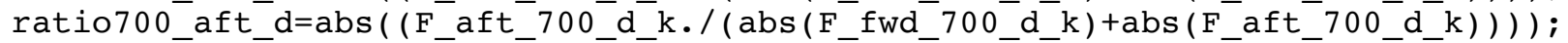

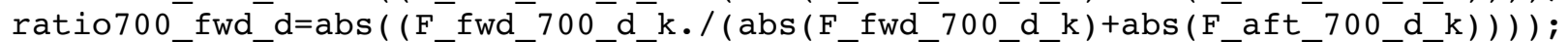

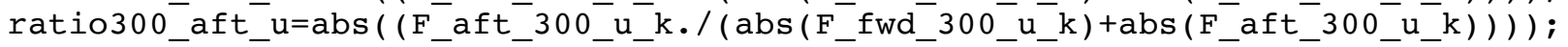

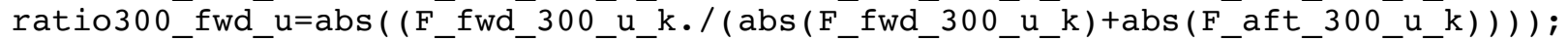
ratio500_aft_u=abs ( F_aft_500_u_k./ (abs (F_fwd_500_u_k ) +abs (F_aft_500_u_k ) ) ) ;

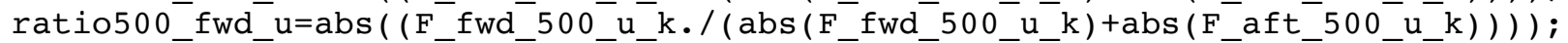

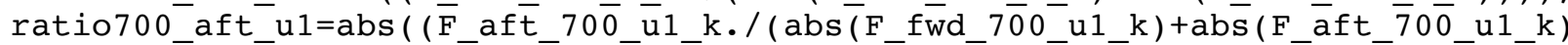
)) ) ;

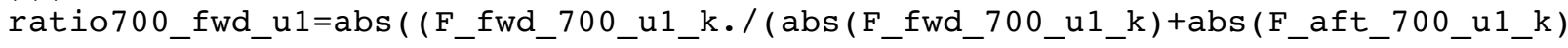
)) ) ; 


\section{B. CAD MODEL}

\section{R-P-R-P BELT DRIVEN MODEL}

$10^{\circ}$ Degree Cant Position

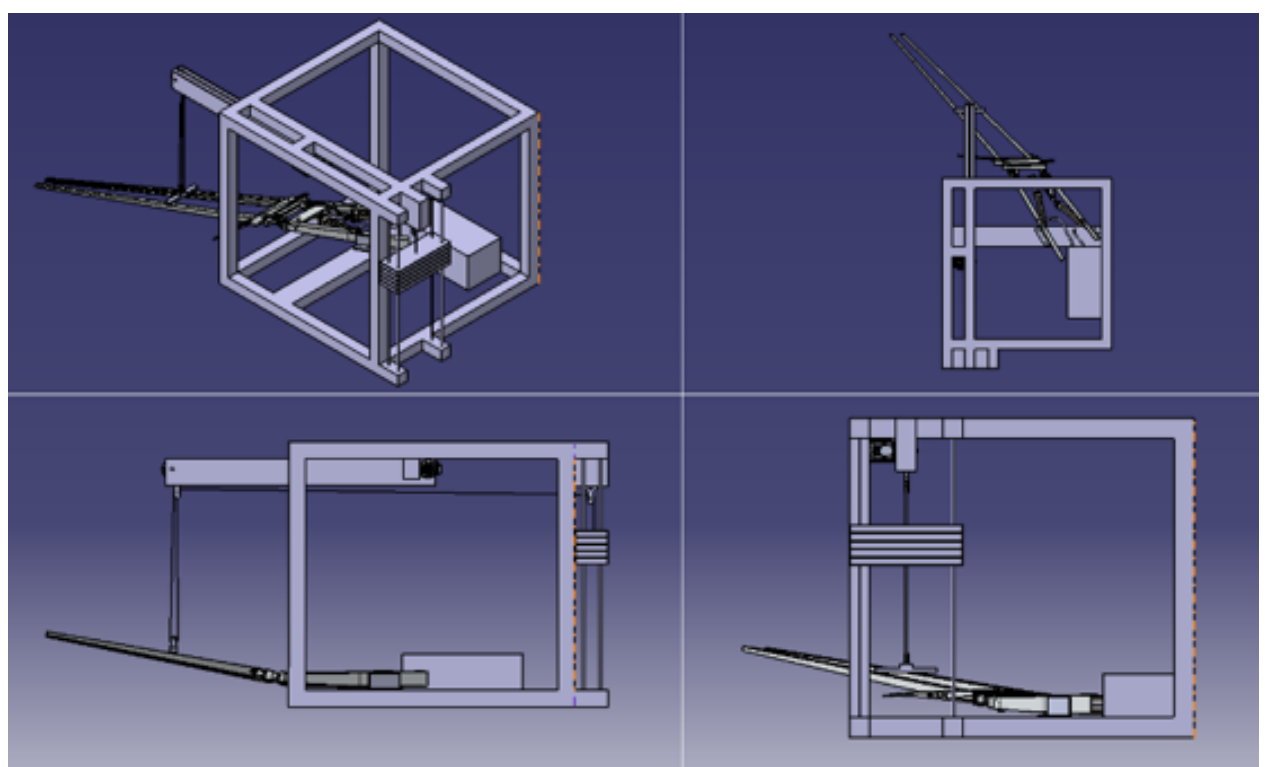

Figure. B-1: R-P-R-P Belt Driven 10 deg

$\underline{80^{\circ}}$ Degree Cant Position

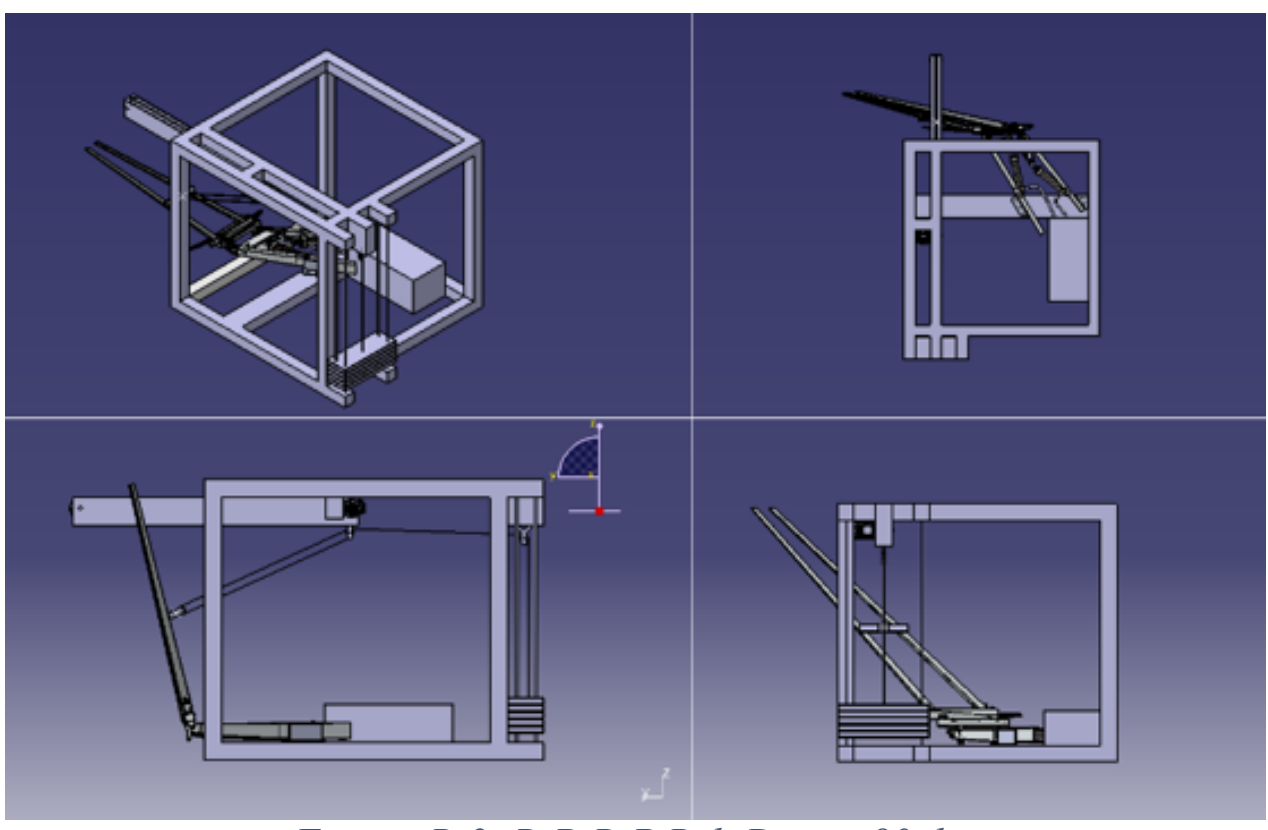

Figure. B-2: R-P-R-P Belt Driven $80 \mathrm{deg}$ 
R-P-R-P ACTUATOR DRIVEN MODEL

$10^{\circ}$ Degree Cant Position

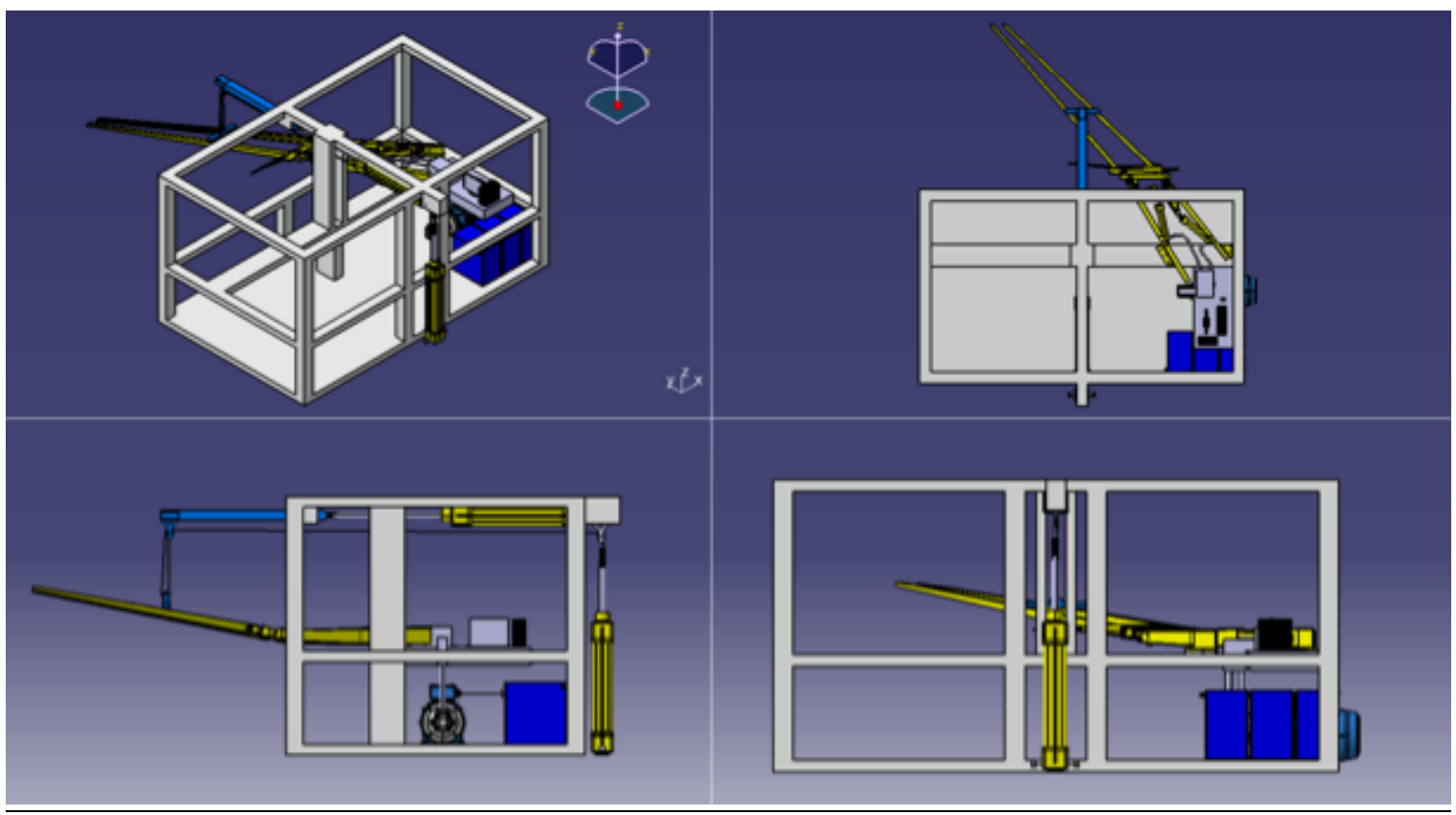

Figure. B-3: R-P-R-P Actuator driven 10 deg

$\underline{80^{\circ}} \underline{\text { Degree Cant Position }}$

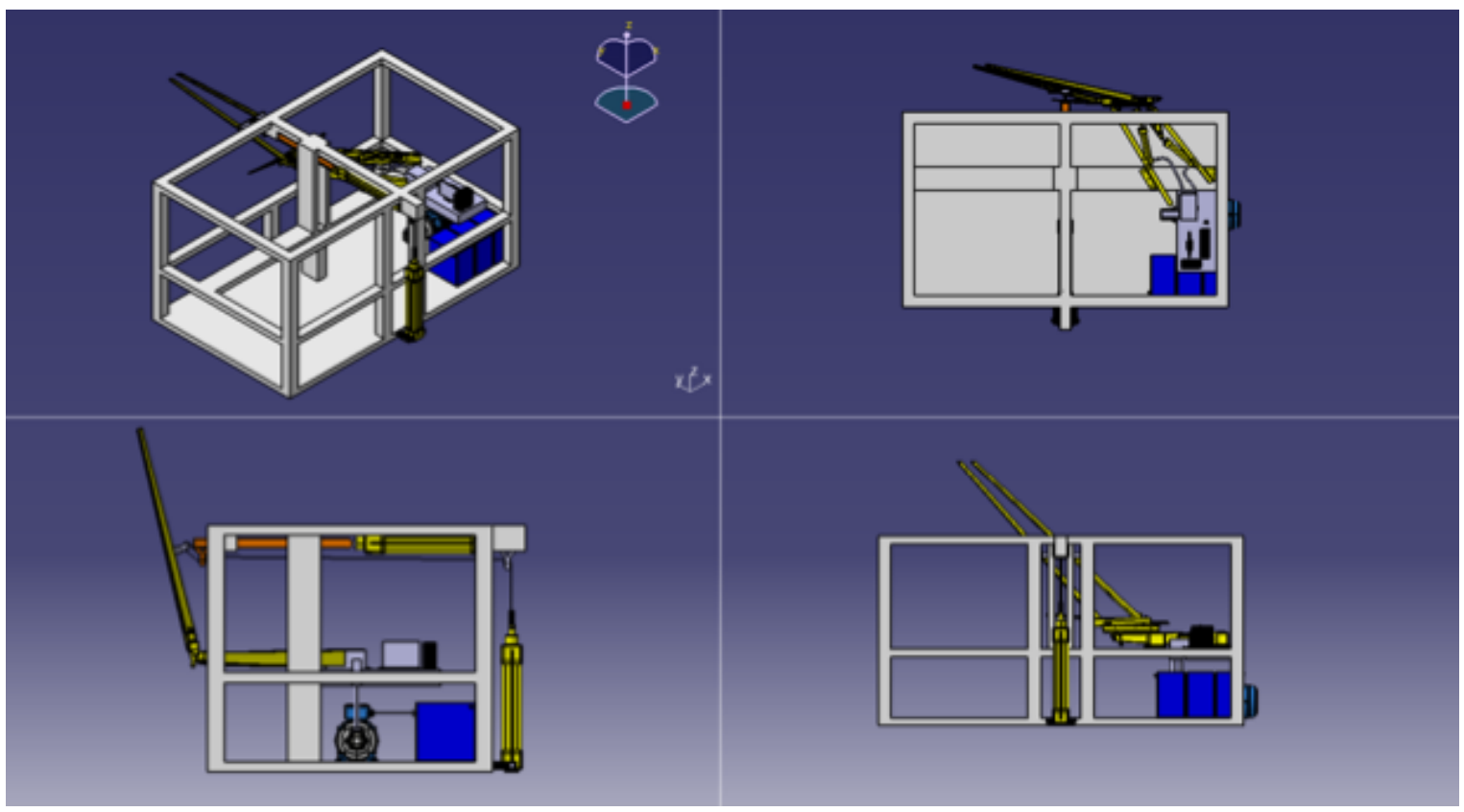

Figure. B-4: R-P-R-P Actuator driven 80 deg 


\section{SHARK-FIN COMPONENT DRAWINGS}

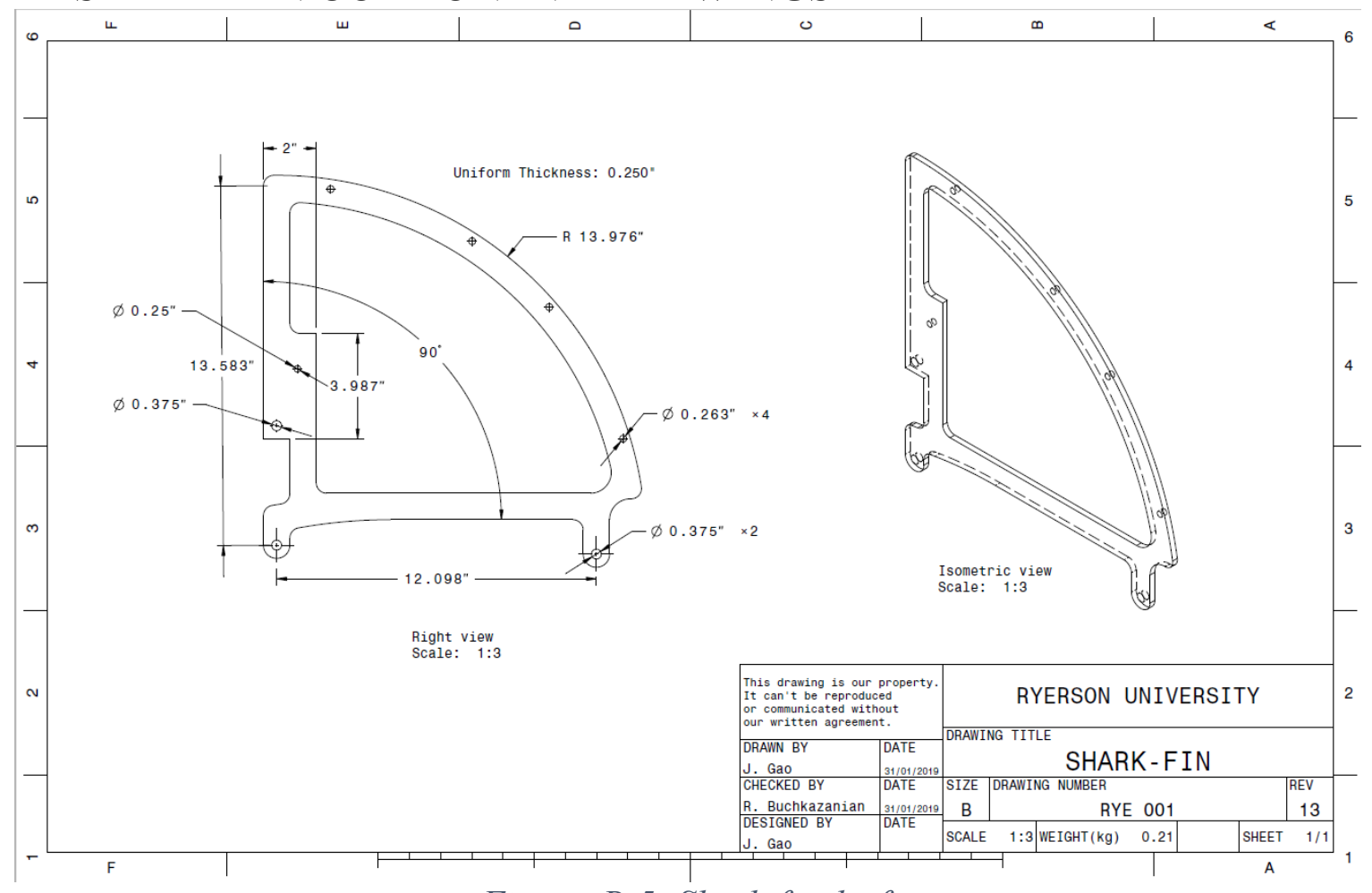

Figure. B-5: Shark-fin draft

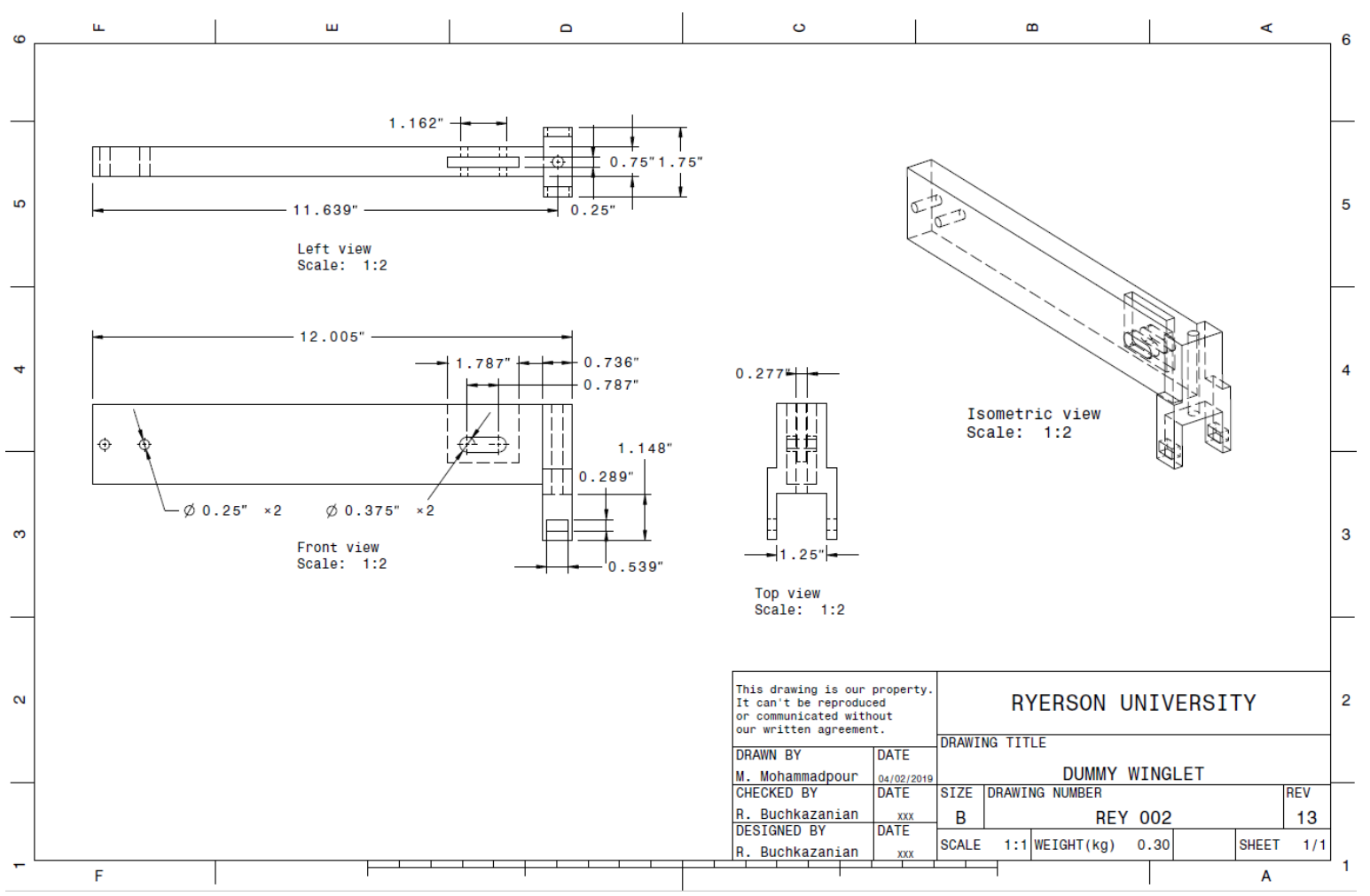

Figure. B-6: Dummy winglet draft 


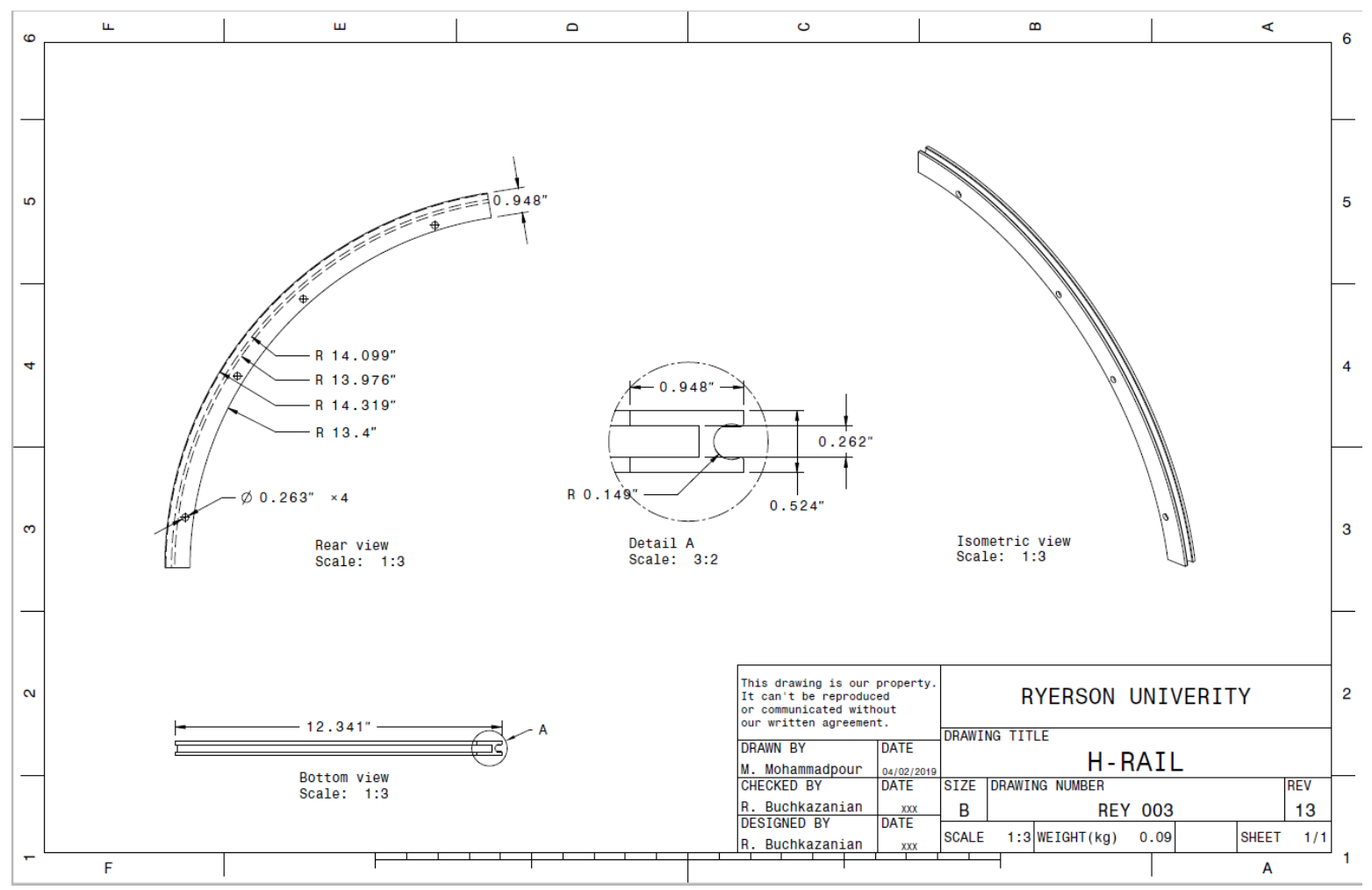

Figure. B-7: H-rail draft

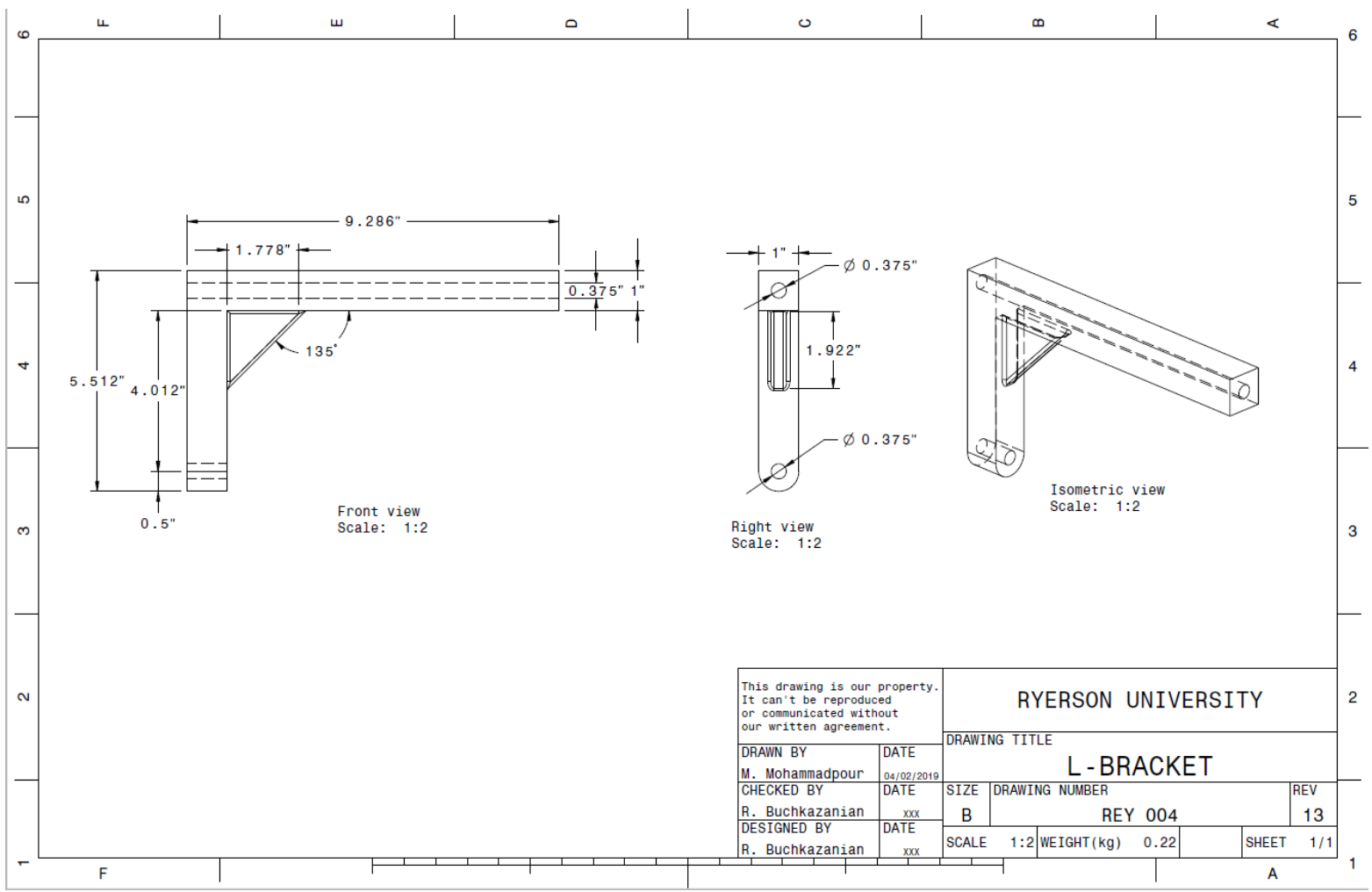

Figure. B-8: L-bracket draft 


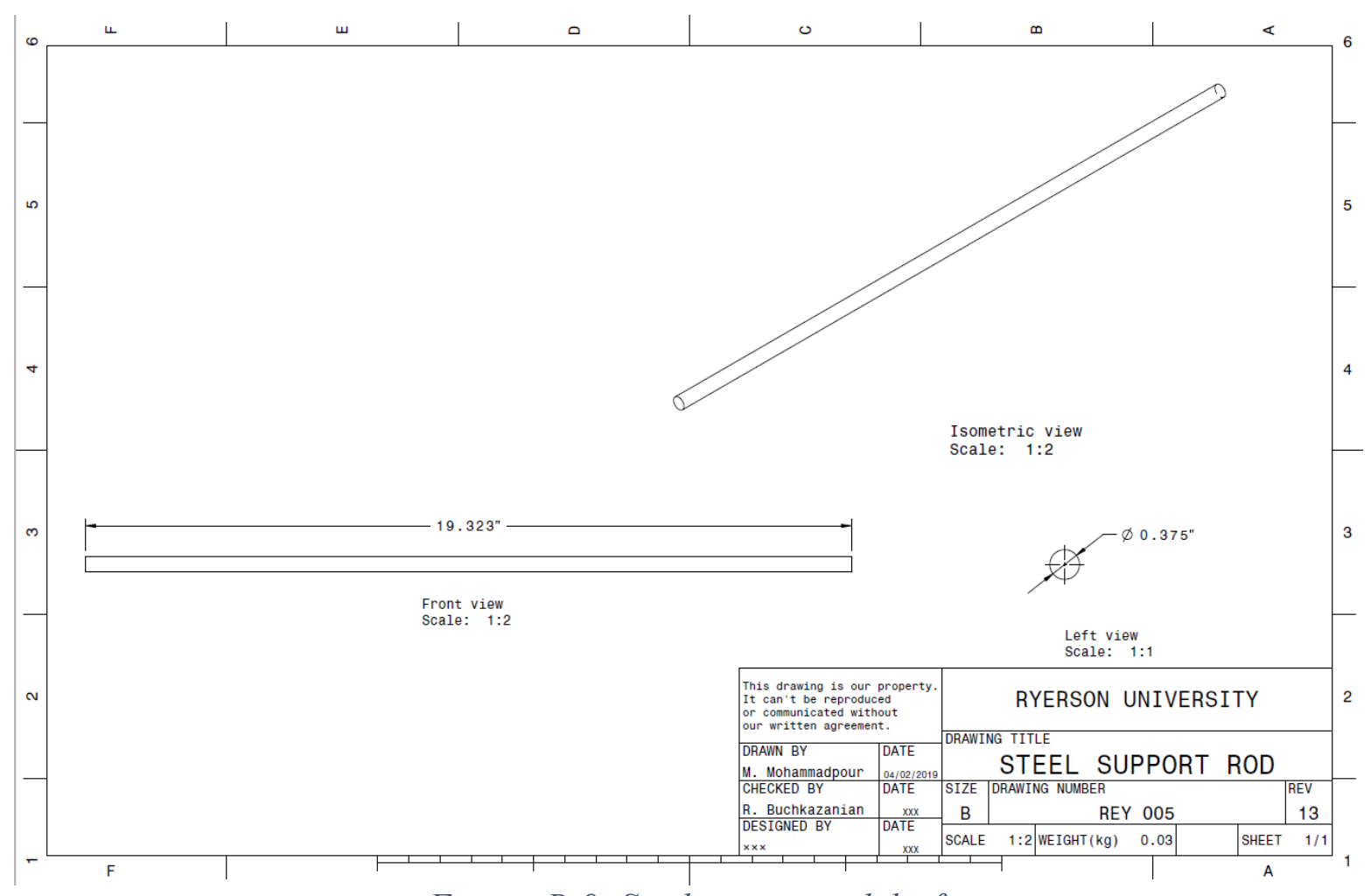

Figure. B-9: Steel support rod draft

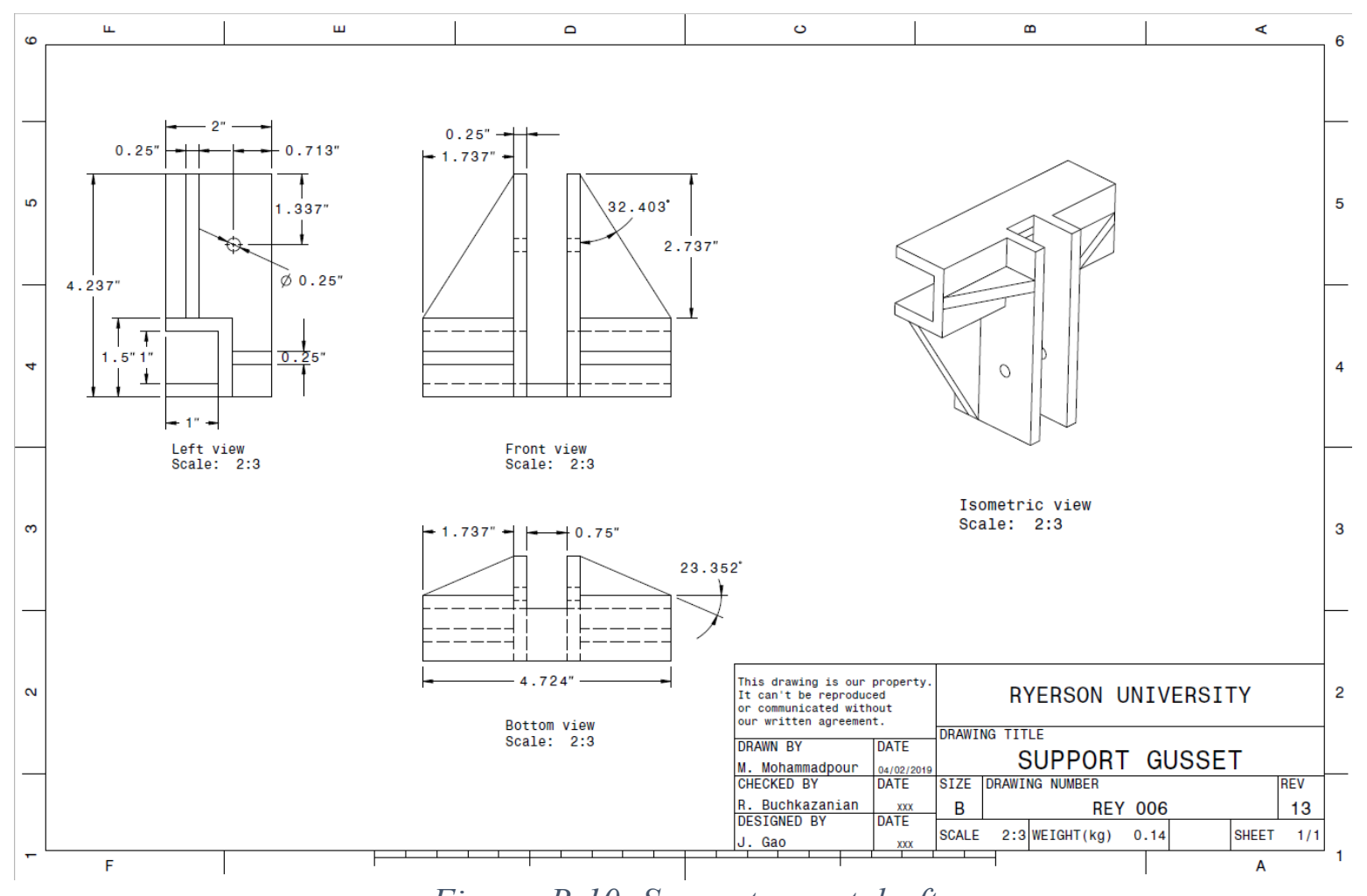

Figure. B-10: Support gusset draft 


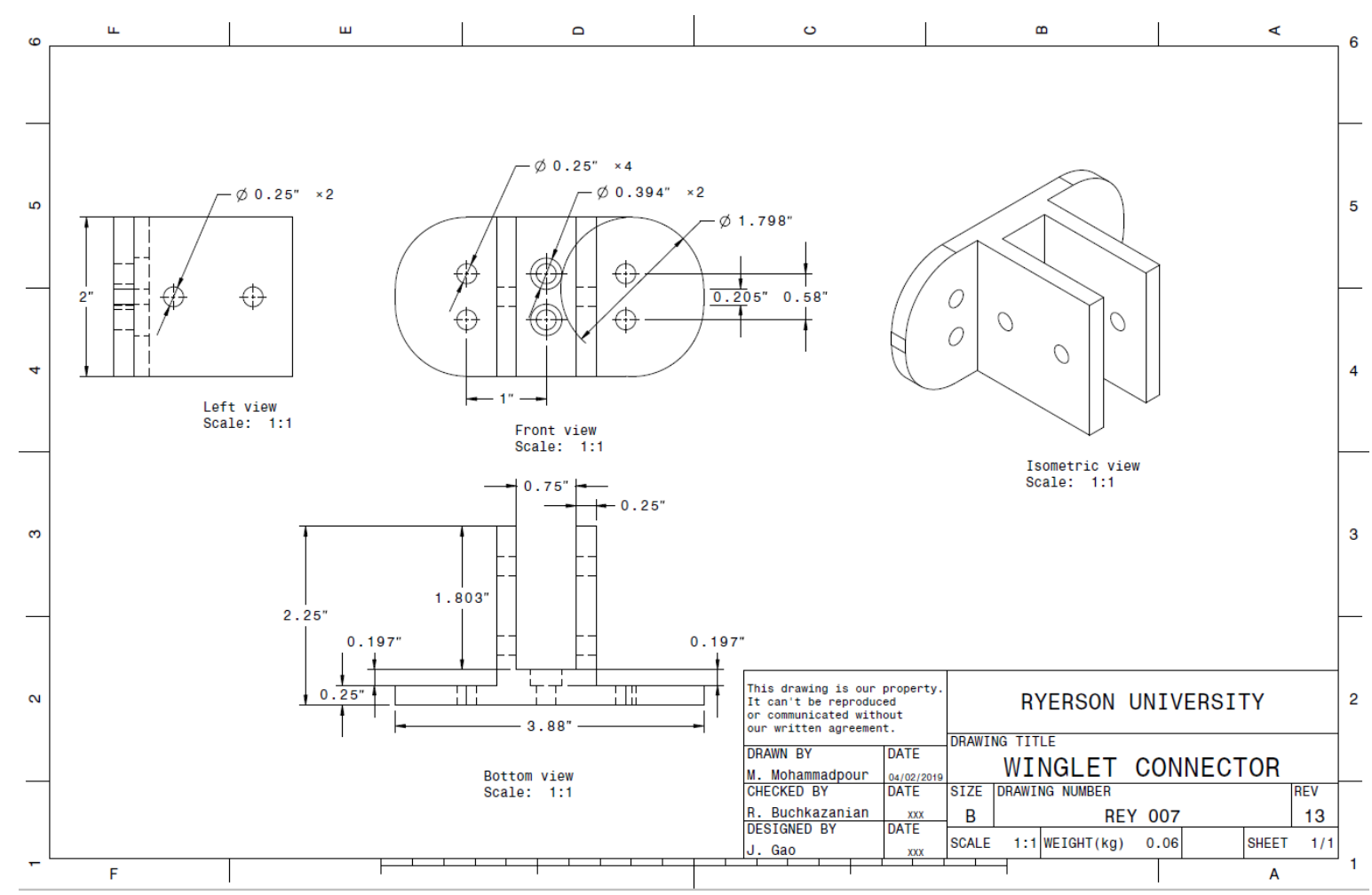

Figure. B-11: Winglet connector draft

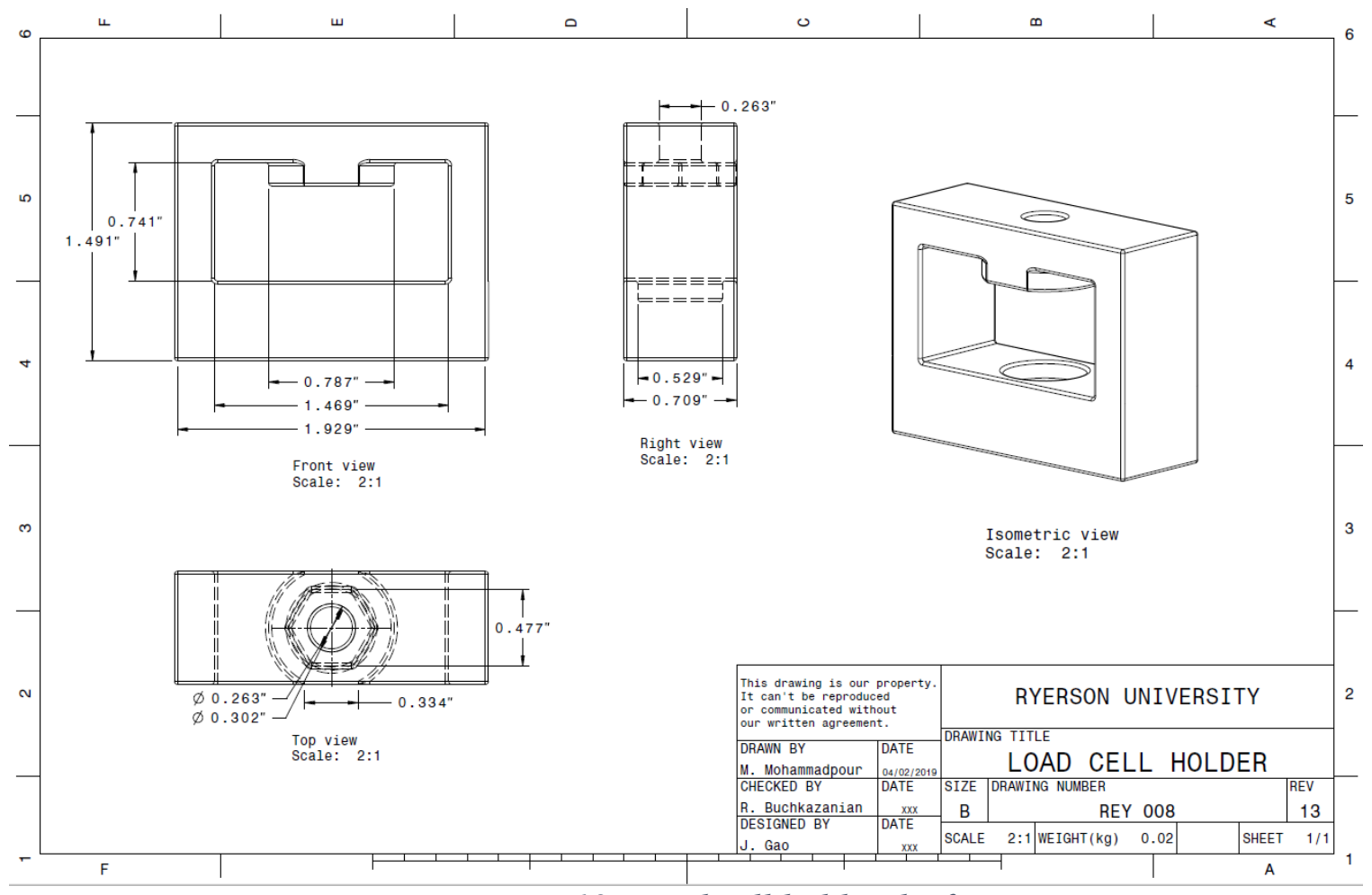

Figure. B-12: Load cell holder draft 


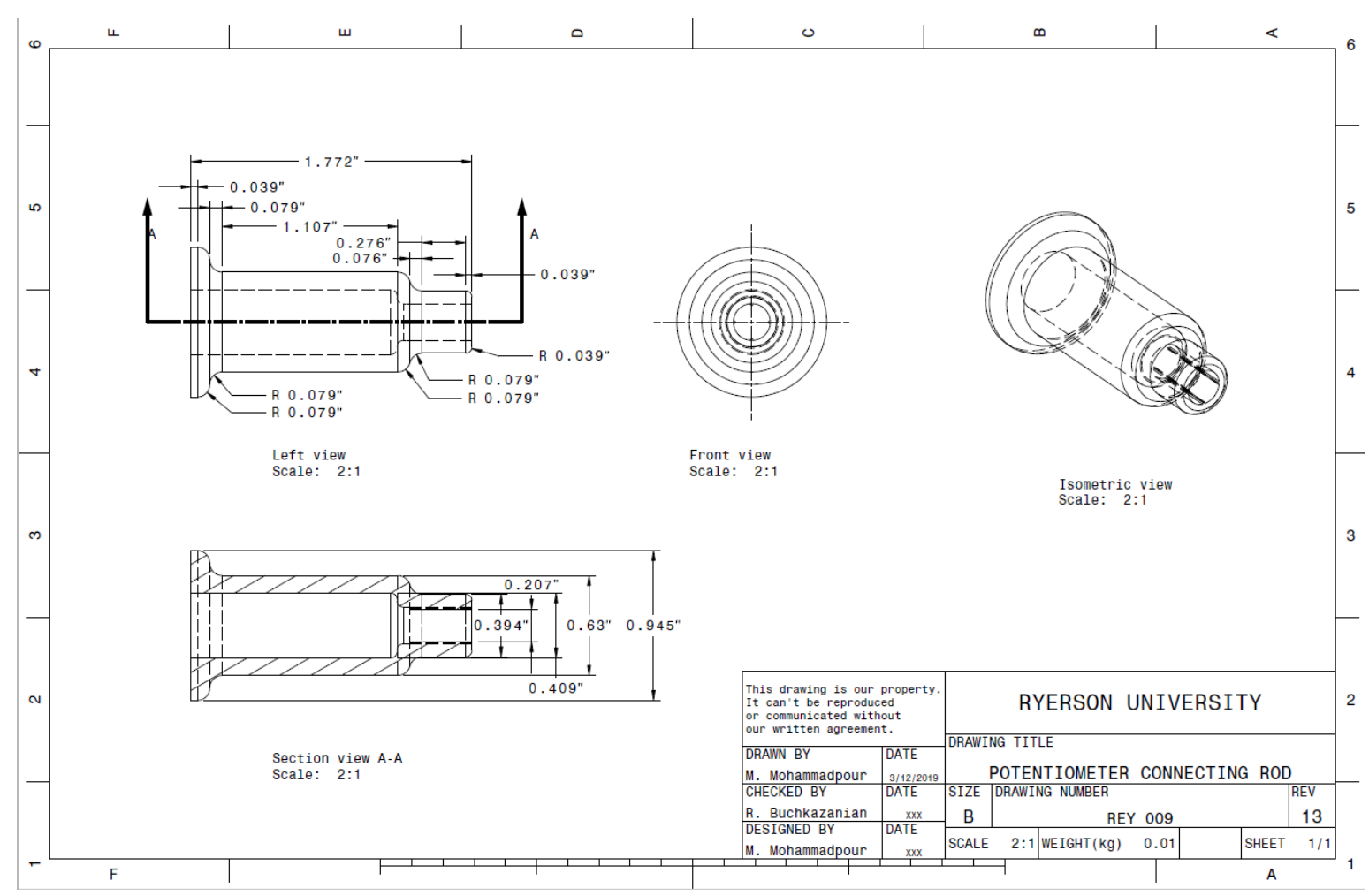

Figure. B-13: Potentiometer connecting rod draft

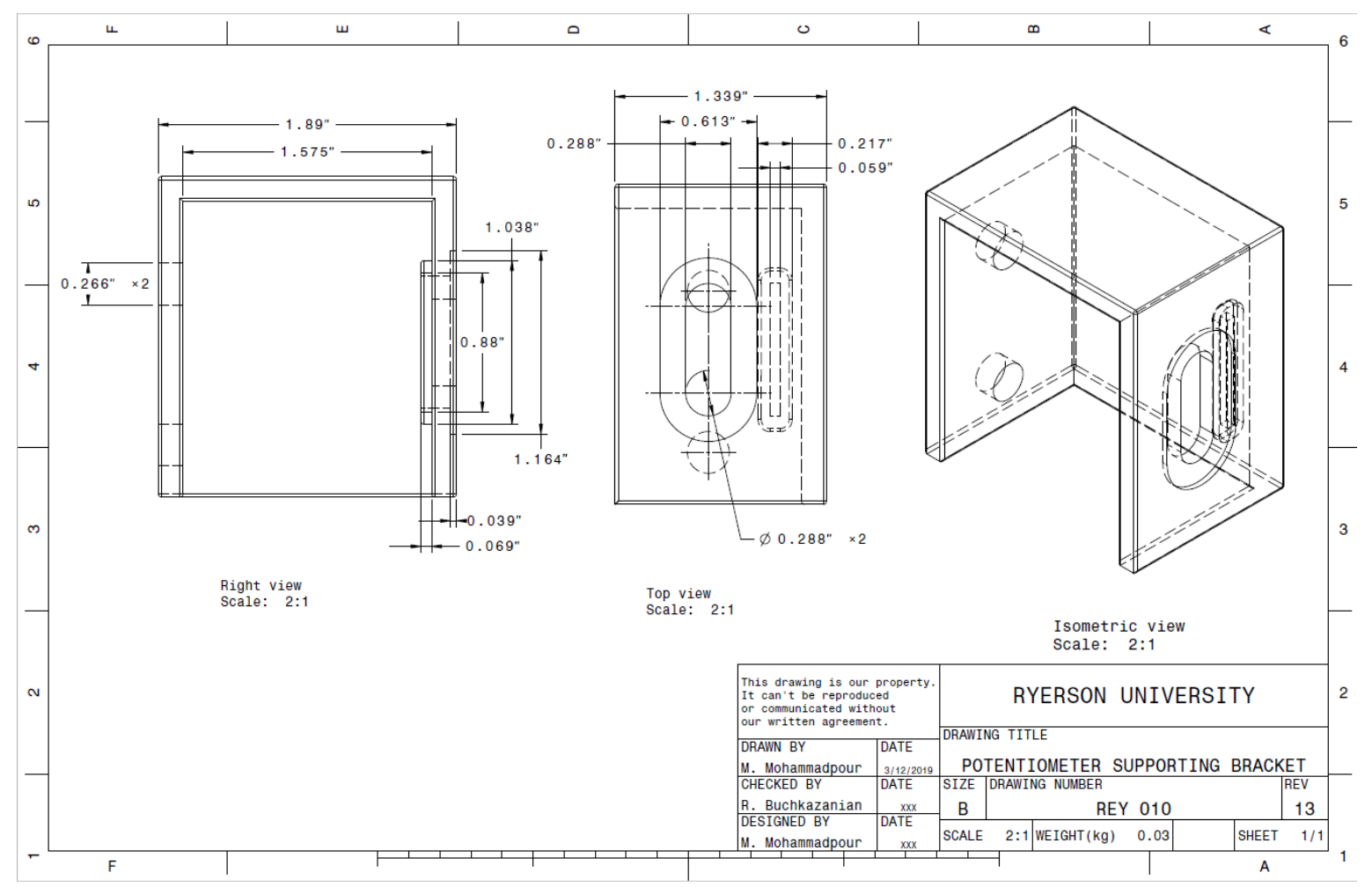

Figure. B-14: Potentiometer supporting bracket draft 


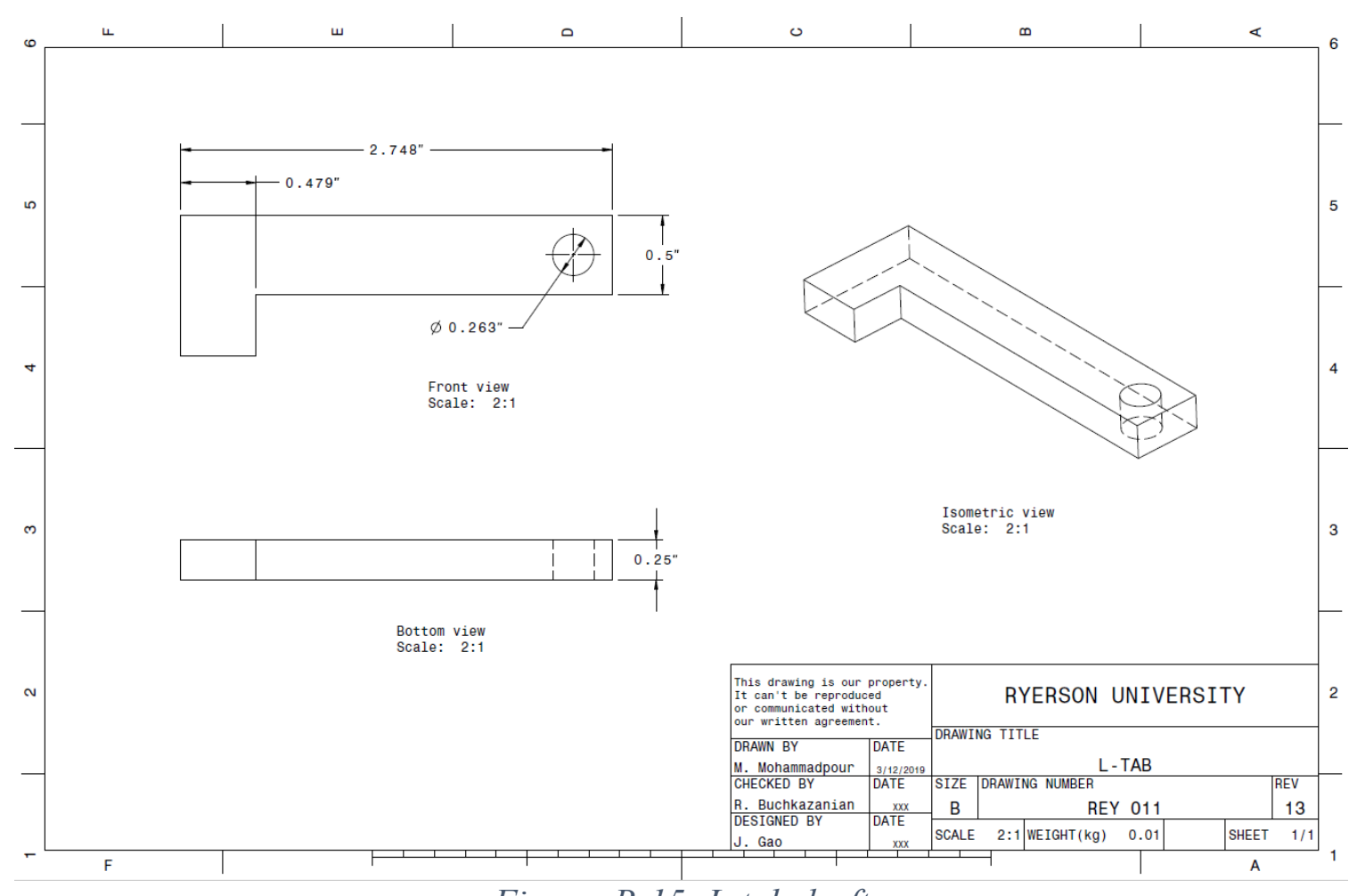

Figure. B-15: L-tab draft

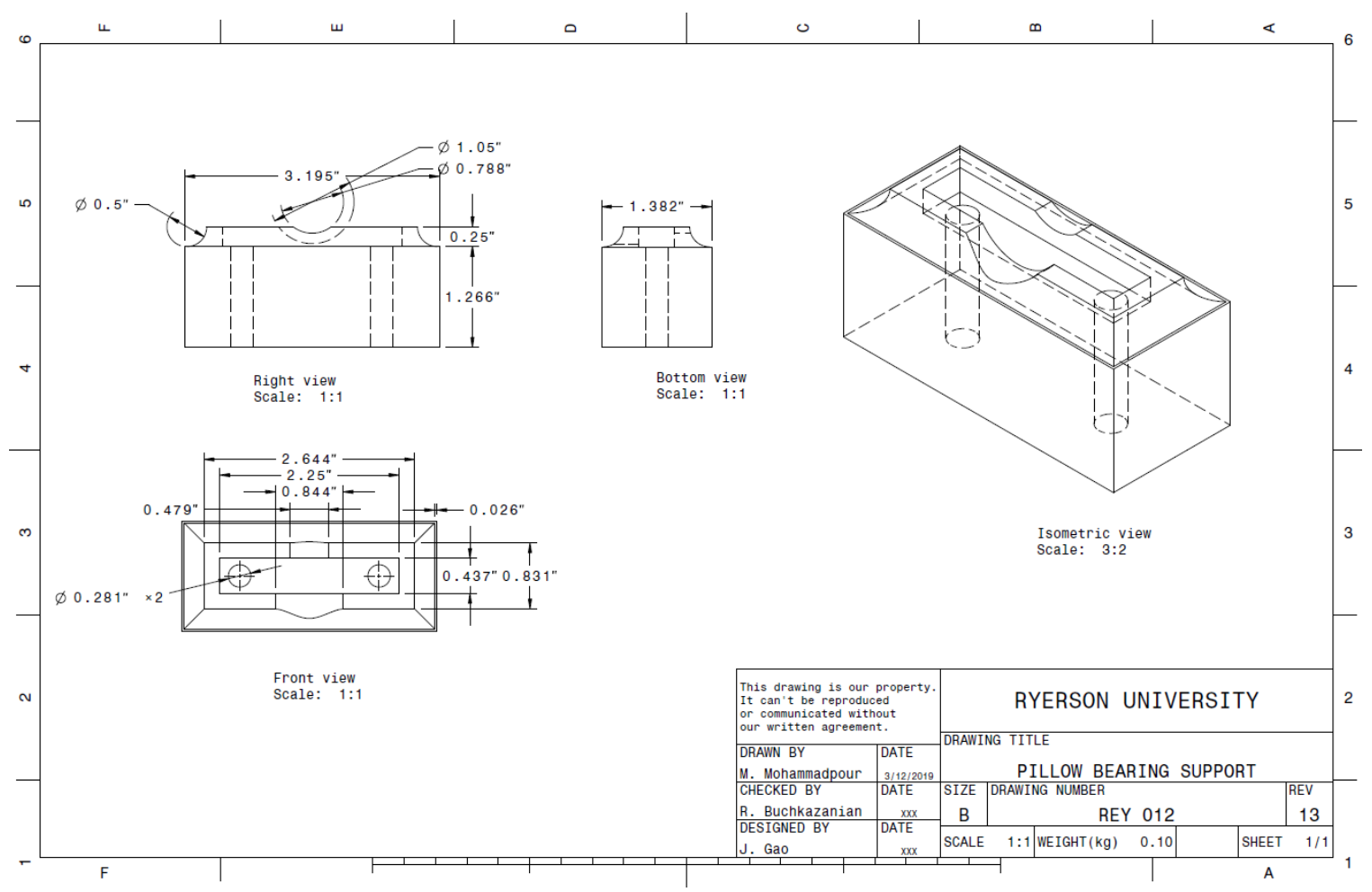

Figure. B-16: Pillow bearing support draft 


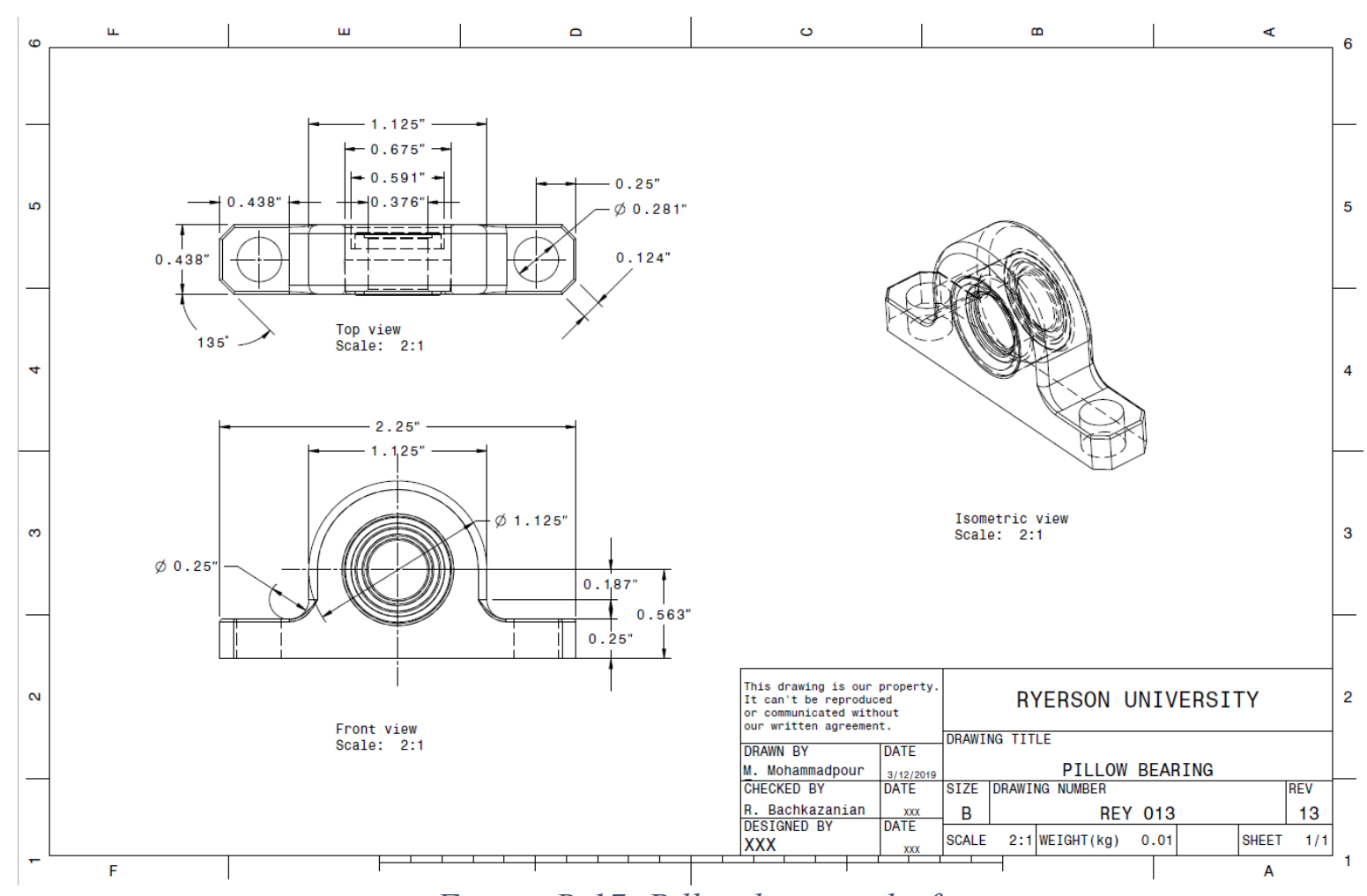

Figure. B-17: Pillow bearing draft

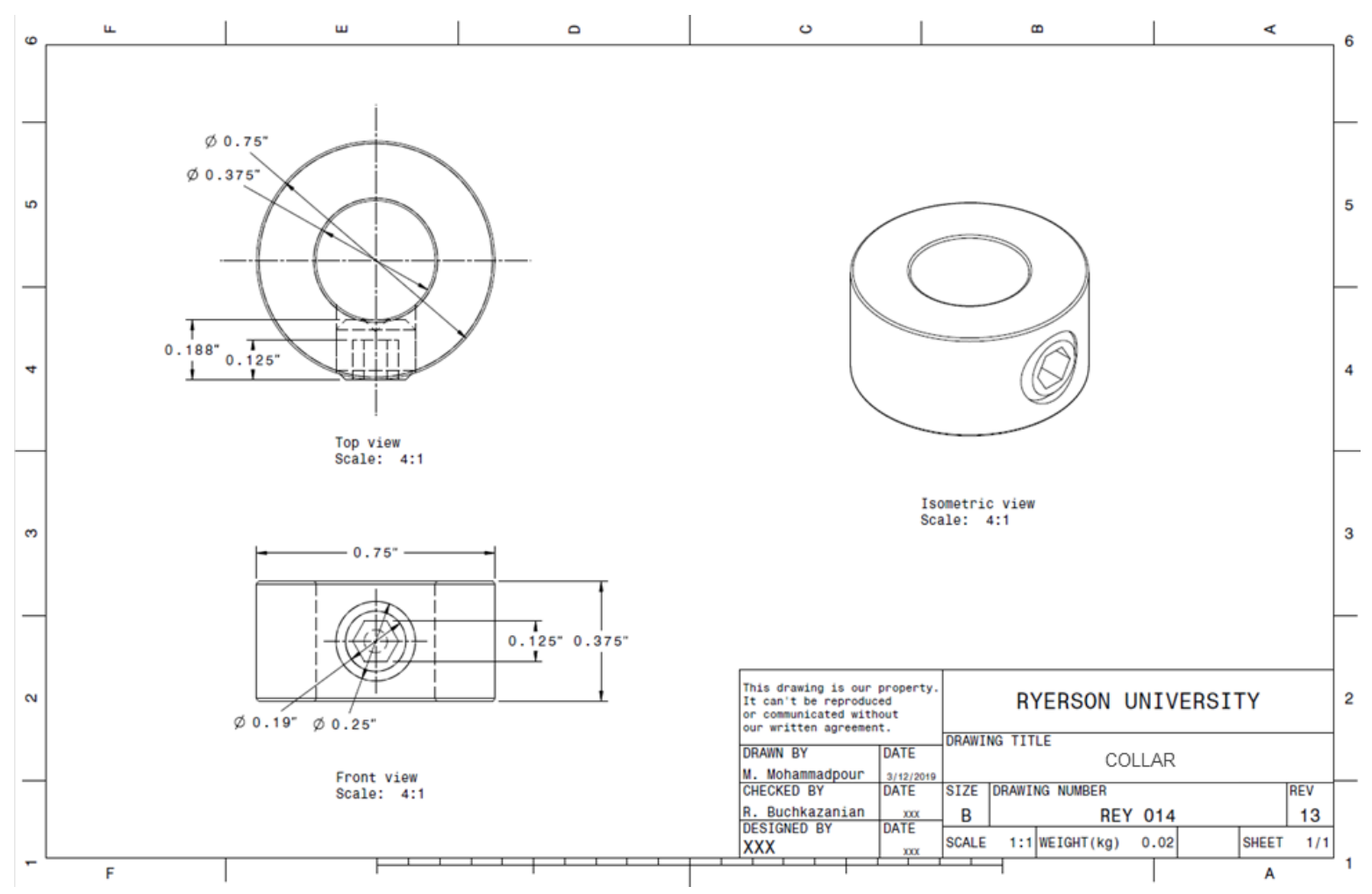

Figure. B-18: Collar draft 


\section{SHARK-FIN ASSEMBLY DRAWINGS}

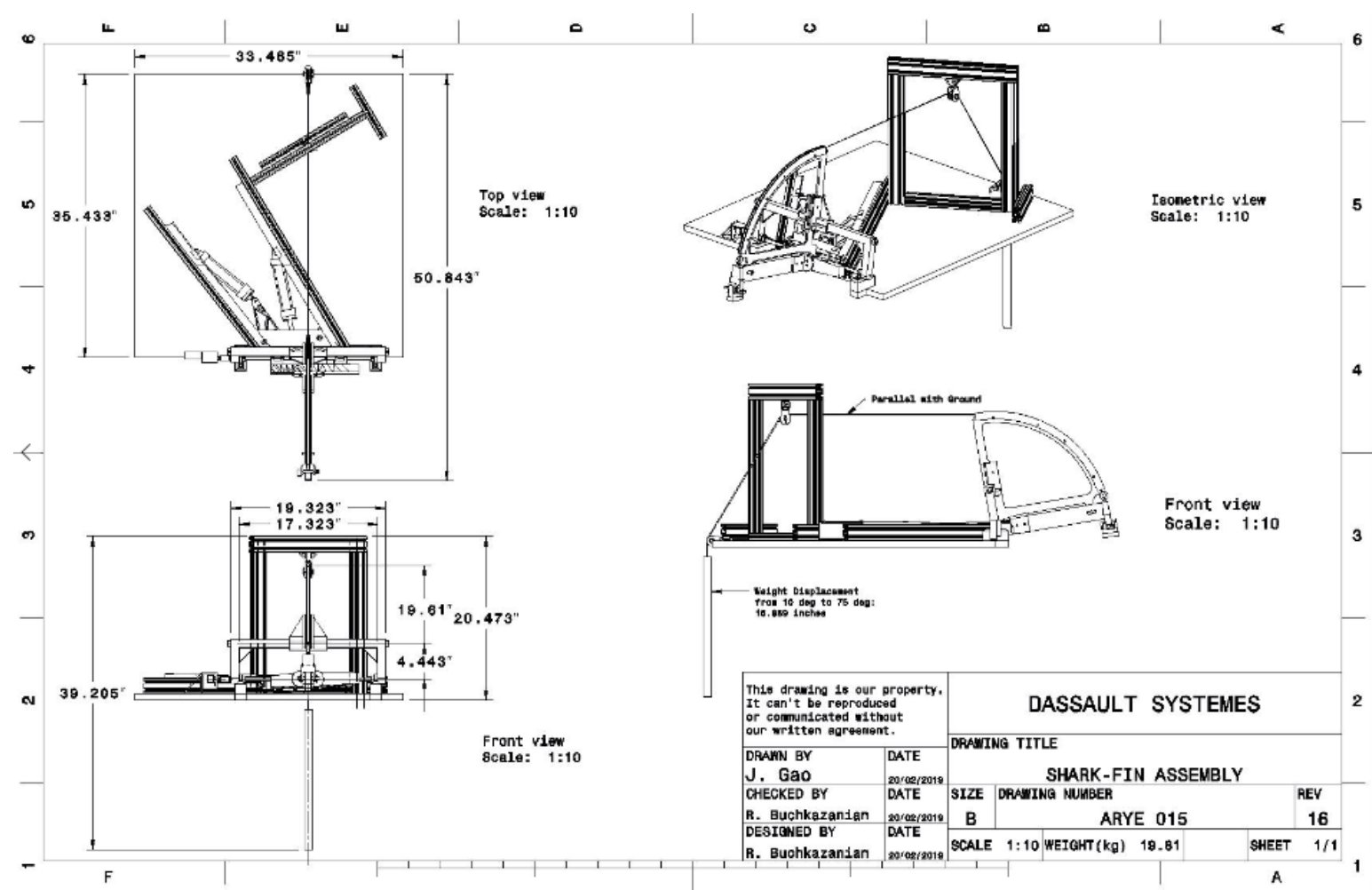

Figure. B-19: Shark-fin fixture assembly draft 


\section{DERIVATION \\ THEORETICAL ACTUATOR FORCE}

The following section refers to the work completed and published by the Morphing Winglet Team at Ryerson University.

Figure. C-1a illustrates the developed CAD model for the cant module, while Figure. C-1b shows the manufactured half size prototype, which was used for the loading prototype.
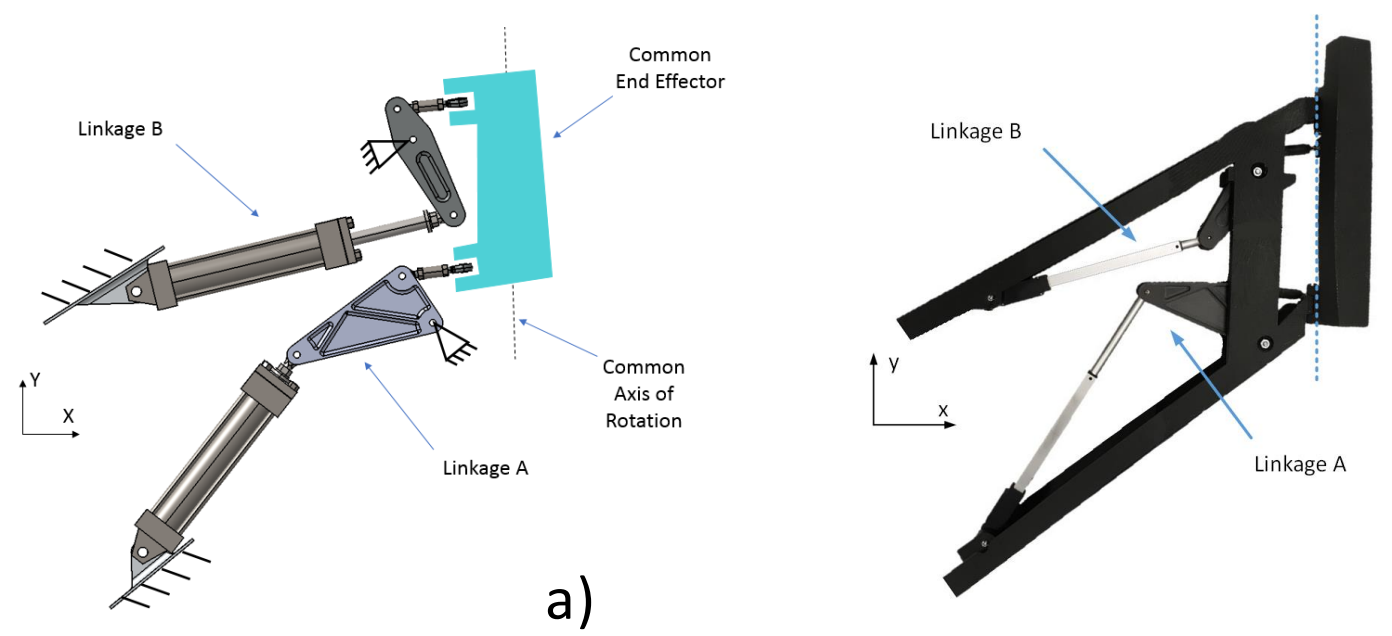

b)

Figure. C-1: Morphing winglet cant model - a) kinematic (cad) model b) prototype model

In order to complete the dynamic analysis of the mechanism, Linkage A and Linkage B were assumed to being static and under no deflection. This assumption simplifies the derivation, and can be acceptable for small rotation speeds and properly designed linkages. To determine the loading in the linkages, the three dimensional mechanism was split into two separate planar sections. While the winglet is rotating about the y axis, the triangular link in Linkage A rotates about the $\mathrm{z}$ axis, as shown in Figure. C-2. While the current derivation is specifically for Linkage A, a similar approach was used for Linkage B. 


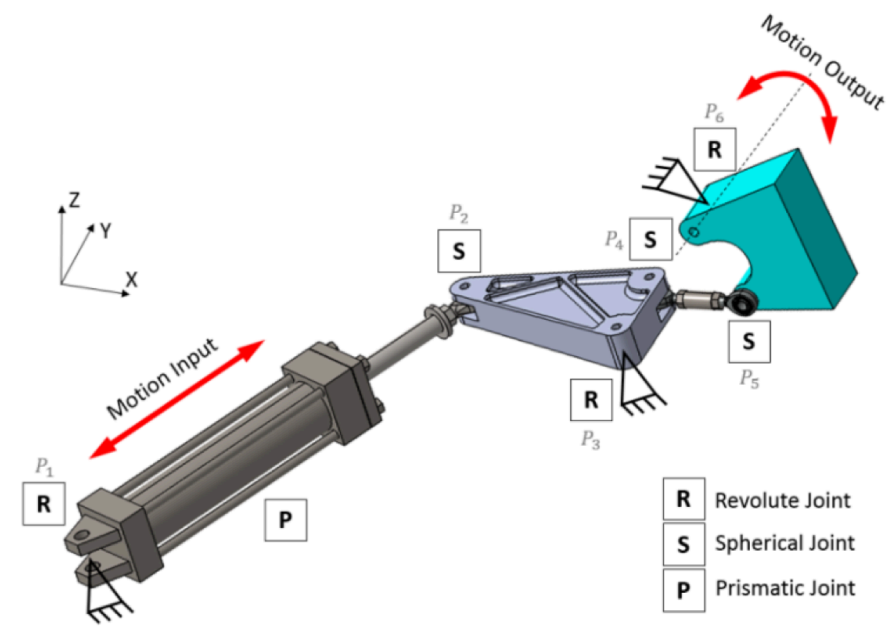

Figure. C-2: Cant module linkage a (detailed view)

By completing the dynamic analysis for the two separate planar systems in series, the actuator loads can be determined as a function of the applied load and cant angle. The first planar section analyzed was the tertiary link defined by points $\mathrm{p}_{2}, \mathrm{p}_{3}$ and $\mathrm{p}_{4}$ in Figure. $\mathrm{C}-2$. The force analysis derivation required the kinematic models displayed in Figure. C-3, Figure. C-4 and Figure. C-5. 


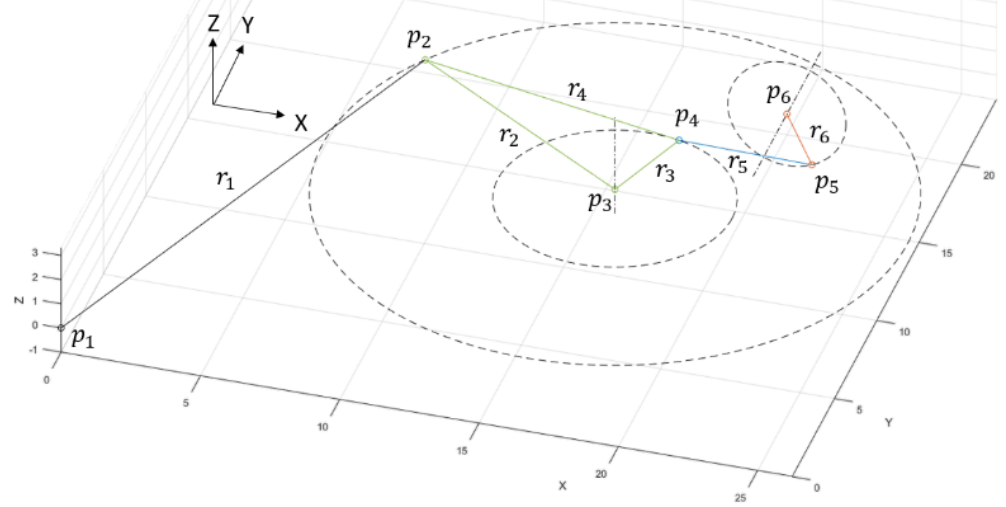

Figure. C-3: Cant mechanism kinematic model for linkage a (3D view)

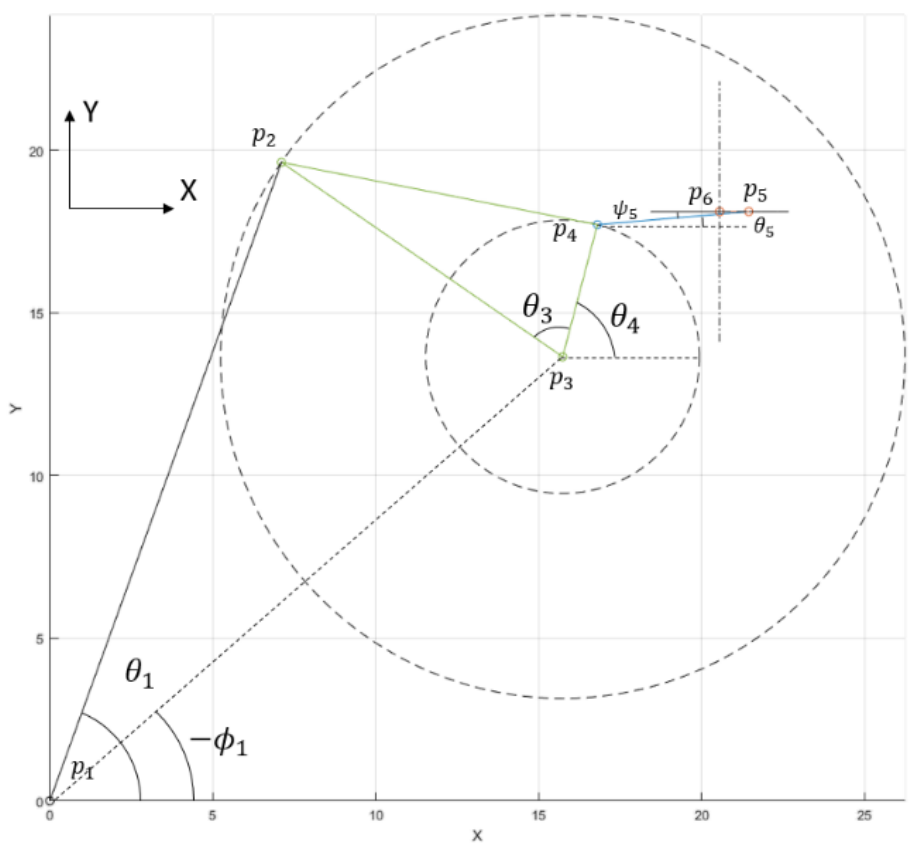

Figure. C-4: Cant mechanism kinematic model for linkage a (xy plane)

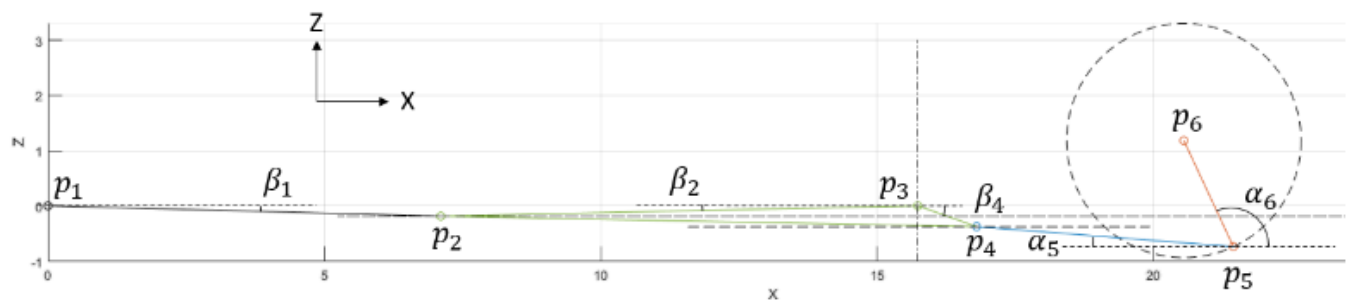

Figure. C-5: Cant mechanism kinematic model for linkage a (xz plane) 
The mechanism has a revolute joint at point $\mathrm{p}_{3}$ and rotates about the $\mathrm{Z}$ axis. The moment balance equation about this point is defined as:

$$
F_{32}^{\prime}\left(r_{2} \cos \beta_{2}\right)-F_{34}^{\prime}\left(r_{3} \cos \beta_{4}\right)=0
$$

where angles $\beta_{2}$ and $\beta_{4}$ shown in Figure. C-5 project the geometry onto the XY plane, centered around $\mathrm{p}_{3}$ and are defined as:

$$
\begin{aligned}
& \beta_{2}=\tan ^{-1}\left(\frac{p_{2_{z}}-p_{3_{z}}}{\sqrt{\left(p_{2_{x}}-p_{3_{x}}\right)^{2}+\left(p_{2_{y}}-p_{3_{y}}\right)^{2}}}\right) \\
& \beta_{4}=\tan ^{-1}\left(\frac{p_{4_{z}}-p_{3_{z}}}{\sqrt{\left(p_{4_{x}}-p_{3_{x}}\right)^{2}+\left(p_{4_{y}}-p_{3_{y}}\right)^{2}}}\right)
\end{aligned}
$$

The projected constraint forces acting on the tertiary link, perpendicular to the direction of links $r_{2}$ and $r_{3}$ projected on the $X Y$ plane are respectively defined as:

$$
\begin{gathered}
F_{32}^{\prime}=F_{A}^{\prime} \sin \left(\theta_{4}+\theta_{3}-\theta_{1}\right) \\
F_{34}^{\prime}=F_{4}^{\prime} \sin \left(\theta_{4}-\theta_{5}\right)
\end{gathered}
$$

where

$$
\begin{gathered}
\theta_{1}=\tan ^{-1}\left(\frac{p_{2_{y}}-p_{1_{y}}}{p_{2_{x}}-p_{1_{x}}}\right) \\
\theta_{4}=\tan ^{-1}\left(\frac{p_{4_{y}}-p_{3_{y}}}{p_{4_{x}}-p_{3_{x}}}\right) \\
\theta_{3}=\tan ^{-1}\left(\frac{p_{2_{y}}-p_{3_{y}}}{p_{2_{x}}-p_{3_{x}}}\right)-\theta_{4} \\
\theta_{5}=\tan ^{-1}\left(\frac{p_{5_{y}}-p_{4_{y}}}{p_{5_{x}}-p_{4_{x}}}\right)
\end{gathered}
$$


$\mathrm{F}_{\mathrm{A}}^{\prime}$ is the actuator force projected in the $\mathrm{XY}$ plane and is calculated by the following equation:

$$
F_{A}^{\prime}=F_{A} \cos \beta_{1}
$$

where $F_{A}$ is the force of interest, acting along the actuator link $r_{1}$. The angle $\beta_{1}$ projects $F_{A}$ onto the $\mathrm{XY}$ plane and is defined as:

$$
\beta_{1}=\tan ^{-1}\left(\frac{p_{2_{z}}-p_{1_{z}}}{\sqrt{\left(p_{2_{x}}-p_{1_{x}}\right)^{2}+\left(p_{2_{y}}-p_{1_{y}}\right)^{2}}}\right)
$$

Projecting $\mathrm{F}_{4}$ onto the $\mathrm{XY}$ plane with $\mathrm{p}_{4}$ as the origin gives $\mathrm{F}_{4}^{\prime}$ :

$$
F_{4}^{\prime}=F_{4} \cos \beta_{5}
$$

where $F_{4}$ is the force acting along the link $r_{4}$ and angle $\beta_{5}$ projects $F_{4}$ onto the $X-Y$ plane.

$$
\beta_{5}=\tan ^{-1}\left(\frac{p_{5_{z}}-p_{4_{z}}}{\sqrt{\left(p_{5_{x}}-p_{4_{x}}\right)^{2}+\left(p_{5_{y}}-p_{4_{y}}\right)^{2}}}\right)
$$

Combining equations (Eq. C-0-2) to (Eq. C-0-13) with equation (Eq. C-0-1) results in the following:

$$
\begin{gathered}
F_{A} \cos \beta_{1} \sin \left(\theta_{4}+\theta_{3}-\theta_{1}\right)\left(r_{2} \cos \beta_{2}\right)-F_{4} \cos \beta_{5} \sin \left(\theta_{4}-\theta_{5}\right)\left(r_{3} \cos \beta_{4}\right)=0 \\
F_{A}=F_{4}\left(\frac{\cos \beta_{5}}{\cos \beta_{1}}\right)\left(\frac{\sin \left(\theta_{4}-\theta_{5}\right)}{\sin \left(\theta_{4}+\theta_{3}-\theta_{1}\right)}\right)\left(\frac{r_{3}}{r_{2}}\right)\left(\frac{\cos \beta_{4}}{\cos \beta_{2}}\right)
\end{gathered}
$$

For the second planar section, the summation of moments is calculated about $\mathrm{p}_{6}$. This summation equates the moment generated by the applied loading and the force required by the linkage system from the actuator:

$$
M_{E} k-F_{5}^{\prime} r_{6}=0
$$

where $\mathrm{F}_{5}^{\prime}$ is $\mathrm{F}_{4}^{\prime \prime}$ projected normal to link $\mathrm{r}_{5}$, centered around $\mathrm{p}_{5}$ 


$$
F_{5}^{\prime}=F_{4}^{\prime \prime} \sin \left(\alpha_{6}-\alpha_{5}\right)
$$

The angles, $\alpha_{5}$ and $\alpha_{6}$ are defined as:

$$
\begin{aligned}
& \alpha_{6}=\tan ^{-1}\left(\frac{p_{6_{z}}-p_{5_{z}}}{p_{6_{x}}-p_{5_{x}}}\right) \\
& \alpha_{5}=\tan ^{-1}\left(\frac{p_{4_{z}}-p_{5_{z}}}{p_{4_{x}}-p_{5_{x}}}\right)
\end{aligned}
$$

To find $\mathrm{F}_{4}^{\prime \prime}, \mathrm{F}_{4}$ is projected onto the $\mathrm{XZ}$ plane:

$$
F_{4}^{\prime \prime}=F_{4} \cos \psi_{5}
$$

where

$$
\psi_{5}=\sin ^{-1}\left(\frac{p_{5_{y}}-p_{4_{y}}}{r_{5}}\right)
$$

$F_{4}$ is calculated by the following:

$$
F_{4}=\frac{M_{E} k}{\cos \psi_{5} \sin \left(\alpha_{6}-\alpha_{5}\right) r_{6}}
$$

In equation (Eq. C-0-22, $M_{E}$ represents the moment generated by winglet under load, which is:

$$
M_{E}=L d_{l o a d}
$$

Equation (Eq. C-0-22) assumes the moment generated by the applied loading is significantly larger than the moment generated by the mass of the winglet.

In equation (Eq. C-0-22), $k$ represents the load distribution between the two linkage systems (A and B). While $M_{E}$ represents the total external moment, the portion on Linkage A is $M_{E} k$, and the portion on Linkage $\mathrm{B}$ is $M_{E}(1-k)$, where $k \in[0,1]$ is the distribution factor. Due to the indeterminate nature of the redundant system, the load distribution between the two actuators 
are determined by the relative stiffness of the two linkages. This value can be determined theoretically via finite element methods or experimentally through test.

Finally, the magnitude of the force in the actuator for Linkage A can be determined by substituting (Eq. C-0-22) into (Eq. C-0-15):

$$
F_{A_{B}}=\frac{M_{E} k}{\cos \psi_{5} \sin \left(\alpha_{5}-\alpha_{6}\right) r_{6}}\left(\frac{\cos \beta_{5}}{\cos \beta_{1}}\right)\left(\frac{\sin \left(\theta_{4}-\theta_{5}\right)}{\sin \left(\theta_{4}+\theta_{3}-\theta_{1}\right)}\right)\left(\frac{r_{3}}{r_{2}}\right)\left(\frac{\cos \beta_{4}}{\cos \beta_{2}}\right)
$$




\section{BIBLIOGRAPHY}

[1] A. Elham and M. Van Tooren, "Winglet multi-objective shape optimization," Aerospace Science and Technology, vol. 37, pp. 93-109, 2014.

[2] I. Kroo, "Nonplanar Wing Concepts for Increased Aircraft Efficiency," Innovative Configurations and Advanced Concepts for Future Civil Aircraft, 2005.

[3] "Winglets," National Aeronatuics and Space Administration, [Online]. Available: https://www.grc.nasa.gov/www/k-12/airplane/winglets.html.

[4] C. Wang, H. Khodaparast and M. Friswell, "Conceptual study of a morphing winglet based on unsymmetrical stiffness," Aerospace Science and Technology, vol. 58, pp. 546-558, 22 September 2016.

[5] U. Choudhuri, "Mathematical Modeling, Design Validation, and Simulation of Morphing Mechanism for Winglet Application: MASc. dissertation," Ryerson University, 2016.

[6] A. Beechook and J. Wang, "Aerodynamic Analysis of Variable Cant Angle Winglets for Improved Aircraft Performance," in Proceedings of the 19th International Conference on Automation \& Computing, London, 2013.

[7] D. Myilsamy, Y. Thirumalai and P. Premkumar, "Performance Investigation of an Aircraft Wing at Various Cant Angles of Winglets using CFD Simulation," Altair Technology Confrerence, India, 2015.

[8] N. M. Ursache, T. Melin, A. T. Isikveren and M. I. Friswell, "Morphing Winglets for Aicraft Multi-phase Improvement," Aviation Technology, Integration and Operations Conference, vol. 7, September 2007.

[9] P. Paudel, "Aerodynamic Aspects in the Development of Morphing Winglet for a Regional Aircraft," Ryerson University, Toronto, 2015.

[10] US Deparment of Trasnportation Deferal Aviation Administration, "Advisory Circular: 25.307-1," 10 July 2014. [Online]. Available:

https://www.faa.gov/documentLibrary/media/Advisory_Circular/AC_25.307-1.pdf. [Accessed 14 April 2018].

[11] G. Amendola, I. Dimino and A. Concilio, "Preliminary Design Process for an Adaptive Winglet," International Journal of Mechanical Engineering and Robotics Research, vol. 7, no. 1, January 2018.

[12] D. Drezga, V. Korian, O. Roock, B. Lopez, A. Fiedler, S. Storm and V. Snop, "Winglet Design, Manufacturing and Testing," in Smart Intelligent Aircraft Structures (SARISTU), 2016.

[13] P. Bourdin, A. Gatto and M. Friswell, "Aircraft Control via Variable Cant-Angle Winglets," Journal of Aircraft, vol. 45, no. 2, pp. 414-423, March 2008.

[14] Y. Nam and S. K. Hong, "Force control system design for aerodynamic load simulator," Control Engineering Practice, vol. 10, no. 5, pp. 549-558, 2002.

[15] L. Pazmany, "EAA," 30 January 1964. [Online]. Available: http://a.moirier.free.fr/Essais\%20statiques/Wing\%20static\%20test.pdf. [Accessed 14 April 2018]. 
[16] E. Limer, "Popular Mechanics," 18 January 2016. [Online]. Available: https://www.popularmechanics.com/flight/g2428/7-airplane-wing-stress-tests/. [Accessed 14 April 2018].

[17] F. Romano, J. Fiori and U. Mercurio, "Structural design and test capability of a CFRP aileron," Composite Structures, vol. 88, no. 3, pp. 333-341, 2009.

[18] M. Prasad and K. Gangadharan, "Aileron endurance test rig design based on high fidelity mathematical modeling," CEAS Aeronautical Journal, vol. 8, no. 4, pp. 653-671, 2017.

[19] AEROSUD, "Integrated Aviation Manufacturing Solutions," [Online]. Available: https://www.aerosud.co.za/home. [Accessed 8 April 2018].

[20] K. Williamson, "Push and pull - testing wind turbine blades," 9 February 2012. [Online]. Available: http://www.renewableenergyfocus.com/view/22799/push-and-pull-testing-windturbine-blades/. [Accessed 5 July 2019].

[21] H. T. Wong, J. G. Teng and Z. C. Wang, "A pulley-based system for the simulation of distributed loading on shell roof structures," Experimental Techniques, vol. 27, no. 5, pp. 21-27, 2003.

[22] J. Robinson, "Structural Testing And Analysis Of A Joined Wing Technology Demonstrator," Design and Analysis Methods Branch (AFRL/VASD), Wright-Patterson AFB, 2004.

[23] J. P. Gray and F. Campagna, "Human-Like Characteristics for High Degree of FreedomRobotic Door-Opening End-Effector," SPIE - The International Society for Optical Engineering, vol. 8045, 2011.

[24] L. N. Robert, Design of Machinery: An Introduction to the Synthesis and Analysis of Mechanisms and Machines, McGraw-Hill, 2012.

[25] C. S. Sharma and K. Purohit, Theory of Mechanisms and Machines, New Delhi: PHI Learning Pvt. Ltd., 2006.

[26] L.-W. Tssai, Mechanism Design: Enumeration of Kinematic Structures According to Function, Riverside: CRC Press, 2000.

[27] Y. Zhang, S. Giner and S. Behrens, "Introduction to Mechanisms," 21 February 1996. [Online]. Available: https://www.cs.cmu.edu/ rapidproto/mechanisms/chpt5.html. [Accessed 2 July 2019].

[28] M. J. McCarthy and G. S. Soh, Geometric Design of Linkages, New York: Springer-Verlag New York, 2011.

[29] R. C. Hibbeler, Engineering Mechanics Statics and Dynamics, 11 ed., Upper Saddle River: Pearson Prentice Hall, 2007.

[30] ANSYS, Inc, "ANSYS Contact Technology Guide," November 2004. [Online]. Available: https://www.cae.tntech.edu/ chriswilson/FEA/ANSYS/g_ctec90.pdf. [Accessed 14 July 2019].

[31] "Onyx," Markforged, [Online]. Available: https://support.markforged.com/hc/enus/articles/209934486-Onyx. [Accessed 12 July 2019].

[32] "Medium Density Fiberboard (MDF)," MakeItFrom, 2 August 2018. [Online]. Available: https://www.makeitfrom.com/material-properties/Medium-Density-Fiberboard-MDF. [Accessed 12 July 2019]. 
[33] "Overview of materials for Polypropylene, Extrusion Grade," MatWeb, [Online]. Available: http://www.matweb.com/search/DataSheet.aspx?MatGUID=a882a1 c603374e278d062f106d fda95b\&ckck=1. [Accessed 12 July 2019].

[34] A. Konak, D. Coit and A. Smith, "Multi-objective optimization using genetic algorithms: A tutorial," Reliability Engineering \& System Safety, vol. 91, no. 9, pp. 992-1007, 2006.

[35] F. Xi, A. Moosavian, G. Campos, U. Choudhuri, C. Z. Sun and R. Buchkazanian, "Analysis and Control of an Actuation-Redundant Parallel Mechanism Requiring Synchronization," $T B C$, vol. TBC, no. TBC, p. TBC, TBC.

[36] T. Kuphaldt, Lessons in Electric Circuits: Voltage Dividers, Bellinham: Design Science License, 2019.

[37] M. Kamenetsky, "Filtered Audio Demo," 1999. [Online]. Available: https://stanford.edu/ boyd/ee102/conv_demo.pdf. [Accessed 24 July 2019].

[38] "Why do aircraft winglets seem to have various designs on otherwise similar aircraft types?," Quora, [Online]. Available: https://www.quora.com/Why-do-aircraft-wingletsseem-to-have-various-designs-on-otherwise-similar-aircraft-types $\#$ !n=12. 